\title{
ADVANCED GASIFICATION MERCURY/TRACE METAL CONTROL WITH MONOLITH TRAPS
}

\author{
Revised Final Scientific/Technical Report \\ (for the period of January 1, 2007, through July 30, 2010) \\ Prepared for: \\ Jenny Tennant \\ National Energy Technology Laboratory \\ U.S. Department of Energy \\ 3610 Collins Ferry Road, MS 921-107 \\ PO Box 880 \\ Morgantown, WV 26507-0880 \\ Cooperative Agreement No. DE-FC26-05NT42461
}

Prepared by:

Mark A. Musich

Michael L. Swanson

Grant E. Dunham Joshua J. Stanislowski

Energy \& Environmental Research Center University of North Dakota 15 North 23rd Street, Stop 9018 Grand Forks, ND 58202-9018 


\section{DISCLAIMER}

This report was prepared as an account of work sponsored by an agency of the United States Government. Neither the United States Government, nor any agency thereof, nor any of their employees makes any warranty, express or implied, or assumes any legal liability or responsibility for the accuracy, completeness, or usefulness of any information, apparatus, product, or process disclosed or represents that its use would not infringe privately owned rights. Reference herein to any specific commercial product, process, or service by trade name, trademark, manufacturer, or otherwise does not necessarily constitute or imply its endorsement, recommendation, or favoring by the United States Government or any agency thereof. The views and opinions of authors expressed herein do not necessarily state or reflect those of the United States Government or any agency thereof.

This report is available to the public from the National Technical Information Service, U.S. Department of Commerce, 5285 Port Royal Road, Springfield, VA 22161; phone orders accepted at (703) 487-4650.

\section{EERC DISCLAIMER}

LEGAL NOTICE: This research report was prepared by the Energy \& Environmental Research Center (EERC), an agency of the University of North Dakota, as an account of work sponsored by the U.S. Department of Energy. Because of the research nature of the work performed, neither the EERC nor any of its employees makes any warranty, express or implied, or assumes any legal liability or responsibility for the accuracy, completeness, or usefulness of any information, apparatus, product, or process disclosed or represents that its use would not infringe privately owned rights. Reference herein to any specific commercial product, process, or service by trade name, trademark, manufacturer, or otherwise does not necessarily constitute or imply its endorsement or recommendation by the EERC. 


\title{
ADVANCED GASIFICATION MERCURY/TRACE METAL CONTROL WITH MONOLITH TRAPS
}

\begin{abstract}
Two Corning monoliths and a non-carbon-based material have been identified as potential additives for mercury capture in syngas at temperatures above $400^{\circ} \mathrm{F}$ and pressure of $600 \mathrm{psig}$. A new Corning monolith formulation, GR-F1-2189, described as an active sample appeared to be the best monolith tested to date. The Corning SR Liquid monolith concept continues to be a strong candidate for mercury capture. Both monolith types allowed mercury reduction to below $5-\mu \mathrm{g} / \mathrm{m}^{3}$ ( $\sim 5 \mathrm{ppb}$ ), a current U.S. Department of Energy (DOE) goal for trace metal control. Preparation methods for formulating the SR Liquid monolith impacted the ability of the monolith to capture mercury.
\end{abstract}

The Energy \& Environmental Research Center (EERC)-prepared Noncarbon Sorbents 1 and 2 appeared to offer potential for sustained and significant reduction of mercury concentration in the simulated fuel gas. The Noncarbon Sorbent 1 allowed sustained mercury reduction to below $5-\mu \mathrm{g} / \mathrm{m}^{3}$ ( $\left.\sim 5 \mathrm{ppb}\right)$. The non-carbon-based sorbent appeared to offer the potential for regeneration, that is, desorption of mercury by temperature swing (using nitrogen and steam at temperatures above where adsorption takes place).

A Corning cordierite monolith treated with a Group IB metal offered limited potential as a mercury sorbent. However, a Corning carbon-based monolith containing prereduced metallic species similar to those found on the noncarbon sorbents did not exhibit significant or sustained mercury reduction. EERC sorbents prepared with Group IB and IIB selenide appeared to have some promise for mercury capture. Unfortunately, these sorbents also released Se, as was evidenced by the measurement of $\mathrm{H}_{2} \mathrm{Se}$ in the effluent gas.

All sorbents tested with arsine or hydrogen selenide, including Corning monoliths and the Group IB and IIB metal-based materials, showed an ability to capture arsine or hydrogen selenide at $400^{\circ} \mathrm{F}$ and 600 psig. Based on current testing, the noncarbon metal-based sorbents appear to be the most effective arsine and hydrogen selenide sorbents. The noncarbon sorbent was able to reduce the concentration to $0 \mathrm{ppb}$ from a starting concentration of $120 \mathrm{ppb}$. This compares to the target value of $5 \mathrm{ppb}\left(\sim 17 \mu \mathrm{g} / \mathrm{m}^{3}\right)$. The EERC-prepared metal-based pellet and coprecipitate sorbents exhibited arsine reductions of $90 \%$ or greater, being below $10 \mathrm{ppb}$. Corning SR Liquid monoliths exhibited brief periods ( $<1$ hour) of attaining $90 \%$ arsine reduction but were able to achieve greater than $80 \%$ reduction for several hours. With respect to hydrogen selenide, all Group IB and IIB metal-based sorbents tested exhibited 100\% reduction from an inlet concentration of approximately 400 ppb. Corning SR Liquid monoliths exhibited an 82\% reduction when two monoliths were tested simultaneously in series. 


\section{TABLE OF CONTENTS}

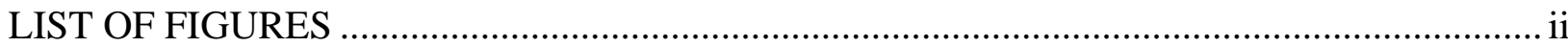

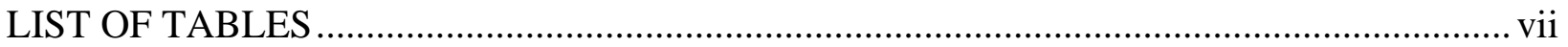

EXECUTIVE SUMMARY ....................................................................................... viii

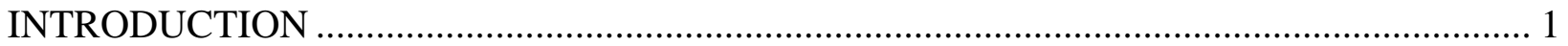

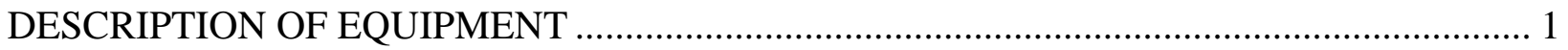

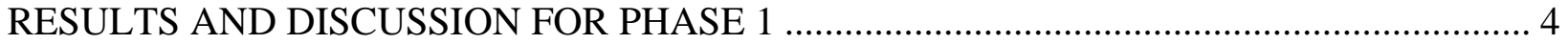

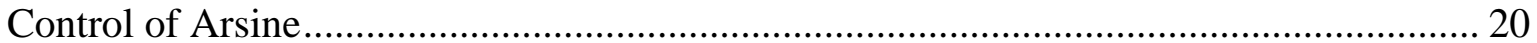

Control of Hydrogen Selenide............................................................................... 21

RESULTS AND DISCUSSION FOR YEAR 2 ….......................................................... 24

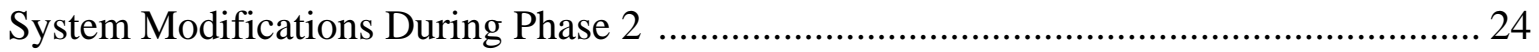

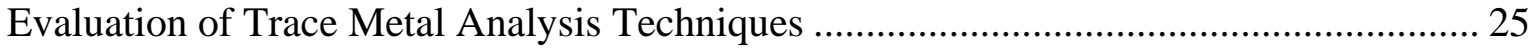

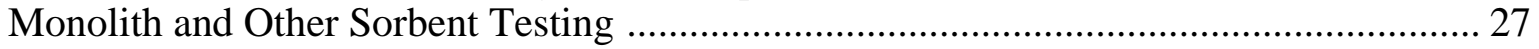

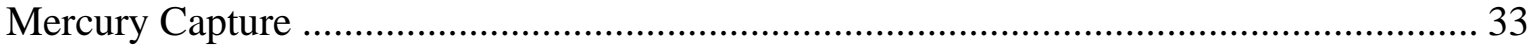

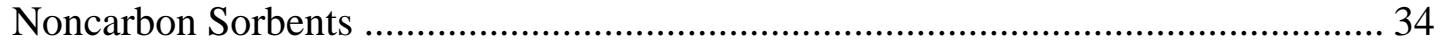

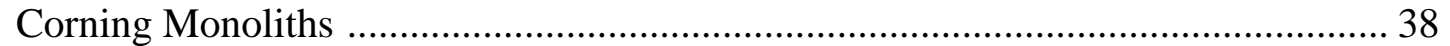

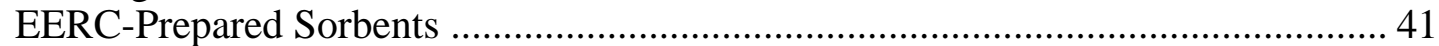

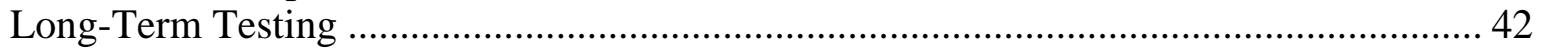

Hydride Capture ......................................................................................... 45

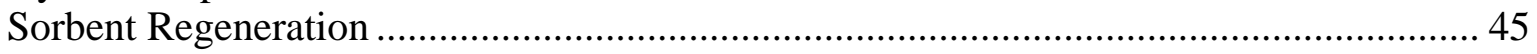

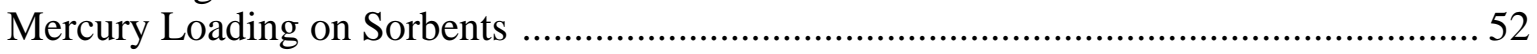

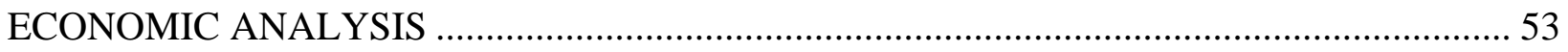

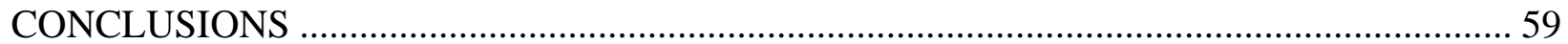

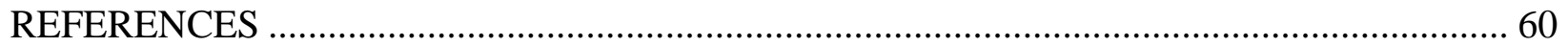

BREAKTHROUGH CURVES FOR CORNING MONOLITHS, EERC

SORBENTS, AND NONCARBON SORBENTS ..................................................... Appendix A

DESIGN AND CONSTRUCTION OF A HIGH-PRESSURE FLUID-BED

GASIFIER

Appendix B 


\section{LIST OF FIGURES}

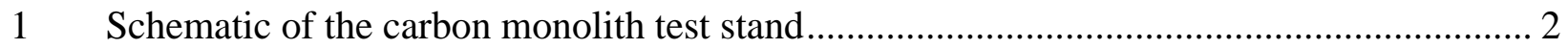

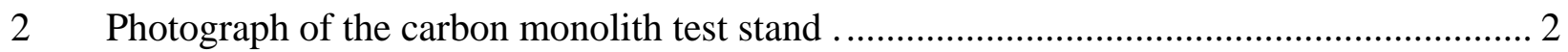

$3 \quad$ Photograph of the carbon monolith test stand ............................................................ 3

$4 \quad$ Breakthrough curves for baseline carbon testing at temperature and pressure ...................... 7

5 Breakthrough curves for EERC-treated carbon at $500^{\circ} \mathrm{F}$ and 300 psig with baseline fuel gas mixture................................................................................................................ 7

$6 \quad$ Breakthrough curves for EERC-treated carbon at $350^{\circ} \mathrm{F}$ and 300 psig with baseline fuel gas mixture and a hydrogen/nitrogen-reducing gas mixture........................................... 8

7 Breakthrough curves for a different EERC-treated carbon as a function of operating temperature...................................................................................................... 9

8 Breakthrough curve for EERC-treated monolith Test 18 (CCZ2O) …............................... 9

$9 \quad$ Breakthrough curve for EERC-treated carbon monolith Test 19 (FC2BO) ……................. 10

10 Breakthrough curve for EERC-treated monolith Test 20 (TCCAT3) ................................ 10

11 Breakthrough curve for EERC-treated carbon monolith Test 24 (TC-CAT1K) ................. 12

12 Breakthrough curve for EERC-treated carbon monolith Test 25 (FC2KO) …..................... 12

13 Breakthrough curve for the EERC-treated carbon as a function of temperature Tests 27 through 29 F2ZO ............................................................................................. 13

14 Breakthrough curves for EERC-treated carbon Tests 27 through 29 with F2ZO at various pressures ........................................................................................................ 13

15 Breakthrough curve for EERC-treated monolith FC2PO at 500 $\mathrm{F}$...................................... 14

16 Breakthrough curve for EERC-treated monolith FC2PO at 350 $\mathrm{F}$...................................... 14

17 Test with Corning-treated monolith TCZO ………............................................................. 15

18 Breakthrough curve for carbon monolith with FCCMO additive ....................................... 16

Continued ... 


\section{LIST OF FIGURES (continued)}

19 Breakthrough curve for carbon monolith with FCZCO additive .........................................16

20 Breakthrough curve for carbon monolith with FCCMSO additive ................................... 17

21 Mercury breakthrough curve for EERC-treated monolith in Test 39 (F2ZO)

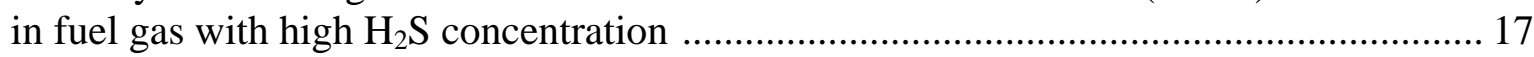

22 Breakthrough curve for Corning-treated monolith utilizing a Catalyst 4

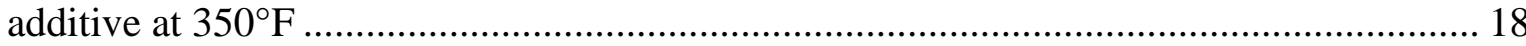

23 Breakthrough curve for Corning-treated monolith utilizing a SR Liquid additive at $350^{\circ} \mathrm{F}$

24 Breakthrough curve for Corning-treated monolith with SR Liquid additive at higher operating pressures and temperatures ........................................................................ 19

25 Breakthrough curve for Corning-treated carbon monolith with Catalyst 2 additive for Hg control 20

26 Breakthrough curve for Corning-treated carbon monolith with Catalyst 2 additive

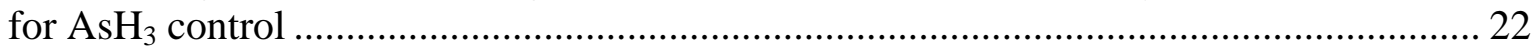

27 Breakthrough curve for the Corning-treated monolith with Catalyst 2 additive for the control of $\mathrm{AsH}_{3}$ at various pressures and temperatures ............................................... 22

28 Breakthrough curve for Corning-treated monolith with Catalyst 2 additive for the control of $\mathrm{AsH}_{3}$ at various pressures and temperatures

29 Breakthrough curve for EERC-treated carbon with F2ZO for $\mathrm{H}_{2} \mathrm{Se}$ control at lower operating temperatures

30 Mercury sorption curve for EERC Noncarbon Sorbent 1 at $350^{\circ} \mathrm{F}$ and 300 psig (Test 18)

31 Mercury sorption curve for EERC Noncarbon Sorbent 1 at $350^{\circ} \mathrm{F}$ and 300 psig (Test 19)

32 Mercury sorption curve for EERC Noncarbon Sorbent 1 at $400^{\circ} \mathrm{F}$ and 600 psig (Test 21) 


\section{LIST OF FIGURES (continued)}

33 Mercury sorption curve for EERC Noncarbon Sorbent 1 at $400^{\circ} \mathrm{F}$ and $600 \mathrm{psig}$ (Test 22)

34 Mercury sorption curve for EERC Noncarbon Sorbent 1 at $400^{\circ} \mathrm{F}$ and 600 psig

(Test 32) 36

35 Mercury sorption curve for EERC Noncarbon Sorbent 1 at $400^{\circ} \mathrm{F}$ and 600 psig (Test 33)

36 Mercury sorption curve for EERC Noncarbon Sorbent 1 at $400^{\circ} \mathrm{F}$ and 600 psig (Test 34)

37 Mercury sorption curve for Corning Monolith SR Liquid 283, 350 ${ }^{\circ} \mathrm{F}$ and $300 \mathrm{psig}$

(Test 51)

38 Mercury sorption curve for Corning Monolith SR Liquid 283, 350 $-400^{\circ} \mathrm{F}$ and 300 psig (Test 52)

39 Mercury sorption curve for Corning Monolith SR Liquid 283, 400 F and 300 psig (Test 53)

40 Mercury sorption curve for Corning Monolith SR Liquid 283, $400^{\circ} \mathrm{F}$ and $300 \mathrm{psig}$ (Test 54)

41 Mercury sorption curve for Corning Monolith SR Liquid 283 and 284, $400^{\circ} \mathrm{F}$ and 600 psig (Test 56)

42 Mercury and arsine sorption curves for Corning Monoliths GR-P1-2189 (1, 2, 3, 4) at $400^{\circ} \mathrm{F}$ and $600 \mathrm{psig}$ (Test 76)

43 Mercury and arsine sorption curves for Corning Monoliths 31308-2, -7, -12, and -16 at $400^{\circ} \mathrm{F}$ and 600 psig (Test 80 )

44 Mercury sorption curve for Corning Monoliths 31308-3, -10, and -20 at $400^{\circ} \mathrm{F}$ and 600 psig (Test 83).

45 Mercury sorption curve for Corning Monoliths 31308-4, -13, and -15 at $400^{\circ} \mathrm{F}$ and 600 psig (Test 88) 


\section{LIST OF FIGURES (continued)}

46 Arsine sorption curve for EERC Noncarbon Sorbent 1 at $400^{\circ} \mathrm{F}$ and $600 \mathrm{psig}$ (Test 64)

47 Arsine sorption curve for Corning Monolith SR Liquid 285 at $400^{\circ} \mathrm{F}$ and $600 \mathrm{psig}$ (Test 65)

48 Arsine sorption curve for EERC Sorbent Group IB and IIB metals on alumina pellet at $400^{\circ} \mathrm{F}$ and 600 psig (Test 66)

49 Arsine sorption curve for Corning Monoliths SR Liquid 285 and 286 at $400^{\circ} \mathrm{F}$ and 600 psig (Test 68).

50 Arsine sorption curve for EERC Sorbent Group IB and IIB metals coprecipitate at $400^{\circ} \mathrm{F}$ and 600 psig (Test 69)

51 Hydrogen selenide sorption curve for EERC Sorbent Group IB and IIB metals coprecipitate at $400^{\circ} \mathrm{F}$ and 600 psig (Test 71)

52 Hydrogen selenide sorption curve for EERC Sorbent Group IB and IIB metals coprecipitate at $400^{\circ} \mathrm{F}$ and 600 psig (Test 73)

53 Hydrogen selenide sorption curve for EERC Sorbent Group IB and IIB metals on alumina pellet at $400^{\circ} \mathrm{F}$ and 600 psig (Test 74)

54 Hydrogen selenide sorption curve for Corning Monoliths SR Liquid 287 and 288 at $400^{\circ} \mathrm{F}$ and 600 psig (Test 75 )

55 Arsine and mercury sorption curves for Corning Monolith GR-F1-2189 at $400^{\circ} \mathrm{F}$ and 600 psig (Test 76)

56 Arsine and mercury sorption curves for Corning Monoliths 31083-3, -8, -13, and -17 at $400^{\circ} \mathrm{F}$ and 600 psig (Test 78)

57 Arsine and mercury sorption curves for Corning Monoliths 31085-6, -11, -17, and -21 at $400^{\circ} \mathrm{F}$ and 600 psig (Test 79)

58 Arsine and mercury sorption curves for Corning Monoliths 31308-2, -7, -12, and -16 at $400^{\circ} \mathrm{F}$ and $600 \mathrm{psig}$ (Test 80 ) 51

Continued ... 


\section{LIST OF FIGURES (continued)}

59 Mercury sorption curve for EERC Noncarbon Sorbent 1 at $350^{\circ} \mathrm{F}$ and $300 \mathrm{psig}$ (Test 20)

60 Mercury sorption curve for regenerated Corning Monoliths 31308-3, -10, and -20 at $400^{\circ} \mathrm{F}$ and 600 psig (Test 84 )

61 ASPEN model for warm-gas cleanup mercury removal at $450^{\circ} \mathrm{F}$................................ 58

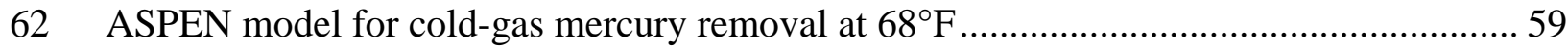




\section{LIST OF TABLES}

1 Test Operating Parameters for Completed Tests Phase 1 ............................................. 5

2 Monolith Mercury-Loading Data on Selected Long-Term Samples .............................. 21

3 Mercury, Arsenic, and Selenium Sampling Results During Evaluation of Trace Metal Analysis Techniques ........................................................................... 26

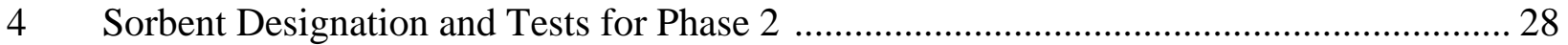

5 Sorbent Designation, Nominal Temperature and Pressure, Space Velocity, and

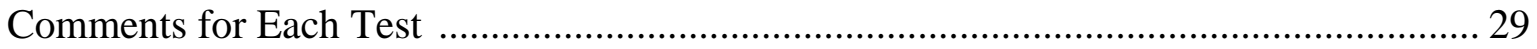

$6 \quad$ Mercury Loading Results for Select Sorbents .......................................................... 53

$7 \quad$ Technology Operating Parameters - Monolith vs. Conventional .................................... 55

8 Sensitivity Analyses on Carbon Monolith Trace Metal Control System ......................... 56 


\section{ADVANCED GASIFICATION MERCURY/TRACE METAL CONTROL WITH MONOLITH TRAPS}

\section{EXECUTIVE SUMMARY}

The Energy \& Environmental Research Center (EERC) and Corning, through a U.S. Department of Energy (DOE)-funded program, continued its teaming arrangement to develop sorbents for controlling mercury and trace metal emissions in solid fuel-derived syngas. In year one of the program, a high-pressure laboratory-scale apparatus was constructed that allowed testing of Corning monoliths as well as EERC-developed powdered and granulated sorbent samples in simulated syngas mixtures.

Project goals included reduction of trace metals to target levels of $5 \mathrm{ppbw}$ for mercury (Hg), $5 \mathrm{ppb}$ for arsenic (As), $0.2 \mathrm{ppm}$ for selenium (Se), and $30 \mathrm{ppb}$ for cadmium (Cd). Testing was performed with elemental $\mathrm{Hg}$ (as vapor), and the reduced gas-phase forms of As and Se arsine and hydrogen selenide, respectively. Testing was not performed with Cd as laboratory preparation of gas-phase cadmium was considered difficult and expensive.

In Phase 1 , testing was performed at temperatures ranging from $300^{\circ}$ to $350^{\circ} \mathrm{F}\left(149^{\circ}\right.$ to $177^{\circ} \mathrm{C}$ ) and a pressure of 300 psig. Results were reported in the Phase I final report. A total of 47 tests were performed to evaluate monoliths and granular sorbents for mercury, arsenic, and selenium removal. The EERC and Corning team developed three potential additives for controlling mercury emissions from syngas at temperatures ranging from $350^{\circ}$ up to $500^{\circ} \mathrm{F}\left(177^{\circ}\right.$ up to $260^{\circ} \mathrm{C}$ ). Project results also indicate that one of the same sorbents could also successfully be utilized for arsenic and hydrogen selenide removal. Preliminary economic analysis suggested that these Corning monoliths potentially could be more cost-effective than the cold-gas presulfided activated carbon beds currently being utilized, contingent upon attaining higher $\mathrm{Hg}$ loadings on the sorbent. However, the analysis did not take into account the significantly improved thermal efficiency of any plant utilizing the warm-gas monolith technology currently being developed.

Testing in Phase 2, based on modified DOE program requirements, refocused efforts on sorbents that are effective at a minimum temperature of $400^{\circ} \mathrm{F}\left(205^{\circ} \mathrm{C}\right)$ and a pressure of 600 psig. A total of 39 different sorbent designations, including 29 different Corning monolith designations, were evaluated for mercury and/or hydride capture. Also, the EERC prepared and tested three carbon-based granular sorbents plus four non-carbon-based granular sorbents. Two commercially available materials, designed for aiding the water-gas shift reaction, were also tested.

The Corning SR Liquid monolith, identified in Phase 1 as the best monolith candidate, continued to be a strong candidate for mercury capture at temperatures above $400^{\circ} \mathrm{F}$ and pressure of 600 psig. However, preparation methods for formulating the SR Liquid monolith impacted the ability of the monolith to capture mercury. A new Corning monolith formulation, GR-F1-2189, described by Corning as an active sample, appeared to be the best monolith tested to date. Both 
monolith types allowed mercury reduction to below $5 \mu \mathrm{g} / \mathrm{m}^{3}$ ( $\left.\sim \mathrm{ppb}\right)$, a current DOE goal for trace metal control.

The Group IB and IIB metal-based Noncarbon Sorbents 1 and 2 appeared to offer the greatest potential for sustained and significant reduction of mercury concentration in the simulated fuel gas. The Noncarbon Sorbent 1 allowed sustained mercury reduction to below $5 \mu \mathrm{g} / \mathrm{m}^{3}$ ( $\left.\sim 5 \mathrm{ppb}\right)$. The non-carbon-based sorbent appeared to offer the potential for regeneration, that is, desorption of mercury by temperature swing (using nitrogen and steam at temperatures above where adsorption takes place).

A Corning cordierite monolith treated with a similar metal impregnation offered limited potential as a mercury sorbent. However, a Corning carbon-based monolith containing prereduced metallic species similar to those found on the noncarbon sorbents did not exhibit significant or sustained mercury reduction. EERC sorbents prepared with Group IB and IIB metal selenides appeared to have some promise for mercury capture. Unfortunately, these sorbents also released Se as evidenced by the measurement of $\mathrm{H}_{2}$ Se in the effluent fuel gas.

All sorbents tested with arsine or hydrogen selenide, including Corning monoliths and Group IB and IIB metal-based materials, showed an ability to capture arsine or hydrogen selenide at $400^{\circ} \mathrm{F}$ and 600 psig. Based on current testing, the metal-based sorbents appear to be the most effective arsine and hydrogen selenide sorbents. The noncarbon sorbent was able to reduce the concentration to $0 \mathrm{ppb}$ from a starting concentration of $120 \mathrm{ppb}$. This compares to the target value of $5 \mathrm{ppb}\left(\sim 17 \mu \mathrm{g} / \mathrm{m}^{3}\right)$. The EERC-prepared metal-based pellet and coprecipitate sorbents exhibited arsine reductions of $90 \%$ or greater, below $10 \mathrm{ppb}$. Corning SR Liquid monoliths exhibited brief periods ( $<1$ hour) of attaining $90 \%$ arsine reduction but were able to achieve greater than $80 \%$ reduction for several hours. With respect to hydrogen selenide, all metal-based sorbents tested exhibited $100 \%$ reduction from an inlet concentration of approximately $400 \mathrm{ppb}$. Corning SR Liquid monoliths exhibited an 82\% reduction when two monoliths were tested simultaneously in series.

An updated economic analysis for the control of mercury emissions using the Corning monolith system in a gasification combined-cycle scenario was performed following the completion of Phase 2 testing. The economic analysis attempted to quantify improvements to efficiency (heat rate) by utilizing the monolith technology over the more conventional granular carbon packed bed utilized by Eastman.

ASPEN modeling for an $\mathrm{O}_{2}$-blown transport gasifier was utilized as the starting point for determining the improved system efficiency for warm-gas cleanup over cold-gas mercury cleanup. This modeling shows that similar gasifier outlet flows and a mercury removal process operating at a higher warm-gas cleanup temperature would result in a net power increase of 15 more megawatts. Assuming an average power selling price of $\$ 45 / \mathrm{MWh}$ would result in $\$ 4.7 \mathrm{M}$ in increased revenues per year. With a similar Hg loading to the conventional carbon, the estimated total annual cost (for $\mathrm{Hg}$ capture) was approximately $\$ 1,011,600$, providing a net profit of \$3.688 million per year. 
Should the mercury loading be limited to $0.04 \mathrm{wt} \%$ (1/10th the loading of the conventional carbon sorbent), then the total annual cost would be approximately $\$ 8$ million, resulting in a net loss of $\$ 3.4$ million, in which case cold-gas cleanup for mercury removal would be more economical. However, the ability to regenerate the monoliths for use in two to three or more cycles could result in a cost advantage for the monoliths over the conventional carbon-based cold-gas cleanup. 


\section{ADVANCED GASIFICATION MERCURY/TRACE METAL CONTROL WITH MONOLITH TRAPS}

\section{INTRODUCTION}

The Energy \& Environmental Research Center (EERC) and Corning, through a U.S. Department of Energy (DOE)-funded program, continued its teaming arrangement to develop sorbents for controlling mercury and trace metal emissions in solid fuel-derived syngas. In the first year of the project, a high-pressure laboratory-scale apparatus was constructed that allowed testing of Corning monoliths as well as EERC-developed powdered and granulated sorbent samples in simulated syngas mixtures at temperatures ranging from $300^{\circ}$ to $350^{\circ} \mathrm{F}\left(149^{\circ}\right.$ to $177^{\circ} \mathrm{C}$ ) and a pressure of 300 psig. Detailed results from Phase I testing are given in the Phase I final report (1). Testing in Phase 2, based on modified DOE program requirements, refocused efforts on sorbents that are effective at a minimum temperature of $400^{\circ} \mathrm{F}\left(205^{\circ} \mathrm{C}\right)$ and a pressure of 600 psig.

\section{DESCRIPTION OF EQUIPMENT}

A high-pressure, laboratory-scale test apparatus has been constructed that allows testing of monoliths as well as powdered and granulated sorbent samples in simulated syngas mixtures at pressures up to 1200 psig. A data acquisition and control system provides for control of process gas flow as well as system pressure. This test apparatus is able to blend bottled gases to simulate the desired gas composition for any of the major gasifier vendors, including that of entrainedflow slurry feed and dry feed gasifiers and fluid-bed gasifiers, including transport reactor and Gas Technology Institute U-gas systems. The mass flow controllers and a high-pressure water pump allow the gas mixtures to be set independently to achieve the desired gas composition. Impurities such as arsenic (as $\mathrm{ArH}_{3}$ at $10 \mathrm{ppm}$ ) and selenium (as $\mathrm{H}_{2} \mathrm{Se}$ at $100 \mathrm{ppm}$ ) are obtained as dedicated cylinders with $\mathrm{N}_{2}$ as the balance component. Similarly, $\mathrm{H}_{2} \mathrm{~S}, \mathrm{COS}$, and $\mathrm{HCl}$ would be added to cylinders of bottled gas $\left(\mathrm{H}_{2}\right.$ or $\left.\mathrm{N}_{2}\right)$ to get the appropriate concentrations in the simulated bottled gas mixture.

A diagram of the designed laboratory-scale test rig is shown in Figure 1. Photographs of the carbon monolith test stands are shown in Figures 2 and 3. Mass flow controllers sized for 6 scfh of $\mathrm{CO}_{2}, 8 \mathrm{scfh}$ of $\mathrm{H}_{2}, 10 \mathrm{scfh}$ of $\mathrm{CO}, 1 \mathrm{scfh}$ of $\mathrm{CH}_{4}$, and 12 scfh of $\mathrm{N}_{2}$ allow the test apparatus to blend bottled gases to simulate the desired gas composition. Mass flow controllers for the mercury source $\mathrm{N}_{2}$ sweep gas and the hydride gas are sized at $200 \mathrm{sccm}$ and $100 \mathrm{sccm}$, respectively. These flow rates were the maximum values required to satisfy expected ranges for space velocity, and operating temperature and pressure. All tubing and fittings downstream from the mercury injection point have been treated with Restek's Silicosteel Hydroguard ${ }^{\mathrm{TM}}$ coating to reduce any chances for mercury and trace metal absorption on the metal surfaces.

The mercury permeation source currently employed is an EERC-developed approach. Initial operations with traditional permeation sources, such as Teflon ${ }^{\circledR}$ permeation tubes from 


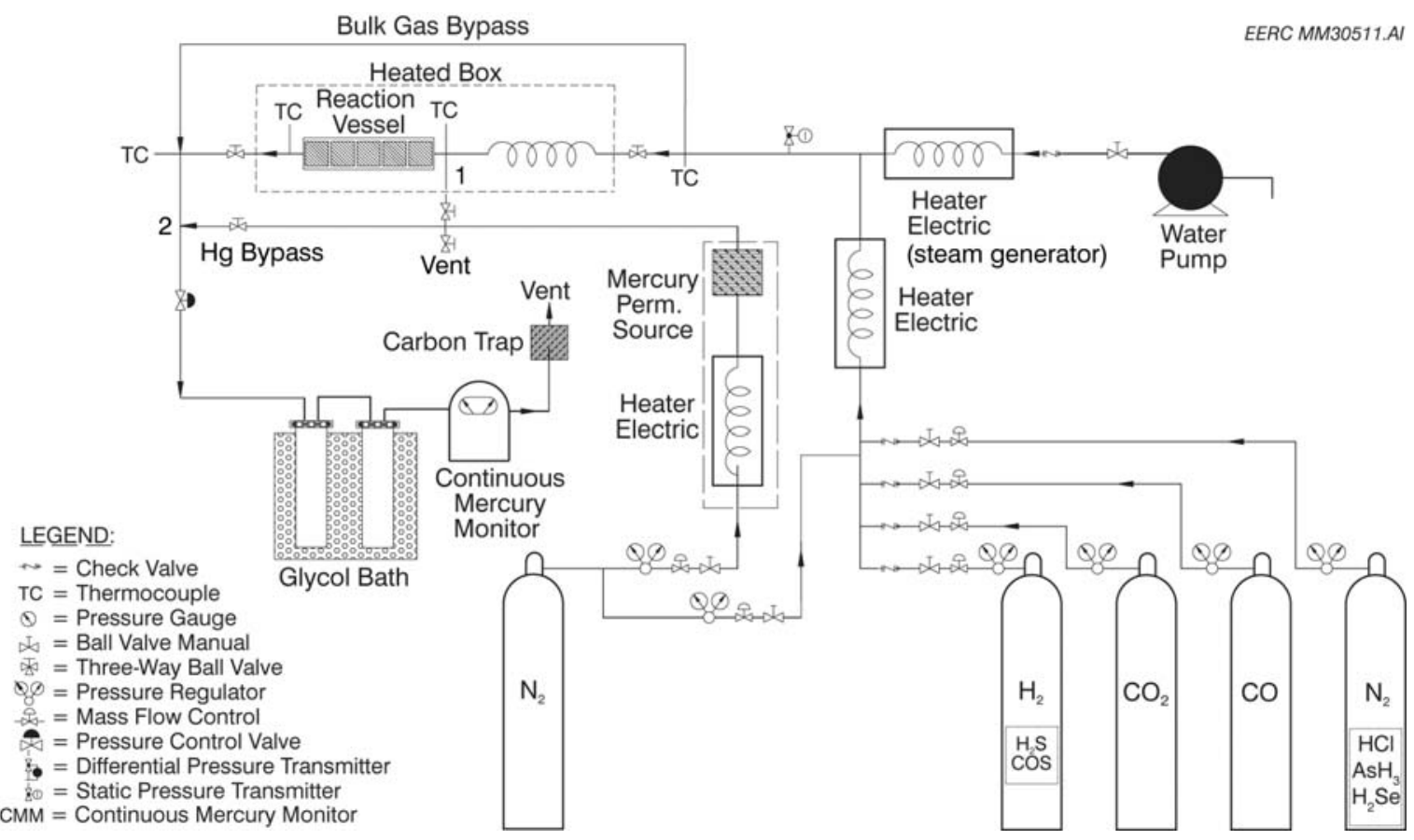

Figure 1. Schematic of the carbon monolith test stand.

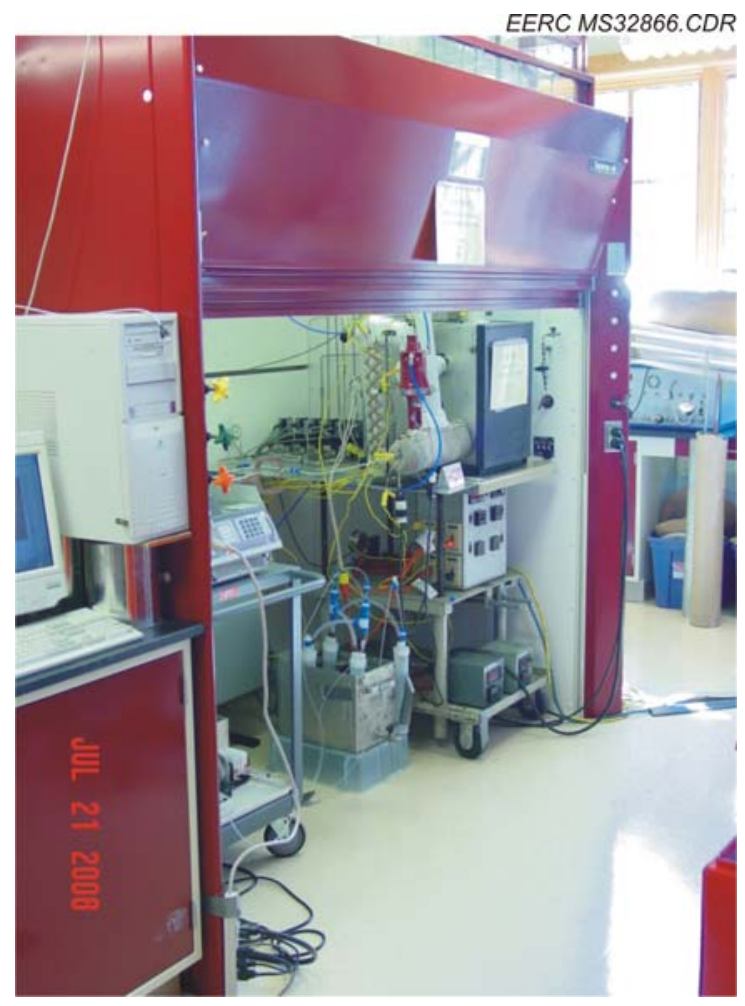

Figure 2. Photograph of the carbon monolith test stand. 


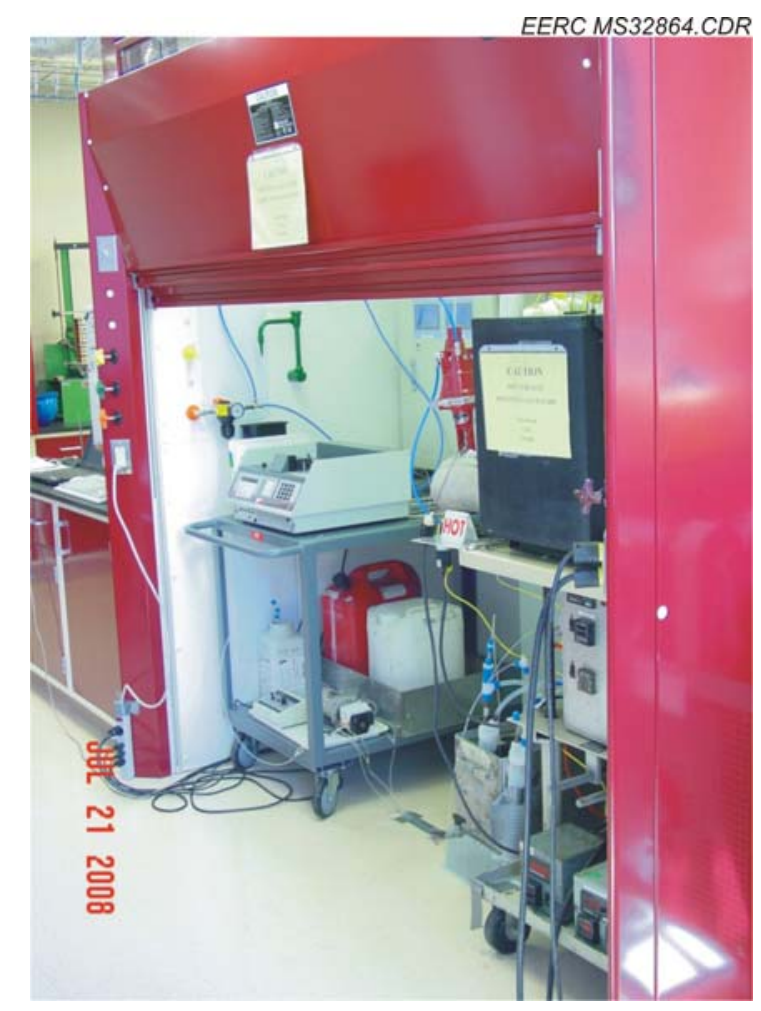

Figure 3. Photograph of the carbon monolith test stand.

VICI Metronics, were found to be susceptible to rupture from use at the elevated test pressures of 300 to 600 psig. The EERC system uses an inflexible 2-mL borosilicate glass auto sampler vial to contain a small quantity of liquid mercury. The Teflon lid on the vial has a small hole through which mercury vapor can escape and pressure can be equalized quickly to prevent rupture of the vial. The lid is secured to the vial using tightly wound Teflon tape.

Seven mercury-filled vials are stacked within a 1-inch-outside-diameter (o.d.) stainless steel tube that is externally heated with an electric muff heater. Nitrogen at $200 \mathrm{~cm}^{3} / \mathrm{min}$ is introduced at the bottom of the 1-inch tube, flowing upward to sweep the mercury away from the glass vials. The mercury concentration is dependent upon the controlled temperature of the 1-inch-o.d. stainless steel tube and the system pressure.

The 200- $\mathrm{cm}^{3} / \mathrm{min}$ mercury/nitrogen stream flows through heated tubing and is blended with the bulk gas flow at either Port 1 (inlet of the sorbent reactor) or Port 2 (bypass of the sorbent reactor). The average mercury concentration will be the same at Ports 1 and 2, with the baseline mercury concentration taken as that value obtained when the mercury/nitrogen stream and the bulk gas flow are mixed at Port 2. The mercury concentration is maintained in the range from 40 to $120 \mu \mathrm{g} / \mathrm{m}^{3}$, values which correspond to those observed for gasification of a number of coals.

The mercury concentration in the simulated fuel gas is measured with a Horiba DM-6B cold-vapor atomic absorption mercury analyzer. The water in the sample gas is removed in an 
ice-chilled impinger train constructed of Teflon components. A $2 \% \mathrm{SnCl}_{2}-20 \% \mathrm{NaOH}$ solution can also be added to the first impinger to remove sulfur impurities - in the mixed gas or from the sorbent - that could interfere with detection of mercury by the continuous mercury monitor (CMM). A Honeywell Analytics CM-4 hydride monitor that can analyze for arsine and hydrogen selenide at concentrations between 5 and $500 \mathrm{ppb}$ and 6 and $500 \mathrm{ppb}$, respectively, is utilized to measure for the removal of these trace elements.

A second pressure control system was received and installed that allows the permeation source pressure to be held constant at all times, especially when the mercury source is bypassed from flow to the sorbent test system. A pressure transducer is used to measure the mercury source system pressure with feedback provided through a control loop to the actuator/positioner of the control valve. This system will alleviate any spikes in mercury concentration resulting from the previous method of deadheading the mercury source when it was not online.

\section{RESULTS AND DISCUSSION FOR PHASE 1}

Table 1 summarizes the operating conditions from all of the successful tests completed on the bench-scale test rig. The baseline fuel gas mixture used for most tests consisted of $25 \% \mathrm{H}_{2}$, $20 \% \mathrm{CO}, 15 \% \mathrm{CO}_{2}, 17.5 \% \mathrm{H}_{2} \mathrm{O}$, and $5 \% \mathrm{CH}_{4}$, with the balance being $\mathrm{N}_{2}$, which would closely simulate an air-blown transport reactor operating on a higher-moisture lignite fuel. Some tests were completed in the presence of hydrogen sulfide to determine its effect on the performance of the additive.

The very first tests looked at the mercury capture ability of the baseline Corning monolith and a presulfided granulated activated carbon (Calgon F-400) utilizing a baseline fuel gas mixture. In these tests, the carbon-based material did not capture any $\mathrm{Hg}$ at the conditions tested. Figure 4 shows the breakthrough curves from these tests. From these tests, it is apparent that carbon by itself is not capable of capturing any $\mathrm{Hg}$ at these elevated temperatures.

Tests were then conducted using EERC-treated granular carbon with the baseline fuel gas mixture. Figures 5 and 6 show the breakthrough curves for these tests utilizing these sorbents at temperatures of $500^{\circ}$ and $350^{\circ} \mathrm{F}$, respectively. These tests show that the sorbent was effective at removing the mercury to very low levels for a significant period of time; however, once the mercury started to break through, the sorbent would start desorbing mercury until the mercury was almost completely desorbed. The tests at the lower temperature also indicated that while the sorbent would control mercury for significantly longer periods, eventually the mercury would still desorb. Less desorption appeared to occur when the fuel gas mixture was switched to a $\mathrm{H}_{2} / \mathrm{N}_{2}$ mixture only. Analysis of the carbon substrate indicated that over $90 \%$ of the active ingredient in the EERC-treated carbon had volatilized at these temperatures in the presence of reducing-gas species. 
Table 1. Test Operating Parameters for Completed Tests Phase 1

\begin{tabular}{|c|c|c|c|c|c|c|c|c|c|c|c|c|}
\hline $\begin{array}{l}\text { Run: } \\
\text { No.: }\end{array}$ & $\begin{array}{c}\text { Sorbent } \\
\text { Type }\end{array}$ & $\begin{array}{c}\text { Sorbent } \\
\text { Type }\end{array}$ & $\begin{array}{c}\text { Sorbent } \\
\text { Weight, g }\end{array}$ & $\begin{array}{c}\text { Temp., } \\
{ }^{\circ} \mathrm{F}\end{array}$ & $\begin{array}{c}\text { Pressure, } \\
\text { psig }\end{array}$ & $\begin{array}{c}\mathrm{H}_{2}, \\
\% \\
\end{array}$ & $\begin{array}{c}\mathrm{CO}, \\
\%\end{array}$ & $\begin{array}{c}\mathrm{CO}_{2}, \\
\% \\
\end{array}$ & $\begin{array}{c}\mathrm{CO}_{2}(\mathrm{Hg}), \\
\text { scf }\end{array}$ & $\begin{array}{c}\mathrm{CH}_{4}, \\
\%\end{array}$ & $\begin{array}{c}\mathrm{H}_{2} \mathrm{O} \\
\% \\
\end{array}$ & $\begin{array}{c}\mathrm{N}_{2}, \\
\% \\
\end{array}$ \\
\hline 1 & No. $412-6$ & Monolith & 2.5773 & 500 & 300 & 25 & 20 & 15 & 0.0155 & 5 & 17.5 & 17.5 \\
\hline 2 & F2BO & Granular & 3.9684 & 500 & 300 & 25 & 20 & 15 & 0.0155 & 5 & 17.5 & 17.5 \\
\hline 3 & F2HO & Granular & 3.6605 & 500 & 300 & 25 & 20 & 15 & 0.0155 & 5 & 17.5 & 17.5 \\
\hline 4 & $\mathrm{~F} 2 \mathrm{ZO}$ & Granular & 3.7775 & $500-350$ & 300 & 25 & 20 & 15 & 0.0155 & 5 & 17.5 & 17.5 \\
\hline 5 & $\mathrm{~F} 2 \mathrm{ZO}$ & Granular & 2.6219 & 400 & 300 & 25 & 20 & 15 & 0.0155 & 5 & 17.5 & 17.5 \\
\hline 6 & $\mathrm{~F} 2 \mathrm{ZO}$ & Granular & 3.5600 & 400 & 300 & 25 & 20 & 15 & 0.0155 & 5 & 17.5 & 17.5 \\
\hline 7 & F2ZO & Granular & 3.5193 & 350 & 300 & 25 & 20 & 15 & 0.0155 & 5 & 17.5 & 17.5 \\
\hline 8 & $\mathrm{~F} 2 \mathrm{HO}$ & Granular & 4.0032 & 350 & 300 & 25 & 20 & 15 & 0.0155 & 5 & 17.5 & 17.5 \\
\hline 9 & $\mathrm{~F} 2 \mathrm{HO}$ & Granular & 0.5056 & 350 & 300 & 25 & 0 & 0 & 0.0155 & 0 & 0 & 75 \\
\hline 10 & F2HO & Granular & 1.0005 & 350 & 300 & 0 & 20 & 15 & 0.0155 & 5 & 0 & 60 \\
\hline 11 & СС5BO & Powdered & 0.5009 & 350 & 300 & 25 & 20 & 15 & 0.15 & 5 & 17.5 & 17.5 \\
\hline 12 & СС2BO & Monolith & 3.7678 & 350 & 300 & 25 & 20 & 15 & 0.15 & 5 & 17.5 & 17.5 \\
\hline 13 & CC2BO & Monolith & 3.7678 & 350 & 300 & 25 & 20 & 15 & 0.15 & 5 & 17.5 & 17.5 \\
\hline 14 & CC2ZO & Monolith & 4.0873 & 350 & 300 & 25 & 20 & 15 & 0.15 & 5 & 17.5 & 17.5 \\
\hline 15 & CC2ZO & Monolith & 4.0873 & 350 & 300 & 25 & 20 & 15 & 0.15 & 5 & 17.5 & 17.5 \\
\hline 16 & F2ZO & Granular & 3.8158 & 500 & 300 & 25 & 20 & 15 & 0.15 & 5 & 17.5 & 17.5 \\
\hline 17 & F2ZO & Granular & 3.8158 & 350 & 300 & 25 & 20 & 15 & 0.15 & 5 & 17.5 & 17.5 \\
\hline 18 & CC2ZO & Monolith (2) ${ }^{1}$ & 6.059 & 350 & 300 & 25 & 20 & 15 & 0.15 & 5 & 9.5 & 25.5 \\
\hline 19 & FC2BO & Monolith (2) & 7.6477 & 350 & 300 & 25 & 20 & 15 & 0.15 & 5 & 9.5 & 25.5 \\
\hline 20 & TCСАТЗ & Monolith & 3.7482 & 350 & 300 & 25 & 20 & 15 & 0.15 & 5 & 9.5 & 25.5 \\
\hline 21 & ТССАТЗ & Monolith & 4.1495 & 500 & 300 & 25 & 20 & 15 & 0.15 & 5 & 9.5 & 25.5 \\
\hline 22 & TCCAT2 & Monolith & 2.8702 & 350 & 300 & 25 & 20 & 15 & 0.15 & 5 & 9.5 & 25.5 \\
\hline 23 & TCCAT1 & Monolith & 3.2218 & 350 & 300 & 25 & 20 & 15 & 0.15 & 5 & 9.5 & 25.5 \\
\hline 24 & TCСАТ1K & Monolith & 5.0363 & 350 & 300 & 25 & 20 & 14.9 & 0.15 & 5 & 9.5 & 25.5 \\
\hline 25 & FC2KO & Monolith & 5.2027 & 350 & 300 & 25 & 20 & 14.9 & 0.15 & 5 & 9.5 & 25.5 \\
\hline 26 & CC2B1 & Monolith & 5.9067 & 350 & 300 & 25 & 20 & 14.9 & 0.15 & 5 & 9.5 & 25.5 \\
\hline 27 & F2ZO & Granular & 3.016 & 650 & 300 & 25 & 20 & 14.9 & 0.15 & 5 & 9.5 & 25.5 \\
\hline 28 & $\mathrm{~F} 2 \mathrm{ZO}$ & Granular & 3.003 & 500 & 300 & 25 & 20 & 14.9 & 0.15 & 5 & 9.5 & 25.5 \\
\hline 29 & $\mathrm{~F} 2 \mathrm{ZO}$ & Granular & 3.0018 & 350 & 300 & 25 & 20 & 14.9 & 0.15 & 5 & 9.5 & 25.5 \\
\hline 30 & $\mathrm{~F} 2 \mathrm{ZO}$ & Granular & 3.0045 & 350 & 150 & 25 & 20 & 14.9 & 0.15 & 5 & 9.5 & 25.5 \\
\hline 31 & $\mathrm{~F} 2 \mathrm{ZO}$ & Granular & 3.0045 & 350 & 600 & 25 & 20 & 14.9 & 0.15 & 5 & 9.5 & 25.5 \\
\hline 32 & FC2PO & Monolith & 3.6494 & 500 & 300 & 25 & 20 & 14.9 & 0.15 & 5 & 9.5 & 25.5 \\
\hline
\end{tabular}


Table 1. Test Operating Parameters for Completed Tests Phase 1(continued)

\begin{tabular}{|c|c|c|c|c|c|c|c|c|c|c|c|c|}
\hline $\begin{array}{l}\text { Run: } \\
\text { No.: }\end{array}$ & $\begin{array}{c}\text { Sorbent } \\
\text { Type }\end{array}$ & $\begin{array}{c}\text { Sorbent } \\
\text { Type }\end{array}$ & $\begin{array}{c}\text { Sorbent } \\
\text { Weight, g }\end{array}$ & $\begin{array}{l}\text { Temp., } \\
{ }^{\circ} \mathrm{F}\end{array}$ & $\begin{array}{l}\text { Pressure, } \\
\text { psig }\end{array}$ & $\begin{array}{c}\mathrm{H}_{2}, \\
\%\end{array}$ & $\begin{array}{c}\mathrm{CO}, \\
\%\end{array}$ & $\begin{array}{c}\mathrm{CO}_{2}, \\
\%\end{array}$ & $\begin{array}{c}\mathrm{CO}_{2}(\mathrm{Hg}), \\
\text { scf }\end{array}$ & $\begin{array}{c}\mathrm{CH}_{4}, \\
\%\end{array}$ & $\begin{array}{c}\mathrm{H}_{2} \mathrm{O}, \\
\%\end{array}$ & $\begin{array}{c}\mathrm{N}_{2}, \\
\%\end{array}$ \\
\hline 33 & FCCMO & Monolith & 3.0234 & 350 & 300 & 25 & 20 & 14.9 & 0.15 & 5 & 9.5 & 25.5 \\
\hline 34 & FCZCO & Monolith & 4.4818 & 350 & 300 & 25 & 20 & 14.9 & 0.15 & 5 & 9.5 & 25.5 \\
\hline 35 & TCZO & Monolith & 2.229 & 350 & 300 & 25 & 20 & 14.9 & 0.15 & 5 & 9.5 & 25.5 \\
\hline 36 & FC2PO & Monolith & 4.0007 & 350 & 300 & 25 & 20 & 14.9 & 0.15 & 5 & 9.5 & 25.5 \\
\hline 37 & FCCMSO & Monolith & 3.1328 & 350 & 300 & 25 & 20 & 14.9 & 0.15 & 5 & 9.5 & 25.5 \\
\hline 39 & F2ZO & Granular & 3.0216 & 350 & 300 & 25 & 20 & 14.9 & 0.15 & 5 & 9.5 & 25.5 \\
\hline 40 & Cat. $^{2}$ No. 4 & Monolith & 5.8929 & 350 & 300 & 25 & 20 & 14.9 & 0.15 & 5 & 9.5 & 25.5 \\
\hline 41 & SR Liquid & Monolith & 3.3597 & 350 & 300 & 25 & 20 & 14.9 & 0.15 & 5 & 9.5 & 25.5 \\
\hline 42 & SR Liquid & Monolith & 3.3708 & 350 & 600 & 25 & 20 & 14.9 & 0.15 & 4 & 9.5 & 26.5 \\
\hline 43 & Cat. No. 2 & Monolith & 3.2475 & 350 & 600 & 25 & 20 & 14.9 & 0.15 & 4 & 9.5 & 26.5 \\
\hline 44 & FC2PO & Monolith & 4.2448 & 350 & 300 & 25 & 20 & 14.9 & 0.15 & 4 & 9.5 & 26.5 \\
\hline 45 & Cat. No. 2 & Monolith & 3.3889 & 350 & 600 & 25 & 50 & 5 & NA & 0 & 8.75 & 11.3 \\
\hline 46 & Cat. No. 2 & Monolith & 3.6178 & 500 & 600 & 25 & 50 & 5 & NA & 0 & 8.75 & 11.3 \\
\hline 47 & F2ZO & Granular & 3.0176 & 235 & 300 & 20 & 15 & 15 & NA & 0 & 0 & 50 \\
\hline
\end{tabular}

${ }^{1}$ Number of monoliths tested in series.

2 Catalyst. 


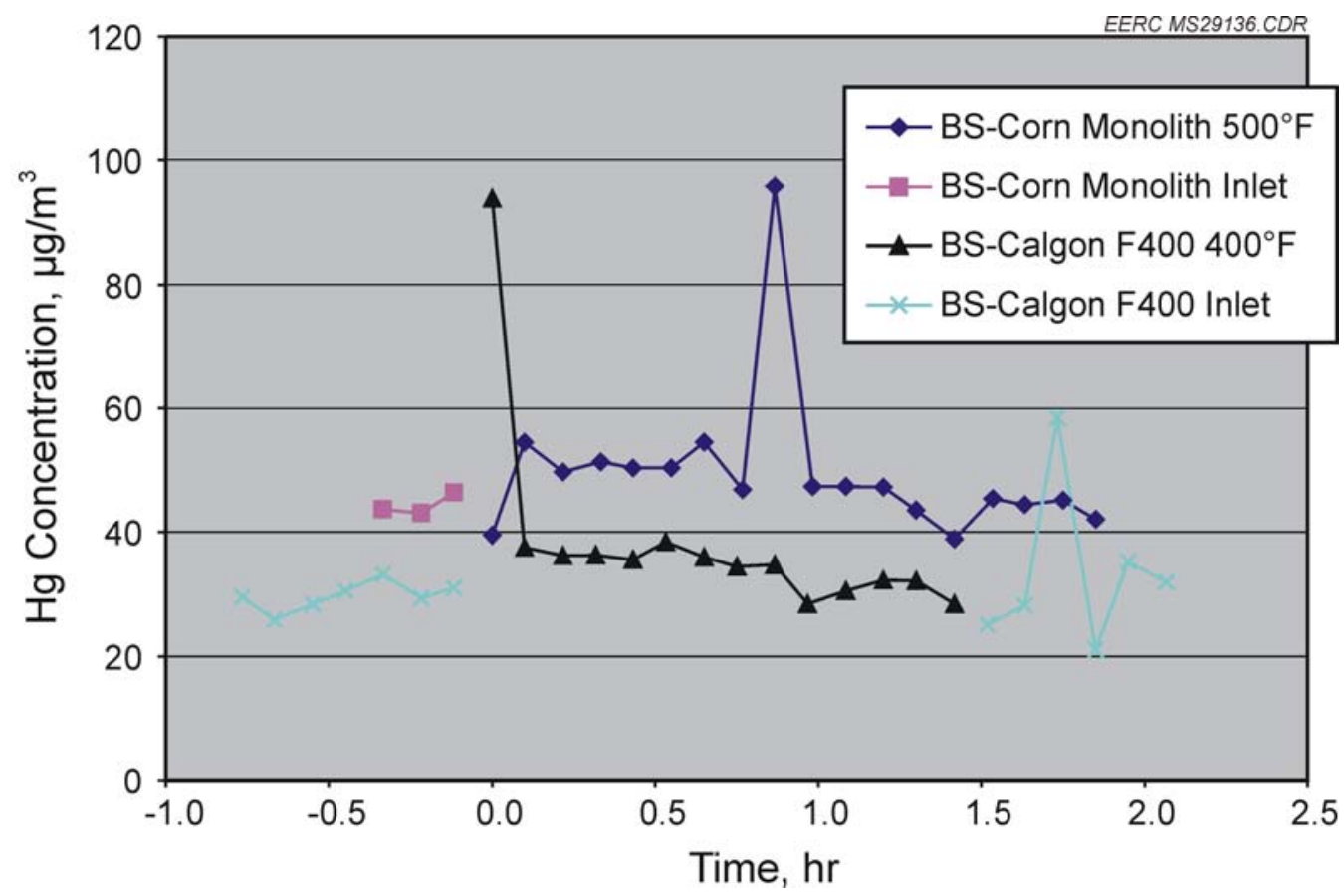

Figure 4. Breakthrough curves for baseline carbon testing at temperature and pressure.

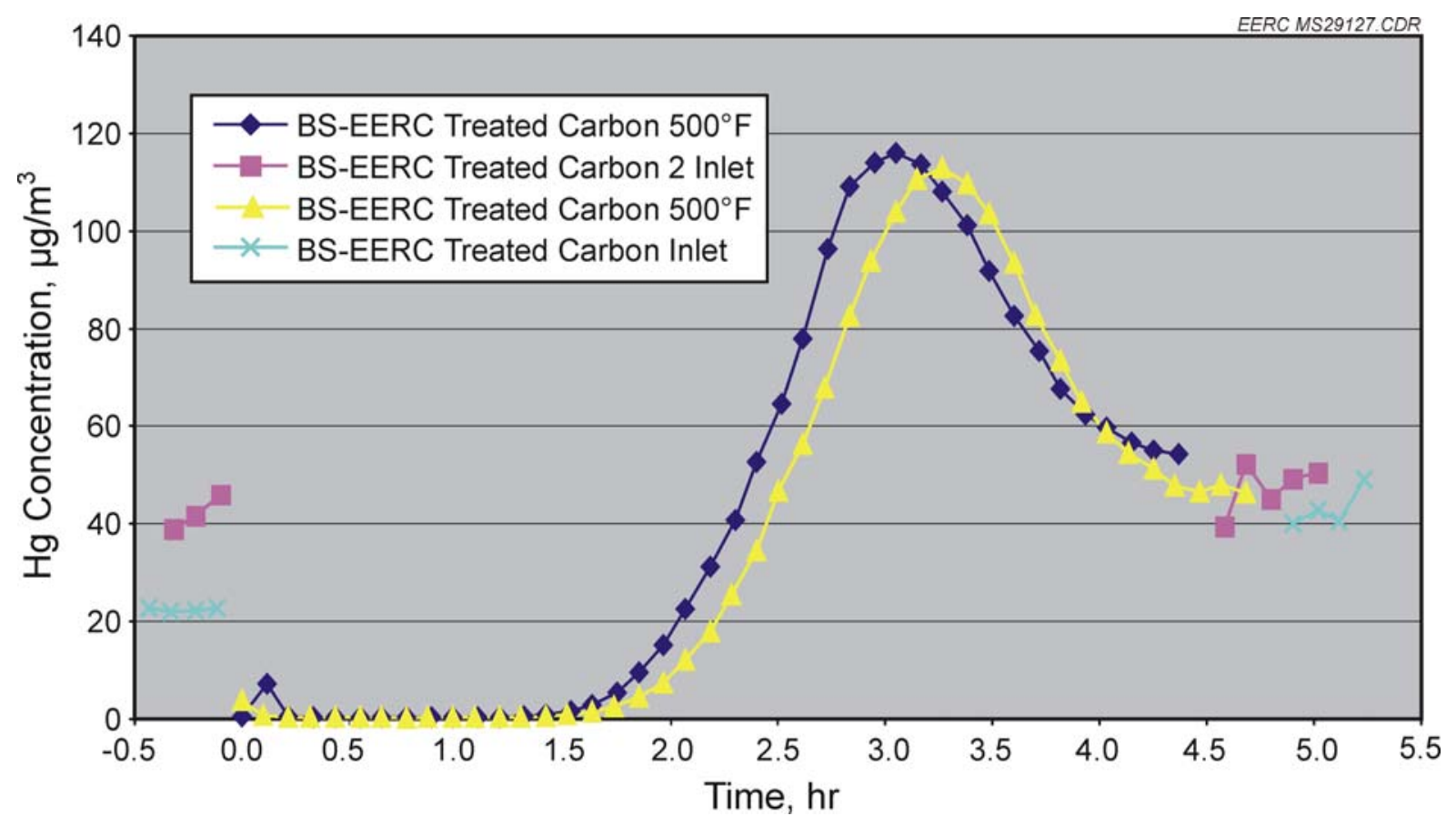

Figure 5. Breakthrough curves for EERC-treated carbon at $500^{\circ} \mathrm{F}$ and 300 psig with baseline fuel gas mixture. 


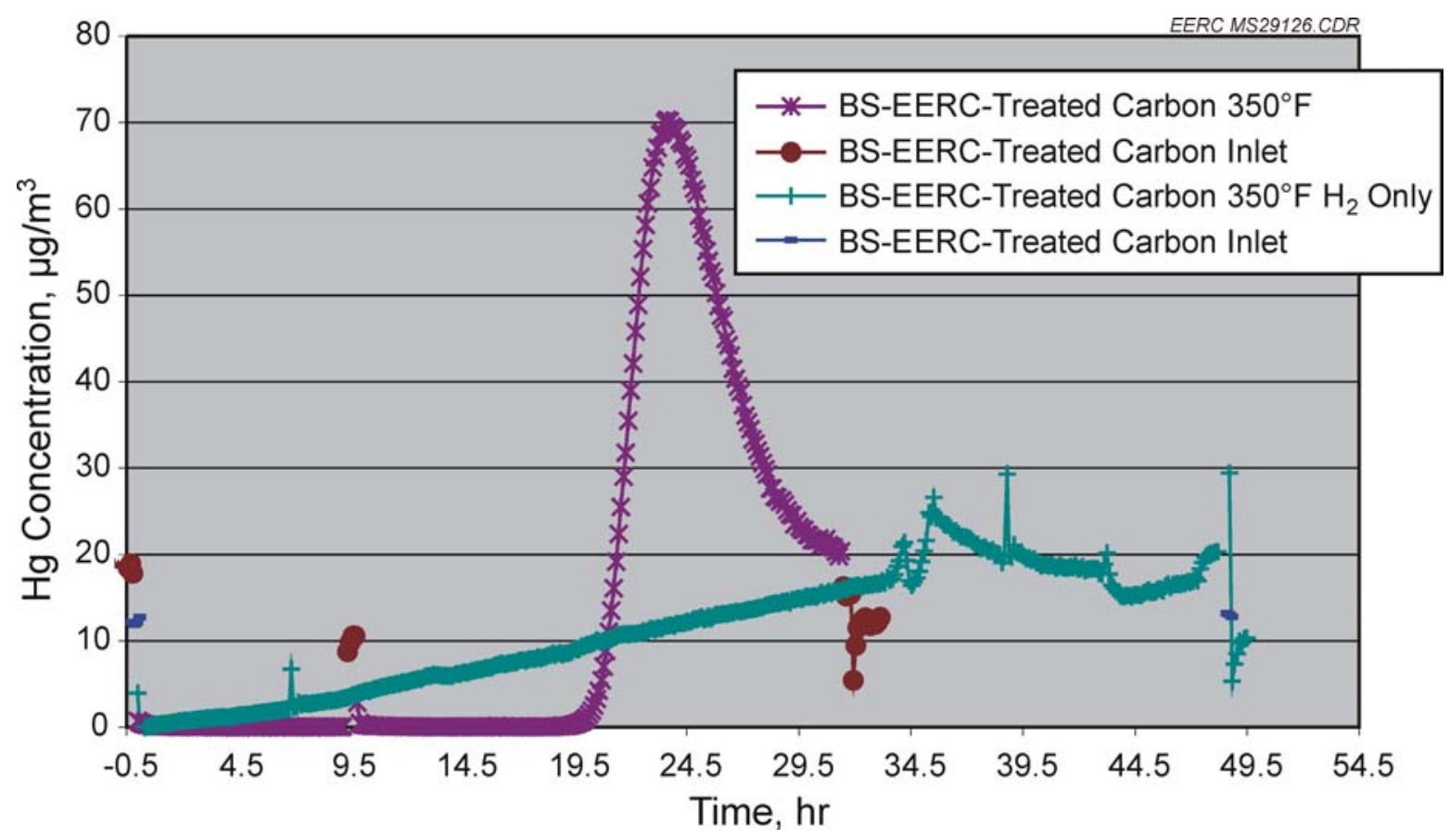

Figure 6. Breakthrough curves for EERC-treated carbon at $350^{\circ} \mathrm{F}$ and 300 psig with baseline fuel gas mixture and a hydrogen/nitrogen-reducing gas mixture.

After experiencing the desorption of the mercury at the lower temperatures, another EERC sorbent on granulated activated carbon was tested. The breakthrough curves for these sorbent tests are shown in Figure 7. This figure shows that the sorbent did not work at all at the higher temperature of $500^{\circ} \mathrm{F}$, but as soon as the temperature was dropped to $350^{\circ} \mathrm{F}$, the sorbent started collecting mercury very well and did not appear to desorb mercury like the previous sorbent. The high spike of $\mathrm{Hg}$ seen during the first test and the variability from test to test on the $\mathrm{Hg}$ starting concentration led to a decision to replace the saturated Hg sorbent with $\mathrm{Hg}$ permeation tubes similar to those utilized on the atmospheric pressure flue gas test rigs utilized at the EERC. This modification required that the system or at least the mercury permeation tubes in the $\mathrm{Hg}$ generation section be either pressurized and depressurized very slowly or that a continuous pressurized stream of $\mathrm{CO}_{2}$ or nitrogen be maintained on the permeation tubes at all times.

As monoliths from Corning became more available, these monoliths were tested with three different additives on the monolith. The breakthrough curves for these different additives on carbon monoliths are shown in Figures 8 through 10. All three figures show a period of $100 \%$ mercury capture, which demonstrates that the monoliths are not mass transfer-limited for mercury capture. Figure 8 shows results from a monolith coated with the same additive as shown in Figure 7. The results indicate that a monolith coated with this material can capture $\mathrm{Hg}$ with a high degree of efficiency for an extended period of time. However, the outlet mercury concentration is reduced to less than $5 \mu \mathrm{g} / \mathrm{m}^{3}$, which is roughly equivalent to the 5-ppbw goal for mercury emissions. The shorter period of high mercury capture may be caused by the sorbent surface becoming saturated with mercury and the diffusion of the $\mathrm{Hg}$ into the lower layers of the additive coating, controlling the rate of $\mathrm{Hg}$ absorption. 


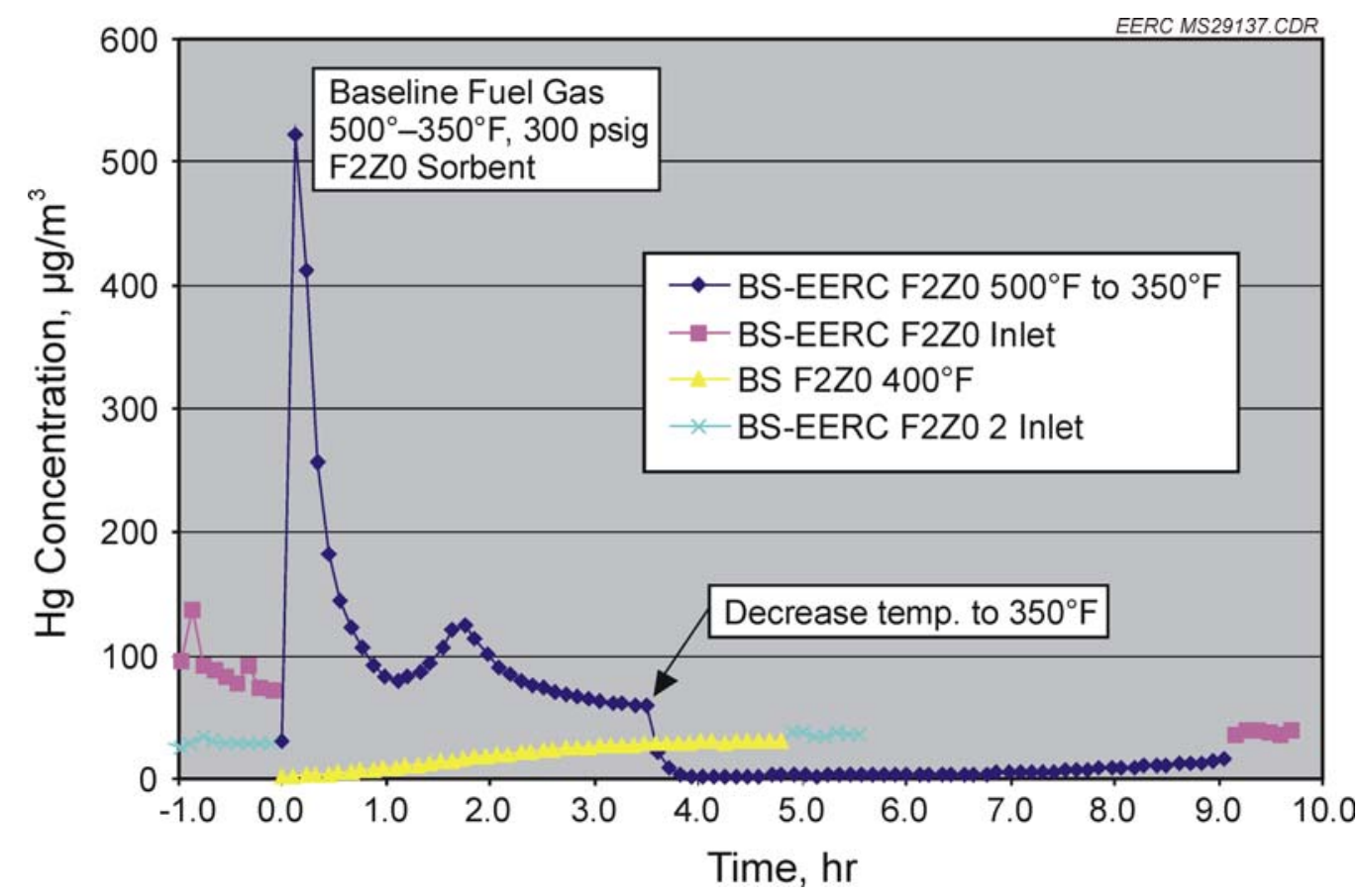

Figure 7. Breakthrough curves for a different EERC-treated carbon as a function of operating temperature.

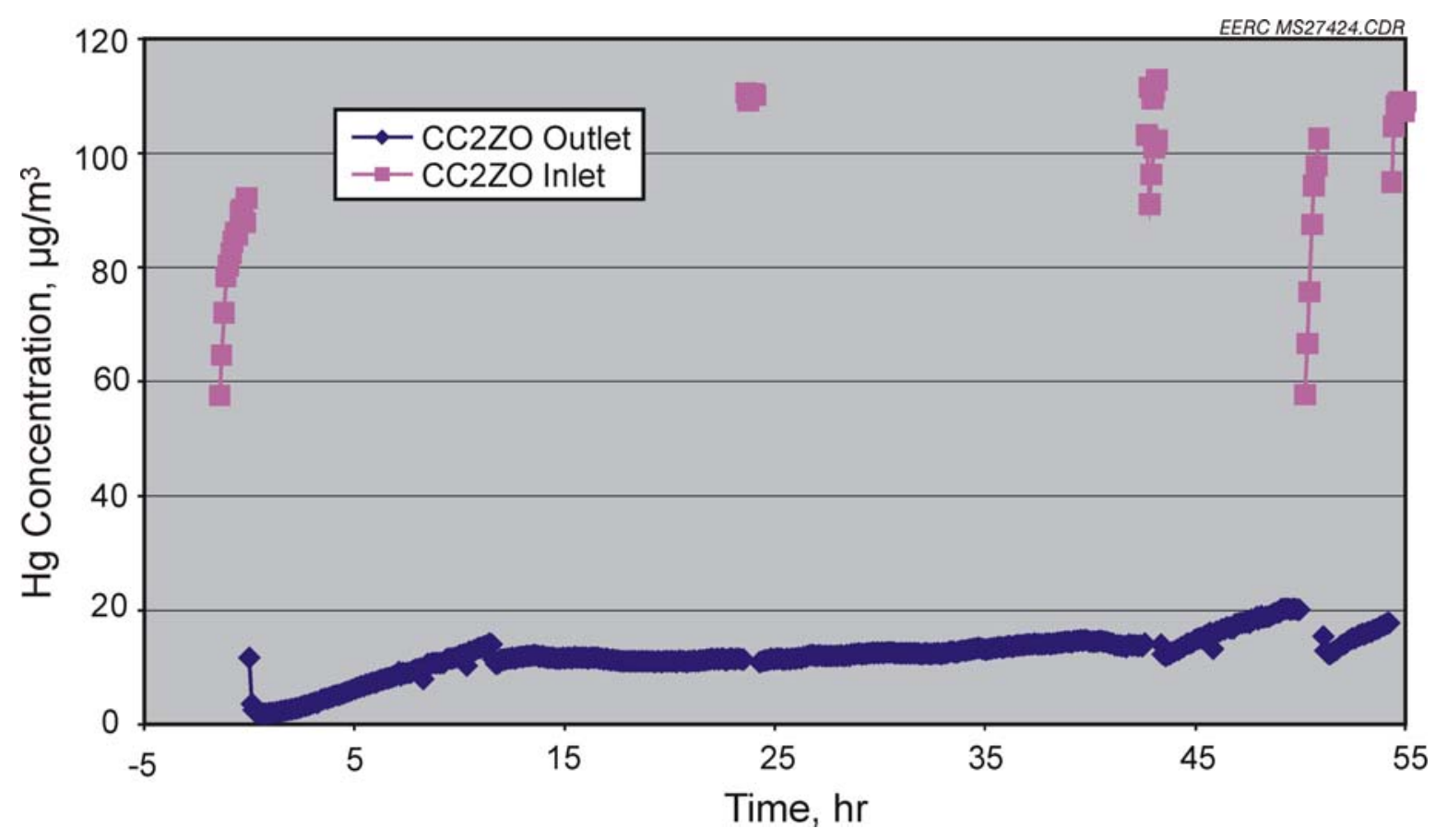

Figure 8. Breakthrough curve for EERC-treated monolith Test 18 (CCZ2O). 


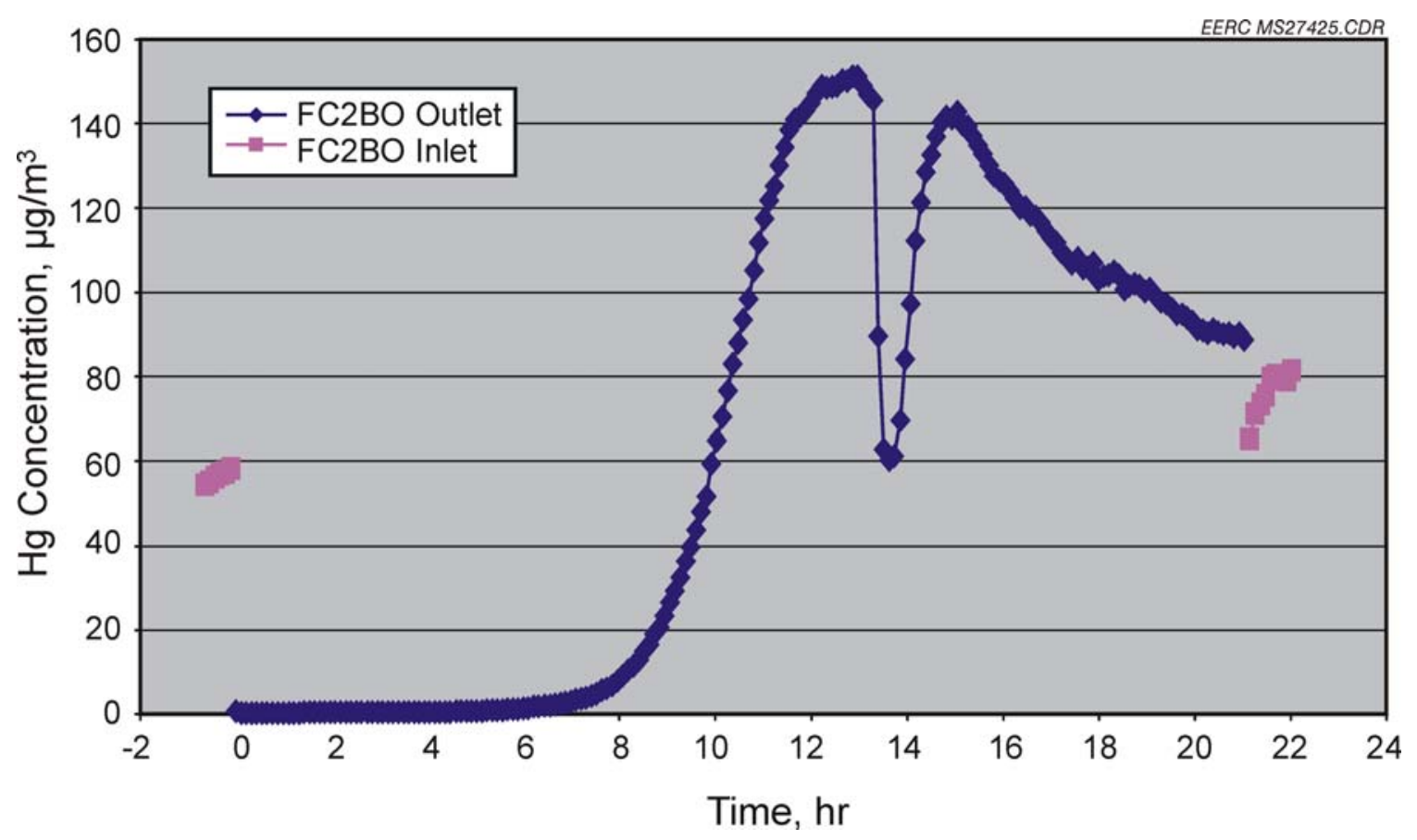

Figure 9. Breakthrough curve for EERC-treated carbon monolith Test 19 (FC2BO).

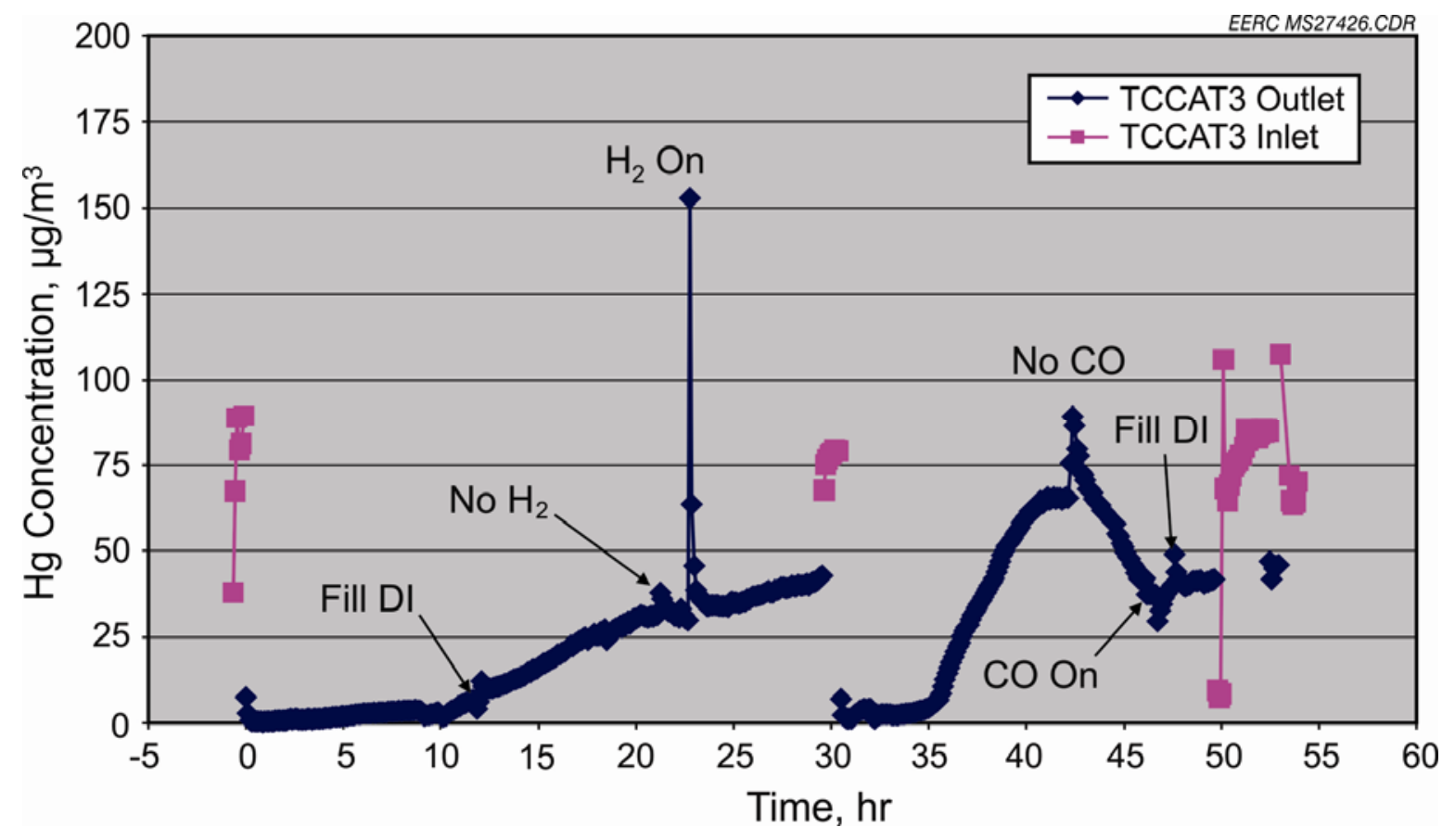

Figure 10. Breakthrough curve for EERC-treated monolith Test 20 (TCCAT3). 
Figure 9 shows that the second EERC-treated carbon monolith provided by Corning, Inc., utilizing the same additive shown in Figures 5 and 6 captures the Hg very well for a period of time before the $\mathrm{Hg}$ starts to break through and eventually desorb. Again, the desorption of the mercury was attributed to the slow devolatilization of the additive as a function of time. The EERC is still currently investigating less volatile forms of the additive that might permanently hold the additive (and, therefore, the mercury) to the carbon monolith.

Figure 10 shows the breakthrough curve for a Corning-treated carbon monolith that has a relatively slow breakthrough curve that also shows the capability to absorb more mercury after the syngas flow has been stopped to the monolith for a short period of time. This suggests a simple sorbent regeneration procedure might be possible to increase the monolith mercuryloading capacity and period of utilization.

A breakthrough curve test on a carbon monolith that was treated at Corning is shown in Figure 11. An additional breakthrough test completed utilizing one of the Corning monoliths but with just one of the additives from the Corning treatment utilized in Figure 11 is shown in Figure 12. The fact that the breakthrough curves for these different additives on the same type of carbon monolith are similar suggests that the one additive might be the key ingredient that is capturing mercury. In fact, the relatively slow reduction of the outlet mercury concentration in Figure 11 as compared to Figure 12 may suggest that the extra catalyst material might even be hindering the effectiveness of the one additive. The results indicate that a monolith coated with this material can capture Hg with a high degree of efficiency for an extended period of time with the outlet mercury concentration being reduced to less than $5 \mu \mathrm{g} / \mathrm{m}^{3}$, which is roughly equivalent to the 5-ppbw goal for mercury emissions for the given molecular weight of the fuel gas mixture utilized. The shorter period of high mercury capture may be caused by the sorbent surface becoming saturated with mercury and diffusion of the $\mathrm{Hg}$ into the lower layers of the additive coating becoming the rate-controlling step.

Figures 13 and 14 show the effect of temperature and pressure on the $\mathrm{Hg}$ absorption performance of the EERC-treated carbon F2ZO as a percentage of the inlet concentration. The data were presented as a function of the inlet concentration because the inlet concentration changed at each different test condition since, at a constant space velocity, the volumetric flow of the bottled gases was different; however, the total amount of $\mathrm{Hg}$ coming from the permeation tubes was constant. Figure 13 shows that, at $650^{\circ} \mathrm{F}$, the sorbent has no effectiveness at capturing $\mathrm{Hg}$, while at $500^{\circ} \mathrm{F}$, the sorbent-only captured the $\mathrm{Hg}$ for a very short period of time. At $350^{\circ} \mathrm{F}$, the sorbent tends to capture the Hg for a greatly extended period of time. Figure 14 shows the effect of system pressure on Hg capture performance. Higher pressures result in lower inlet concentration and, thus, a lower concentration gradient driving force to absorb the $\mathrm{Hg}$ on the surface.

Figures 15 and 16 show the results from EERC-treated carbon monolith tests using a less volatile form of the original EERC additive tested in Figures 8, 9, and 12. Previous tests have shown that the EERC additive captures the Hg very well for a period of time before the Hg starts to break through and eventually desorb. The desorption of the mercury was attributed to the slow devolatilization of the additive as a function of time. Both of these figures show that the Hg was captured on the monolith without major desorption of the additive. 


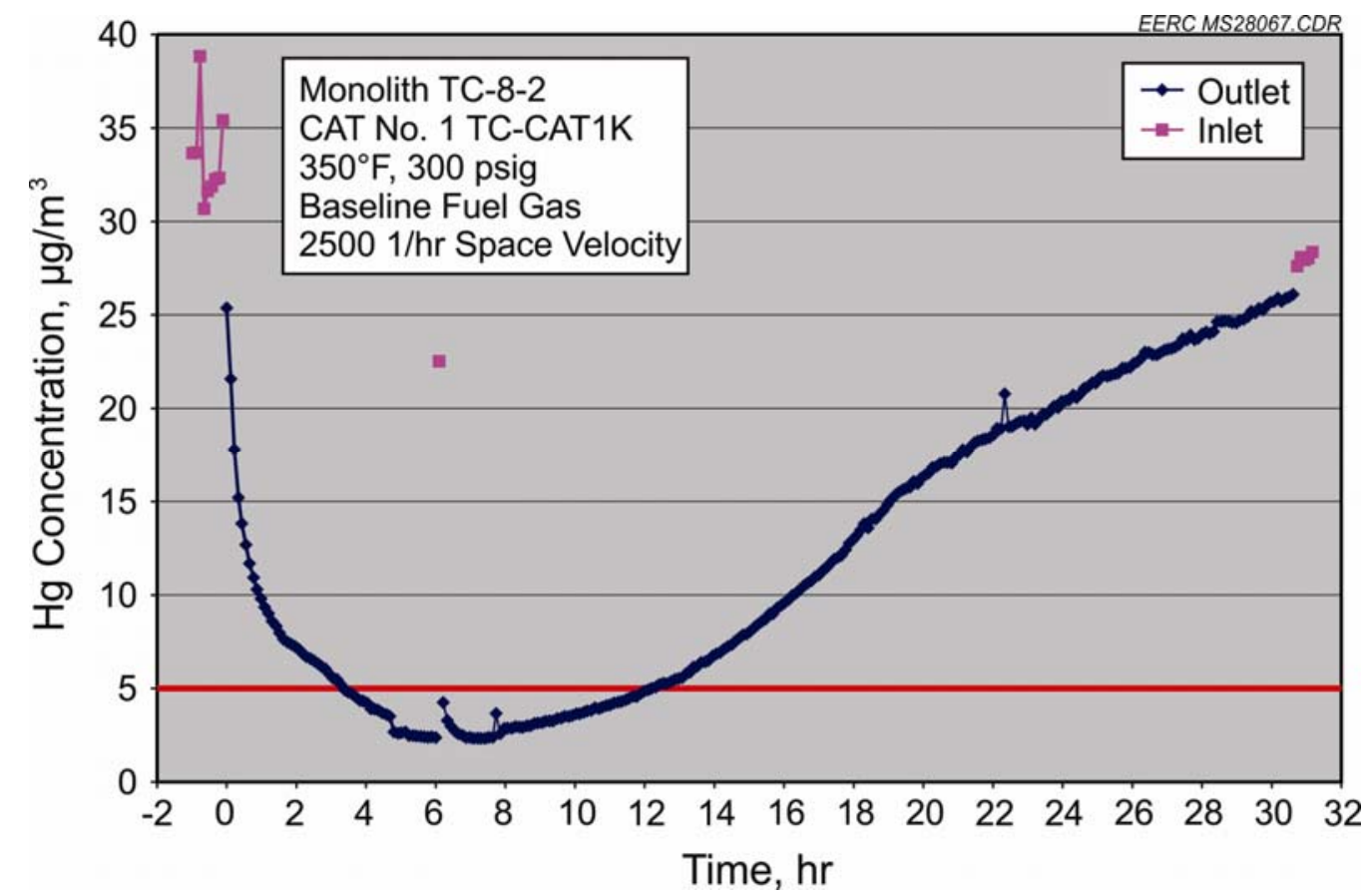

Figure 11. Breakthrough curve for EERC-treated carbon monolith Test 24 (TC-CAT1K).

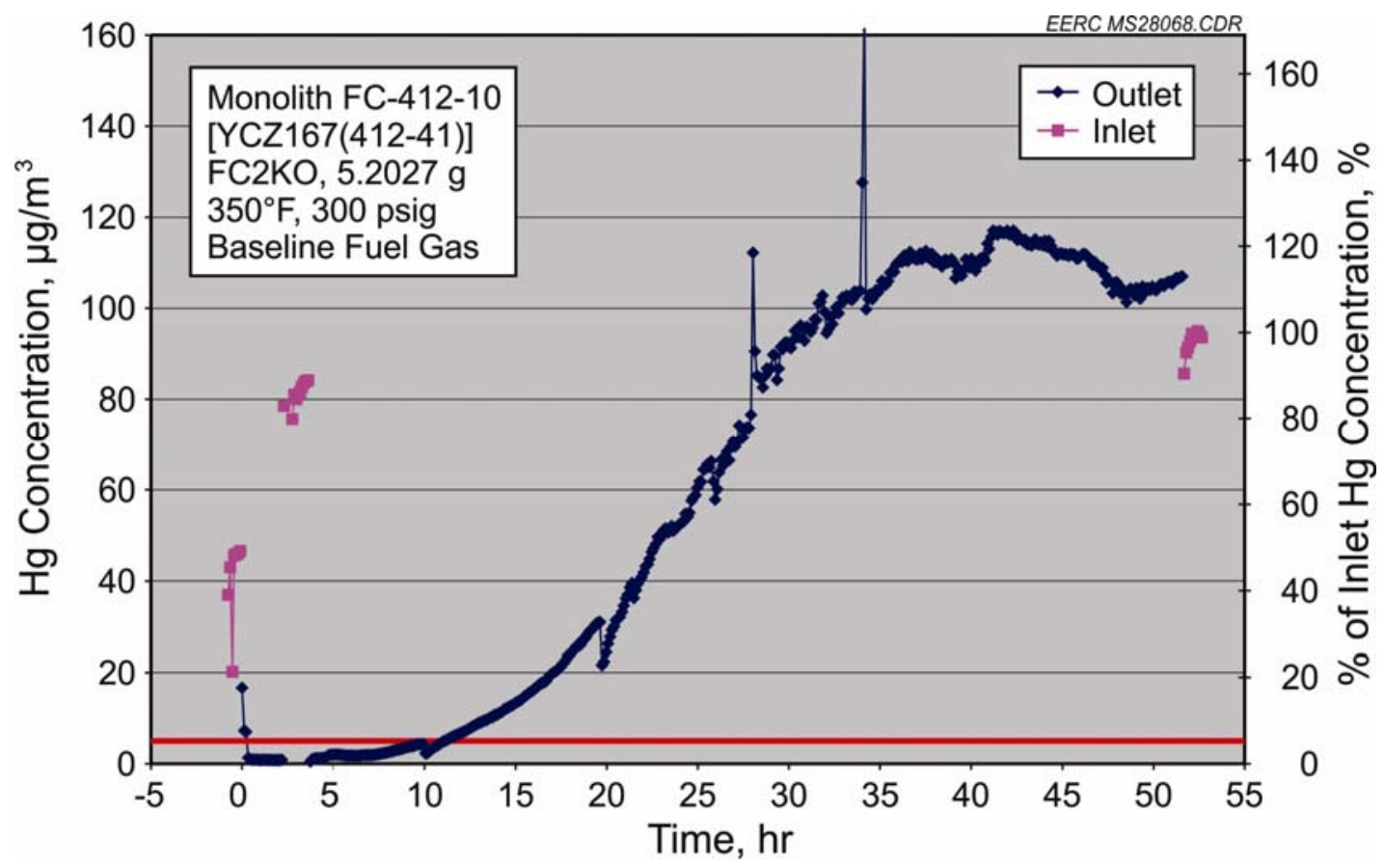

Figure 12. Breakthrough curve for EERC-treated carbon monolith Test 25 (FC2KO). 


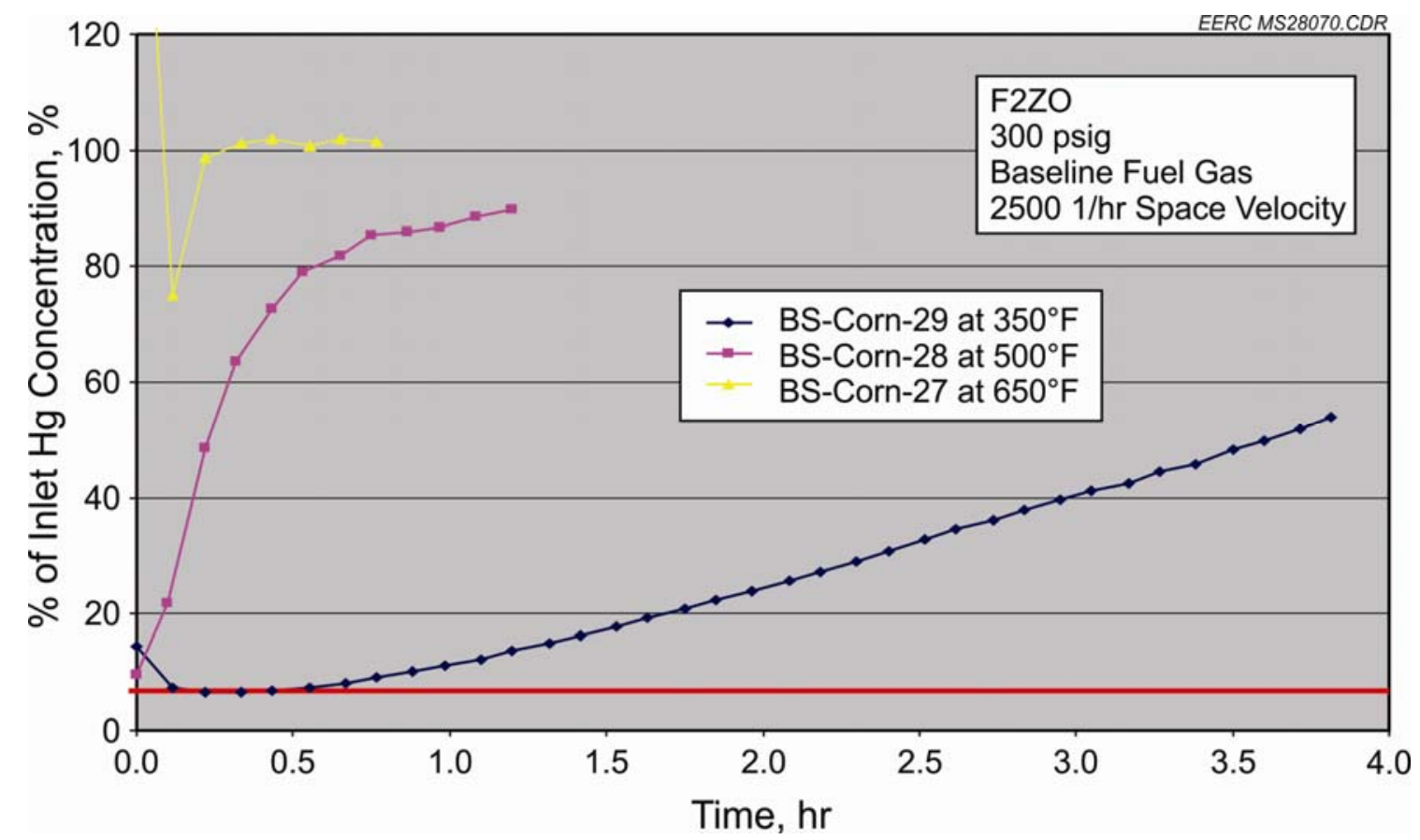

Figure 13. Breakthrough curve for the EERC-treated carbon as a function of temperature Tests 27 through 29 F2ZO.

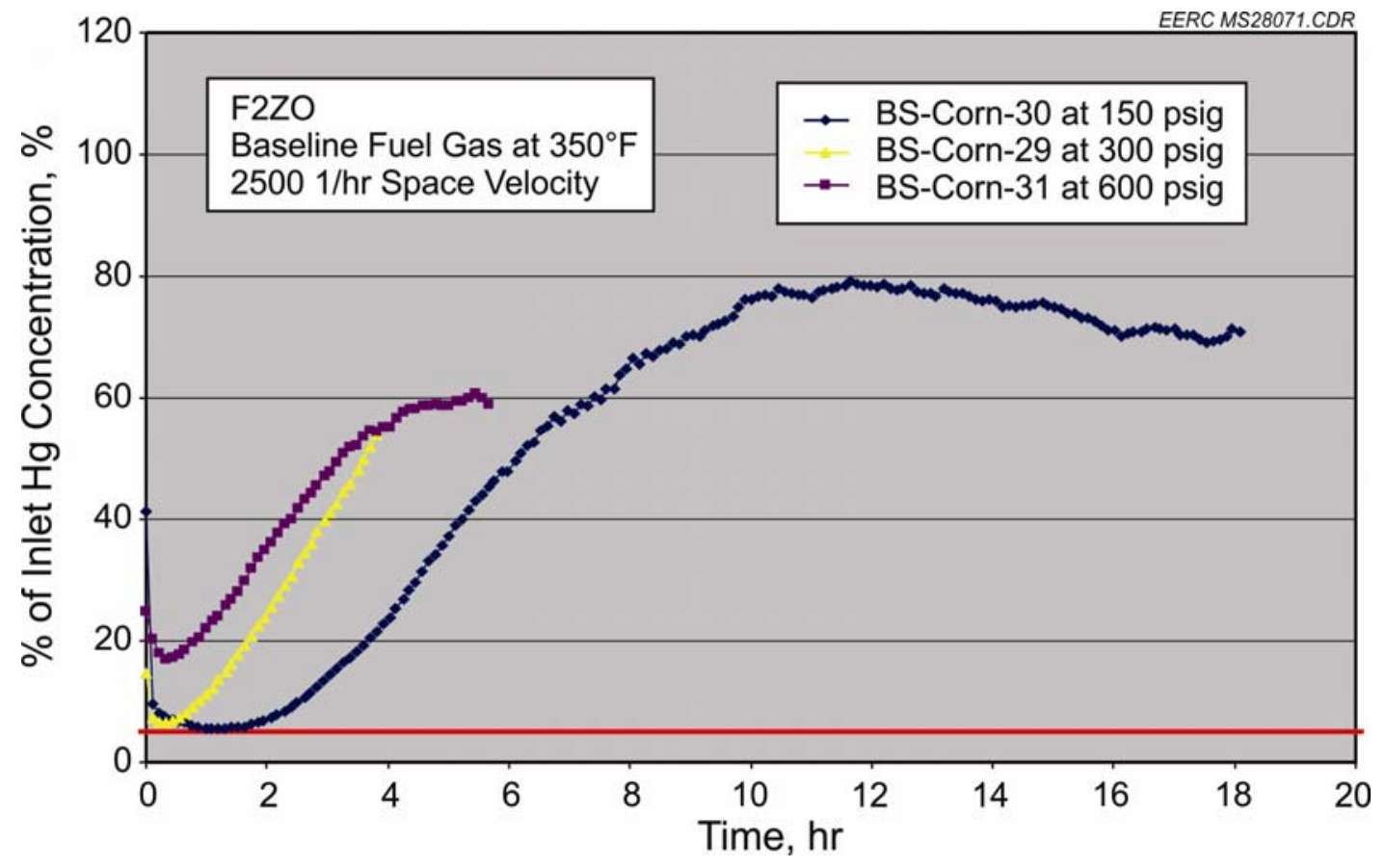

Figure 14. Breakthrough curves for EERC-treated carbon Tests 27 through 29 with F2ZO at various pressures. 


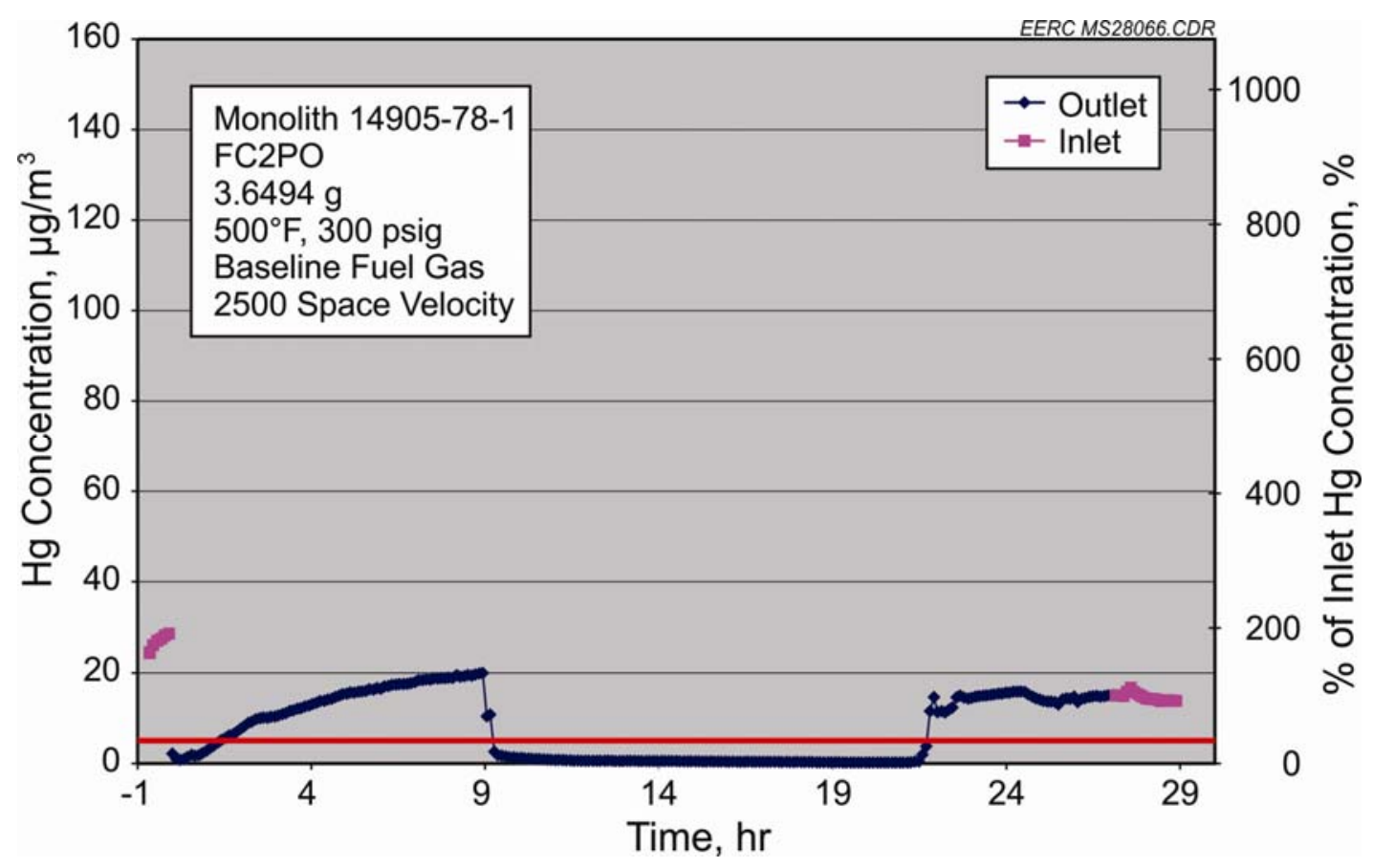

Figure 15. Breakthrough curve for EERC-treated monolith FC2PO at $500^{\circ} \mathrm{F}$.

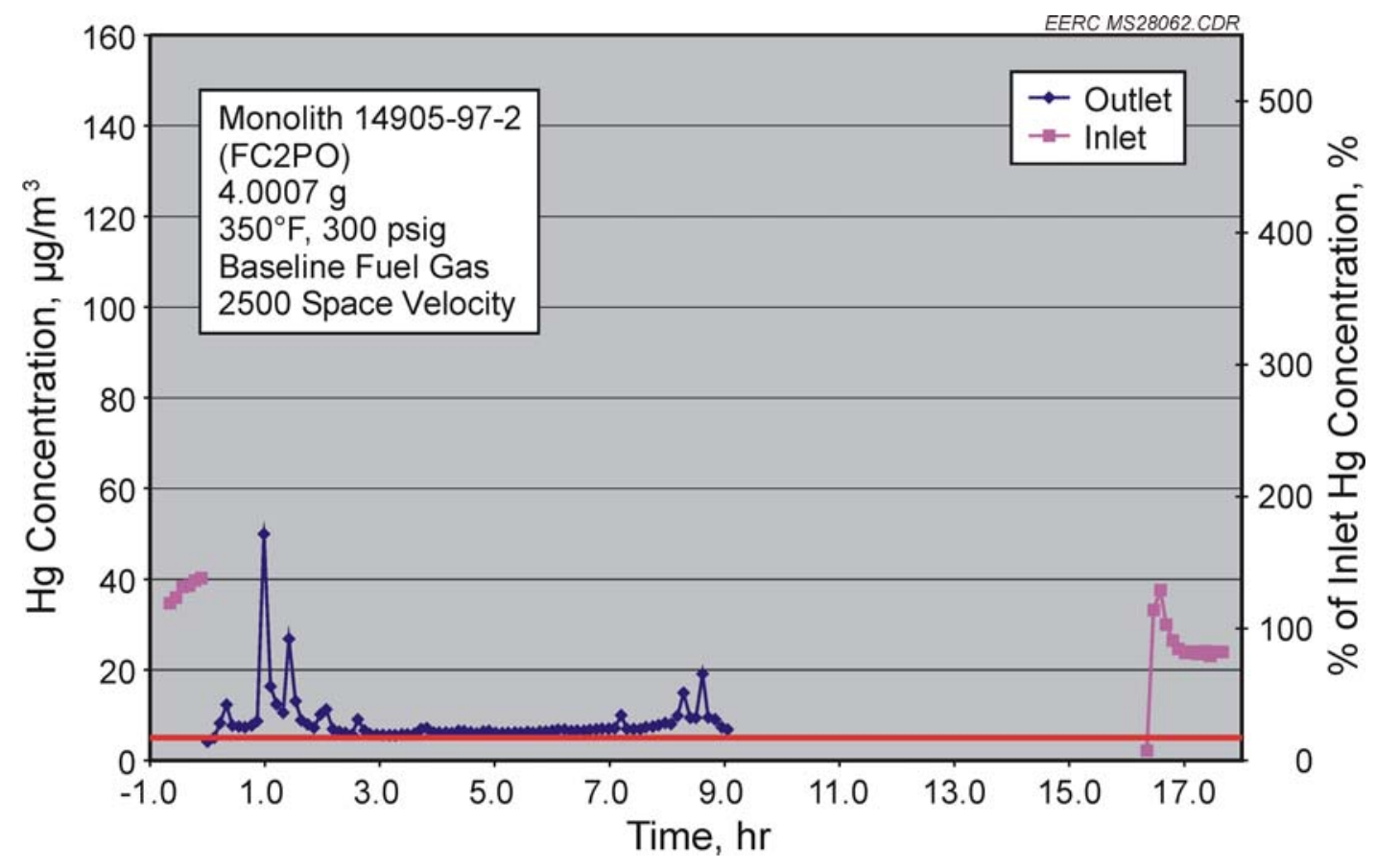

Figure 16. Breakthrough curve for EERC-treated monolith FC2PO at $350^{\circ} \mathrm{F}$. 
Figure 17 shows the breakthrough curve for a Corning-treated monolith utilizing the same additive as the additive for Figures 10 and 11 except the additive was incorporated in the Corning monolith production process. A comparison with other tests suggests that the Corning monolith production process incorporates a curing process at a temperature high enough to decompose the additive. This leads to the poor Hg capture performance shown in Figure 17.

Other tests with FCZCO, FCCMO, and FCCMSO all showed little Hg capture at $350^{\circ} \mathrm{F}$ and 300 psig. Figures 18 through 21 show the breakthrough curves for these particular sorbents.

A breakthrough curve test, shown in Figure 21, on a treated carbon sample, F2ZO, was tested with the baseline fuel gas mixture except that $1750 \mathrm{ppm}$ of hydrogen sulfide was present in the gas stream. From these results, the additive performance was significantly affected by the presence of the $\mathrm{H}_{2} \mathrm{~S}$. This was not entirely unexpected since one part of the additive is known to be potentially reactive toward sulfur.

Figure 22 shows the results from Corning-treated carbon monolith with Catalyst 4 that was not a good additive for controlling the mercury; however, Figures 23 and 24 show tests with a Corning-treated monolith that was very effective at controlling the mercury. This SR Liquid additive never did break through on the Hg removal tests in over 150 hours of testing. This sorbent was tested at higher pressures (up to $600 \mathrm{psig}$ ) and higher temperatures up to $700^{\circ} \mathrm{F}$ and was found to be very effective at controlling the mercury to levels equal to or lower than the concentrations required by the test program.

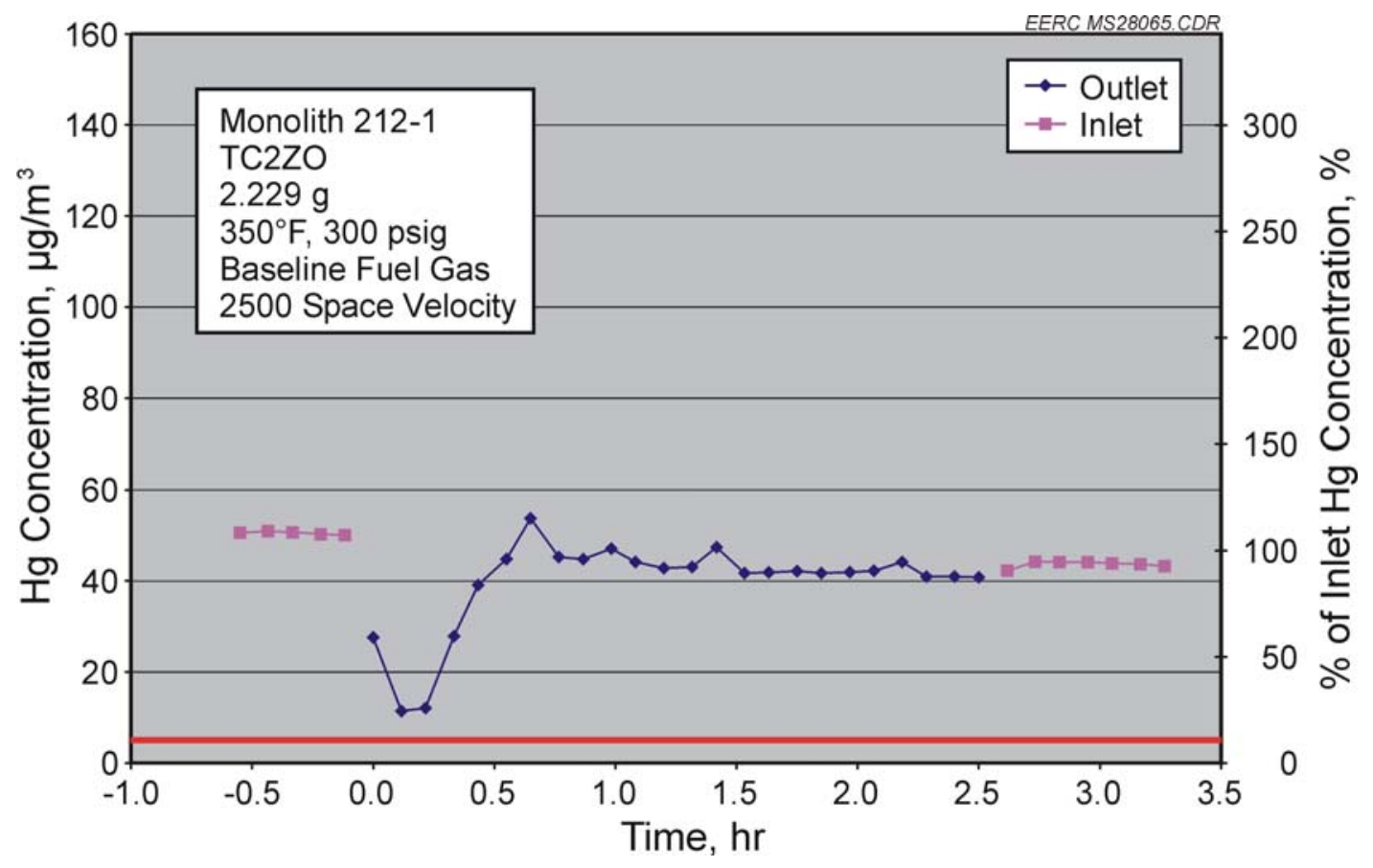

Figure 17. Test with Corning-treated monolith TCZO. 


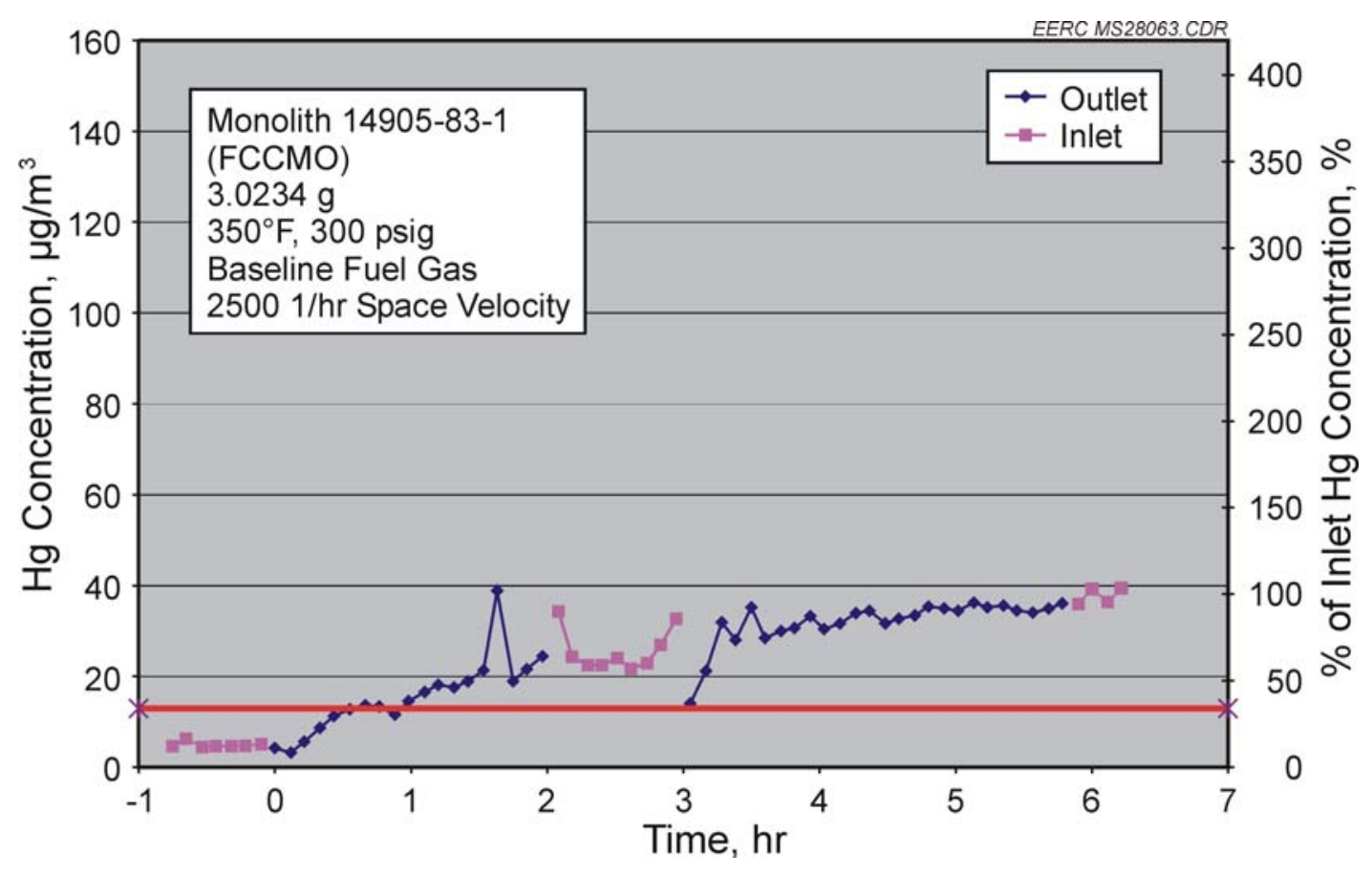

Figure 18. Breakthrough curve for carbon monolith with FCCMO additive.

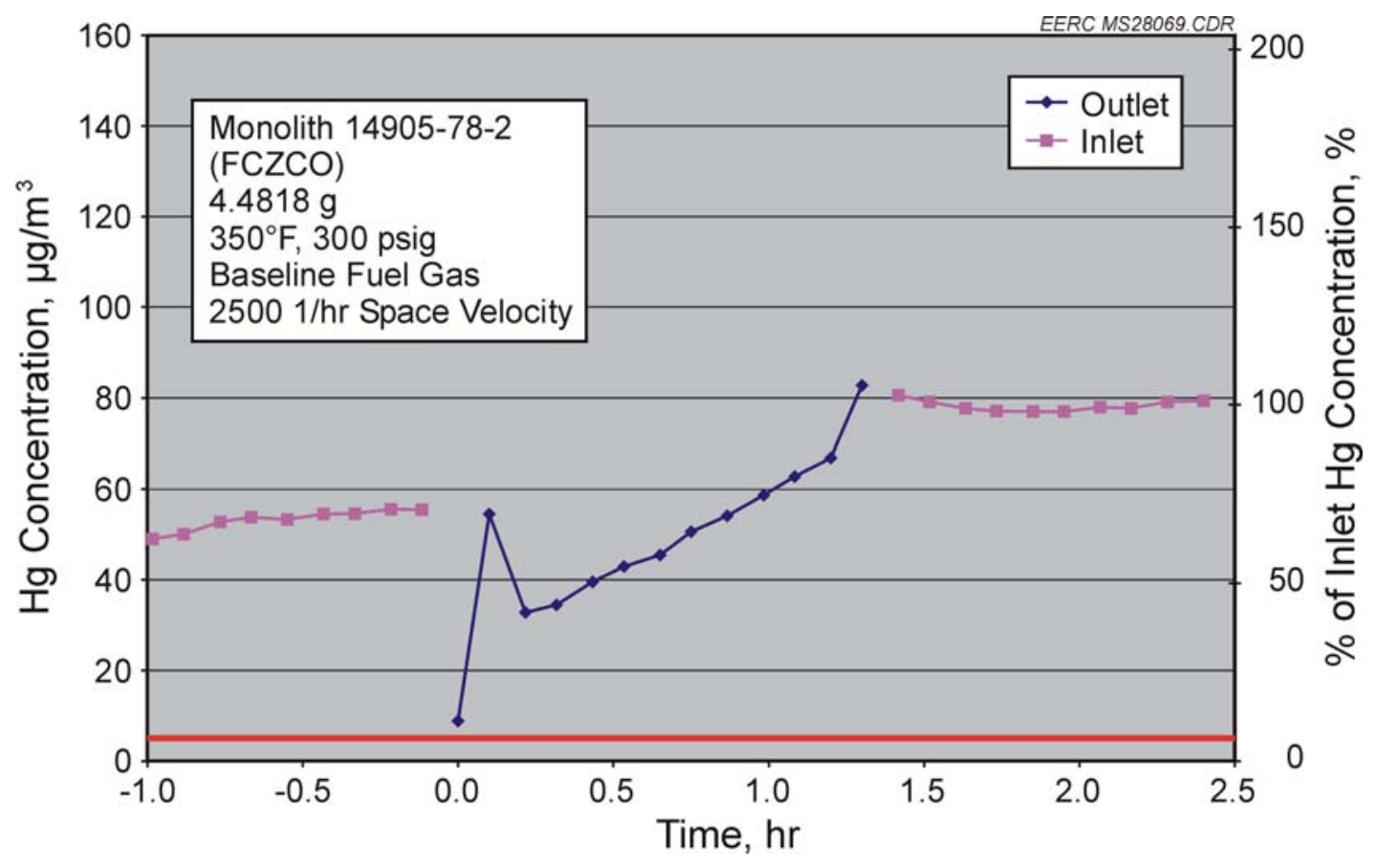

Figure 19. Breakthrough curve for carbon monolith with FCZCO additive. 


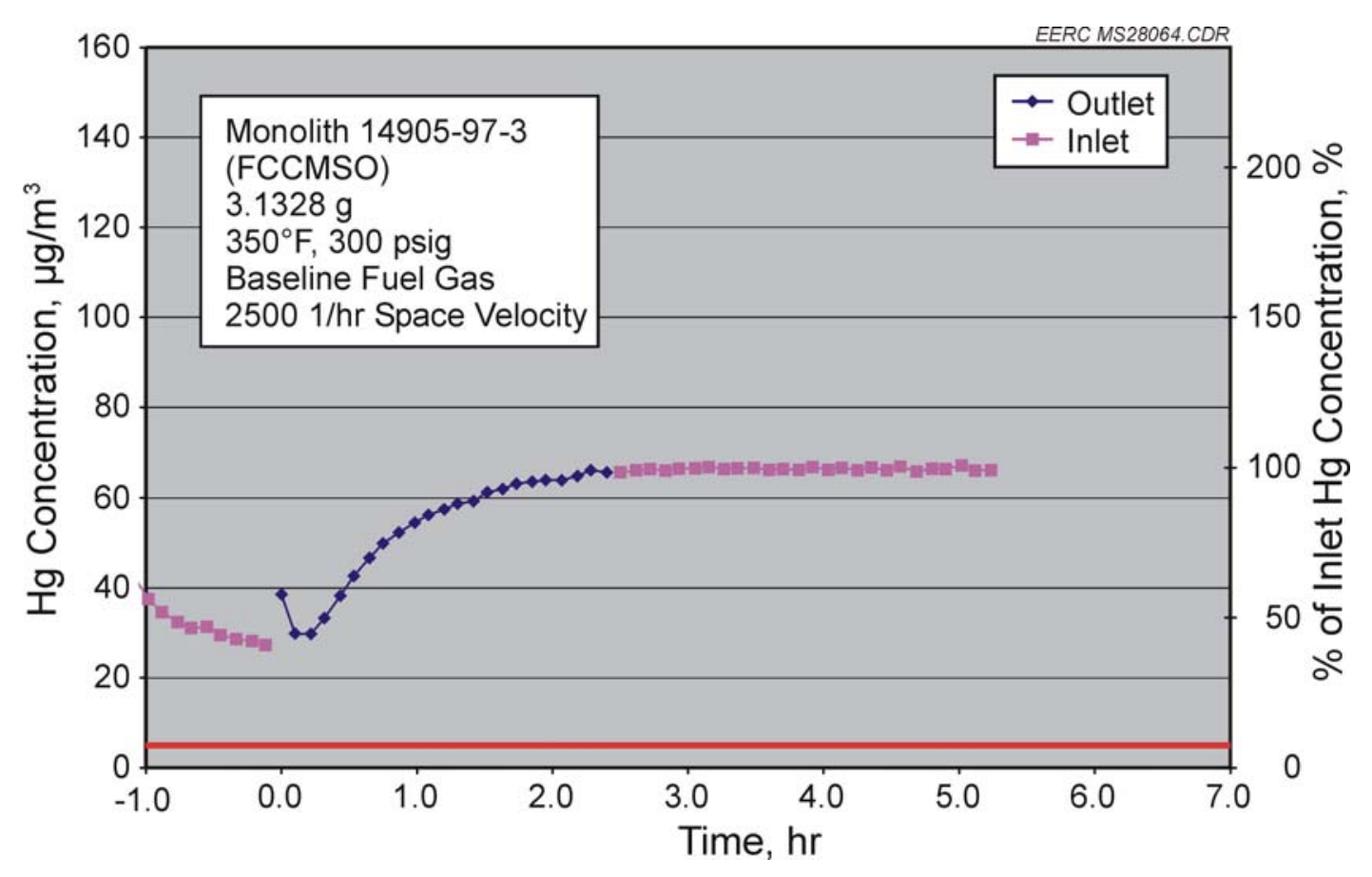

Figure 20. Breakthrough curve for carbon monolith with FCCMSO additive.

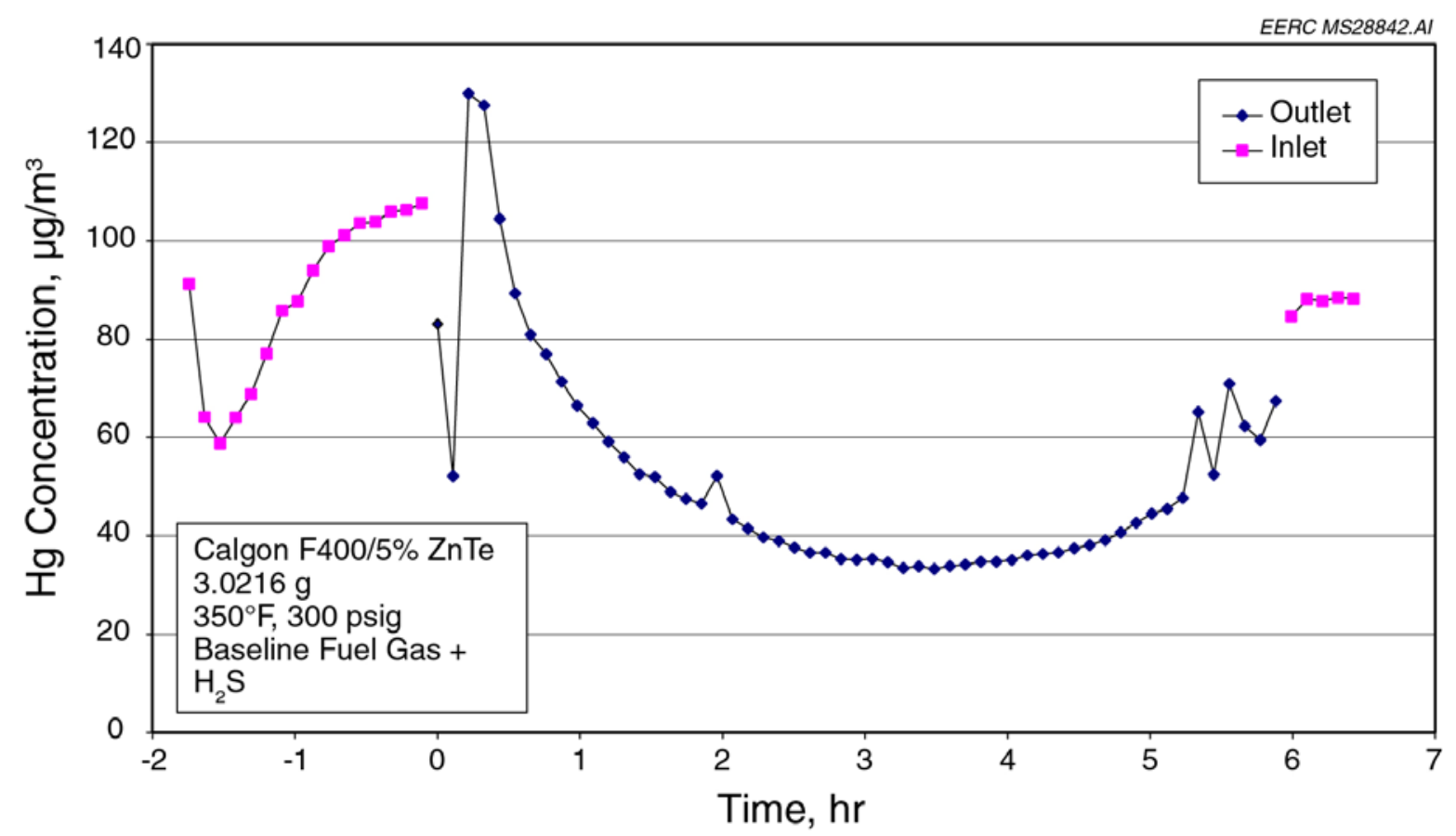

Figure 21. Mercury breakthrough curve for EERC-treated monolith in Test 39 (F2ZO) in fuel gas with high $\mathrm{H}_{2} \mathrm{~S}$ concentration. 


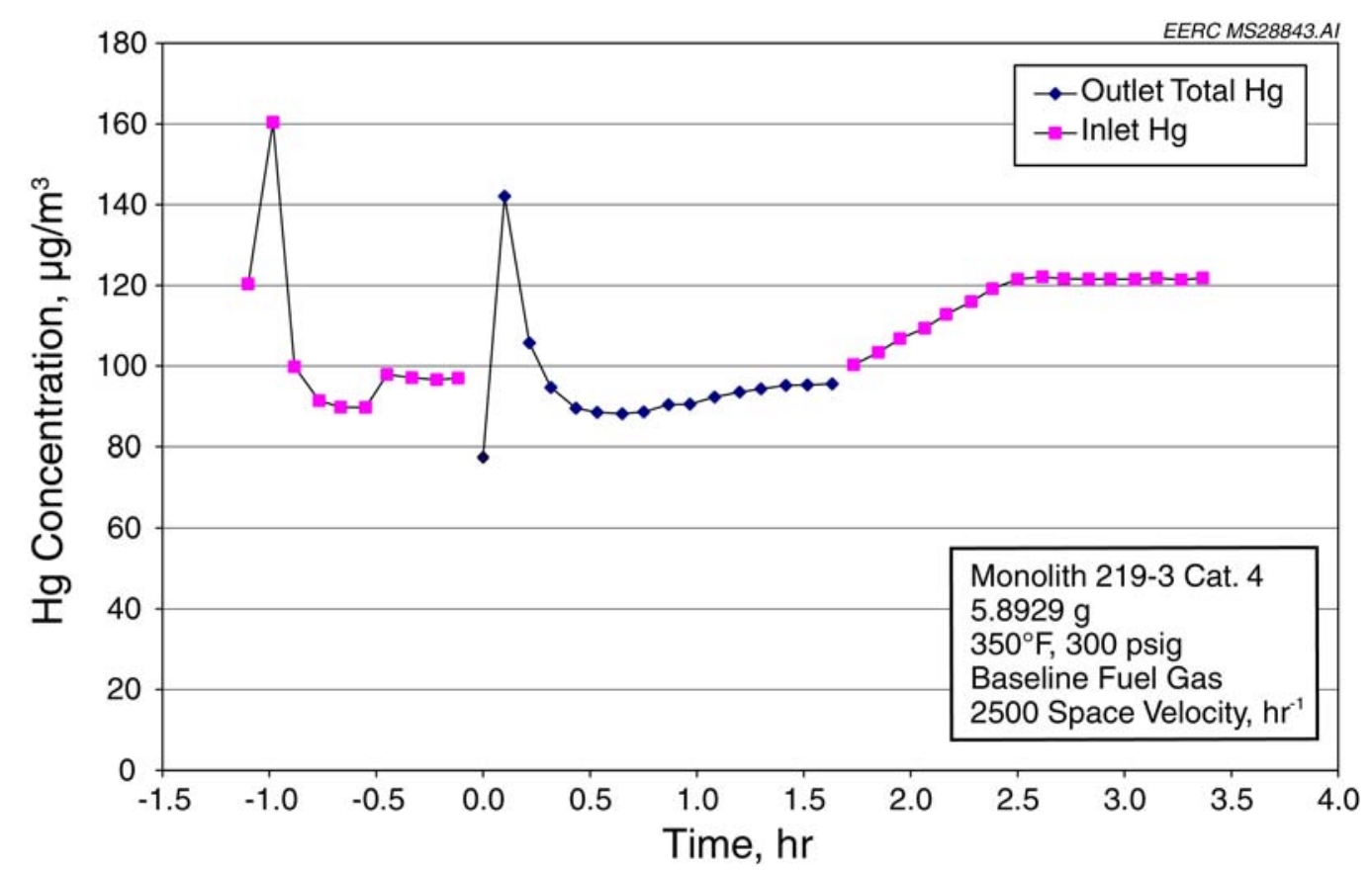

Figure 22. Breakthrough curve for Corning-treated monolith utilizing a Catalyst 4 additive at $350^{\circ} \mathrm{F}$.

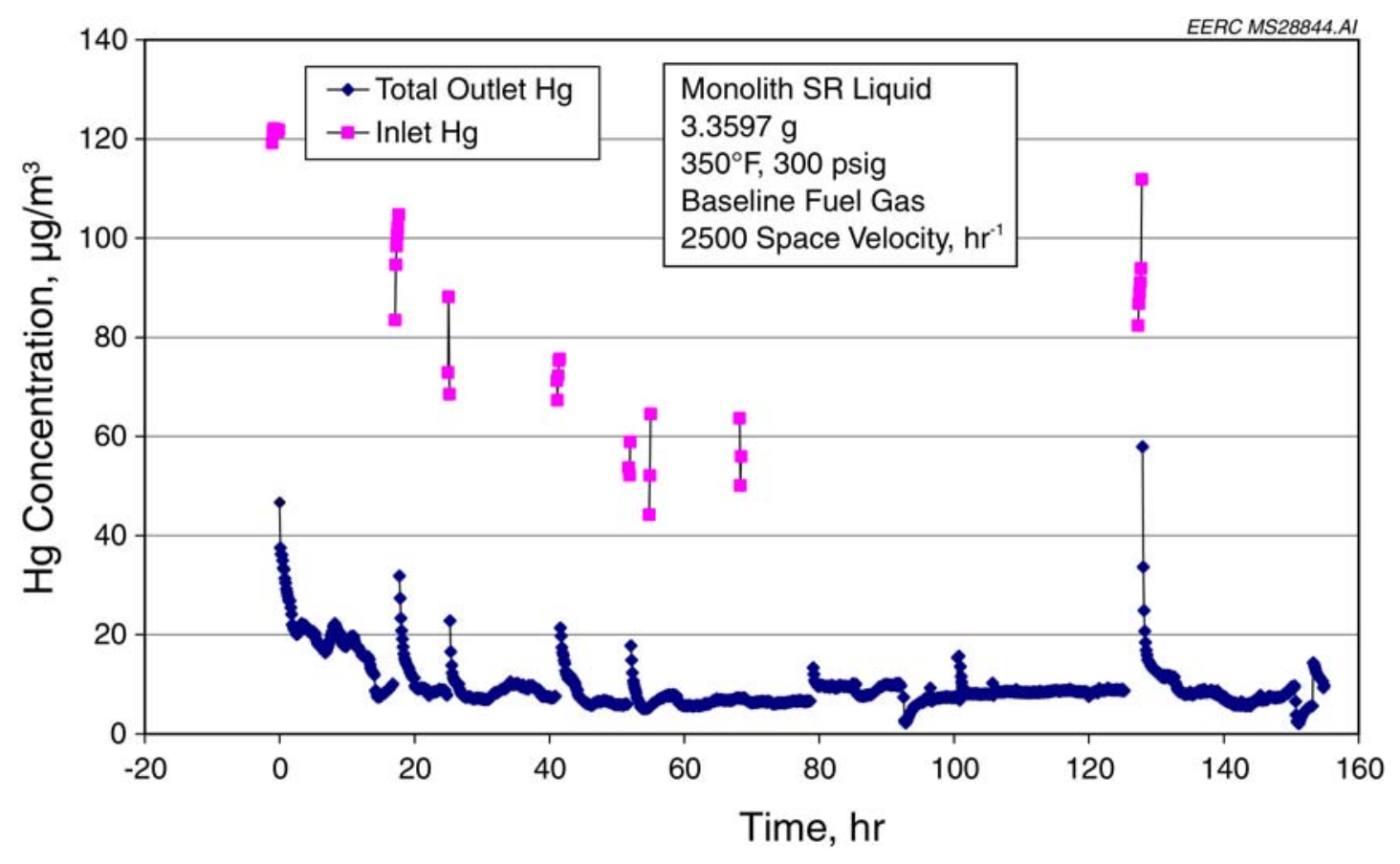

Figure 23. Breakthrough curve for Corning-treated monolith utilizing a SR Liquid additive at $350^{\circ} \mathrm{F}$. 


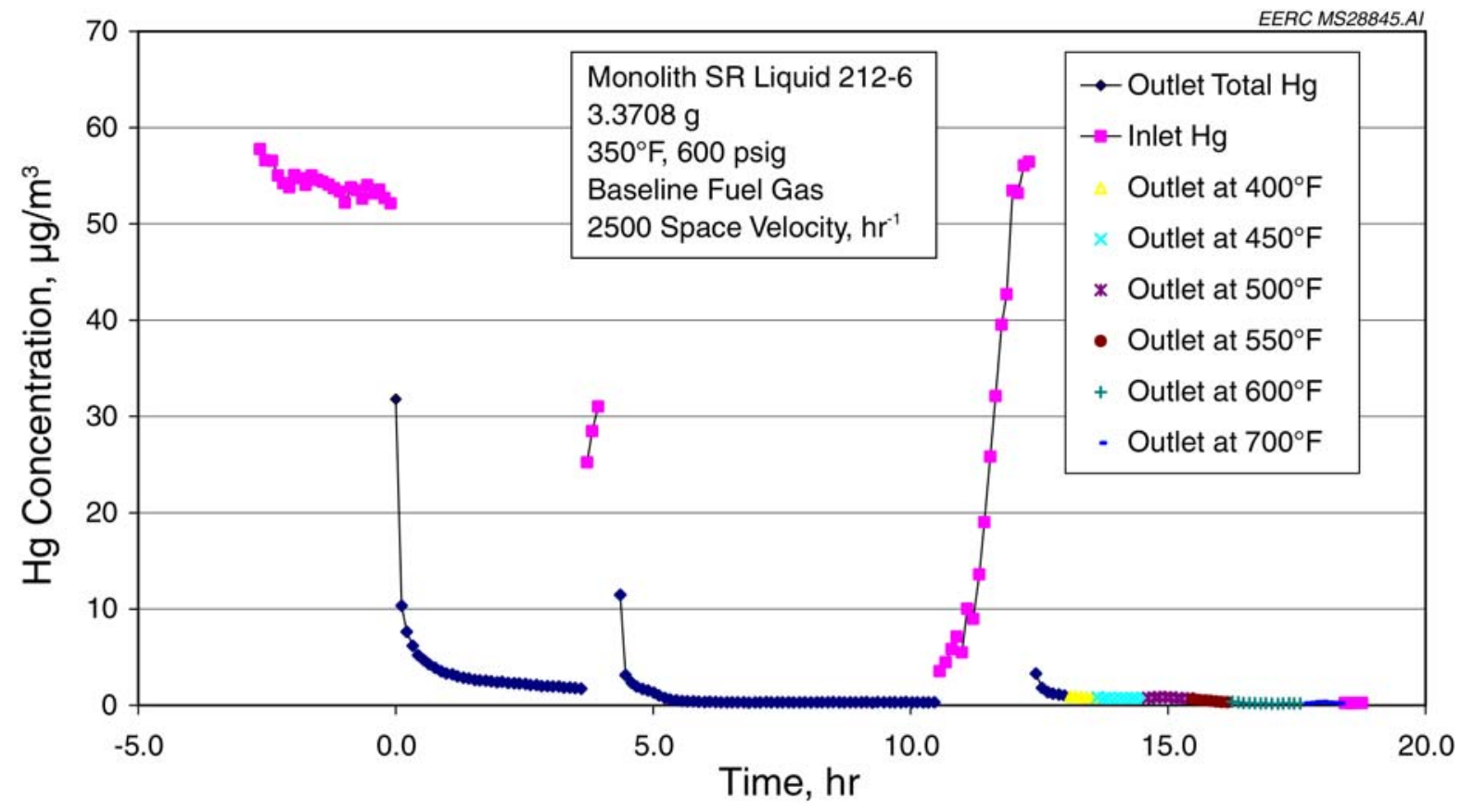

Figure 24. Breakthrough curve for Corning-treated monolith with SR Liquid additive at higher operating pressures and temperatures.

Figure 25 shows a test which was conducted with the Corning-treated carbon monolith that had Catalyst 2, (which is just one of the combined additives present in the SR Liquid additive) in the presence of hydrogen sulfide. This test showed that this additive had some properties similar to the earlier SR Liquid tests (capture at higher temperatures up to $450^{\circ} \mathrm{F}$ and control to levels close to that desired in the program, even in the presence of $\mathrm{H}_{2} \mathrm{~S}$ ); however, the $\mathrm{Hg}$ control is not as effective as the SR Liquid-treated monolith. This test was also completed with $\mathrm{SnCl}_{2} / \mathrm{NaOH}$ pretreatment steps to ensure that the $\mathrm{H}_{2} \mathrm{~S}$ had not converted the elemental $\mathrm{Hg}$ that the PSA Sir Galahad measures to some form that the analyzer would not detect.

Mercury loadings for three of the best monoliths tested were completed. Table 2 shows the measured Hg loadings as determined by acid leaching into aqua regia and then followed by analysis of the solution by cold-vapor atomic adsorption (CVAA).

These data show that the first sorbent was achieving a mercury loading that was not saturated, and good mercury closures were found. These results are very similar to the mercury loadings reported by Alptekin, G., et al. (2) in which Hg sorbent loadings of 114 to $1231 \mu \mathrm{g} / \mathrm{g}$ were achieved. Mercury closure for the SR Liquid sorbent were poor, with $1 \% \mathrm{Hg}$ being recovered, and the maximum $\mathrm{Hg}$ loading being approximately $43 \mu \mathrm{g} / \mathrm{g}$. There is some concern that the mercury stabilizing compound in this additive may not be acid leachable and, therefore, would not measured by the CVAA technique utilized to conduct these analyses. The final 


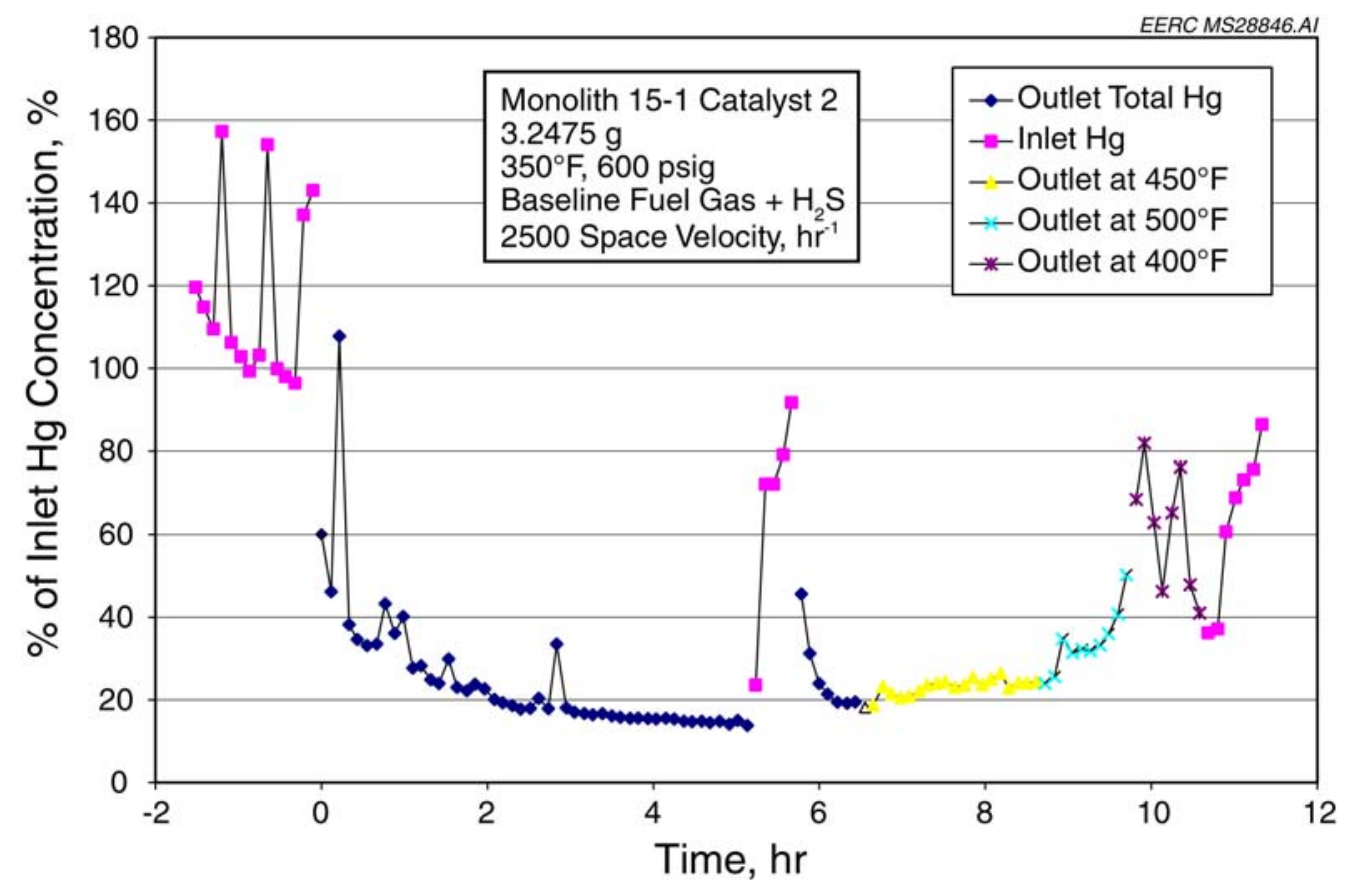

Figure 25. Breakthrough curve for Corning-treated carbon monolith with Catalyst 2 additive for $\mathrm{Hg}$ control.

monolith utilized a more stable form of the additive that had been shown to volatilize in the presence of reducing gases. The relatively lower closure (28\%) for this test might indicate that some of the $\mathrm{Hg}$ had desorbed from the monolith, resulting in the lower $\mathrm{Hg}$ loading of approximately $58 \mu \mathrm{g} / \mathrm{g}$ that was measured.

\section{Control of Arsine}

Figures 26-28 show some of the breakthrough curves generated utilizing the Corningtreated monolith with the Catalyst 2 additive for the control of arsine gas being added to the baseline fuel gas mixture. The initial test, shown in Figure 26 (Test 45 utilized an initial $\mathrm{AsH}_{3}$ concentration of $50 \mathrm{ppb}$ ), was controlled to approximately $5 \mathrm{ppb}$ for over 5 hours; however, the arsine did not recover right away after the reactor was bypassed again. Figure 27 shows the next test (Test 46), where the arsine concentration was increased to $250 \mathrm{ppb}$ and the level of control was only down to approximately $50 \mathrm{ppb}$. The second part of the test, shown in more detail in Figure 28, shows where the system pressure was increased from 300 to 600 psig and the temperature was increased from $350^{\circ}$ to $500^{\circ} \mathrm{F}$ without affecting the sorbent performance (in fact, perhaps slightly improving performance). However, a further increase in temperature above $500^{\circ} \mathrm{F}$ results in a significant amount of arsenic release, indicating the maximum operating temperature for arsine removal with this sorbent is approximately $500^{\circ} \mathrm{F}$. 
Table 2. Monolith Mercury-Loading Data on Selected Long-Term Samples

\begin{tabular}{lccc}
\hline Monolith Section & \multicolumn{4}{c}{} \\
\hline Hg Loading on CC2ZO & Section Weight, g & $\begin{array}{c}\text { Section Hg } \\
\text { Concentration, } \mu \mathrm{g} / \mathrm{g}\end{array}$ & Section Hg, $\mu \mathrm{g}$ \\
\hline 1a & 1.031 & 74 & 76.3 \\
$\mathrm{2a}$ & 0.825 & 90.2 & 74.4 \\
3a & 0.669 & 149 & 99.7 \\
4a & 0.829 & 405 & 335.7 \\
1b & 0.843 & 206 & 173.7 \\
2b & 0.593 & 158 & 93.7 \\
3b & 0.828 & 138 & 114.3 \\
$4 \mathrm{~b}$ & 1.11 & 108 & 119.9 \\
Total & & & 1087.6 \\
Closure & & & $90 \%$ \\
\hline & & Section Hg & \\
Hg Loading on SR-Liquid & Section Weight, g & Concentration, $\mu \mathrm{g} / \mathrm{g}$ & Section Hg, $\mu \mathrm{g}$ \\
\hline 1 & 0.904 & 1.05 & 1.0 \\
2 & 0.598 & 1.14 & 1.1 \\
3 & 0.731 & 42.9 & 37.3 \\
4 & 0.795 & 34.3 & 29.9 \\
Total & & & 69.3 \\
Closure & & & $1 \%$ \\
\hline & & Section Hg & \\
Hg Loading on FC2PO & Section Weight, g & Concentration, $\mu \mathrm{g} / \mathrm{g}$ & Section Hg, $\mu \mathrm{g}$ \\
\hline 1 & 0.956 & 6.8 & 6.1 \\
2 & 0.964 & 6.52 & 3.9 \\
3 & 0.87 & 14.2 & 10.4 \\
4 & 0.871 & 57.9 & 46.0 \\
Total & & & 66.5 \\
Closure & & & $28 \%$ \\
\hline
\end{tabular}

\section{Control of Hydrogen Selenide}

Hydrogen selenide control testing was attempted in the same manner that the arsine testing was completed. However, as the hydrogen selenide was fed to the reactor at higher temperatures, the hydrogen selenide being measured by the Honeywell CM4 hydride analyzer would disappear. Temperatures below $230^{\circ} \mathrm{F}$ gave $\mathrm{H}_{2} \mathrm{Se}$ concentrations around $500 \mathrm{ppb}$; however, as temperatures were increased to $275^{\circ} \mathrm{F}$, the $\mathrm{H}_{2} \mathrm{Se}$ concentrations decreased to $75 \mathrm{ppb}$. By $350^{\circ} \mathrm{F}$, the hydrogen selenide had dropped to less than $5 \mathrm{ppb}$. Figure 29 shows the results from a test conducted at $235^{\circ} \mathrm{F}$ where the $\mathrm{H}_{2} \mathrm{Se}$ still had a significant concentration. The breakthrough curve for the EERC-treated carbon in this test shows that the hydrogen selenide is almost completely removed at these lower temperatures with this additive. Subsequent Method 29 wet-chemistry sampling on the empty reactor system heated to $400^{\circ} \mathrm{F}$ was completed with a known concentration of 


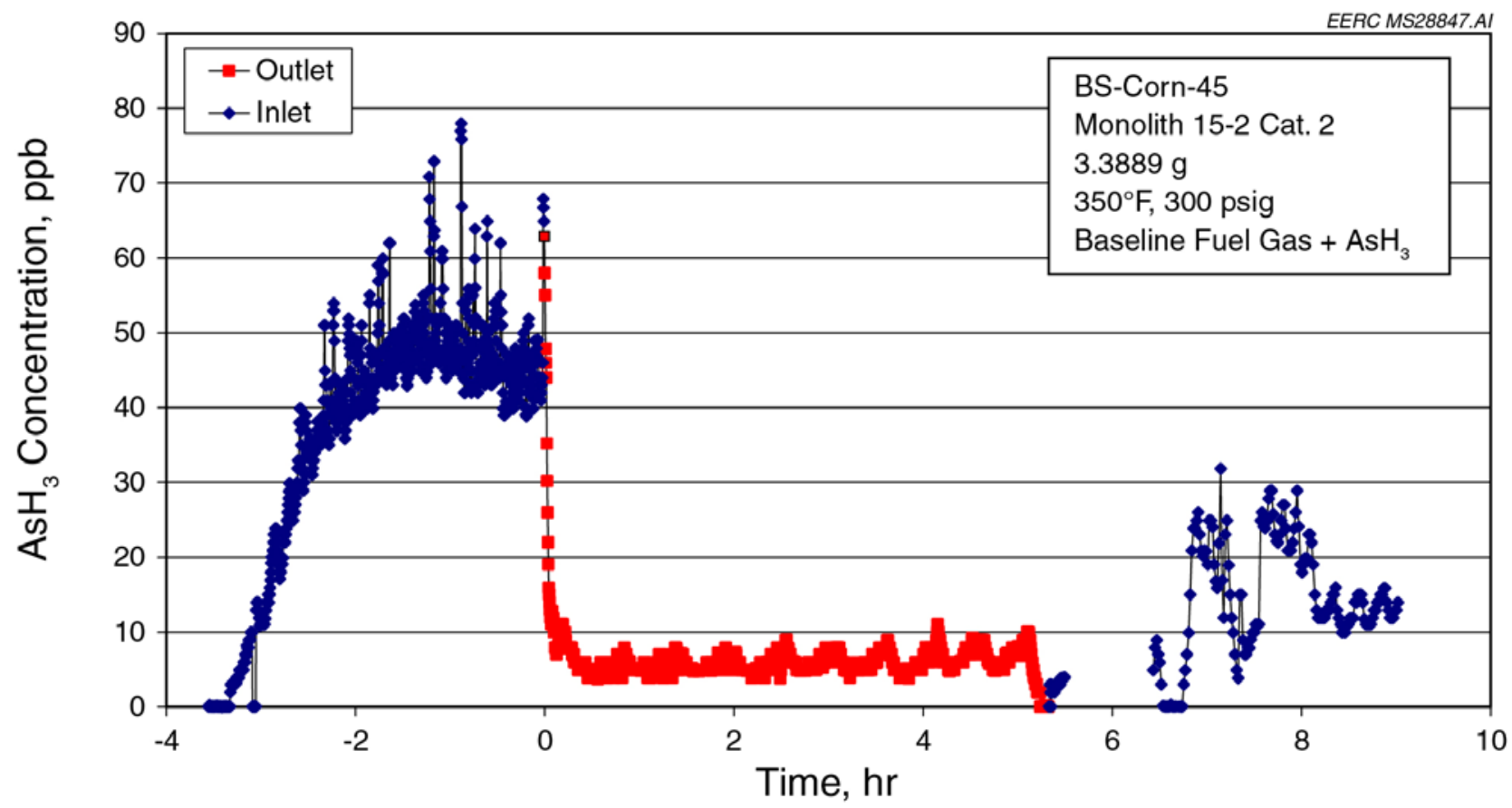

Figure 26. Breakthrough curve for Corning-treated carbon monolith with Catalyst 2 additive for $\mathrm{AsH}_{3}$ control.

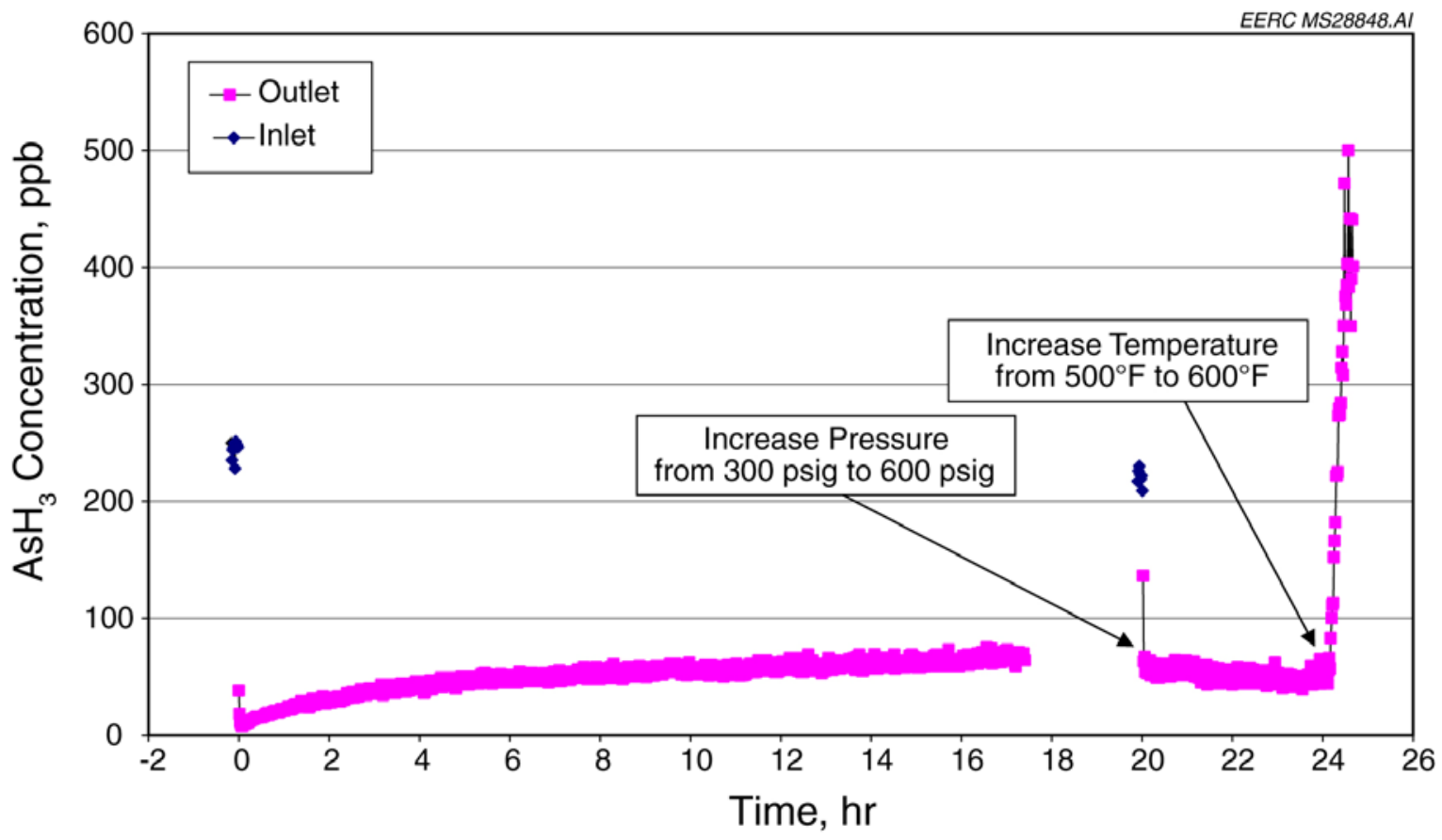

Figure 27. Breakthrough curve for the Corning-treated monolith with Catalyst 2 additive for the control of $\mathrm{AsH}_{3}$ at various pressures and temperatures. 


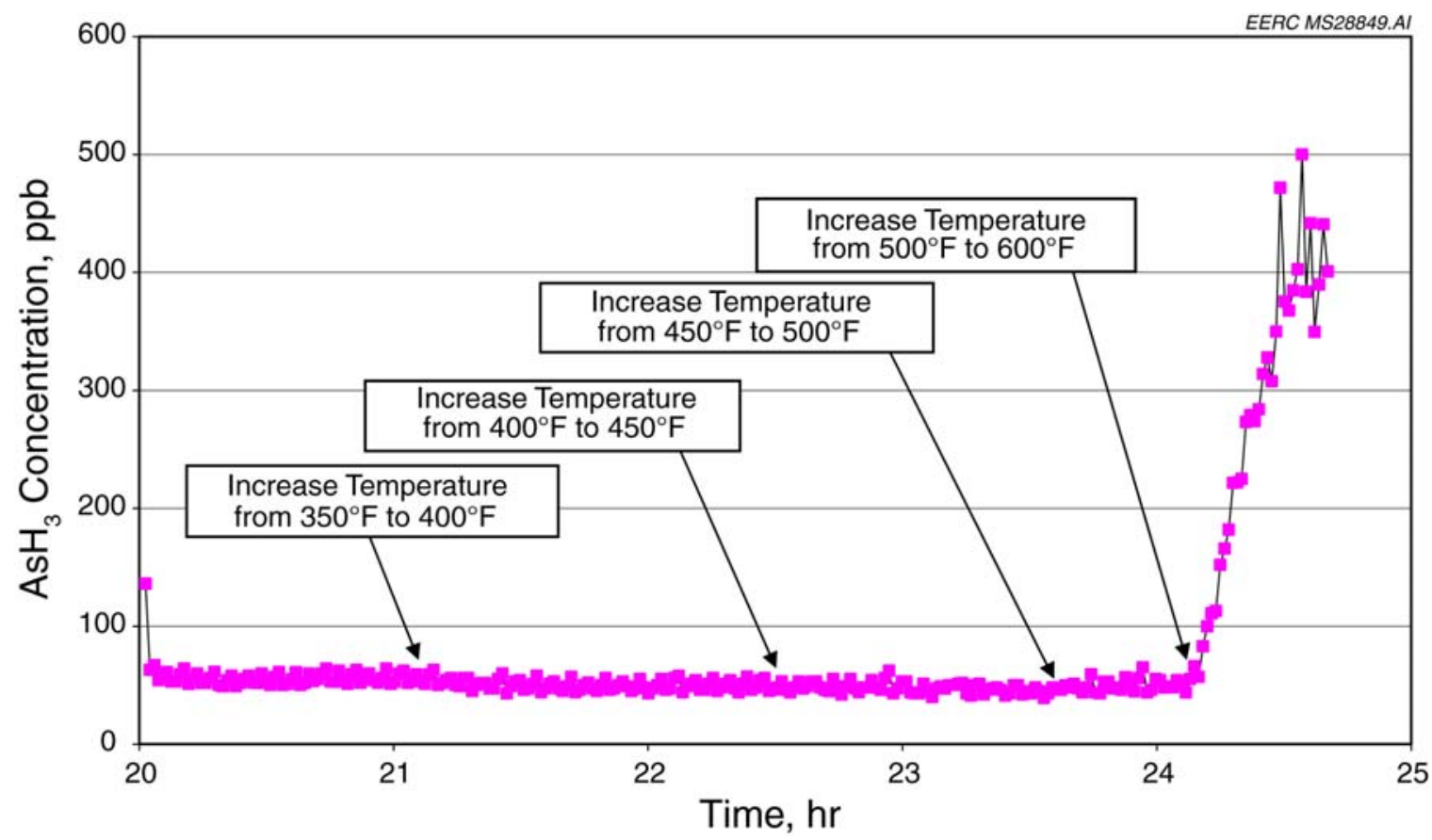

Figure 28. Breakthrough curve for Corning-treated monolith with Catalyst 2 additive for the control of $\mathrm{AsH}_{3}$ at various pressures and temperatures.

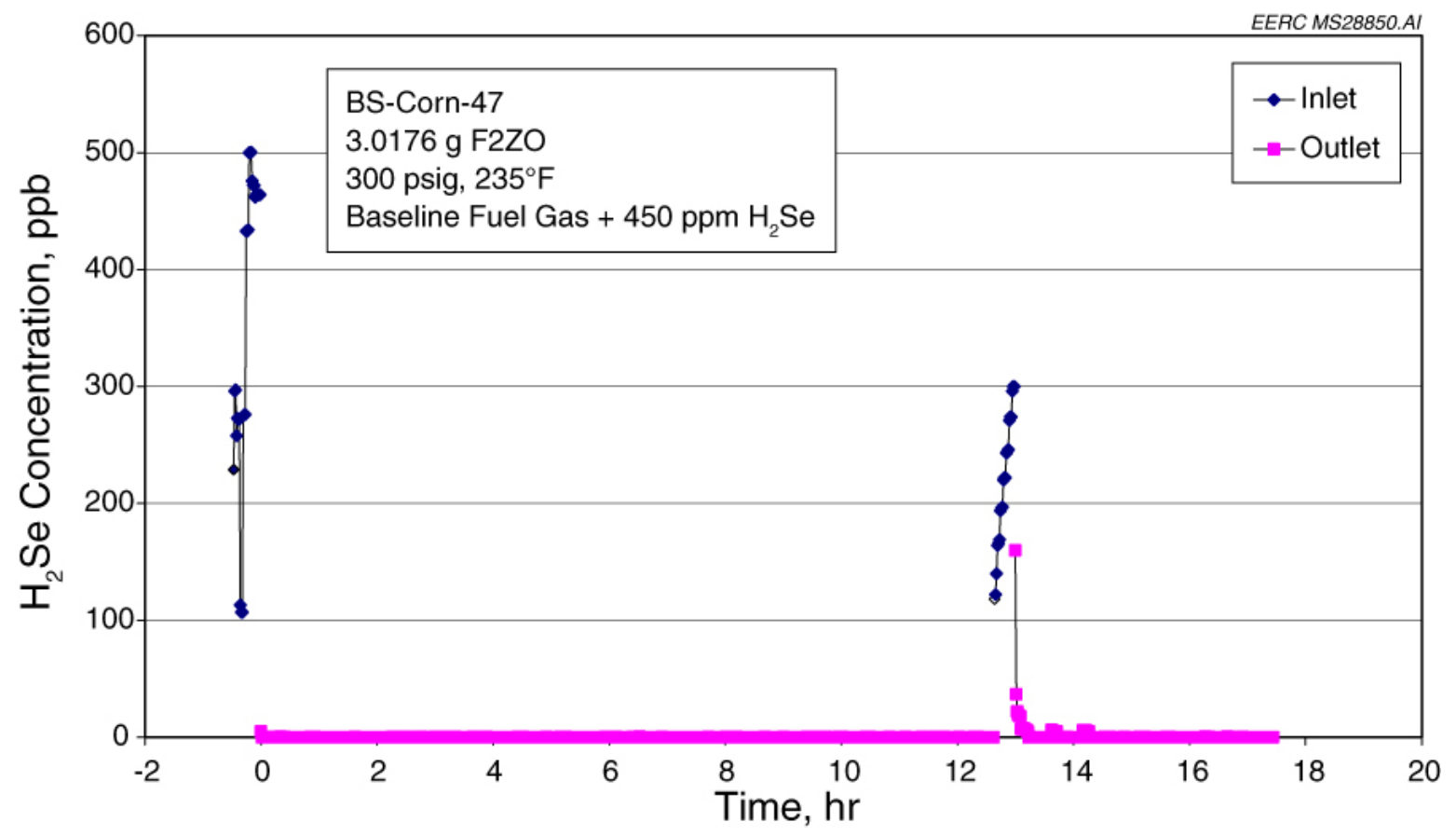

Figure 29. Breakthrough curve for EERC-treated carbon with F2ZO for $\mathrm{H}_{2} \mathrm{Se}$ control at lower operating temperatures. 
hydrogen selenide, and only $1 \%$ of the total selenium was found to be exiting the Sulfinertcoated tubing and reactor. This result suggests that high-silicone coatings such as Sulfinert are not inert to hydrogen selenide at elevated temperatures and appear to be absorbing or reacting with the $\mathrm{H}_{2} \mathrm{Se}$. Other testing with nonpassivated stainless steel tubing provided similar results. However, low-pressure tests with Teflon tubing at temperatures up to $400^{\circ} \mathrm{F}$ did not result in the disappearance of the hydrogen selenide.

These results led to conversations with Dr. Gokhan Alptekin at TDA Research, Inc., in which he reported that they did not see the hydrogen selenide react with their quartz tube liner inside their metal reactor. Another conversation with Dr. Rachid Slimane about GTI's trace gassampling systems that utilize Sulfinert-coated tubing revealed that GTI has not conducted any selenide sampling with its trace gas-sampling system.

\section{RESULTS AND DISCUSSION FOR YEAR 2}

\section{System Modifications During Phase 2}

Testing during Phase 1 indicated an interaction between hydrides and stainless steel tubing that was causing adsorption or degradation of the hydrides, specifically hydrogen selenide (1). Additional testing was conducted to find tubing or a material that was compatible with hydrogen selenide in order to eliminate its disappearance from the simulated fuel gas mixture at the elevated operating temperatures of sorbent testing. Initial flow-through tests were conducted with hydrogen selenide through a coil of Teflon tubing that was run in the heated oven at atmospheric pressure and a temperature of $400^{\circ} \mathrm{F}$. The hydrogen selenide concentration did not appear to be affected by temperature. However, flow-through tests with stainless steel and Resteck Sulfinert ${ }^{\mathrm{TM}}$-coated tubing both exhibited significant interaction with hydrogen selenide as temperature was increased.

Follow-up testing with Resteck's Hydroguard ${ }^{\mathrm{TM}}$ tubing appeared to show no interaction with the hydrogen selenide that the Sulfinert tubing displayed, at least up to temperatures of $500^{\circ}$ to $550^{\circ} \mathrm{F}$. To allow representative hydrogen selenide sampling, the tubing in the laboratory rig was replaced with the Hydroguard tubing. Further, all fittings that were exposed to elevated temperature were electropolished and then treated via Resteck’s Hydroguard process.

Given the low volumetric flow of the contaminant-containing gas stream as compared to the bulk bottled syngas flow, the test rig was reconfigured with 1/8-inch-o.d. Hydroguard tubing to inject the nitrogen stream containing the $\mathrm{Hg}$, arsine, or hydrogen selenide into the test rig either right before the monolith trap or right before the back-pressure control valve. This change minimized the amount of tubing exposed to the contaminant at elevated temperature. Two sets of treated tubing were also prepared to minimize the potential for any deposited metal such as selenium to influence the outlet concentration of a different contaminant such as mercury.

With testing also occurring at higher pressures, the back-pressure control valve stem and seat were replaced with a smaller $\mathrm{Cv}$ (orifice flow coefficient) in order to prevent the control valve from operating near its closed position. 
Improvements to the mercury permeation source were made. The previous approach utilized traditional Teflon permeation tubes supplied by VICI Metronics. This permeation system was found susceptible to rupture from use at elevated test pressures of 300 to 600 psig. The EERC-developed system uses seven inflexible 2-mL borosilicate glass auto sampler vials, each containing a small quantity of liquid mercury. The Teflon lid on the vial has a small hole through which mercury vapor can escape and pressure can be equalized quickly to prevent rupture of the vial. The lid is secured to the vial using tightly wound Teflon tape. The seven mercury-filled vials are stacked within a 1-inch-o.d. stainless steel tube that is externally heated with an electric muff heater. Preheated nitrogen is introduced at the bottom of the 1-inch tube, flowing upward to sweep the mercury away from the glass vials. The mercury concentration is dependent upon the controlled temperature of the 1-inch-o.d. stainless steel tube and the system pressure.

A second pressure control system was installed to allow the permeation source pressure to be held constant at all times, especially when the mercury source is bypassed from flow to the sorbent test system. A pressure transducer is used to measure the mercury source system pressure with feedback provided through a control loop to the actuator/positioner of the control valve. This system will alleviate any spikes in mercury concentration resulting from the previous method of deadheading the mercury source when it was not online.

\section{Evaluation of Trace Metal Analysis Techniques}

Previous testing conducted under a U.S. Environmental Protection Agency (EPA)-funded Center for Air Toxic Metals ${ }^{\circledR}\left(\mathrm{CATM}^{\circledR}\right)$ project surprisingly determined that the hydrides, such as arsine and hydrogen selenide in reducing gas, were not being captured for measurement with the conventional EPA Method 29. Calculated arsine and hydrogen selenide concentrations, in the flowing syngas, were generally within $22 \%$ of the measured values using the hydride monitor. This indicated that the hydride analyzer provided adequate measurement of arsine/hydrogen selenide in single-contaminant bottled syngas tests.

However, because of vendor-reported interferences from multiple hydrides and the presence of hydrogen sulfide that will be present when testing with coal-derived syngas, an additional technique was desired for measuring these trace metal species. Eleven tests were performed to evaluate several methods for measuring the contaminant concentrations, with special significance to break through testing on treated carbon monoliths or other sorbents. Five tests were performed using Method 29 (M29), a wet-chemistry technique, to compare against the poor performance achieved with this method under the CATM test program. Six tests were performed using two-segment carbon traps (EPA Method 30B), a dry technique. The carbon traps are a measurement technique that is approved for $\mathrm{Hg}$ measurement in coal combustion flue gases. The conditions and results of the tests are presented in Table 3.

The syngas composition for Tests 1 through 5 comprised $30 \% \mathrm{H}_{2}, 25 \% \mathrm{CO}, 15 \% \mathrm{CO}_{2}$, and $30 \% \mathrm{~N}_{2}$. The syngas composition for Tests 6 through 11 comprised $25 \% \mathrm{H}_{2}, 20 \% \mathrm{CO}, 15 \% \mathrm{CO}_{2}$, 
Table 3. Mercury, Arsenic, and Selenium Sampling Results During Evaluation of Trace Metal Analysis Techniques

\begin{tabular}{|c|c|c|c|c|c|c|c|c|c|c|}
\hline Test & 1 & 2 & 3 & 4 & 5 & 6 & 7 & 8 & 9 & 10 \\
\hline Component & $\mathrm{HG}^{0}$ & $\mathrm{AsH}_{3}$ & $\mathrm{H}_{2} \mathrm{Se}$ & $\mathrm{HG}^{0}$ & $\mathrm{HG}^{0}$ & $\mathrm{HG}^{0}$ & $\mathrm{HG}^{0}$ & $\mathrm{AsH}_{3}$ & $\mathrm{AsH}_{3}$ & $\mathrm{H}_{2} \mathrm{Se}$ \\
\hline Trapping Method & M29 & M29 & M29 & M29 & M29 & Carbon trap & Carbon trap & Carbon trap & Carbon trap & Carbon trap \\
\hline Gas Type & Syngas & Syngas & Syngas & $\mathrm{N}_{2}$ & Syngas & Syngas & Syngas & $\mathrm{N}_{2}$ & Syngas & Syngas \\
\hline Test Duration, min. & 90 & 120 & 120 & 66 & 61 & 30 & 30 & 30 & 30 & 32 \\
\hline Total Gas Rate, scfh & 13.0 & 13.0 & 12.8 & 12.9 & 12.8 & 12.8 & 12.8 & 12.9 & 12.9 & 12.9 \\
\hline $\begin{array}{l}\text { Gas Rate Through Trap, } \\
\text { scfh }\end{array}$ & 13.0 & 13.0 & 12.8 & 12.9 & 12.8 & 1.17 & 1.17 & 1.17 & 1.17 & 1.17 \\
\hline $\begin{array}{l}\text { Concentration in Gas, } \\
\mu \mathrm{g} / \mathrm{NM}^{3}\end{array}$ & 235 & 231 & 1410 & 202 & 202 & 136 & 124 & 455 & 455 & 1840 \\
\hline $\begin{array}{l}\text { Analyte Entering Trap, } \\
\mu \mathrm{g}\end{array}$ & 130 & 170 & 1024 & 81.2 & 74.7 & 2.24 & 2.05 & 7.51 & 7.51 & 32.4 \\
\hline Recovered by Trap, $\mu \mathrm{g}$ & 551 & $<0.25$ & 125 & 273 & 290 & 1.03 & 0.994 & 5.55 & 6.32 & 12.8 \\
\hline Analyte Recovery, \% & 324 & $<0.15$ & 12.2 & 336 & 388 & 46.0 & 48.5 & 73.9 & 84.2 & 39.5 \\
\hline
\end{tabular}


and $40 \% \mathrm{~N}_{2}$. Continuous mercury ( $\mathrm{Hg}^{0}$ ) concentration measurement was performed using a PSA Sir Galahad atomic fluorescence analyzer in Tests 1, 4, and 5 and a Horiba (Nippon) atomic absorption analyzer in Tests 6 and 7. A Honeywell CM4 continuous 4-point hydride monitor was used to analyze arsenic (as arsine) and selenium (as hydrogen selenide) in Tests 2, 3, and 8 through 11.

To perform a test, a baseline concentration $\left(\mu \mathrm{g} / \mathrm{m}^{3}\right.$ or $\left.\mathrm{ppb}\right)$ in the simulated syngas was established with the appropriate continuous analyzer/monitor. Syngas flow was then directed to the specific trapping method for a period ranging from 1 to 2 hours for the M29 and for 16 to 32 minutes for the two-segment carbon traps. The carbon traps were subjected to acid extraction to recover the adsorbed trace metal. In Tests 6,8 , and 10, the trap segments were combined prior to acid extraction. In Tests 7, 9, and 11, the trap segments were analyzed individually to provide an indication of the efficiency of the first or upstream segment for collecting the trace metal.

Mercury-containing solutions were analyzed by cold-vapor atomic absorption (CVAA), while arsenic and selenium-containing solutions were analyzed by inductively coupled plasmamass spectrometry (ICP-MS). For M29 tests, both the peroxide $\left(\mathrm{H}_{2} \mathrm{O}_{2}\right)$ and permanganate $\left(\mathrm{KMnO}_{4}\right)$ solutions were analyzed, while only the peroxide solution was analyzed when testing for arsenic or selenium.

The results in Table 3 showed that the carbon trap tended to provide much better closure for the hydrides than the M29 technique. Recovery using M29 was over 300\% in three tests when evaluating mercury trapping but was only about 20\% when evaluating selenium. M29 showed essentially no potential for trapping arsenic. The results with the two-segment carbon trap suggest that this technique be given greater scrutiny. The carbon trap appeared to have collected the selenium and arsenic about equally. Also, analysis results showed that the first or upstream segment contained approximately $99 \%$ of the trace metal mass collected by the entire trap. This would suggest little breakthrough to the second trap segment.

\section{Monolith and Other Sorbent Testing}

In Phase 2, a total of 39 different sorbent designations including 29 different Corning monolith designations were evaluated for mercury and/or hydride capture. Table 4 presents the monoliths and other sorbents tested. Additionally, a Corning cordierite monolith was treated at the EERC to impregnate a Group IB metal as a potential mercury capture agent. Also, the EERC prepared and tested three carbon-based granular sorbents plus four non-carbon-based granular sorbents. Two commercially available materials, designed for aiding the water-gas shift reaction, were also tested. These materials were observed, in pilot-scale coal gasification tests at the EERC, to have an influence on mercury concentration in the syngas. Detailed results from the testing are given in the Phase I final report.

A total of 89 tests were performed with the testing conditions presented in Table 5. Mercury and/or hydride sorption curves for all tests are presented in Appendix A. In Tests 1 through 6, the nominal gas composition (dry) was 25\% $\mathrm{H}_{2}, 20 \% \mathrm{CO}, 15 \% \mathrm{CO}_{2}$, and $40 \% \mathrm{~N}_{2}$. Starting at Test 7 and for all remaining tests, the nominal gas composition (dry) was $35 \% \mathrm{H}_{2}$, 
Table 4. Sorbent Designation and Tests For Phase 2

\begin{tabular}{|c|c|c|}
\hline No. & Designation & Test No. \\
\hline 1 & 20012-SR1-013-5C58 & 1 \\
\hline 2 & 20012-SR1-013-6C59 & 2 \\
\hline 3 & 20012-SR2-011-0C83 & 3 \\
\hline 4 & 10017-FC4-011-7C87 & 4 \\
\hline 5 & 10017-FC4-011-7C88 & 5 \\
\hline 6 & 10017-FC4-011-7C159 & 7,13 \\
\hline 7 & 10017-FC4-011-7C158 & 7,14 \\
\hline 8 & 10017-FC4-011-7C160 & 9,11 \\
\hline 9 & 10017-FC4-011-7C161 & 10,15 \\
\hline 10 & MS23573-1 & 23 \\
\hline 11 & GEN1C-1 & 24 \\
\hline 12 & MS23574-1 & 30 \\
\hline 13 & MS23423-1 & 31 \\
\hline 14 & SR Liquid & $36-39$ \\
\hline 15 & 274 & 40, 41 \\
\hline 16 & 272 & 42,43 \\
\hline 17 & 276 & 44,45 \\
\hline 18 & SR Liquid 283 & 51-54, 56-59 \\
\hline 19 & SR Liquid 284 & 56-59 \\
\hline 20 & SR Liquid 282 & 60,61 \\
\hline 21 & SR Liquid 285 & 65,68 \\
\hline 22 & SR Liquid 286 & 68 \\
\hline 23 & SR Liquid 287 & 75 \\
\hline 24 & SR Liquid 288 & 75 \\
\hline 25 & GR-F1-2189 & 76 \\
\hline 26 & 31082 & $77,81,82$ \\
\hline 27 & 31083 & 78 \\
\hline 28 & 31085 & 79 \\
\hline 29 & 31308 & $80,83,84,88,89$ \\
\hline 30 & $\begin{array}{l}\text { CORDH-1 impregnated with Group IB } \\
\text { metal }\end{array}$ & 35 \\
\hline 31 & Carbon F2Z0 & 6 \\
\hline 32 & Carbon 15615-3-1 & 12 \\
\hline 33 & Carbon 15615-1-1 & 16,17 \\
\hline 34 & Noncarbon Sorbent 1 & $\begin{array}{c}18-22,32-34,62- \\
64\end{array}$ \\
\hline 35 & Noncarbon Sorbent 2 & 25-29 \\
\hline 36 & Group IIB metal selenide on zeolite & $46,47,50$ \\
\hline 37 & Group IB metal selenide on zeolite & 48,49 \\
\hline 38 & Group IB and IIB metal on alumina pellet & $66,74,86,87$ \\
\hline 39 & Group IB and IIB metal coprecipitate & $69,71-73,85$ \\
\hline
\end{tabular}


Table 5. Sorbent Designation, Nominal Temperature and Pressure, Space Velocity, and Comments for Each Test

\begin{tabular}{|c|c|c|c|c|c|}
\hline $\begin{array}{l}\text { Test } \\
\text { No. }\end{array}$ & Sorbent & $\begin{array}{c}\text { Pressure, } \\
\text { psig }\end{array}$ & $\begin{array}{c}\text { Oven } \\
\text { Temp., } \\
{ }^{\circ} \mathrm{F} \\
\end{array}$ & SV, hr-1 & Comment \\
\hline 1 & Corning Monolith 20012-SR1-013-5C58 & 600 & 400 & 1500 & \\
\hline 2 & Corning Monolith 20012-SR1-013-6C59 & 600 & 400 & 1500 & \\
\hline 3 & Corning Monolith 20012-SR2-011-0C83 & 600 & 400 & 1500 & \\
\hline 4 & Corning Monolith 10017-FC4-011-7C87 & 600 & 400 & 1500 & \\
\hline 5 & Corning Monolith 10017-FC4-011-7C88 & 600 & 400 & 1500 & \\
\hline 6 & EERC Carbon F2Z0 & 600 & 400 & 1500 & \\
\hline 7 & Corning Monolith 10017-FC4-011-7C159 & 600 & 400 & 1500 & \\
\hline 8 & Corning Monolith 10017-FC4-011-7C158 & 600 & 400 & 1500 & \\
\hline 9 & Corning Monolith 10017-FC4-011-7C160 & 600 & 400 & 1500 & \\
\hline 10 & Corning Monolith 10017-FC4-011-7C161 & 600 & 400 & 1500 & \\
\hline 11 & Corning Monolith 10017-FC4-011-7C160 & 300 & 350 & 2750 & Reuse Test 9 sorbent \\
\hline 12 & EERC Carbon 15615-3-1 & 300 & 350 & 2750 & Prereduced \\
\hline 13 & Corning Monolith 10017-FC4-011-7C159 & 300 & 350 & 2750 & Reuse Test 7 sorbent \\
\hline 14 & Corning Monolith 10017-FC4-011-7C158 & 300 & 350 & 2750 & Reuse Test 8 sorbent \\
\hline 15 & Corning Monolith 10017-FC4-011-7C161 & 300 & 350 & 2750 & Reuse Test 10 sorbent \\
\hline 16 & EERC Carbon 15615-1-1 & 300 & 350 & 2750 & Presulfided sorbent \\
\hline 17 & EERC Carbon 15615-1-1 & 300 & 350 & 2750 & $100 \% \mathrm{~N}_{2}$ flow \\
\hline 18 & Noncarbon Sorbent 1 & 300 & 350 & 2750 & Steam rate as variable \\
\hline 19 & Noncarbon Sorbent 1 & 300 & 385 & 2750 & Oven temp. as variable \\
\hline 20 & Noncarbon Sorbent 1 & 300 & 385 & 2750 & Evaluate desorption potential \\
\hline 21 & Noncarbon Sorbent 1 & 600 & 400 & 1500 & Steam rate, oven temp. as variables \\
\hline 22 & Noncarbon Sorbent 1 & 600 & 400 & 1500 & Simulate shifted gas \\
\hline 23 & Corning Monolith MS23573-1 & 600 & 400 & 1500 & \\
\hline 24 & Corning Monolith GEN1C-1 & 600 & 400 & 1500 & Crushed prior to testing \\
\hline 25 & Noncarbon Sorbent 2 & 600 & 400 & 1500 & 3.2 grams \\
\hline 26 & Noncarbon Sorbent 2 & 600 & 400 & 1500 & 3.3 grams added to Test 25 sorbent \\
\hline 27 & Noncarbon Sorbent 2 & 600 & 400 & 1500 & $100 \% \mathrm{~N}_{2} ;$ used Test 26 charge \\
\hline
\end{tabular}


Table 5. Sorbent Designation, Nominal Temperature and Pressure, Space Velocity, and Comments for Each Test (continued)

\begin{tabular}{|c|c|c|c|c|c|}
\hline $\begin{array}{l}\text { Test } \\
\text { No. }\end{array}$ & Sorbent & $\begin{array}{l}\text { Pressure } \\
\text { psig }\end{array}$ & $\begin{array}{c}\text { Oven } \\
\text { Temp., }{ }^{\circ} \mathrm{F}\end{array}$ & $\mathrm{SV}, \mathrm{hr}^{-1}$ & Comment \\
\hline 30 & Corning Monolith MS23574-1 & 600 & 400 & 1500 & \\
\hline 31 & Corning Monolith MS23423-1 & 600 & 400 & 1500 & \\
\hline 34 & Noncarbon Sorbent 1 & 600 & 400 & 1500 & Evaluate influence of temperature \\
\hline 35 & $\begin{array}{l}\text { Corning Monolith CORDH-1 impregnated with } \\
\text { Group IB metal }\end{array}$ & 600 & 400 & 1500 & \\
\hline 36 & Corning Monolith SR Liquid & 300 & 350 & 2750 & Half monolith \\
\hline 37 & Corning Monolith SR Liquid & 300 & 350 & 2750 & $\begin{array}{l}\text { Full monolith crushed and blended with } \\
\text { silica sand; no steam }\end{array}$ \\
\hline 42 & Corning Monolith 272 & 300 & 350 & 2750 & \\
\hline 43 & Corning Monolith 272 & 300 & 350 & 2750 & Repeat Test 42 with same monolith \\
\hline 44 & Corning Monolith 276 & 300 & 350 & 2750 & \\
\hline 45 & Corning Monolith 276 & 300 & 350 & 2750 & Repeat Test 44 with same monolith \\
\hline 46 & $\begin{array}{l}\text { EERC Sorbent impregnated with Group IIB metal } \\
\text { selenide on zeolite }\end{array}$ & 300 & $350-400$ & 2750 & $\begin{array}{l}\text { Reduced with hydrogen during } \\
\text { preparation }\end{array}$ \\
\hline 47 & EERC Sorbent Group IIB metal selenide on zeolite & 300 & 400 & 2920 & Same material as Test 46 \\
\hline 48 & EERC Sorbent Group IB metal selenide on zeolite & 300 & 400 & 2920 & Reduced with hydrogen \\
\hline 49 & EERC Sorbent Group IB metal selenide on zeolite & 300 & 400 & 2920 & Repeat Test 48 with same material \\
\hline 50 & EERC Sorbent Group IIB metal selenide on zeolite & 300 & 400 & 2920 & $\begin{array}{l}\text { Reduced with hydrazine during } \\
\text { preparation }\end{array}$ \\
\hline
\end{tabular}


Table 5. Sorbent Designation, Nominal Temperature and Pressure, Space Velocity, and Comments for Each Test (continued)




Table 5. Sorbent Designation, Nominal Temperature and Pressure, Space Velocity, and Comments for Each Test (continued)

\begin{tabular}{|c|c|c|c|c|c|}
\hline $\begin{array}{l}\text { Test } \\
\text { No. }\end{array}$ & Sorbent & $\begin{array}{c}\text { Pressure } \\
\text { psig }\end{array}$ & $\begin{array}{c}\text { Oven } \\
\text { Temp., }{ }^{\circ} \mathrm{F}\end{array}$ & SV, $\mathrm{hr}^{-1}$ & Comment \\
\hline 73 & EERC Sorbent Group IB and IIB metals coprecipitate & 600 & 400 & 1500 & $\mathrm{H}_{2} \mathrm{Se}$ \\
\hline 74 & EERC Sorbent Group IB and IIB metals on alumina pellet & 600 & 400 & 1500 & $\mathrm{H}_{2}$ Se capture \\
\hline 75 & Corning Monolith SR Liquids 287 and 288 & 600 & 400 & 750 & $\mathrm{H}_{2}$ Se capture \\
\hline 76 & Corning Monolith GR-F1-2189 (1, 2, 3, 4) & 600 & 400 & 375 & Described as active samples by Corning \\
\hline 77 & Corning Monolith $31082(1,7,13,18)$ & 600 & 400 & 375 & Catalyst was added to the extrusion batch \\
\hline 78 & Corning Monolith $31083(3,8,13,17)$ & 600 & 400 & 375 & $\begin{array}{c}\text { Active components include } \mathrm{CuO} \text { and } \mathrm{ZnO} \\
\text { (18 wt\%) }\end{array}$ \\
\hline 79 & Corning Monolith 31085 (6, 11, 17, 21) & 600 & 400 & 375 & $\begin{array}{l}\text { Same composition as those for mercury capture in } \\
\text { combustion applications }\end{array}$ \\
\hline 80 & Corning Monolith $31308(2,7,12,16)$ & 600 & 400 & 375 & SR Liquid monoliths \\
\hline 81 & Corning Monolith $31082(6,12,19)$ & 600 & 400 & 500 & \\
\hline 82 & Corning Monolith $31082(6,12,19)$ & 600 & 400 & 500 & Arsine capture \\
\hline 83 & Corning Monolith $31308(3,10,20)$ & 600 & 400 & 500 & \\
\hline 84 & Corning Monolith 31308 (3, 10, 20) & 600 & 400 & 500 & Regenerated and reused \\
\hline 85 & EERC Sorbent Group IB and IIB metals coprecipitate & 600 & 400 & 1500 & Same charge used in Tests $69,71-73$ \\
\hline 86 & EERC Sorbent Group IB and IIB metals on alumina pellet & 600 & 400 & 1500 & Same charge used in Tests 66, 74 \\
\hline 87 & EERC Sorbent Group IB and IIB metals on alumina pellet & 600 & 400 & 1500 & Regenerated and reused \\
\hline 88 & Corning Monolith $31308(4,13,15)$ & 600 & 400 & 500 & \\
\hline 89 & Corning Monolith $31308(4,13,15)$ & 600 & 400 & 500 & Regenerated and reused \\
\hline
\end{tabular}


$25 \% \mathrm{CO}$, and $40 \% \mathrm{~N}_{2}$. Steam was added at a rate to produce $9 \mathrm{vol} \% \mathrm{H}_{2} \mathrm{O}$ on a wet basis. The majority of tests employed a water-only impinger train to condense and remove water vapor. In a limited number of tests, as indicated in Table 5, a $2 \% \mathrm{SnCl}_{2}-20 \% \mathrm{NaOH}$ solution addition was employed.

\section{Mercury Capture}

Figures 30-44 present sorption curves for several sorbents that displayed the greatest potential for long-term development as mercury capture materials. Mercury sorption curves for all tested monoliths and sorbents are presented in Appendix A. A summary of observed results for the 89 tests is presented below.

The Corning SR Liquid monolith concept continues to be a strong candidate for mercury capture.

- A new Corning monolith formulation, GR-F1-2189, described as an active sample, appeared to be the best monolith tested to date.

- The Corning GR and SR Liquid monoliths allowed mercury reduction to below $5 \mu \mathrm{g} / \mathrm{m}^{3}$ $(\sim 5 \mathrm{ppb})$ at $400^{\circ} \mathrm{F}$, a current DOE goal for trace metal control.

- Preparation methods for formulating the SR Liquid monolith impacted the ability of the monolith to capture mercury.

- Noncarbon Sorbents 1 and 2 appeared to offer potential for sustained and significant reduction of mercury concentration in the simulated fuel gas.

- The Noncarbon Sorbent 1 allowed mercury reduction to below $5-\mu \mathrm{g} / \mathrm{m}^{3}(\sim 5 \mathrm{ppb})$ at $400^{\circ} \mathrm{F}$, a current DOE goal for trace metal control.

- The non-carbon-based sorbent appeared to offer the potential for regeneration, that is, desorption of mercury by temperature swing (using nitrogen and steam at temperatures above where adsorption takes place).

- A Corning cordierite monolith impregnated with Group IB metal offered limited potential as a mercury sorbent.

- A Corning monolith containing reduced metallic species similar to those found on the noncarbon sorbents did not exhibit significant or sustained mercury reduction.

- EERC sorbents prepared with Groups IB and IIB selenides appeared to have some promise for mercury capture. Unfortunately, these sorbents also released Se as evidenced by the measurement of $\mathrm{H}_{2} \mathrm{Se}$ in the effluent gas. 


\section{Noncarbon Sorbents}

One of the most promising materials tested in Phase 2 was the Noncarbon sorbent/lowtemperature shift catalyst. Figures 30-36 present results for tests with Noncarbon Sorbent 1, which was reduced in situ at $430^{\circ} \mathrm{F}$ using hydrogen. The same charge of sorbent was used in all tests. Figure 30 (Test 18) shows that at an oven temperature of $350^{\circ} \mathrm{F}$ and $300 \mathrm{psig}$, the reactor outlet temperatures increased up to a range of $390^{\circ}$ to $415^{\circ} \mathrm{F}$ during which time mercury removal was essentially $100 \%$. This increase in the reactor outlet temperature is thought to be due to an exothermic water-gas shift reaction on the surface of the sorbent. Increasing the oven temperature to $385^{\circ} \mathrm{F}$ in Test 19 (Figure 31) to produce a reactor outlet temperature of $455^{\circ} \mathrm{F}$ did not reduce the mercury capture efficiency. Over the period of testing, no diminishment of mercury capture efficiency was observed.

Increasing the system pressure to 600 psig in Tests 21 and 22 (Figures 32 and 33) showed no diminishment in capture of mercury. Figure 32 shows that by increasing the steam flow rate (which enhanced the water-gas shift reaction) a definite reduction in mercury capture was observed. At $464^{\circ} \mathrm{F}$, mercury capture had been reduced to $\sim 80 \%$; at $477^{\circ} \mathrm{F}$, mercury capture had been reduced to $\sim 59 \%$. After replacing the reducing gas with $100 \% \mathrm{~N}_{2}$ and increasing the oven temperature to attain a reactor outlet temperature near $500^{\circ} \mathrm{F}$, desorption of mercury appeared to be occurring. Capture of mercury (at $100 \% \mathrm{~N}_{2}$ flow) was attained upon reduction of the oven temperature. Capture of mercury near $100 \%$ appeared to occur at a reactor outlet temperature below $\sim 460^{\circ} \mathrm{F}$.

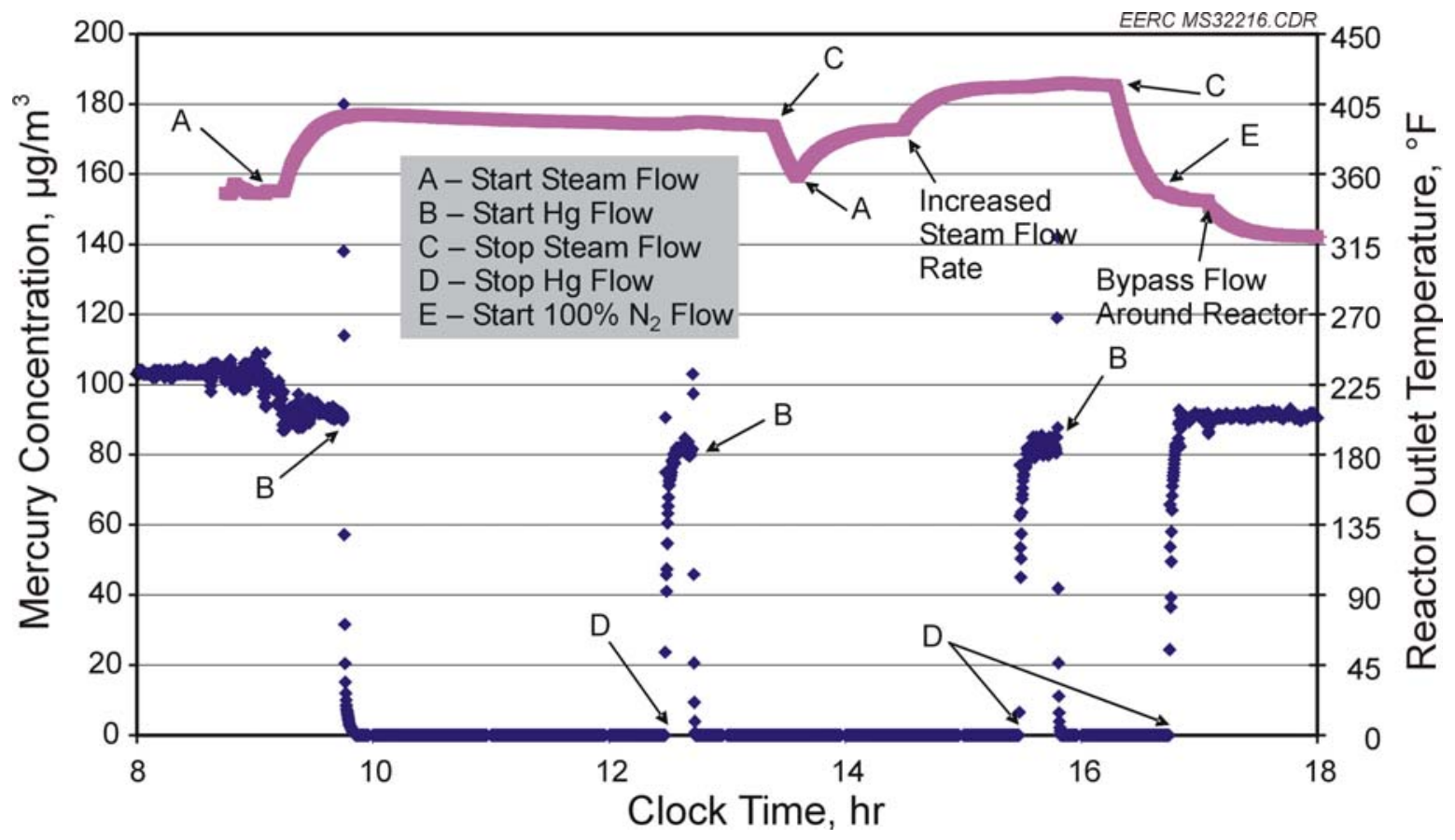

Figure 30. Mercury sorption curve for EERC Noncarbon Sorbent 1 at $350^{\circ} \mathrm{F}$ and 300 psig (Test 18). 


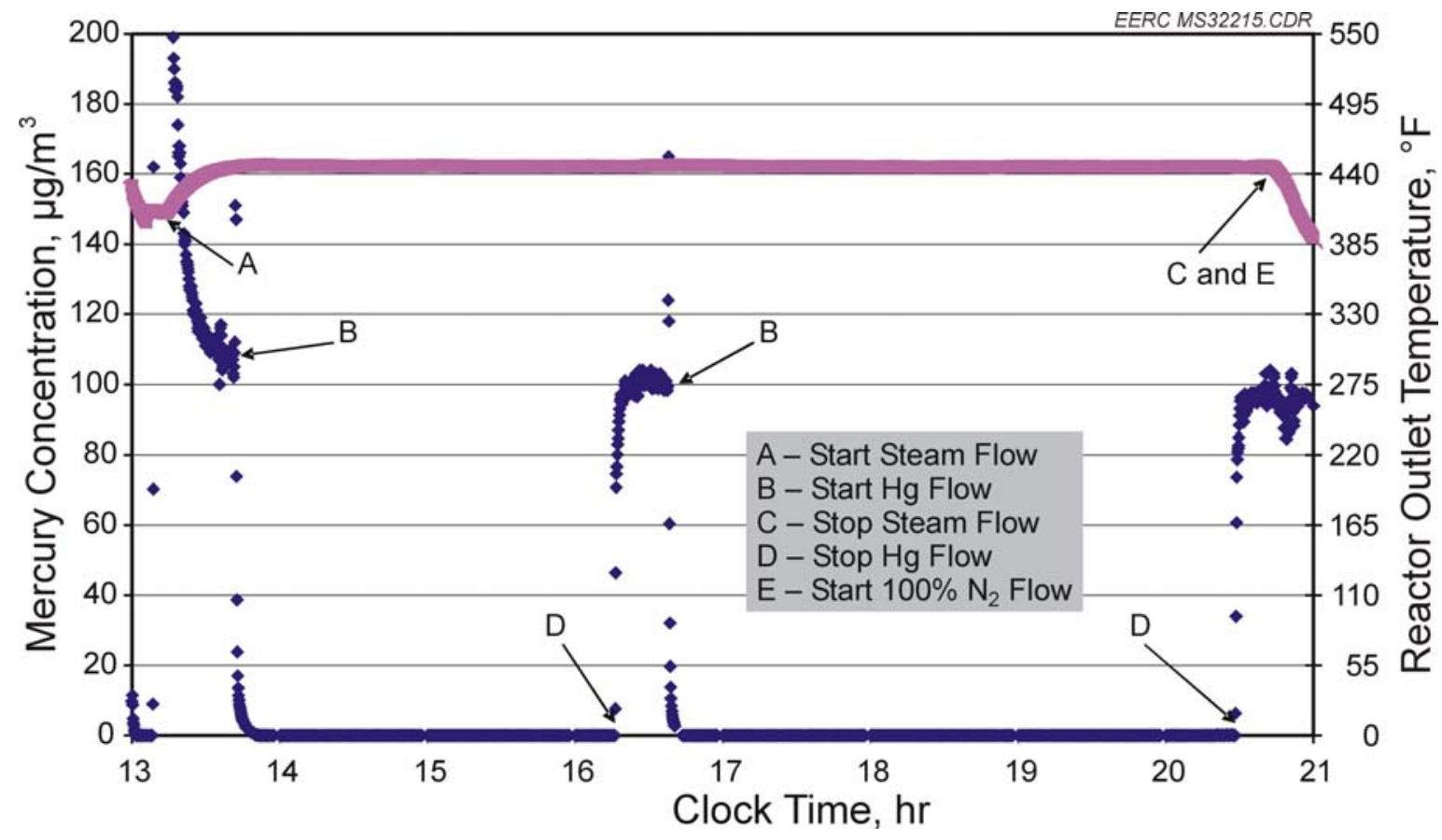

Figure 31. Mercury sorption curve for EERC Noncarbon Sorbent 1 at $350^{\circ} \mathrm{F}$ and 300 psig (Test 19).

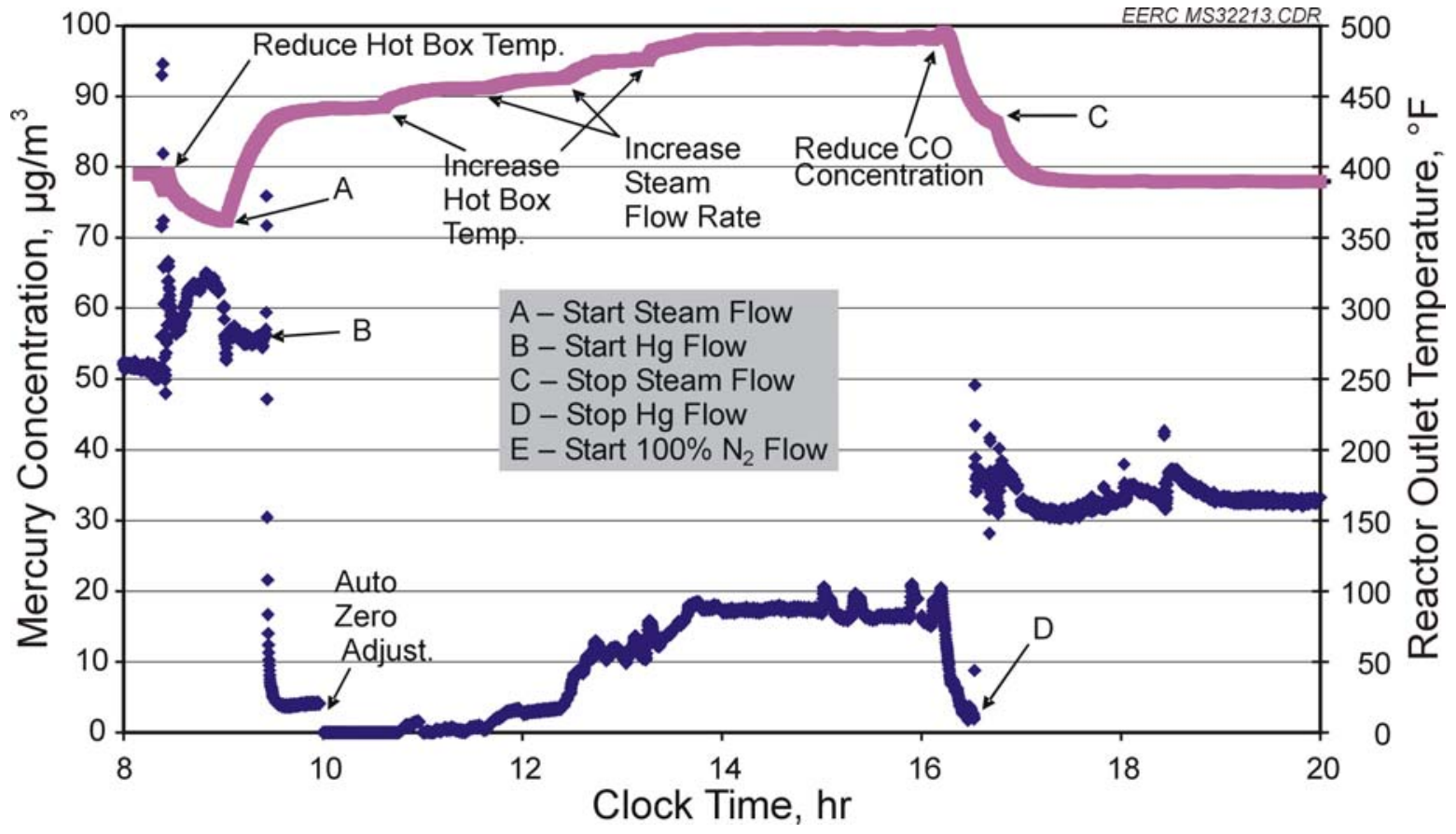

Figure 32. Mercury sorption curve for EERC Noncarbon Sorbent 1 at $400^{\circ} \mathrm{F}$ and 600 psig (Test 21). 


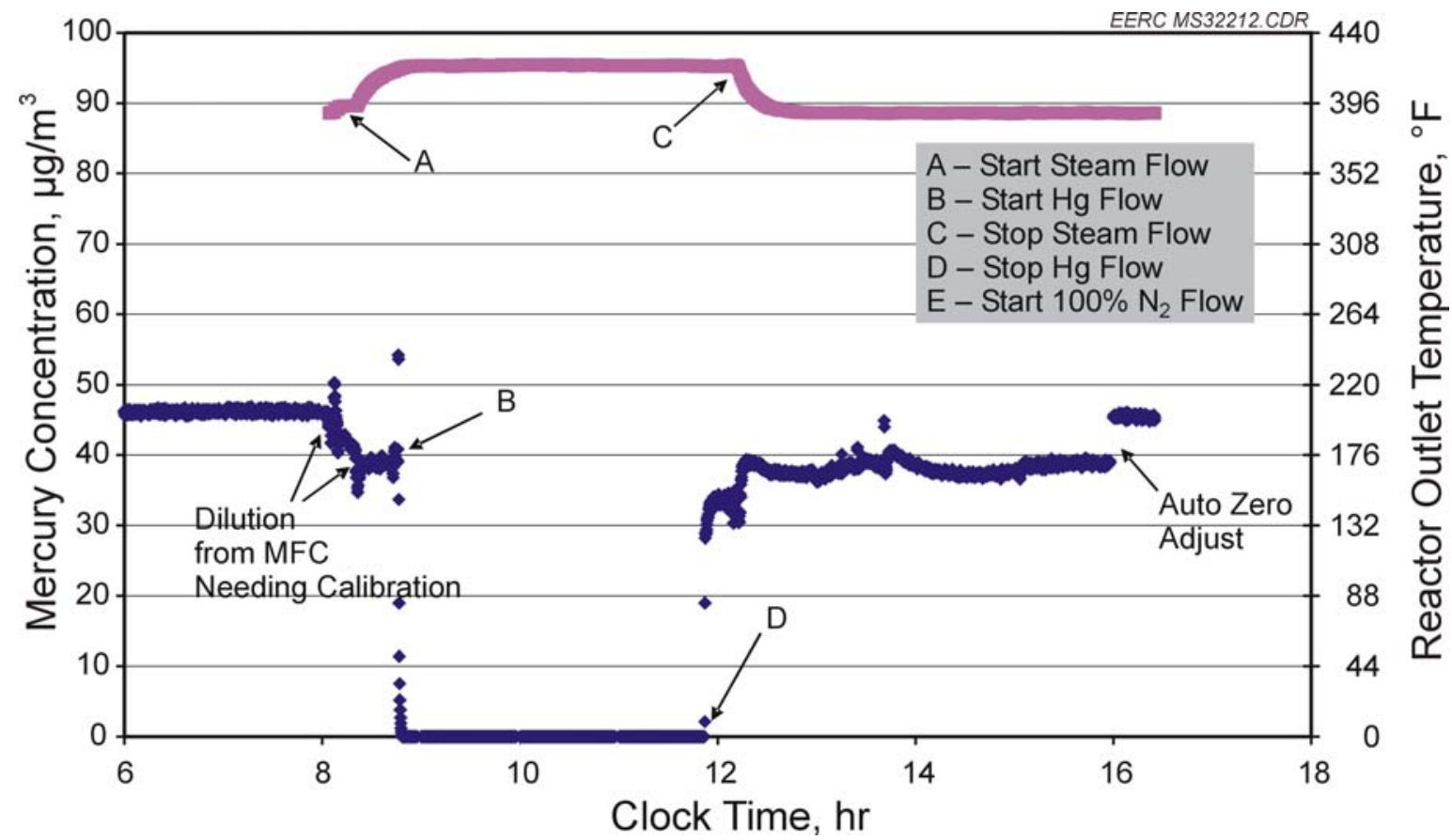

Figure 33. Mercury sorption curve for EERC Noncarbon Sorbent 1 at $400^{\circ} \mathrm{F}$ and 600 psig (Test 22).

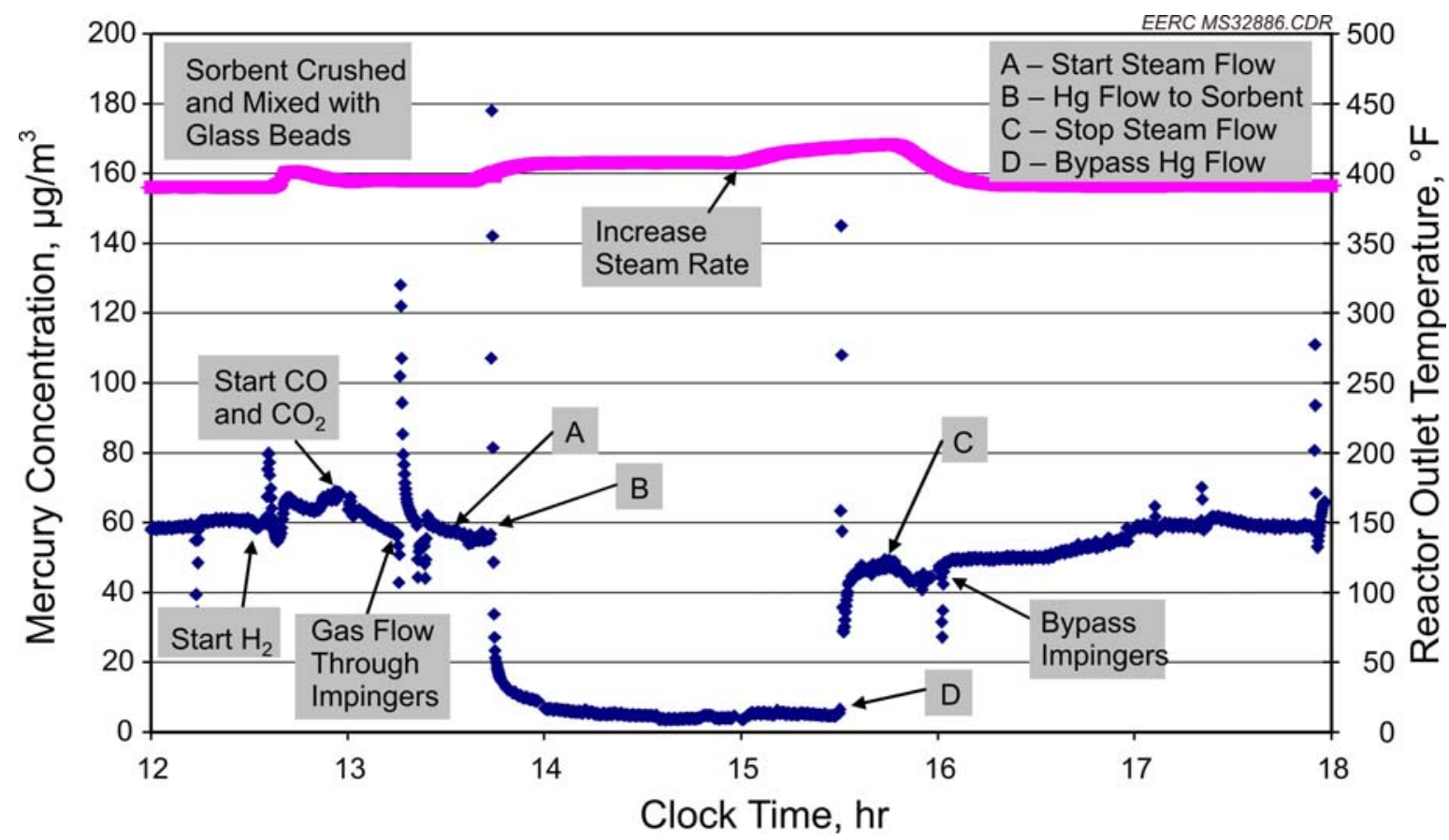

Figure 34. Mercury sorption curve for EERC Noncarbon Sorbent 1 at $400^{\circ} \mathrm{F}$ and 600 psig (Test 32). 


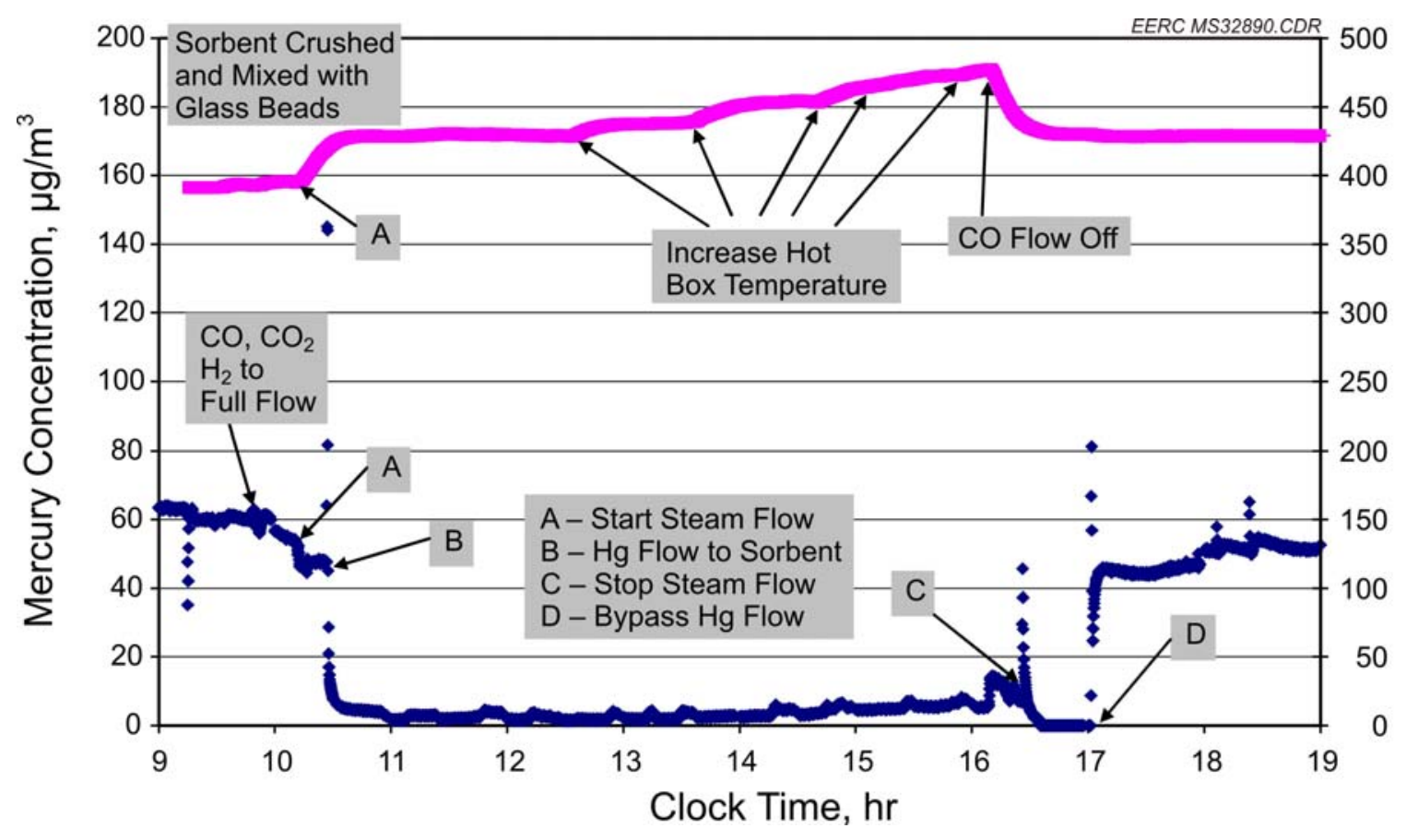

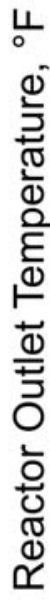

Figure 35. Mercury sorption curve for EERC Noncarbon Sorbent 1 at $400^{\circ} \mathrm{F}$ and 600 psig (Test 33).

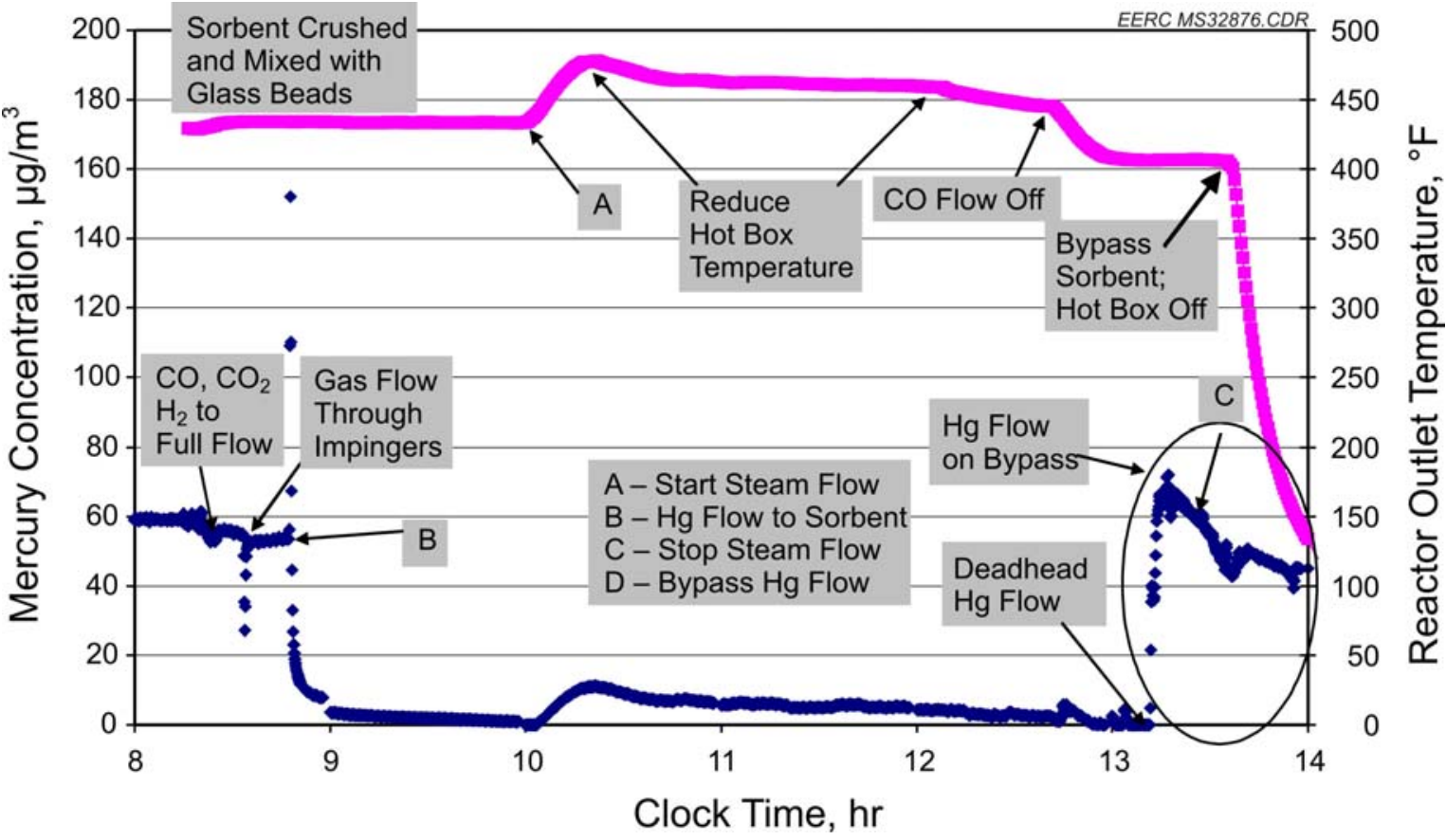

Figure 36. Mercury sorption curve for EERC Noncarbon Sorbent 1 at $400^{\circ} \mathrm{F}$ and $600 \mathrm{psig}$ (Test 34 ). 
For these Tests 32-34, presented in Figures 34-36, the pellets were crushed with mortar/pestle and then diluted at a 3/1 mass ratio with inert glass beads. The intent was to determine if the heat from the water-gas shift reaction could be dissipated quicker through the reactor wall, reducing the temperature increase and impact on mercury capture. As with previous tests, this material appeared to be effective for mercury reductions of $90 \%$ (down to $5 \mu \mathrm{g} / \mathrm{m}^{3}$ ) when the reactor temperature was below $450^{\circ}$ to $460^{\circ} \mathrm{F}$.

Tests 25-29 were conducted with Noncarbon Sorbent 2 low-temperature shift catalyst at $400^{\circ} \mathrm{F}$ and 600 psig. This material also showed a diminished capacity for mercury capture, relative to Noncarbon Sorbent 1 , not attaining a $90 \%$ reduction or reduction to below $5 \mu \mathrm{g} / \mathrm{m}^{3}$ ( 5 ppb).

\section{Corning Monoliths}

In Phase 1 testing, Corning monoliths with the designator SR Liquid showed the greatest potential for mercury capture when testing was performed at $350^{\circ} \mathrm{F}$ and 300 psig. Phase 2 testing was initiated at $400^{\circ} \mathrm{F}$ and 600 psig with new monoliths that employed similar chemistry to the monoliths, specifically SR Liquid, which had shown promise for mercury capture at less severe shown conditions. Tests 1-5 and 7-10, shown in Table 4, indicated that none of the materials could attain $90 \%$ reduction or reduction to below $5 \mu \mathrm{g} / \mathrm{m}^{3}(\sim 5 \mathrm{ppb})$ and periods of mercury capture were brief-less than 1 to 2 hours. Upon retesting at 300 psig and $350^{\circ} \mathrm{F}$ (Tests 11 and 13-15), each monolith showed a desired response to initial contact with mercury: the concentration decreased. However, with all monoliths selected for retesting, the drop in mercury concentration was brief, never reaching a stable minimum value. Peak reductions ranged from approximately 18\%-64\%.

Tests 36-39 were conducted at 300 psig and $350^{\circ} \mathrm{F}$ with a monolith with the designation SR Liquid. To corroborate the mercury concentrations determined by the Horiba analyzer, a Semtech Hg 2000 analyzer was used simultaneously. Results from both analyzers showed that this monolith had a limited capacity for mercury capture, even when attempts were made to enhance gas contact (Test 37) and remove steam (Test 39). Discussion of the test results with Corning, relating to the ineffectiveness of this sorbent relative to the SR Liquid tested in 2006 and 2007, indicated that preparation techniques were not identical. Consequently, the preparation methodology used to prepare the original SR Liquid was to be followed as closely as possible.

After preparation by Corning using the “original” methodology, Tests 51-54 with SR Liquid 283 monolith at 300 psig and $350^{\circ} \mathrm{F}$ showed (Figures 37-40) a significant improvement in mercury capture. Increasing the reactor outlet temperature to $400^{\circ} \mathrm{F}$ appeared to cause a slight reduction in the equilibrium concentration of mercury. In Tests 56 through 59, an identically prepared SR Liquid 284 monolith was combined with the 283 monolith to determine if a mercury concentration as low as $5 \mu \mathrm{g} / \mathrm{m}^{3}$ could be attained. In the first test with the dual monoliths, shown in Figure 41, there was very good mercury reduction-to below the $5-\mu \mathrm{g} / \mathrm{m}^{3}$ DOE target level—for about 7 hours. 


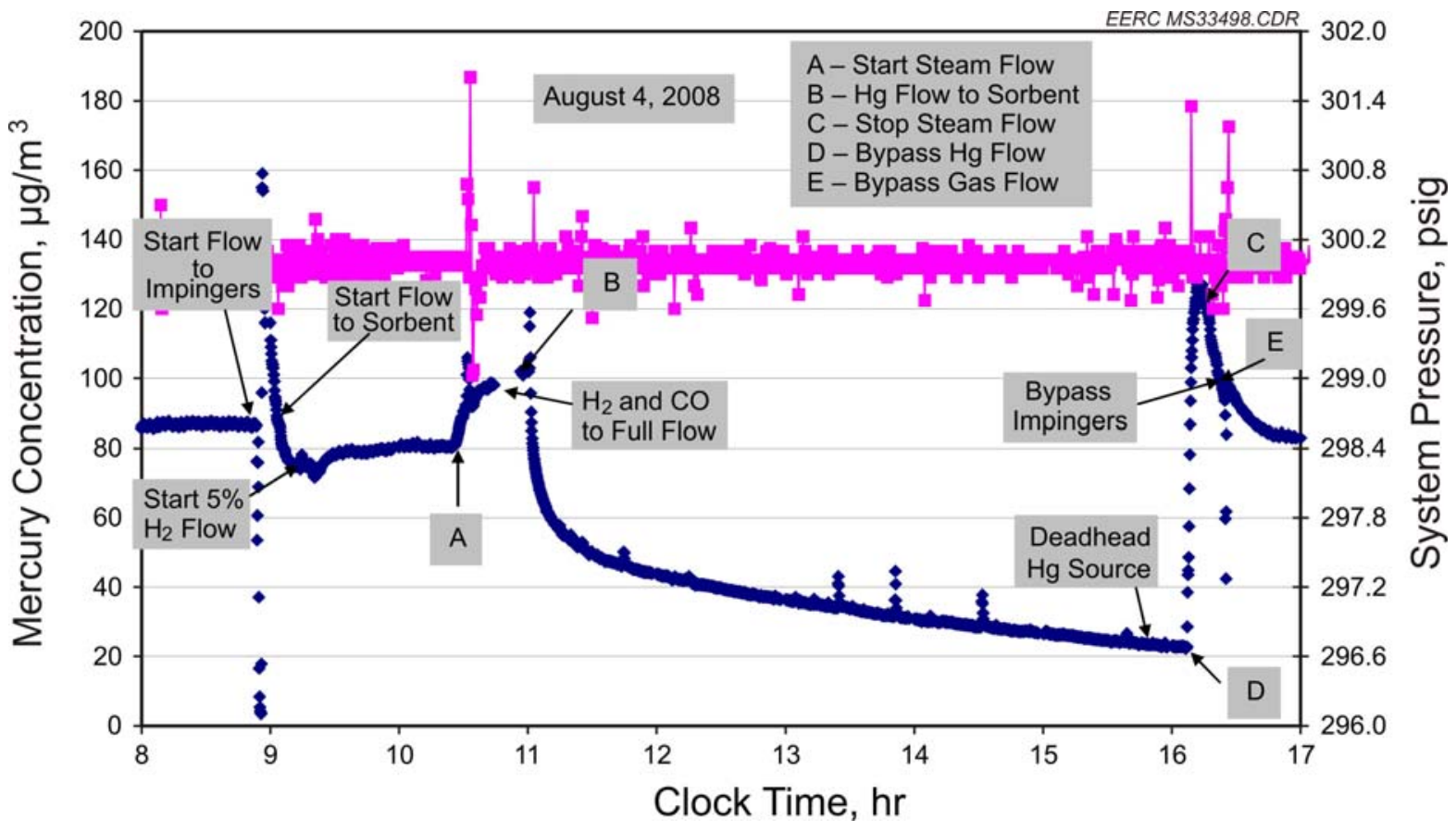

Figure 37. Mercury sorption curve for Corning Monolith SR Liquid 283, $350^{\circ} \mathrm{F}$ and 300 psig (Test 51).

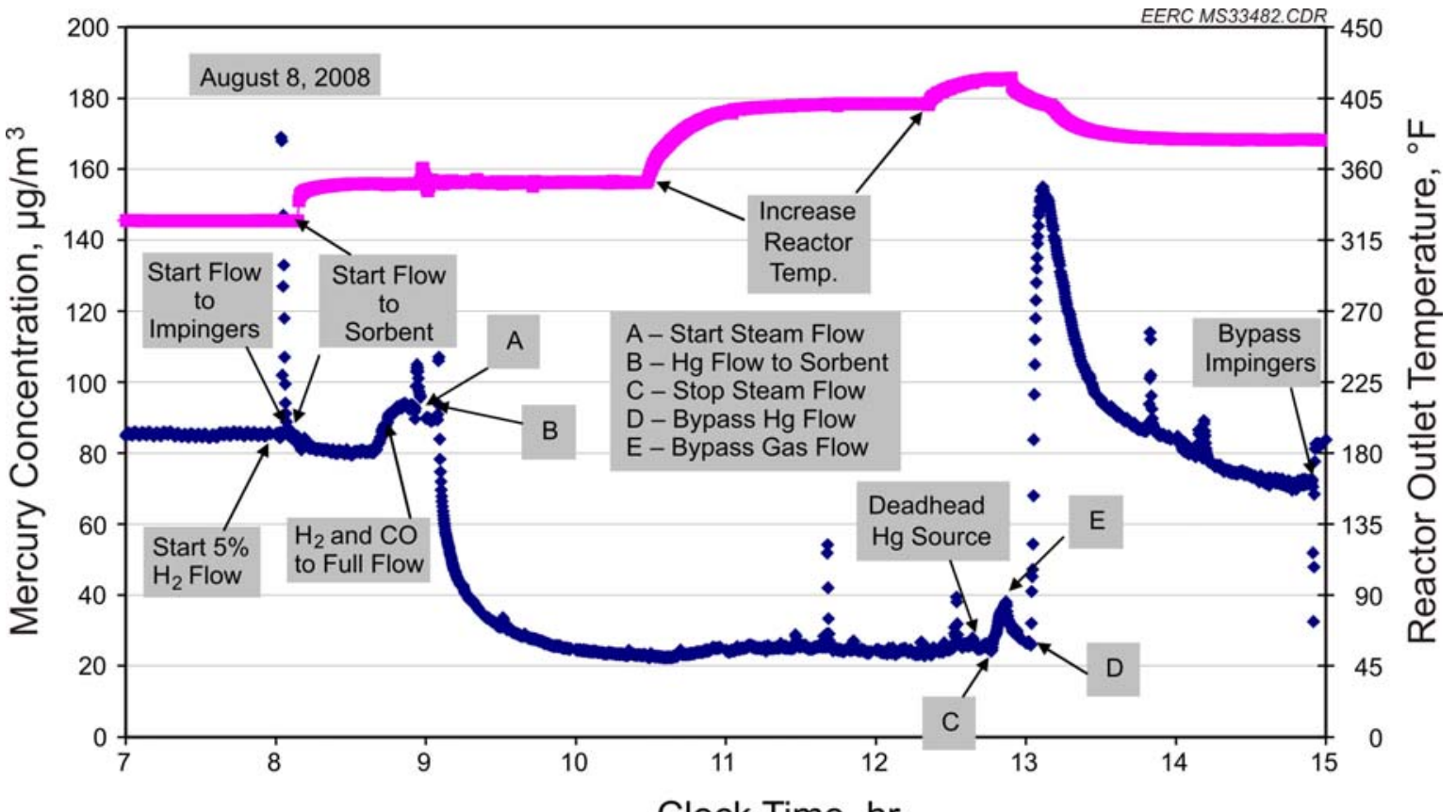

Clock Time, hr

Figure 38. Mercury sorption curve for Corning Monolith SR Liquid 283, $350^{\circ}-400^{\circ} \mathrm{F}$ and $300 \mathrm{psig}$ (Test 52). 


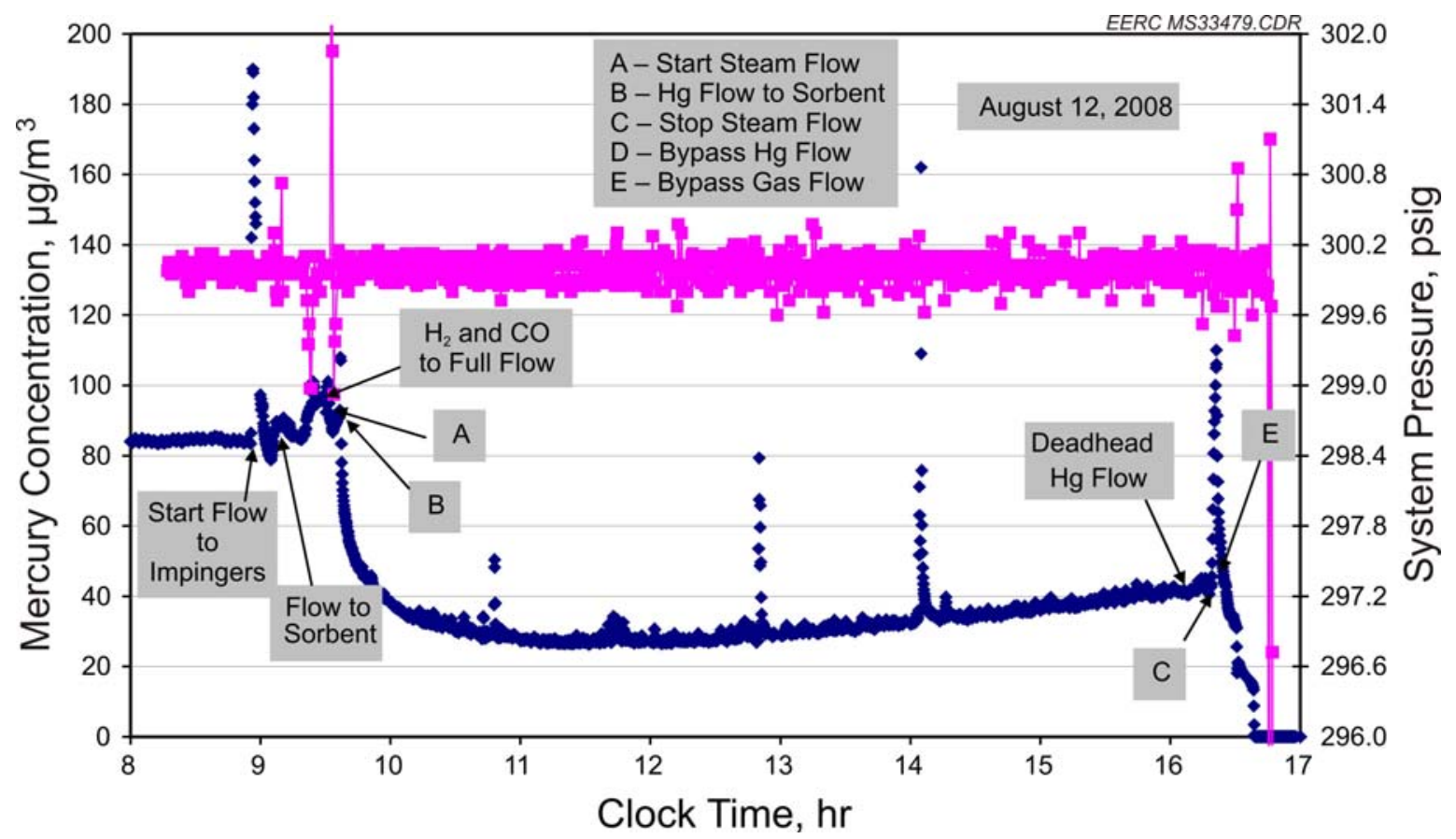

Figure 39. Mercury sorption curve for Corning Monolith SR Liquid 283, $400^{\circ} \mathrm{F}$ and 300 psig (Test 53).

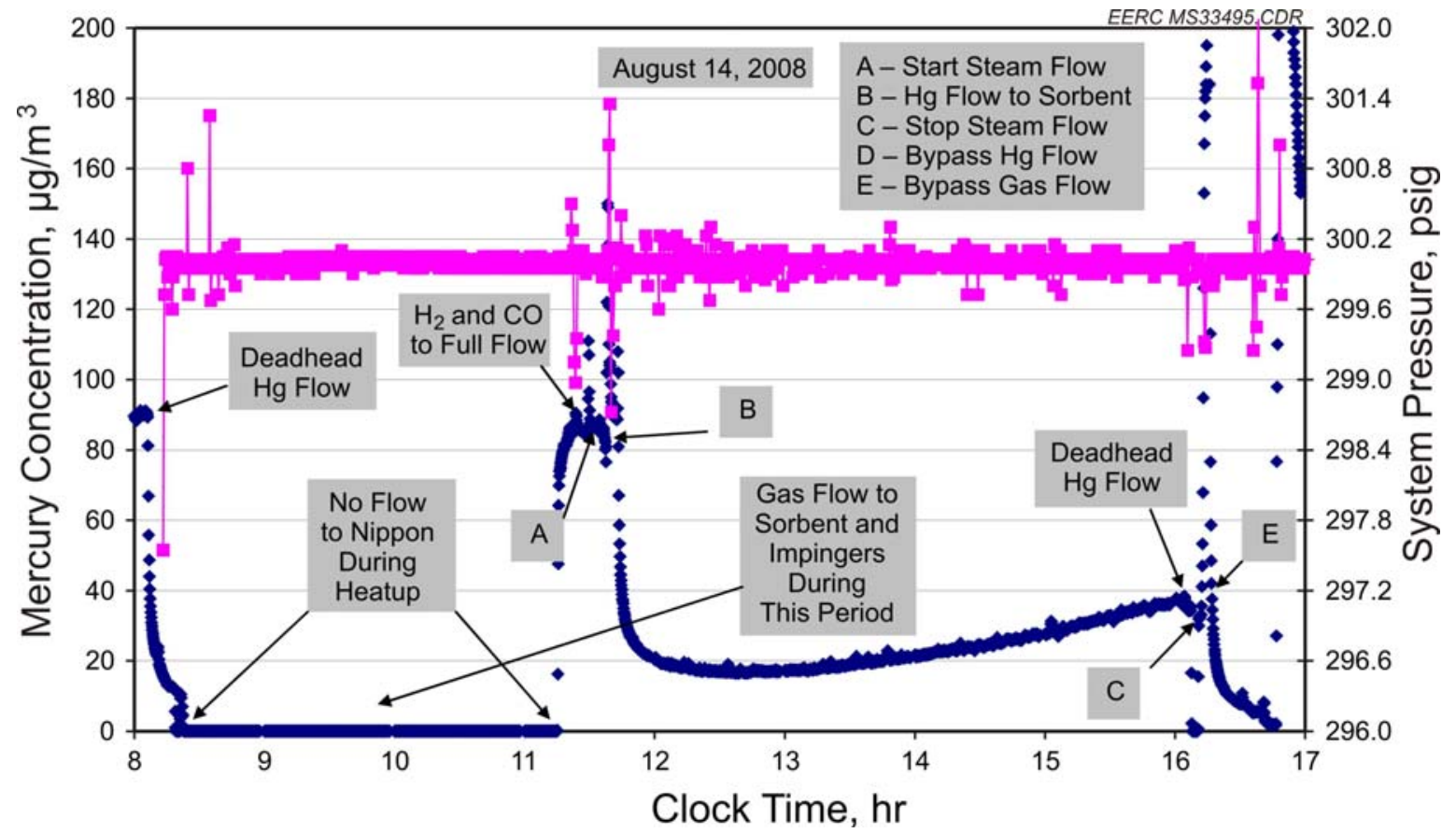

Figure 40. Mercury sorption curve for Corning Monolith SR Liquid 283, $400^{\circ} \mathrm{F}$ and 300 psig (Test 54). 


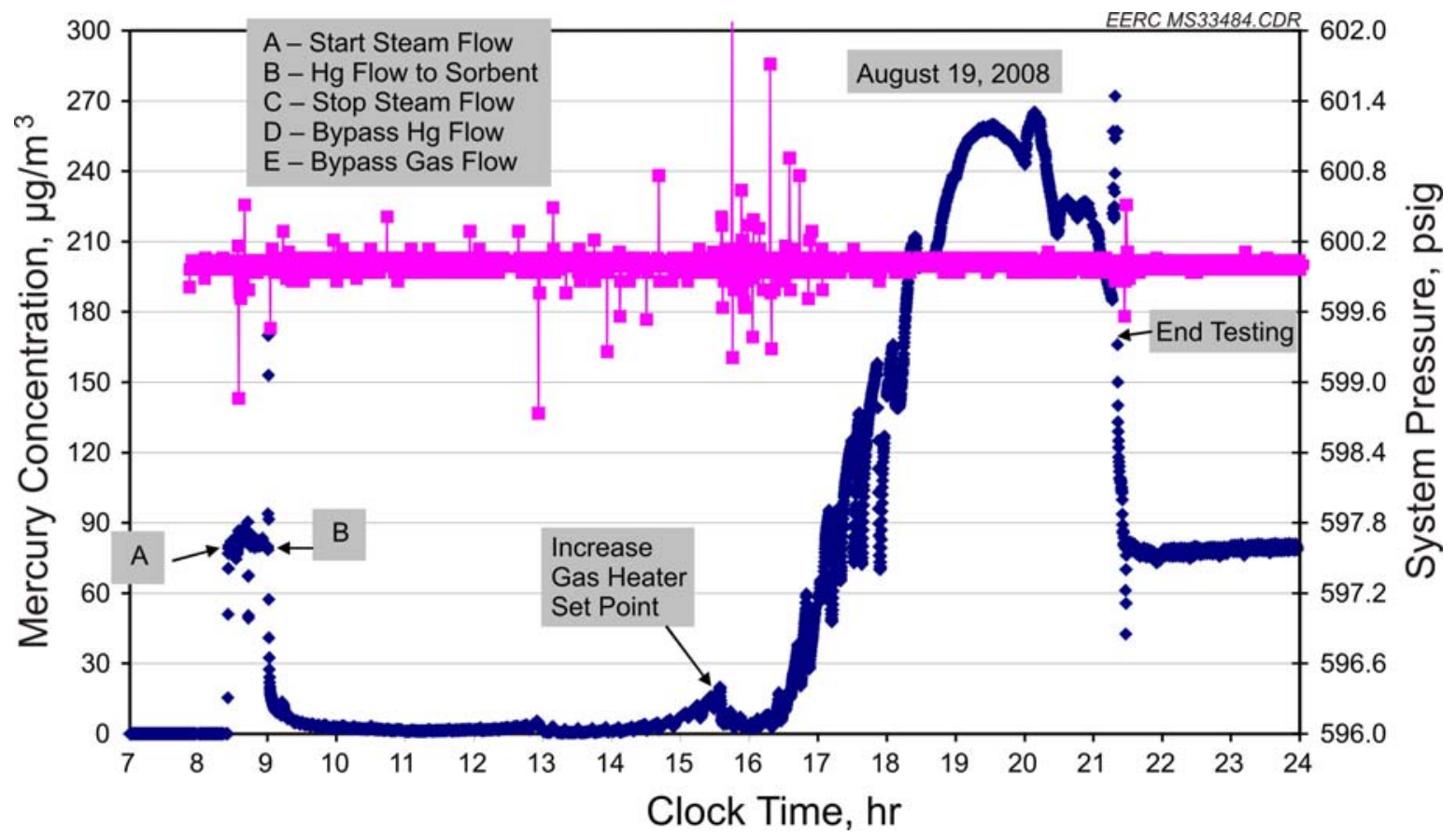

Figure 41. Mercury sorption curve for Corning Monolith SR Liquid 283 and $284,400^{\circ} \mathrm{F}$ and 600 psig (Test 56).

As a follow-up, Tests 60 and 61 were performed with Corning monolith SR Liquid 282, which was not prepared using the "original" methodology. These tests again demonstrated poor potential for mercury reduction.

Corning monoliths were also prepared using Group IB and IIB metal components owing to the success with the noncarbon sorbent tests. Monoliths in Tests 40 and 41 contained the metals in a prereduced metallic state while monoliths in Tests 42 to 45 required in situ reduction of the metals with hydrogen. All tests were conducted at $350^{\circ} \mathrm{F}$ and 300 psig, but all monoliths indicated no significant or sustained mercury reduction.

\section{EERC-Prepared Sorbents}

Test 6 was performed using EERC-developed carbon-based granular sorbents that showed promise in Phase 1 for mercury capture at 300 psig and $350^{\circ} \mathrm{F}$. However at 600 psig and $400^{\circ} \mathrm{F}$, this material did not demonstrate significant or sustained mercury reduction. Two additional EERC carbon-based sorbents, evaluated in Tests 12, 16, and 17, at the less severe conditions of 300 psig and $350^{\circ} \mathrm{F}$, were similarly ineffective for mercury reduction.

Tests 46 to 50 were conducted with two EERC-prepared selenium-based sorbents, with one of the granular sorbents prepared with Group IIB metal selenide and the other prepared with a Group IB metal selenide. These sorbents appeared to offer some promise for mercury capture. Unfortunately, these sorbents also released Se, as evidenced by the measurement of $\mathrm{H}_{2} \mathrm{Se}$ in the effluent gas. The release of $\mathrm{H}_{2}$ Se seemed to coincide with the initiation of $\mathrm{CO}$ flow, and the 
actual $\mathrm{H}_{2} \mathrm{Se}$ gas may have been responsible for mercury capture during periods of low-measured mercury concentration.

Tests 85 and 86 were performed with EERC-prepared sorbents that utilized similar Group IB and IIB metals, either on alumina pellets or as an aluminum oxide coprecipitate. Neither was effective for mercury capture, although both appeared to be highly effective for arsine and/or hydrogen selenide capture.

\section{Long-Term Testing}

A total of eight long-term mercury and/or hydride sorption tests were performed; Tests 7681, 83, and 88. All sorbents were carbon-based monoliths prepared by Corning. Tests used three or four monoliths each with the intent to maximize the amount of sorbent in the reactor and achieve longer tests. Select sorbents were submitted for determination of total mercury content.

Figures 42-46 present sorption curves for select tests. The GR-F1 and SR Liquid (31308) monoliths appeared to be very effective sorbents for mercury and arsine removal. The mercury concentration remained below $5 \mu \mathrm{g} / \mathrm{m}^{3}$ for $\sim 92$ hours for the GR-F1 monoliths and 55 hours for the SR Liquid (31308) monoliths, tests that used four monoliths each.

The GR-F1 and SR Liquid (31308) monoliths exhibited a rapid rise in the outlet mercury concentration, with the GR-F1 monolith apparently undergoing desorption as the outlet concentration was well above the inlet baseline value. Testing with the SR Liquid (31308) sample was halted to prevent a desorption scenario. The GR-F1 monoliths were cut in half

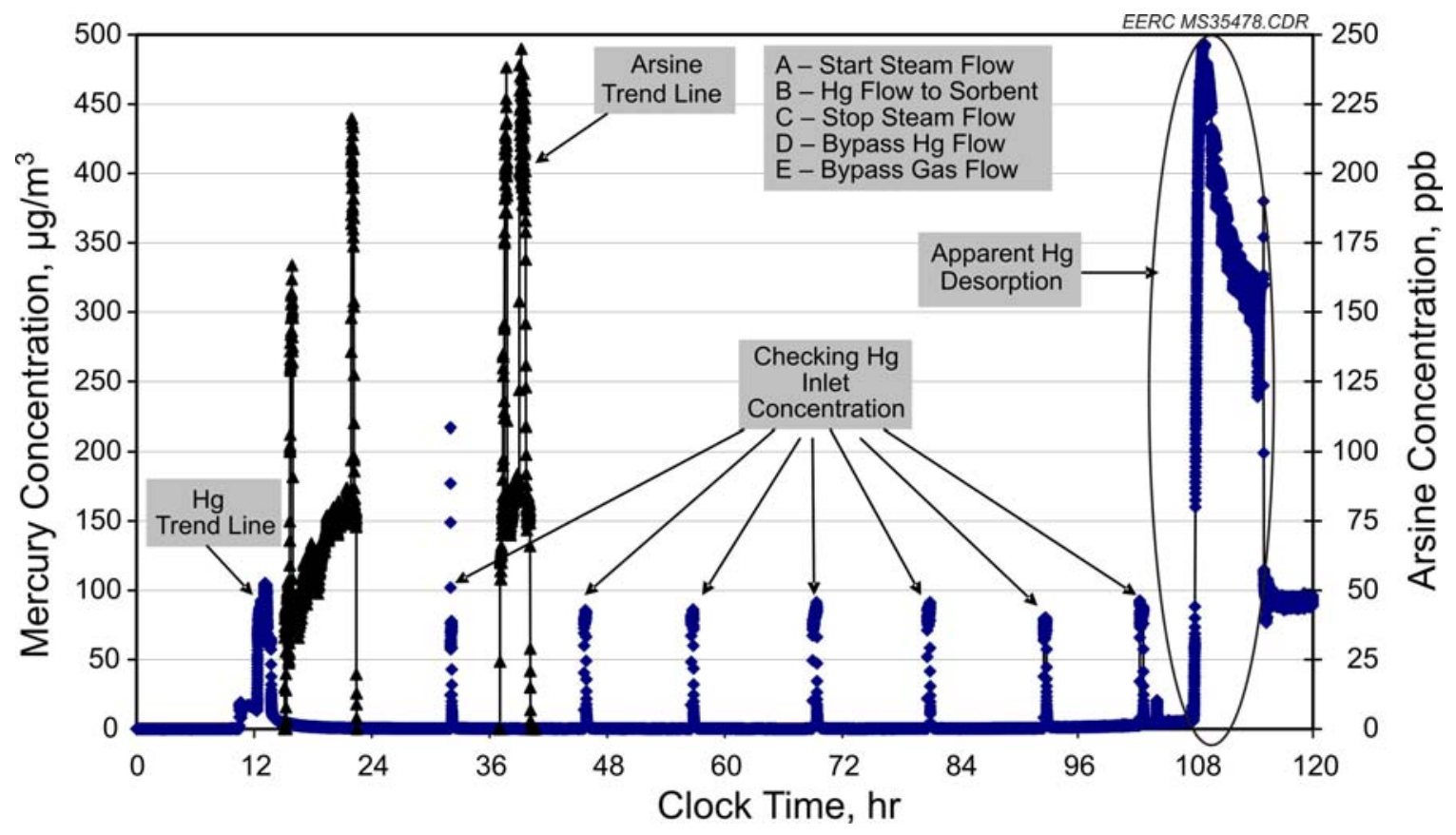

Figure 42. Mercury and arsine sorption curves for Corning Monoliths GR-P1-2189 $(1,2,3,4)$ at $400^{\circ} \mathrm{F}$ and 600 psig (Test 76). 


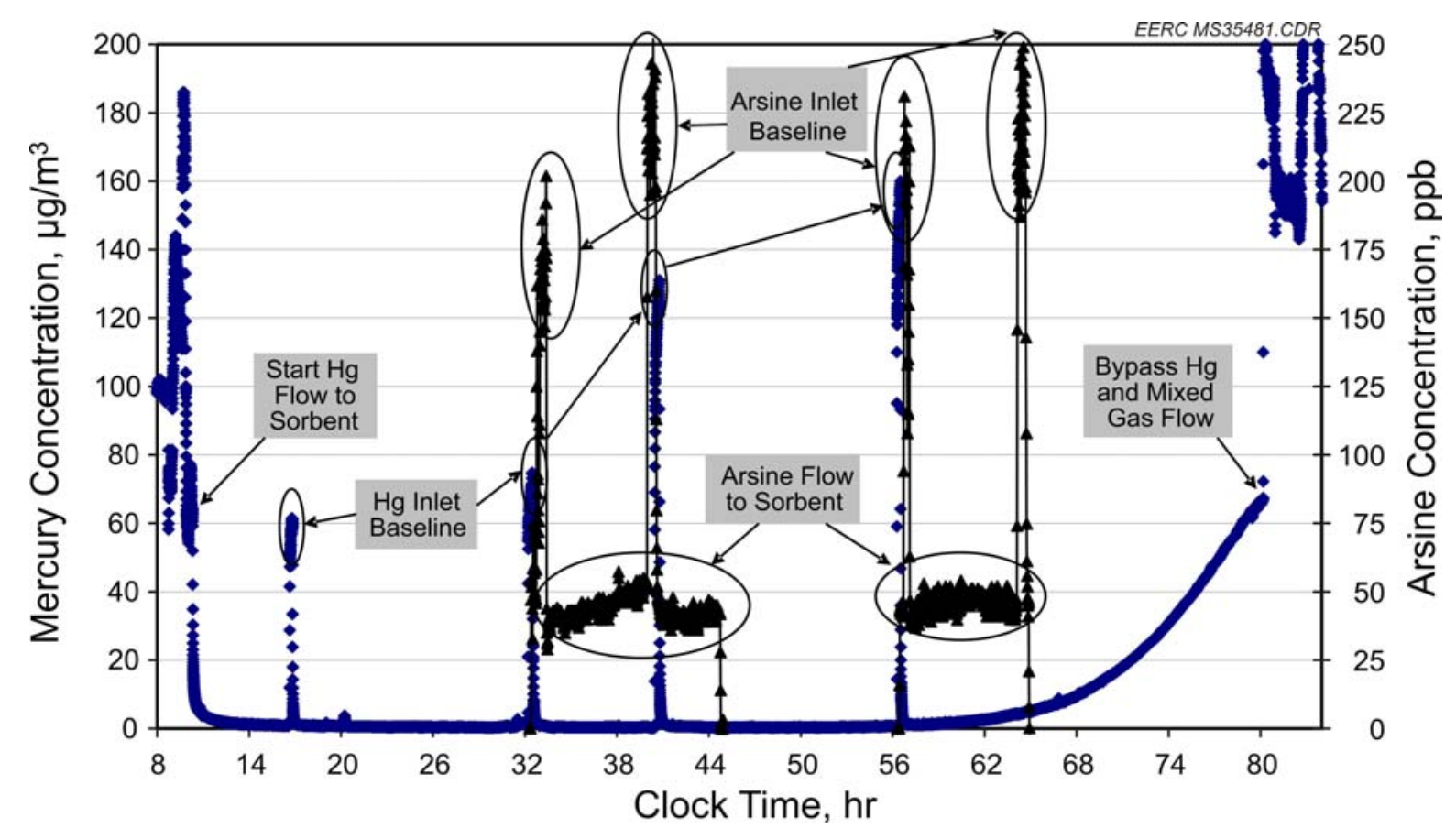

Figure 43. Mercury and arsine sorption curves for Corning Monoliths 31308-2, $-7,-12$, and -16 at $400^{\circ} \mathrm{F}$ and 600 psig (Test 80 ).

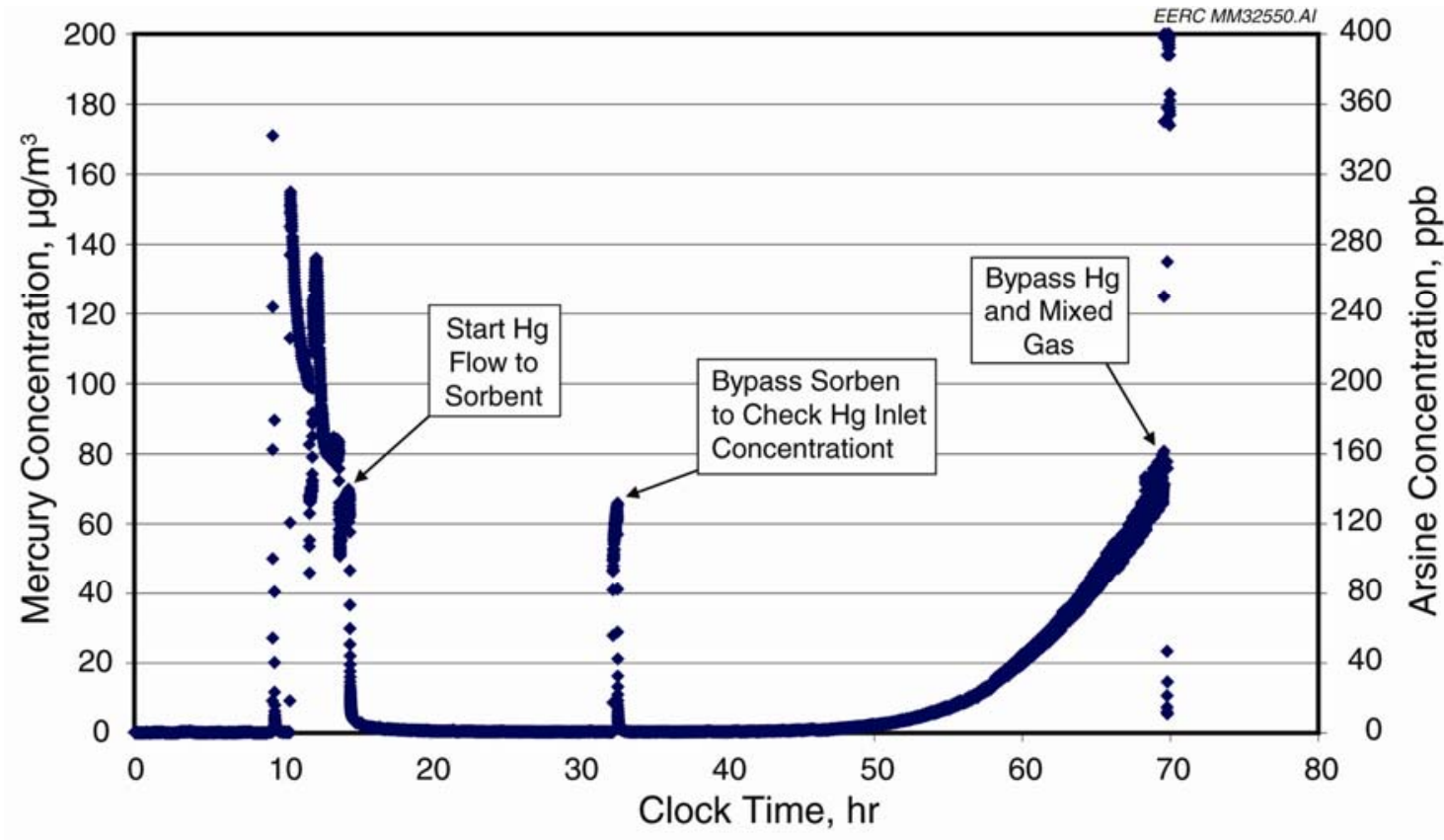

Figure 44. Mercury sorption curve for Corning Monoliths 31308-3, -10, and -20 at $400^{\circ} \mathrm{F}$ and $600 \mathrm{psig}$ (Test 83). 


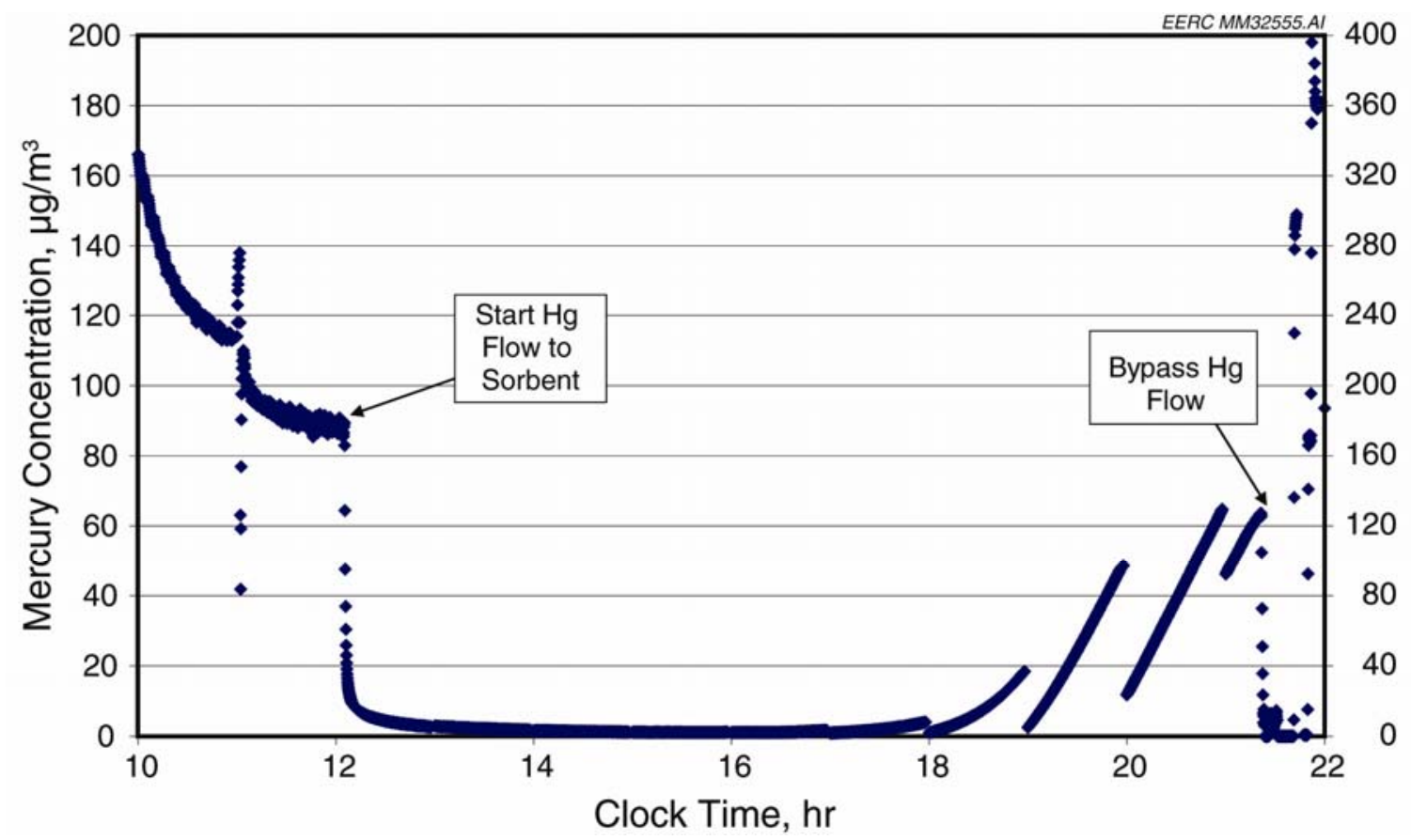

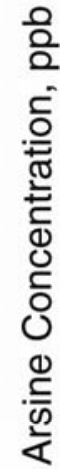

Figure 45. Mercury sorption curve for Corning Monoliths 31308-4, -13, and -15 at $400^{\circ} \mathrm{F}$ and 600 psig (Test 88).

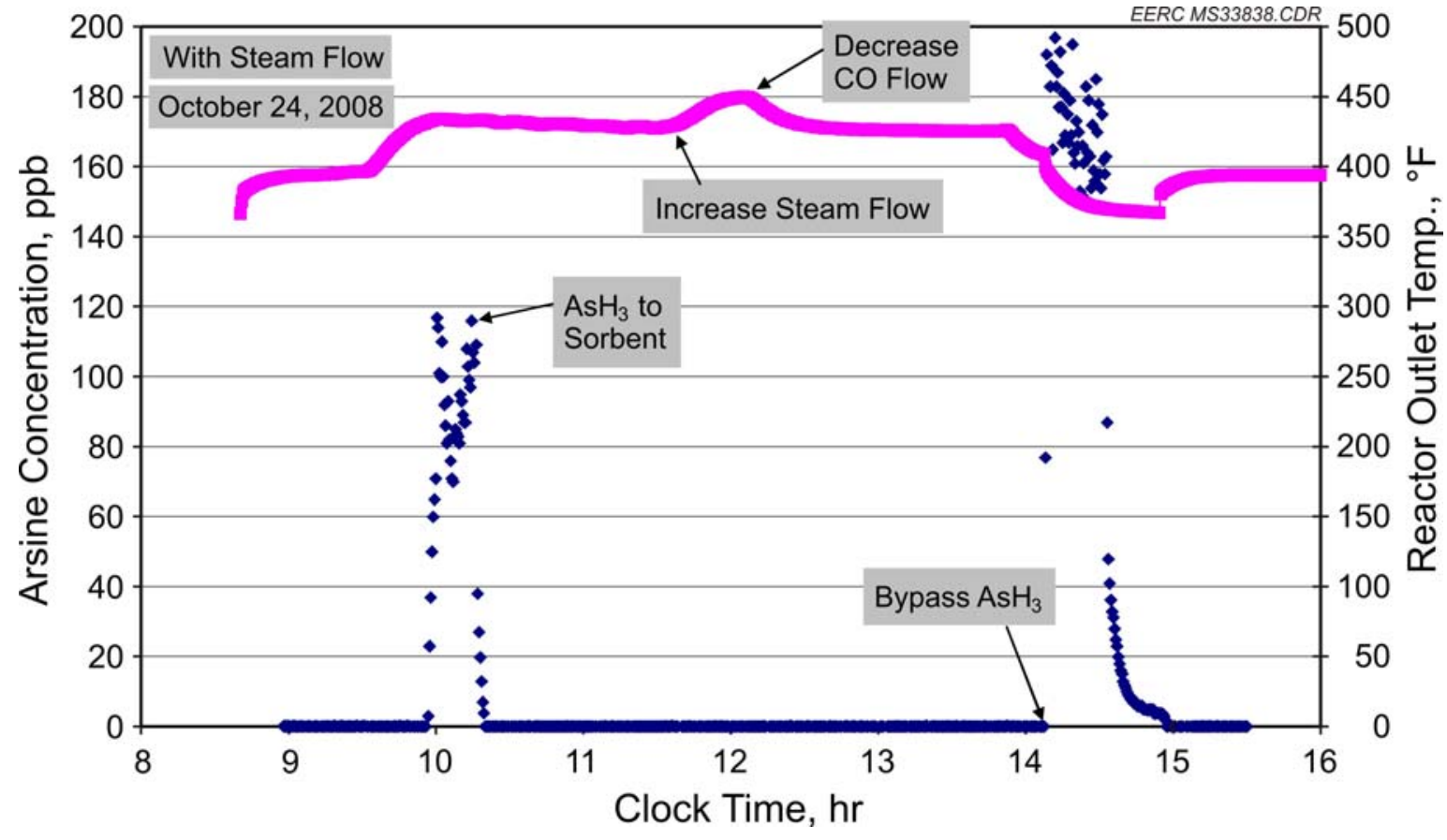

Figure 46. Arsine sorption curve for EERC Noncarbon Sorbent 1 at $400^{\circ} \mathrm{F}$ and 600 psig (Test 64). 
vertically, with half of each submitted for mercury analysis. The concentrations of mercury on the monoliths (moving from inlet to outlet) were 49.2, 60.1, 66.6, and $49.7 \mu \mathrm{g} / \mathrm{g}$. The SR Liquid (31308) monoliths were similarly split and analyzed. The concentrations of mercury on the monoliths (from inlet to outlet) were 5.9, 110, 264, and $192 \mu \mathrm{g} / \mathrm{g}$.

\section{Hydride Capture}

Essentially all the sorbents, designed principally for mercury capture, appeared to be highly effective for arsine or hydrogen selenide capture at $400^{\circ} \mathrm{F}$ and 600 psig. Tests evaluating hydride capture included 64-66, 68, 69, 71, 73, 74-76, 78-80. Sorption curves are presented in Figures 46-58. Effective sorbents included the Corning SR Liquid monoliths ("original" formulation), noncarbon sorbents, and EERC-prepared Group IB and IIB metal-based materials.

\section{Sorbent Regeneration}

A test was performed to determine if mercury could be desorbed from the SR Liquid 283 and 284 monoliths, and the results are presented in Figure 59. Upon initiating flow (only $\mathrm{N}_{2}$ ) through the monoliths at $400^{\circ} \mathrm{F}$ and $600 \mathrm{psig}$, mercury release appeared to occur. After a large spike to $375 \mu \mathrm{g} / \mathrm{m}^{3}$, the mercury concentration remained above baseline for over 1 hour. While the mercury concentration was decreasing, an attempt was made to reverse the trend by reducing system pressure. It was expected that if pressure swing desorption was successful, an increase in mercury concentration would be observed. However, the mercury concentration decreased and stayed near zero even after reduction in pressure to as low as 355 psig.

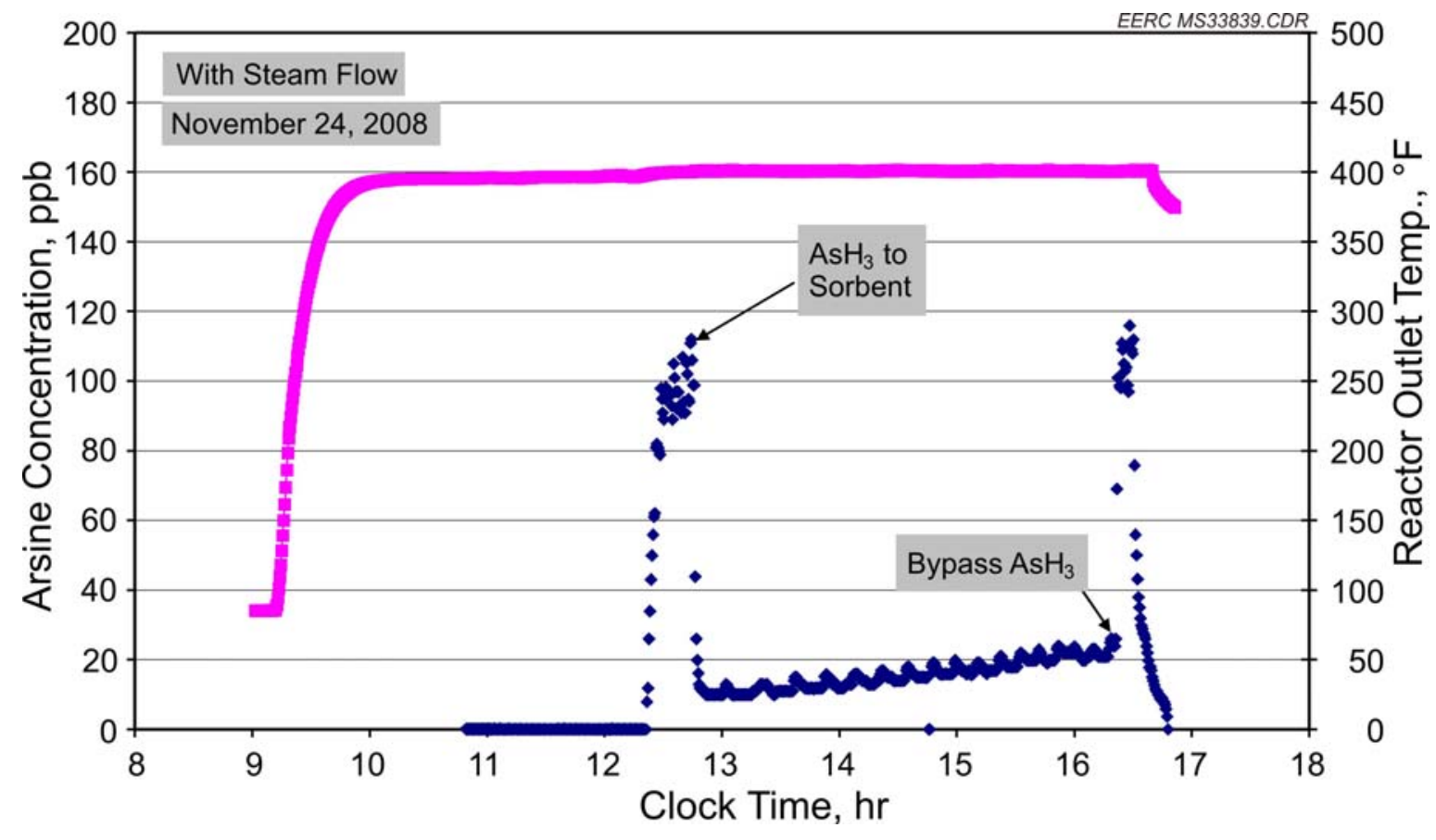

Figure 47. Arsine sorption curve for Corning Monolith SR Liquid 285 at $400^{\circ} \mathrm{F}$ and $600 \mathrm{psig}$ (Test 65). 


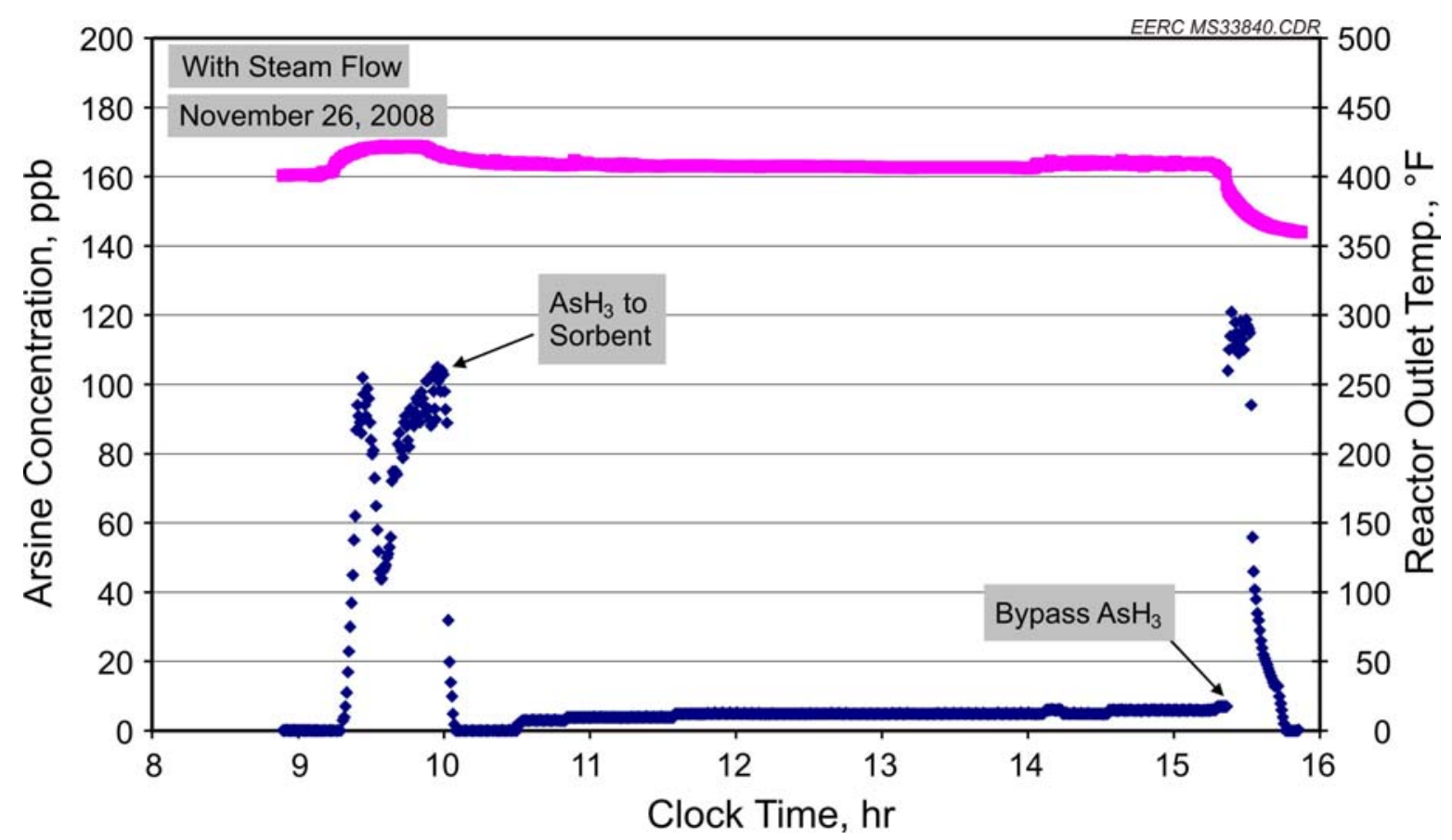

Figure 48. Arsine sorption curve for EERC Sorbent Group IB and IIB metals on alumina pellet at $400^{\circ} \mathrm{F}$ and 600 psig (Test 66).

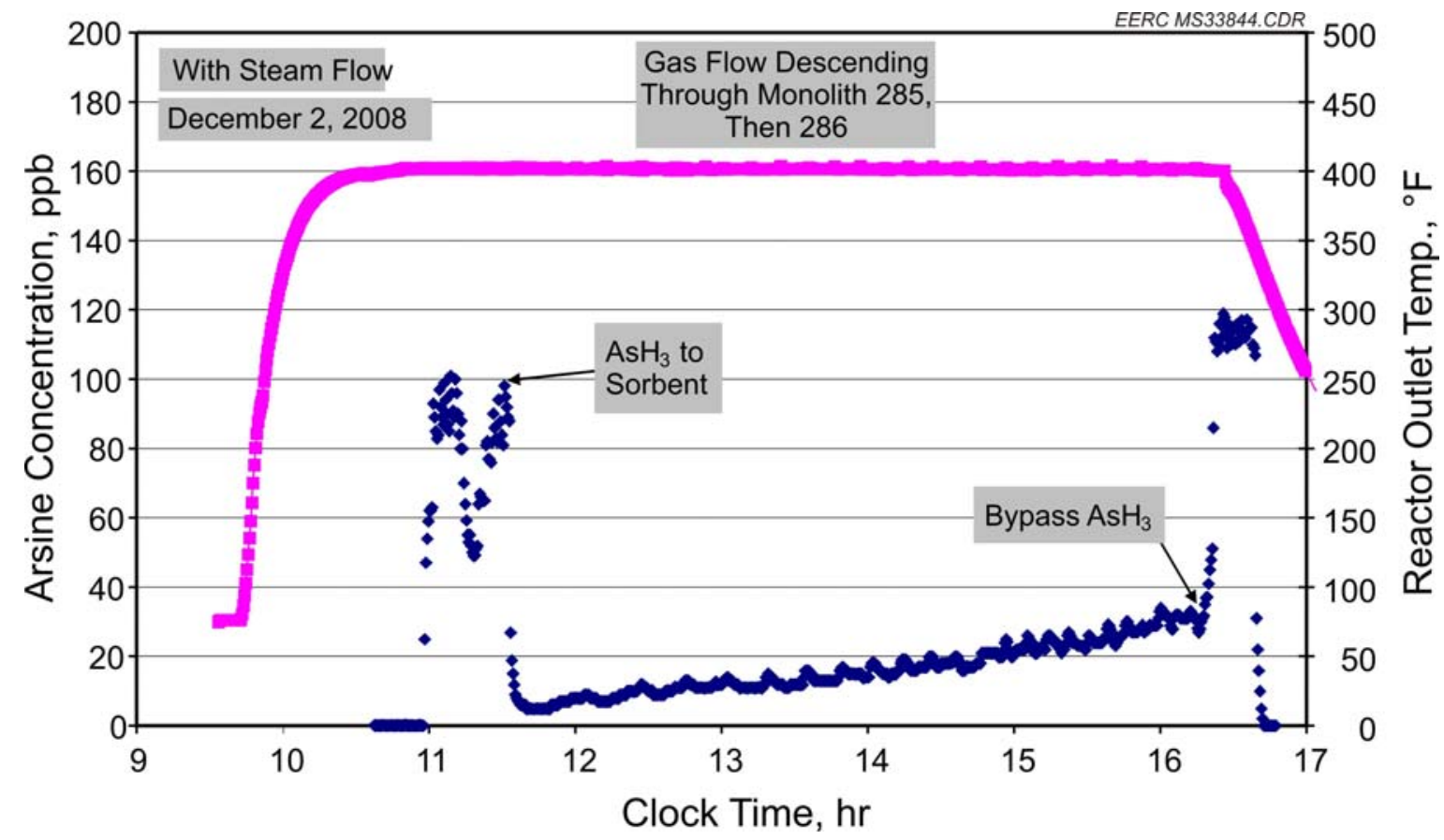

Figure 49. Arsine sorption curve for Corning Monoliths SR Liquid 285 and 286 at $400^{\circ} \mathrm{F}$ and 600 psig (Test 68). 


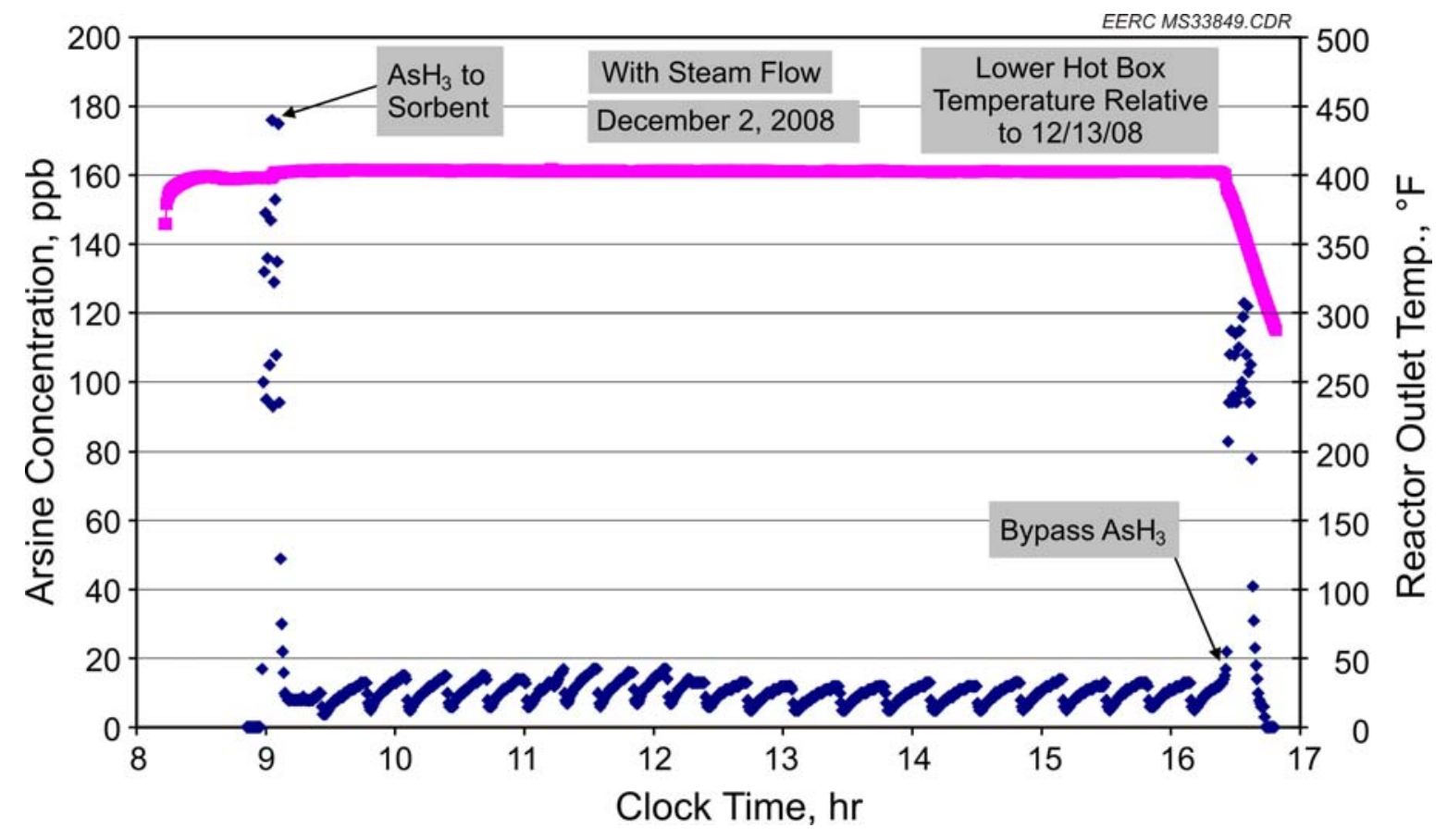

Figure 50. Arsine sorption curve for EERC Sorbent Group IB and IIB metals coprecipitate at $400^{\circ} \mathrm{F}$ and 600 psig (Test 69).

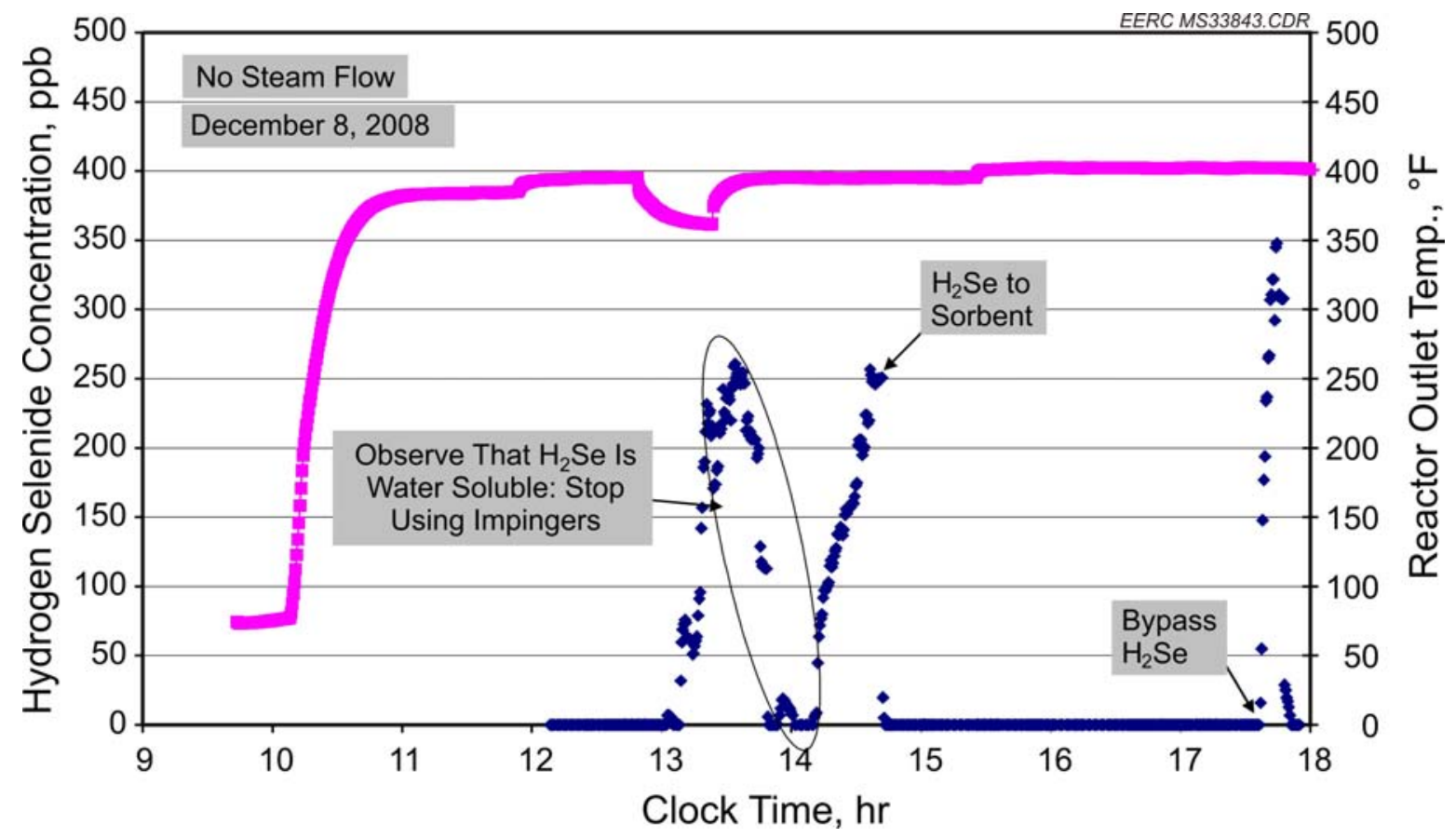

Figure 51. Hydrogen selenide sorption curve for EERC Sorbent Group IB and IIB metals coprecipitate at $400^{\circ} \mathrm{F}$ and 600 psig (Test 71). 


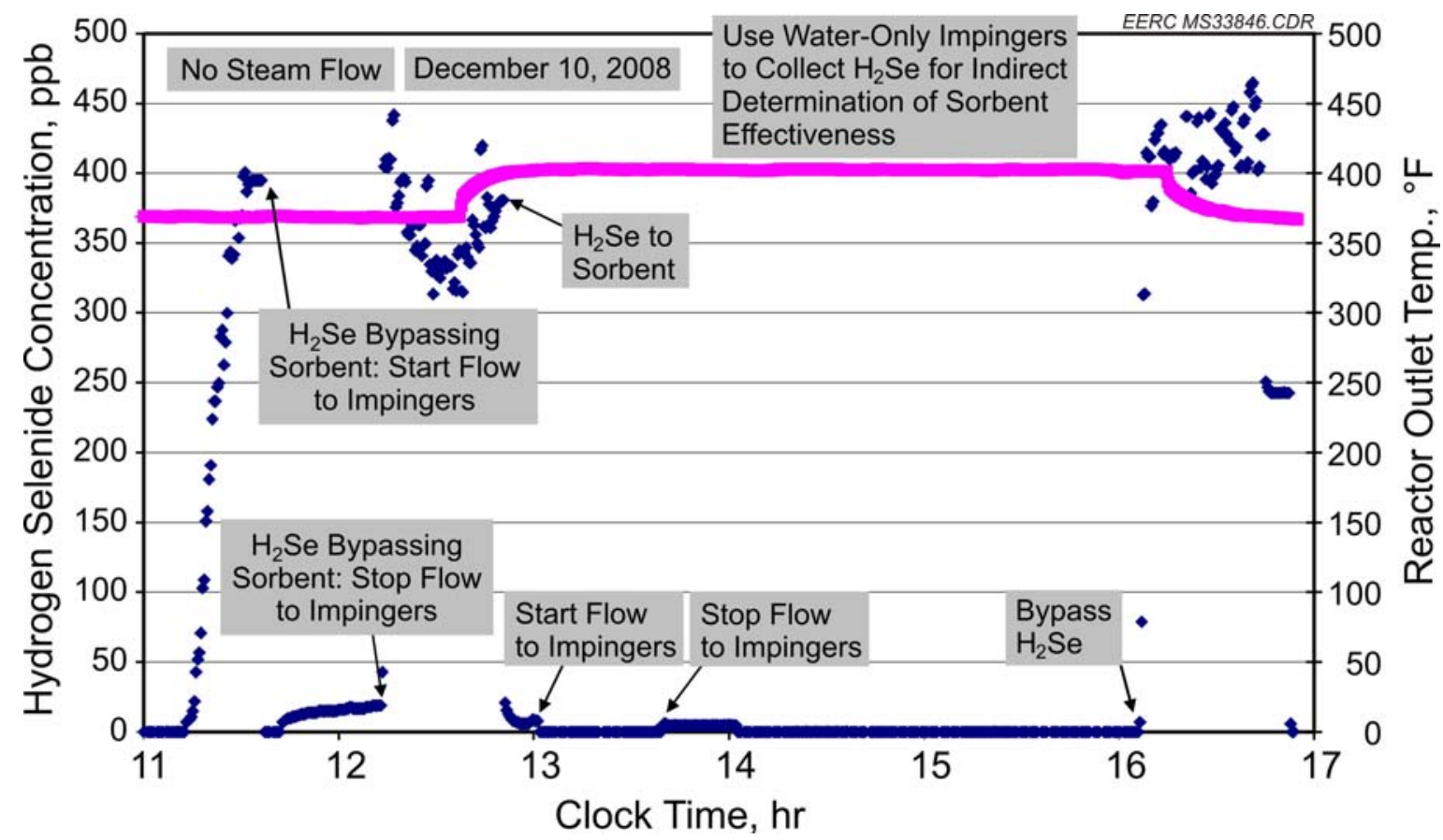

Figure 52. Hydrogen selenide sorption curve for EERC Sorbent Group IB and IIB metals coprecipitate at $400^{\circ} \mathrm{F}$ and $600 \mathrm{psig}$ (Test 73).

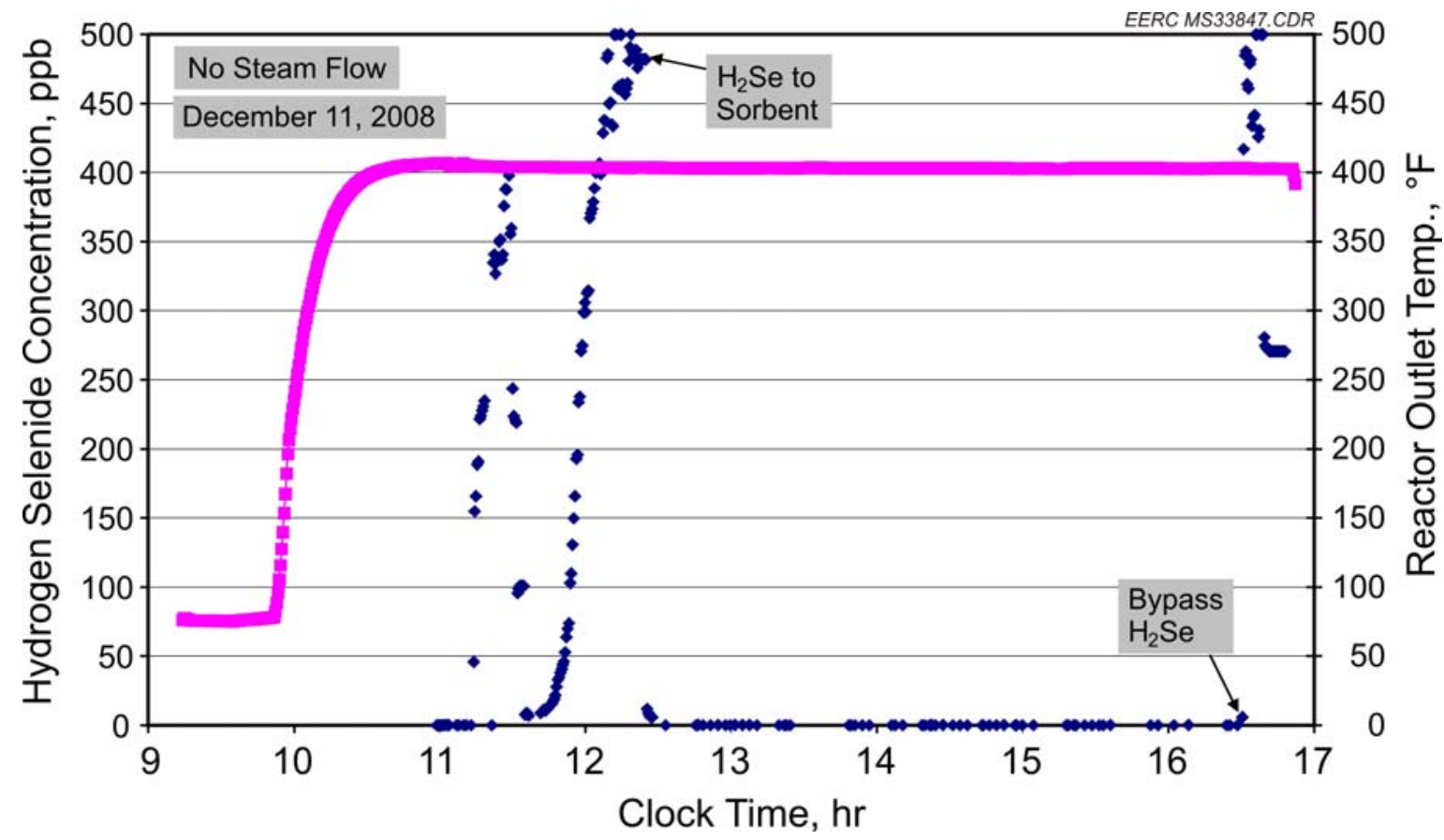

Figure 53. Hydrogen selenide sorption curve for EERC Sorbent Group IB and IIB metals on alumina pellet at $400^{\circ} \mathrm{F}$ and $600 \mathrm{psig}$ (Test 74). 


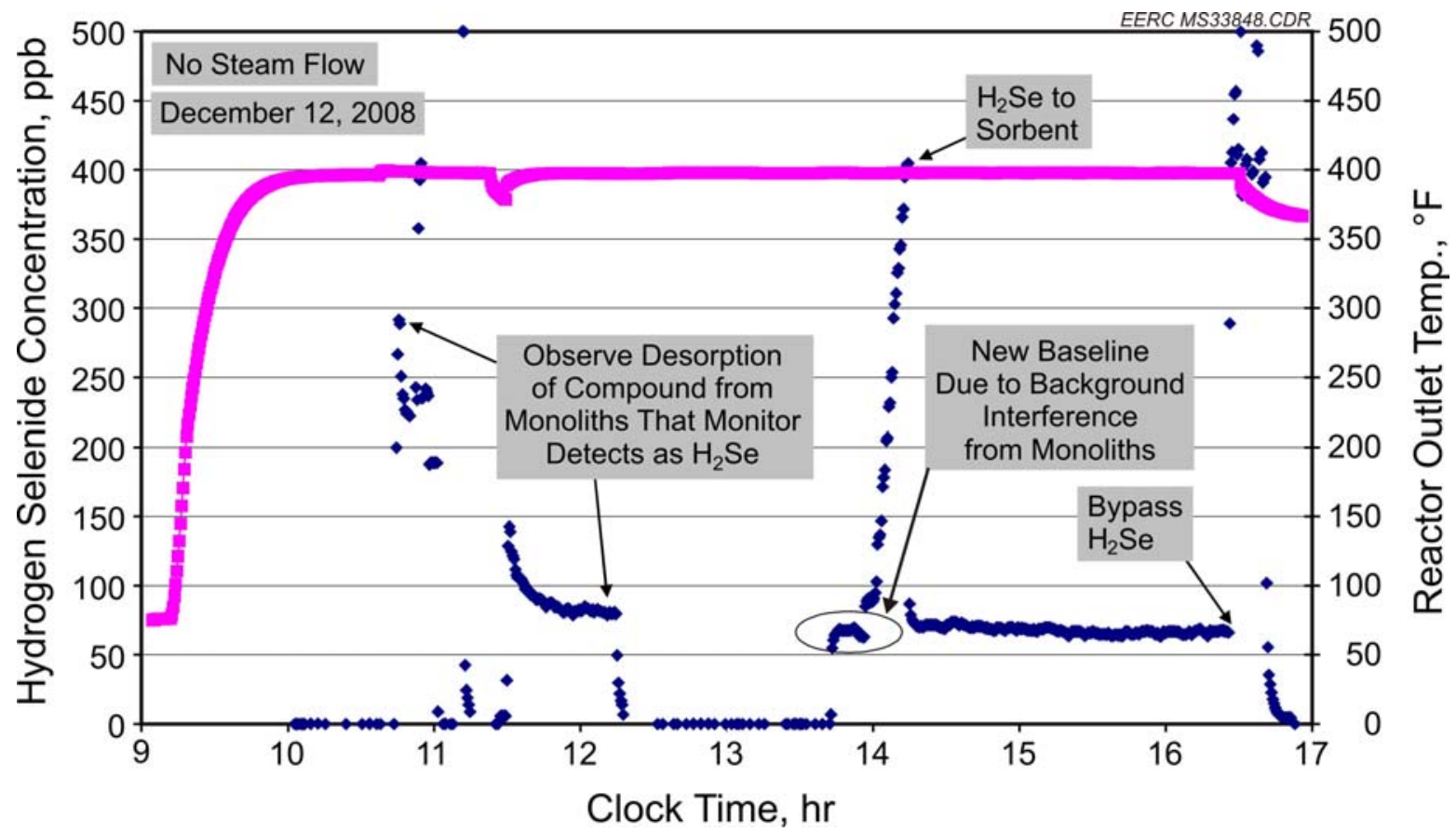

Figure 54. Hydrogen selenide sorption curve for Corning Monoliths SR Liquid 287 and 288 at $400^{\circ} \mathrm{F}$ and 600 psig (Test 75).

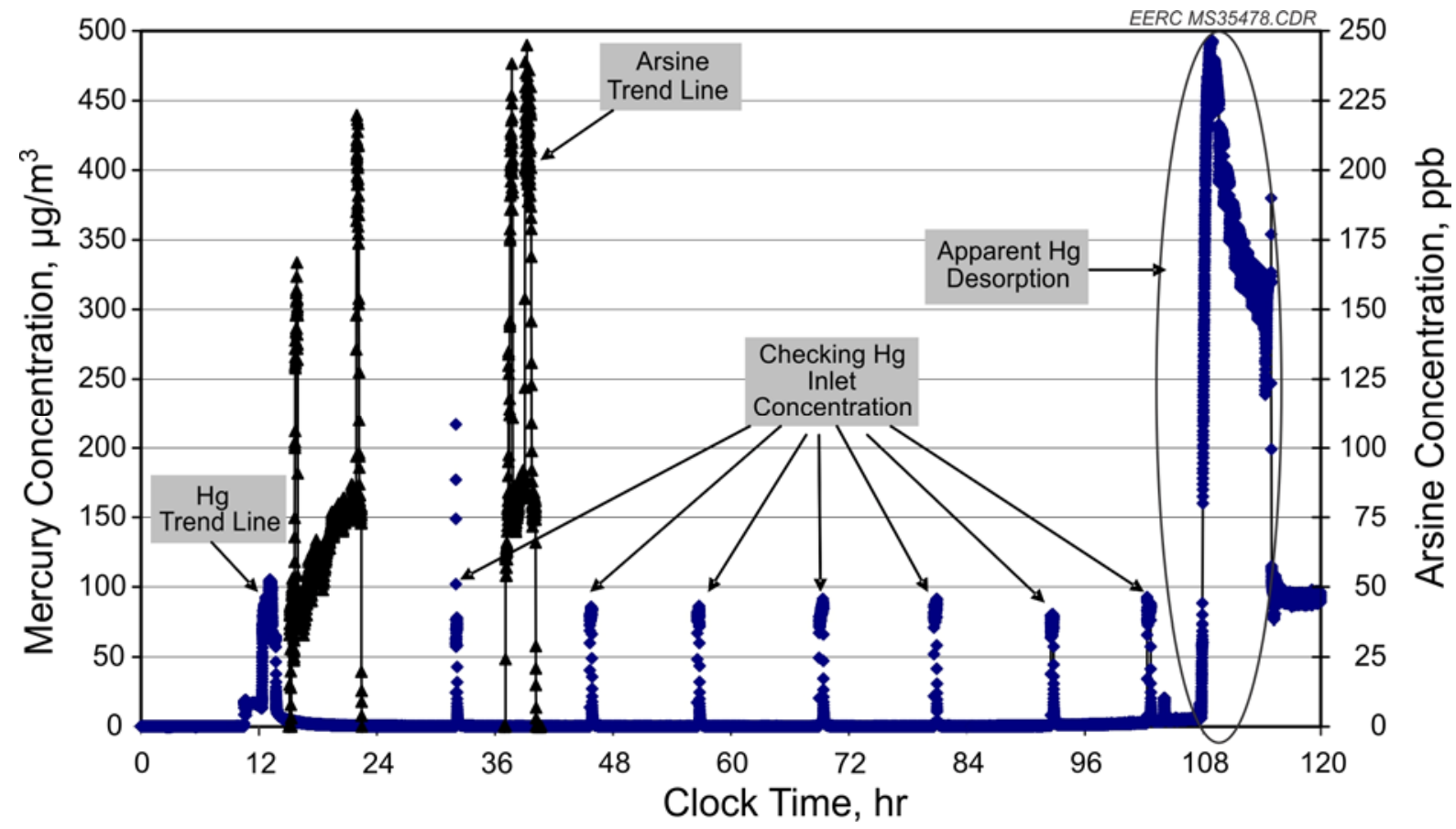

Figure 55. Arsine and mercury sorption curves for Corning Monolith GR-F1-2189 at $400^{\circ} \mathrm{F}$ and $600 \mathrm{psig}$ (Test 76). 


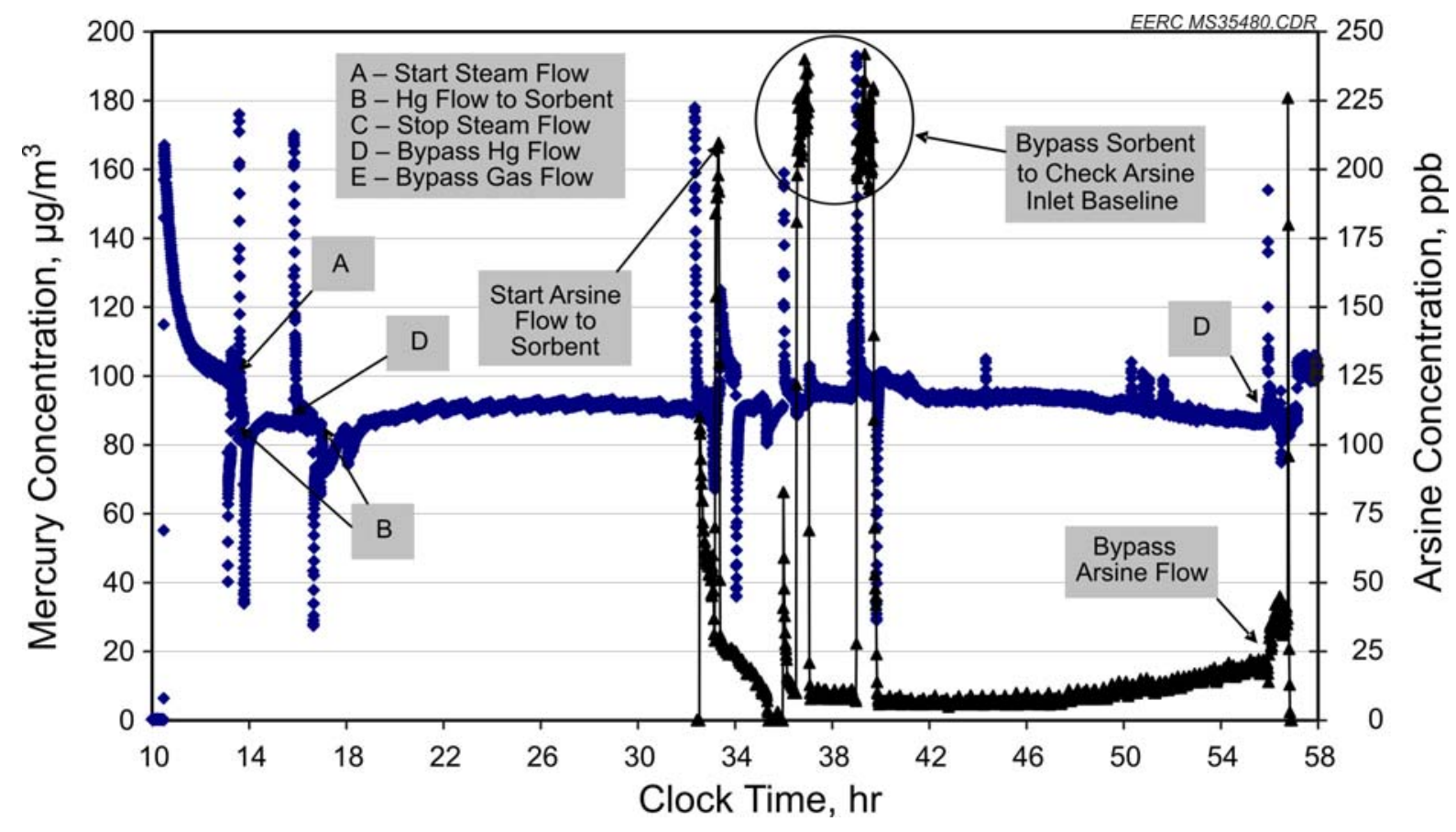

Figure 56. Arsine and mercury sorption curves for Corning Monoliths 31083-3, $-8,-13$, and -17 at $400^{\circ} \mathrm{F}$ and 600 psig (Test 78).

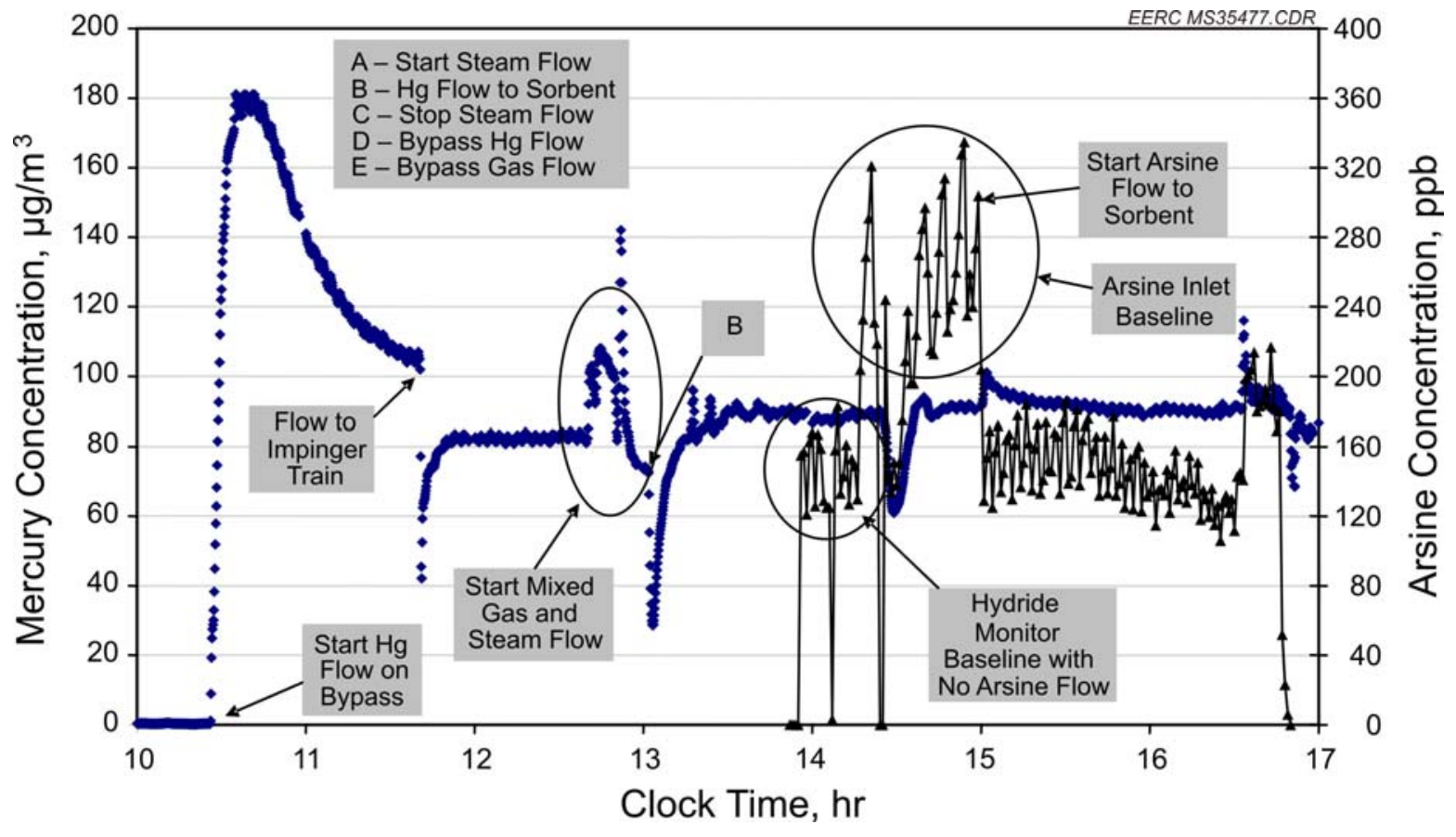

Figure 57. Arsine and mercury sorption curves for Corning Monoliths 31085-6, $-11,-17$, and -21 at $400^{\circ} \mathrm{F}$ and $600 \mathrm{psig}$ (Test 79). 


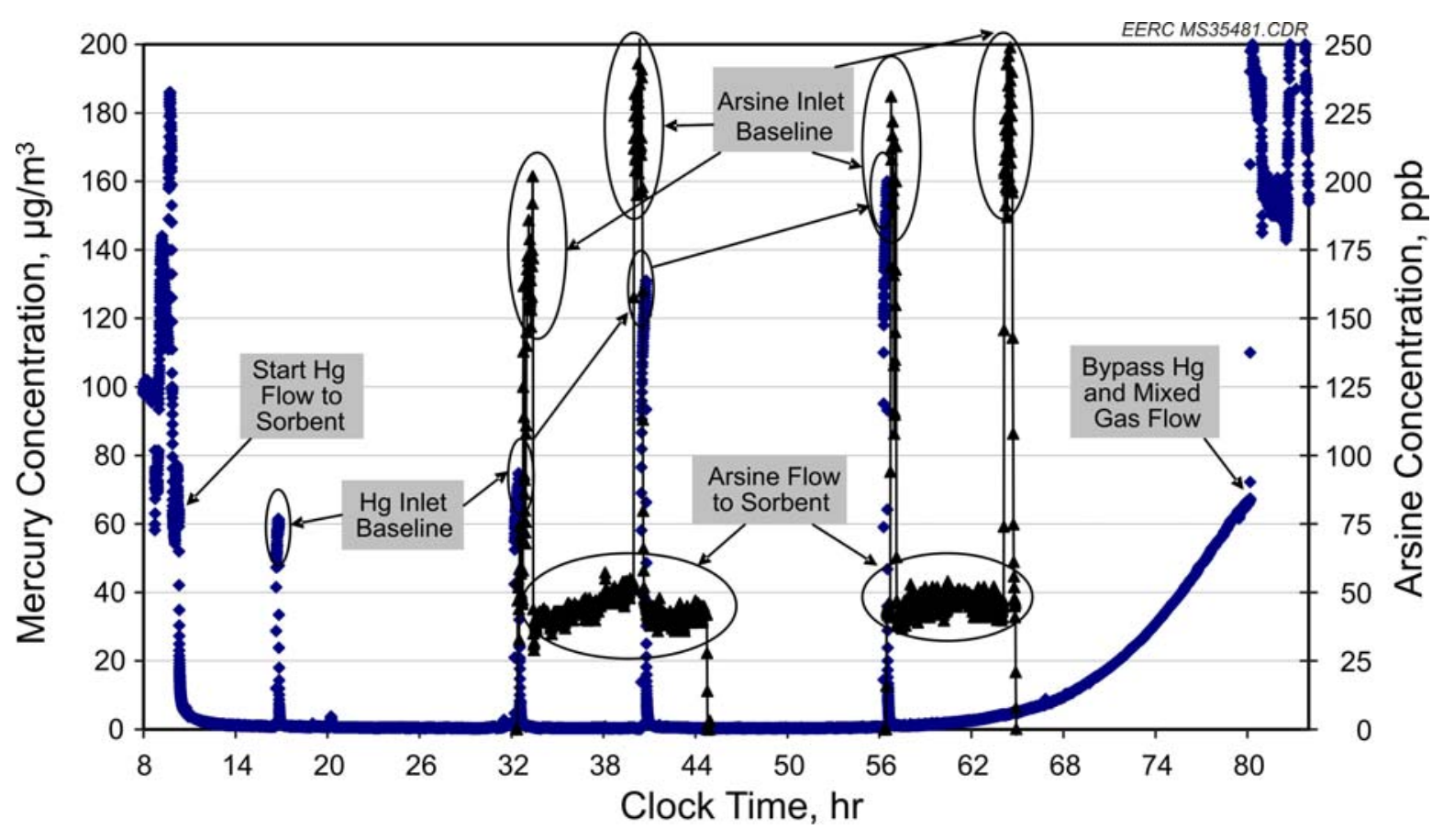

Figure 58. Arsine and mercury sorption curves for Corning Monoliths 31308-2, $-7,-12$, and -16 at $400^{\circ} \mathrm{F}$ and 600 psig (Test 80 ).

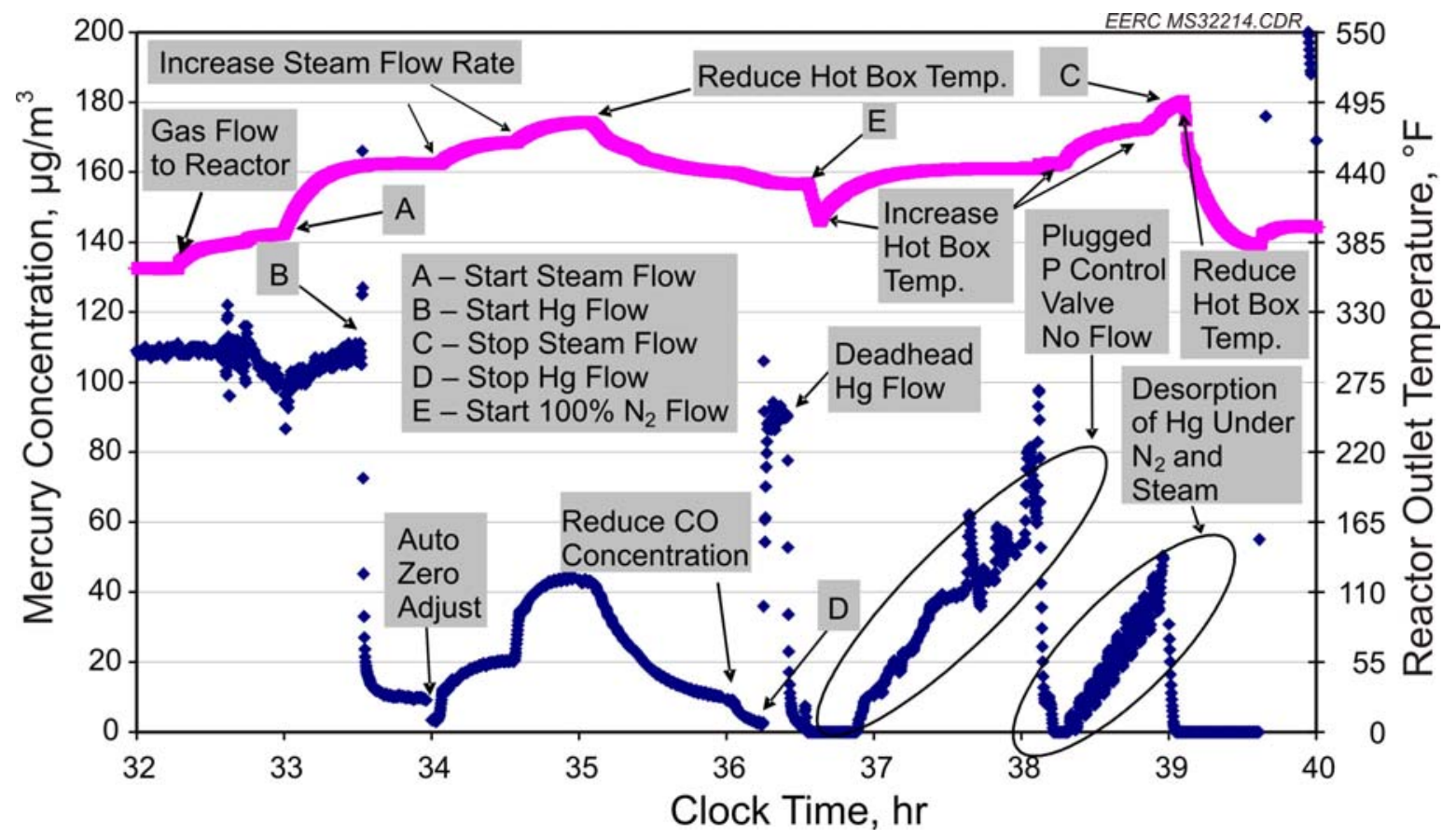

Figure 59. Mercury sorption curve for EERC Noncarbon Sorbent 1 at $350^{\circ} \mathrm{F}$ and 300 psig (Test 20). 
After bringing the system pressure back to 600 psig, the mercury concentration started coming up. Adding steam to the system resulted in a rapid reduction of mercury to $0 \mu \mathrm{g} / \mathrm{m}^{3}$. Again, it was presumed that there would have been a significant increase in the rate of mercury release when adding steam.

A third adsorption test was performed with the SR Liquid 283 and 284 monoliths, and the results are presented in Figure 60. In this test, the mercury concentration dropped as low as $\sim 3 \mu \mathrm{g} / \mathrm{m}^{3}$ and then began a steady ascent in concentration. The test was suspended after the mercury concentration appeared to level out, but again, this concentration was lower than the baseline or inlet concentration.

\section{Mercury Loading on Sorbents}

Table 6 presents the results for Tests 3-6 to assess mercury loading on the sorbents. The mercury breakthrough curves are shown in Figures A-1 through A-4 in the Appendix. The Corning monoliths were better than the EERC granular carbon for mercury control, principally with respect to the length of time over which mercury was being captured and the mass uptake ( $\mu \mathrm{g} / \mathrm{g}$ ) of mercury. None of the sorbents achieved a sustained ( $>24$ hours) low ( $>90 \%$ reduction or less than $5 \mu \mathrm{g} / \mathrm{m}^{3}$ ) concentration of mercury in the simulated fuel gas. Corning Monolith 7C87 did achieve a minimum concentration of $5-\mu \mathrm{g} / \mathrm{m}^{3}$ and maintained a concentration below $10 \mu \mathrm{g} / \mathrm{m}^{3}$ for 3.7 hours. The sorbents 0C83, 7C87, and the EERC sorbent all appeared to capture $\mathrm{Hg}$ at $400^{\circ} \mathrm{F}$ and 600 psig for a short period of time, with Sorbent 7C87 having the best capture of Hg as shown in Table 6.

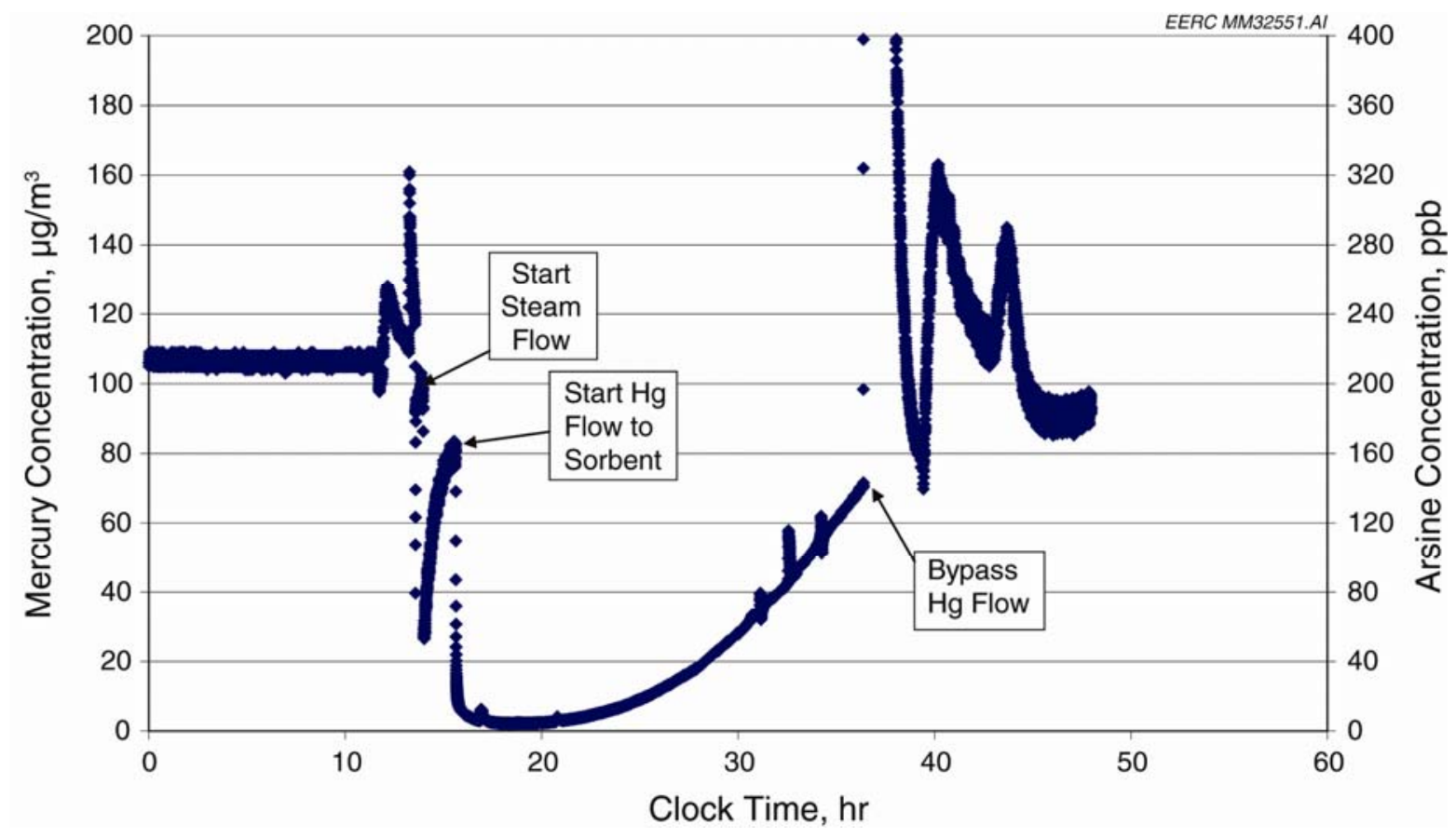

Figure 60. Mercury sorption curve for regenerated Corning Monoliths 31308-3, -10 , and -20 at $400^{\circ} \mathrm{F}$ and 600 psig (Test 84 ). 
Table 6. Mercury Loading Results for Select Sorbents

\begin{tabular}{|c|c|c|c|c|c|}
\hline Test Number & & $3^{\mathrm{a}}$ & $4^{\mathrm{b}}$ & $5^{\mathrm{c}}$ & $6^{\mathrm{d}}$ \\
\hline Average Gas Mercury Concentration & $\mu \mathrm{g} / \mathrm{m}^{3}$ & 60.0 & 84.0 & 72.5 & 70.8 \\
\hline Test Duration & hrs & 18.2 & 22.7 & 22.0 & 5.73 \\
\hline Estimated Mercury to Sorbent ${ }^{1}$ & $\mu \mathrm{g}$ & 399 & 697 & 583 & 148 \\
\hline Estimated Mercury Captured by Sorbent ${ }^{1}$ & wt\% & 40.0 & 70.4 & 31.4 & 48.9 \\
\hline Estimated Mercury Captured by Sorbent ${ }^{1}$ & $\mu \mathrm{g}$ & 160 & 491 & 183 & 72.3 \\
\hline Mercury Captured by Sorbent ${ }^{2}$ & $\mu \mathrm{g}$ & 113 & 394 & 209 & 43.0 \\
\hline Mercury Captured by Sorbent ${ }^{2}$ & $\mathrm{wt} \%$ & 28.3 & 56.5 & 35.8 & 29.1 \\
\hline Mass of Sorbent & $\mathrm{g}$ & 1.8946 & 4.0002 & 2.9644 & 3.5838 \\
\hline Estimated Mercury Conc. on Sorbent ${ }^{1}$ & $\mu \mathrm{g} / \mathrm{g}$ & 84.5 & 123 & 61.7 & 20.1 \\
\hline Mercury Conc. on Sorbent ${ }^{2}$ & $\mu \mathrm{g} / \mathrm{g}$ & 59.8 & 98.5 & 70.5 & 12.0 \\
\hline
\end{tabular}

${ }^{1}$ Estimate based on mercury concentration in gas measured by continuous mercury monitor.

2 Based on measurement of mercury on sorbent by CVAA.

${ }^{a}$ Corning Monolith 20012-SR2-011-0C83.

b Corning Monolith 20012-FC4-011-7C87.

c Corning Monolith 20012-FC4-011-7C88.

d EERC Carbon F2Z0.

\section{ECONOMIC ANALYSIS}

A preliminary economic analysis was performed for the control of mercury emissions using the Corning monolith system in a gasification combined-cycle scenario. The economic analysis looked at both the monolith technology itself and attempted to quantify improvements to efficiency (heat rate) of the entire gasification combined-cycle process by utilizing the monolith technology over the more conventional granular carbon packed bed utilized by Eastman. A limited sensitivity analysis was also performed.

The economic analysis results for the "conventional" mercury removal technology is from the Parsons study, "The Cost of Mercury Removal in an IGCC Plant" (3). The "conventional" technology consists of parallel cylindrical vessels with internal diameters of approximately $7 \mathrm{ft}$, each containing granular carbon beds with depths of $20 \mathrm{ft}$. The application is well proven for mercury capture, based on Tennessee Eastman experience at its Kingsport, Tennessee, acetyl chemicals plant that employs coal gasification as a precursor for syngas-to-chemicals production. For utilization in an integrated gasification combined-cycle (IGCC) scenario Parsons used inhouse data to estimate equipment costs. The "conventional" packed-bed sorbent-Calgon Carbon Corporation's HGR-P sulfur-impregnated carbon pellets-is commercially available with an established cost history.

For the preliminary comparison of the Corning monolith against the "conventional" technology, a number of the plant as well as mercury control parameters were maintained at levels used in the Parsons study. These parameters and their values include the following:

- Plant load: approximately 250 MWe (255 MWe with warm-gas cleanup vs. 240 MWe with cold-gas cleanup) 
- Plant capacity factor: $80 \%$

- Mercury inlet concentration: 52 ppbw

- Mercury reduction by technology: 90\% (131 lb/yr)

- Sorbent life: 1.5 years (10,502 hours)

In addition, the operations and maintenance shift labor requirements for the add-on mercury control technology, as well as economic parameters (e.g., capital cost, labor and overhead rates, taxes, etc.) were also kept constant relative to the Parsons study. As a matter of reference, values for these parameters are listed in Appendix A. Design and operating parameters for the Corning monolith technology that are different from those of the "conventional" technology are presented in Table 7.

The initial configuration of the Corning technology, envisioned for this analysis, consists of cylindrical monoliths, approximately 12 inches in diameter and up to 1 foot in length. The monoliths would be stacked within containment tubes that are arranged in parallel within a pressure vessel. Inlet and outlet tube sheets, sealed to the containment tubes would function to distribute flow to the tubes and through the channels of the monoliths. The number of parallel tubes (and pressure vessels) would depend upon the total volume rate of gas to be treated, and the height of stacked monoliths within a containment tube would depend upon the desired space velocity (or residence time) for gas contacting and the particular mercury loading that can be achieved on the given quantity of monolith sorbent in the vessel.

Based on the gas flow rate for the approximately 250-MWe plant (6.76 million scfh) and the assumed space velocity (4038 $\mathrm{hr}^{-1}$ based on standard conditions), the present configuration consists of 142 monolith tubes with a stacked monolith height of $15 \mathrm{ft}$, all within a single pressure vessel. Without the benefit of a rigorous vessel design effort, for this first-level analysis, it was assumed that the single vessel for the Corning monolith technology (with headers and monolith tubes) would have a capital cost equivalent to that required for the two pressure vessels of the "conventional" technology. Further, it was presumed that maintenance labor requirements for recharging structured monoliths in the Corning technology would be similar to the maintenance labor requirements for recharging loose, granular carbon used in the "conventional" technology.

Table 8 shows the economic sensitivity analysis for the carbon monolith based on four main parameters, including monolith cost, purchased equipment cost, monolith life and monolith replacement rate. The ranges of values used in the sensitivity analysis are shown below.

- Initial estimated monolith cost $\left(\$ 450 / \mathrm{ft}^{3}\right.$ and $\left.\$ 1200 / \mathrm{ft}^{3}\right)$

- Baseline $=\$ 700 / \mathrm{ft}^{3}$

- Purchased equipment cost $(\$ 814,000$ and $\$ 2,035,000$ )

- Baseline $=\$ 407,000$ 
Table 7. Technology Operating Parameters - Monolith vs. Conventional

\begin{tabular}{|c|c|c|c|}
\hline \multirow[b]{2}{*}{ Parameter } & \multirow[b]{2}{*}{ Units } & \multicolumn{2}{|c|}{ Value } \\
\hline & & Monolith & Conventional \\
\hline Plant Net Capacity & MWe & 250 & \\
\hline Capacity Factor & $\%$ & 80 & \\
\hline Molecular Weight & $\mathrm{lb} / \mathrm{lb} \mathrm{mol}$ & 21.0 & \\
\hline Gas Temperature & ${ }^{\circ} \mathrm{F}$ & 400 & 105 \\
\hline Pressure & psia & 415 & 378 \\
\hline Mercury Concentration & ppbw & 52 & 52 \\
\hline Monolith Density & $\mathrm{lb} / \mathrm{ft}^{3}$ & 30 & \\
\hline Space Velocity (actual volume) & $\mathrm{hr}^{-1}$ & 250 & 178 \\
\hline Monolith ID & inches & 12 & \\
\hline Stacked Monolith Height & $\mathrm{ft}$ & 15 & \\
\hline Monolith Life & $\mathrm{hr}$ & 10,502 & \\
\hline Monolith Life & cycles & 1 & \\
\hline Output Parameter & Units & \multicolumn{2}{|c|}{ Value } \\
\hline Syngas Molar Rate & lb-mol/hr & 18,824 & \\
\hline Syngas Mass Rate & $\mathrm{lb} / \mathrm{hr}$ & 396,099 & \\
\hline Syngas Volume Rate & $\mathrm{sft}^{3} / \mathrm{hr}$ & $6,757,816$ & \\
\hline Syngas Volume Rate & $\mathrm{aft}^{3} / \mathrm{hr}$ & 418,417 & \\
\hline Sorbent Charge Volume & $\mathrm{ft}^{3}$ & 1674 & 1689 \\
\hline Space Velocity (standard volume) & $\mathrm{hr}^{-1}$ & 4038 & 4000 \\
\hline Initial Monolith Charge Mass & ton & 25.1 & 25.0 \\
\hline Monolith ID & $\mathrm{ft}$ & 1.00 & \\
\hline Number of Monolith Elements (parallel) & & 142 & \\
\hline Gas Superficial Velocity & $\mathrm{ft} / \mathrm{sec}$ & 1.0 & 1 \\
\hline Gas Residence Time & sec & 14.4 & 20 \\
\hline Monolith Replacement Cycle & yr & 1.50 & \\
\hline Sorbent Replacement Rate & ton/yr & 16.8 & 16.9 \\
\hline Sorbent Replacement Rate & $\mathrm{ft}^{3} / \mathrm{yr}$ & 1117 & 1142 \\
\hline Hg Loading on Sorbent & lb Hg/lb monolith & 0.0039 & 0.0039 \\
\hline Plant Parameters & Units & \multicolumn{2}{|c|}{ Value } \\
\hline Plant Net Capacity & MWe & 250 & \\
\hline Gas Rate & $\mathrm{lb} / \mathrm{hr}$ & 396,099 & \\
\hline Hg Level Before Fixed Bed & ppbw & 52 & \\
\hline Mercury Reduction & $\%$ & 90 & \\
\hline Hg Level after Monolith Bed & ppbw & 5 & \\
\hline Capacity Factor & $\%$ & 80 & \\
\hline Mercury Reduction & lb/yr & 131 & \\
\hline Labor & hrs/shift & 1 & \\
\hline Maintenance & hrs/shift & 0.5 & \\
\hline Monolith Utilization Rate & $\mathrm{lb} / \mathrm{yr}$ & 33,505 & \\
\hline Electricity Consumption & $\mathrm{kWh} / \mathrm{yr}$ & 100,000 & $\sim 1,000,000$ \\
\hline Monolith/Carbon Cost & $\$ / \mathrm{ft}^{3}$ & $700 *$ & 193 \\
\hline
\end{tabular}

* Initial preliminary cost estimate from Corning based on small-scale development work. 


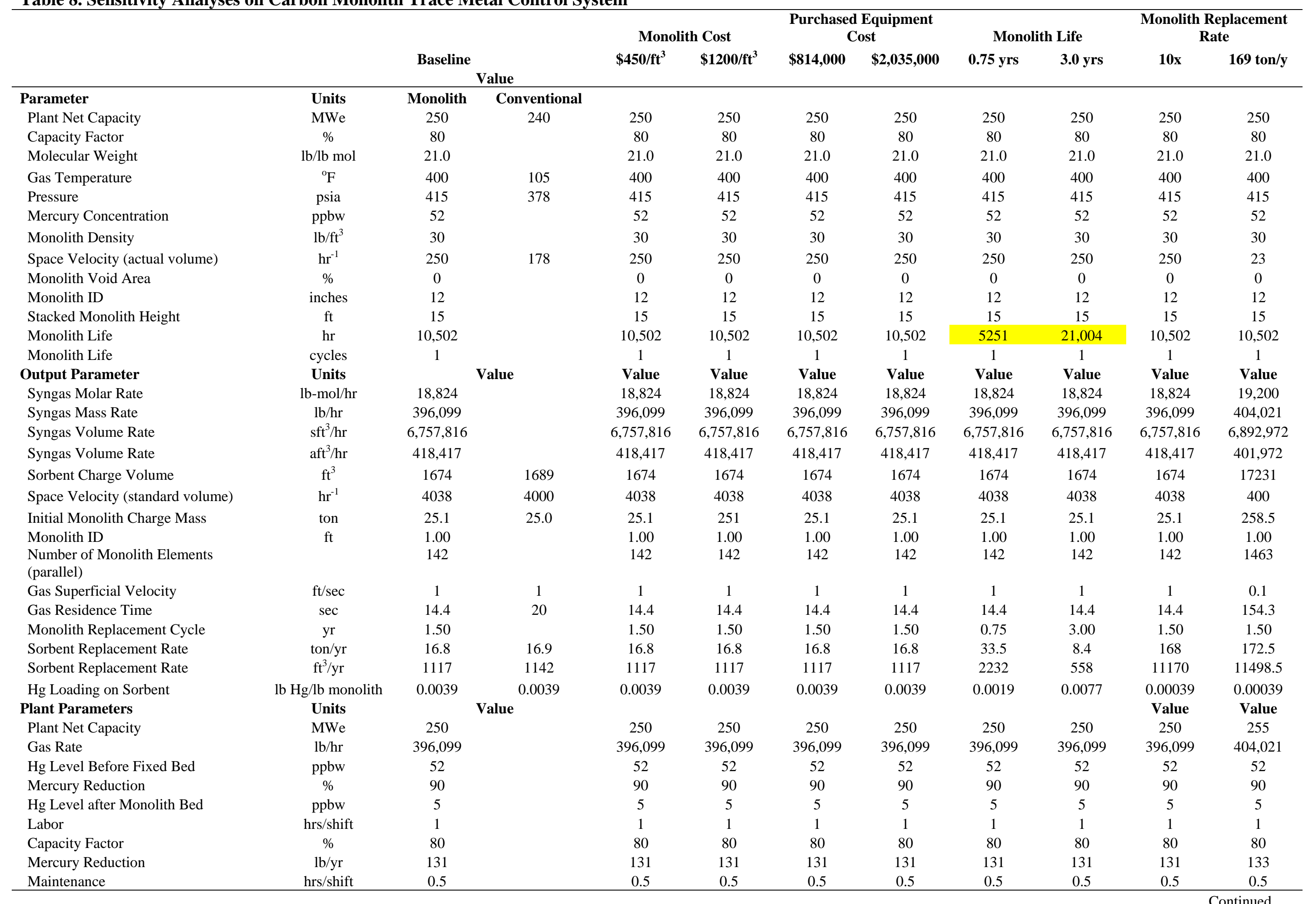


Table 8. Sensitivity Analyses on Carbon Monolith Trace Metal Control System (continued)

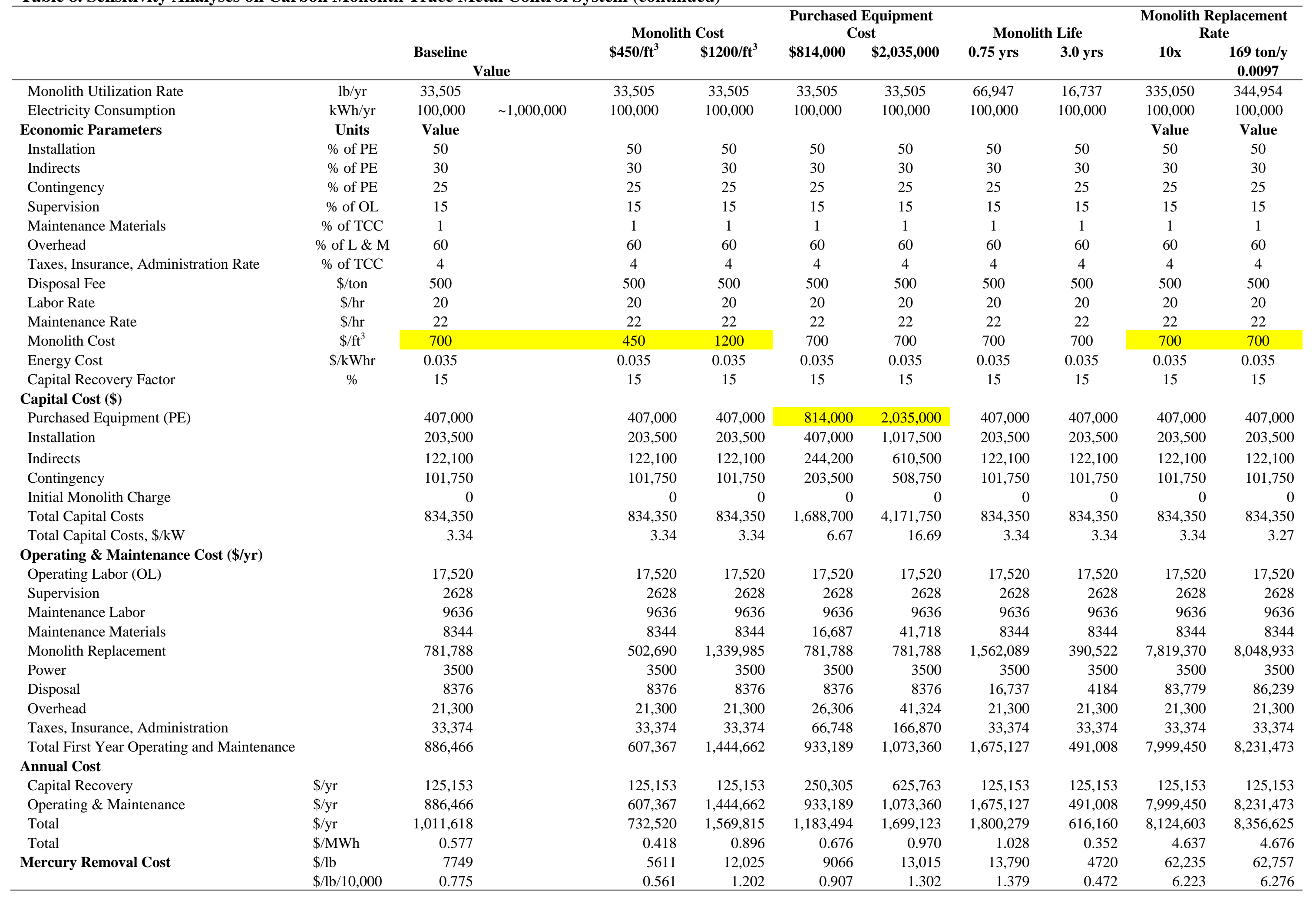


- Monolith life (0.75 and 3.0 years)

- Baseline $=1.5$ years $(10,502$ hours $)$

- Monolith replacement rate (25.1 ton with 167.1 ton/yr replacement rate; 10x conventional)

- Baseline $=25.1$ ton

The estimated total annual cost was approximately $\$ 1,011,600$ based on a capital recovery factor of $15 \%$. This equates to an incremental electricity cost of $\$ 0.577 / \mathrm{MWh}$ (or $0.577 \mathrm{mills} / \mathrm{kWh}$ ) for the baseline monolith configuration. For the assumed mercury removal level of $90 \mathrm{wt} \%$ (131 lb/yr), the cost of mercury reduction was estimated at $\$ 7749 / \mathrm{lb} \mathrm{Hg}$ removed. This latter value is approximately an order of magnitude less than estimates for mercury removal in pulverized coal systems.

ASPEN modeling utilizing results from a previous ASPEN model generated by EG\&G (4) for an $\mathrm{O}_{2}$-blown transport gasifier were utilized as the starting point for determining the improved system efficiency for warm-gas cleanup over cold-gas mercury cleanup. These modeling results at $230^{\circ} \mathrm{C}\left(450^{\circ} \mathrm{F}\right)$ versus $20^{\circ} \mathrm{C}\left(68^{\circ} \mathrm{F}\right)$ are shown in Figures 61 and 62 . This modeling shows that for similar gasifier outlet flows and for a mercury removal process operating at a higher warm-gas cleanup temperature would result in a net power increase of 15 more megawatts. Assuming an average power selling price of $\$ 45 / \mathrm{MWh}$ would result in $\$ 4.7 \mathrm{M}$ in increased revenues per year. With a similar loading to the conventional carbon, the

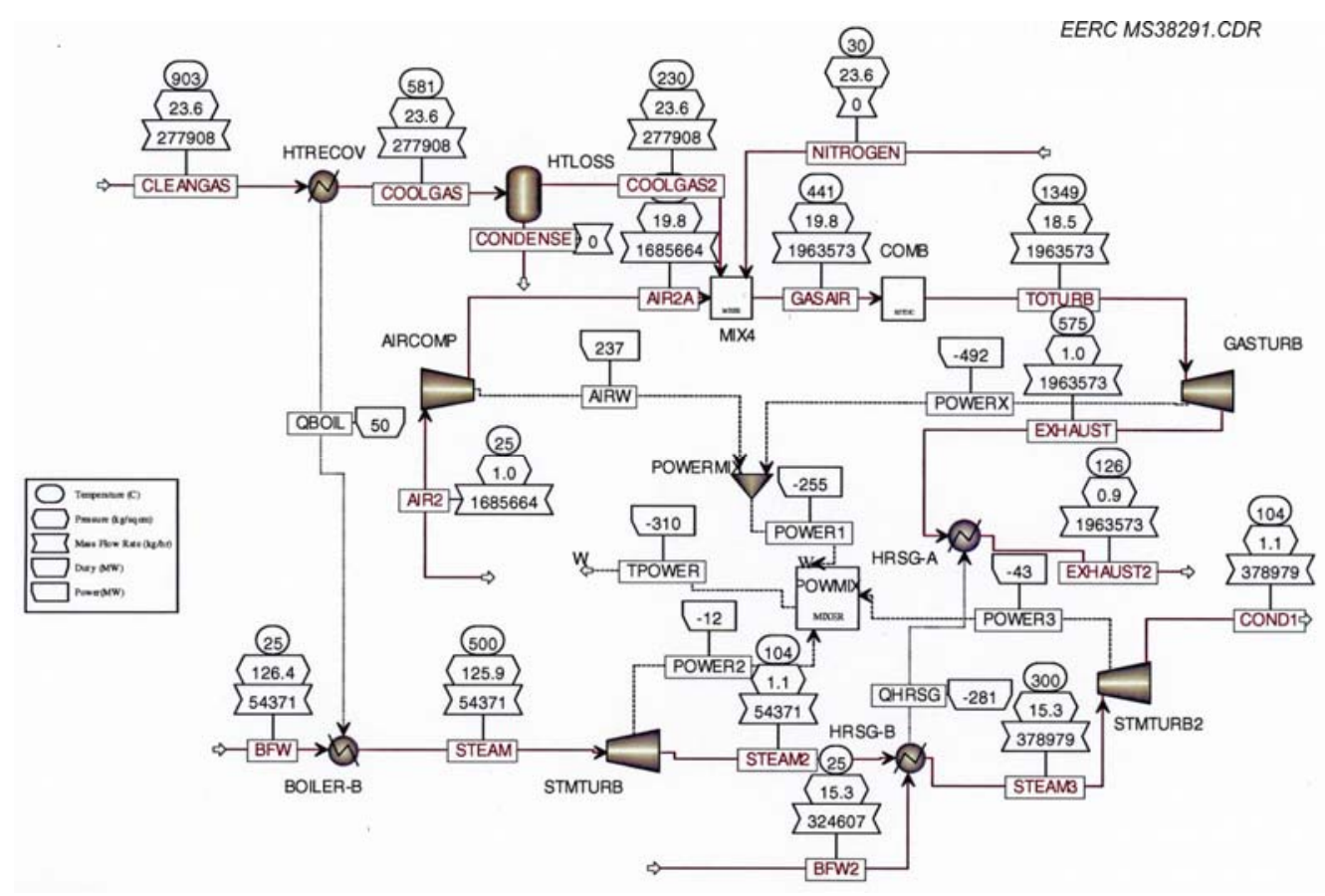

Figure 61. ASPEN model for warm-gas cleanup mercury removal at $450^{\circ} \mathrm{F}$. 


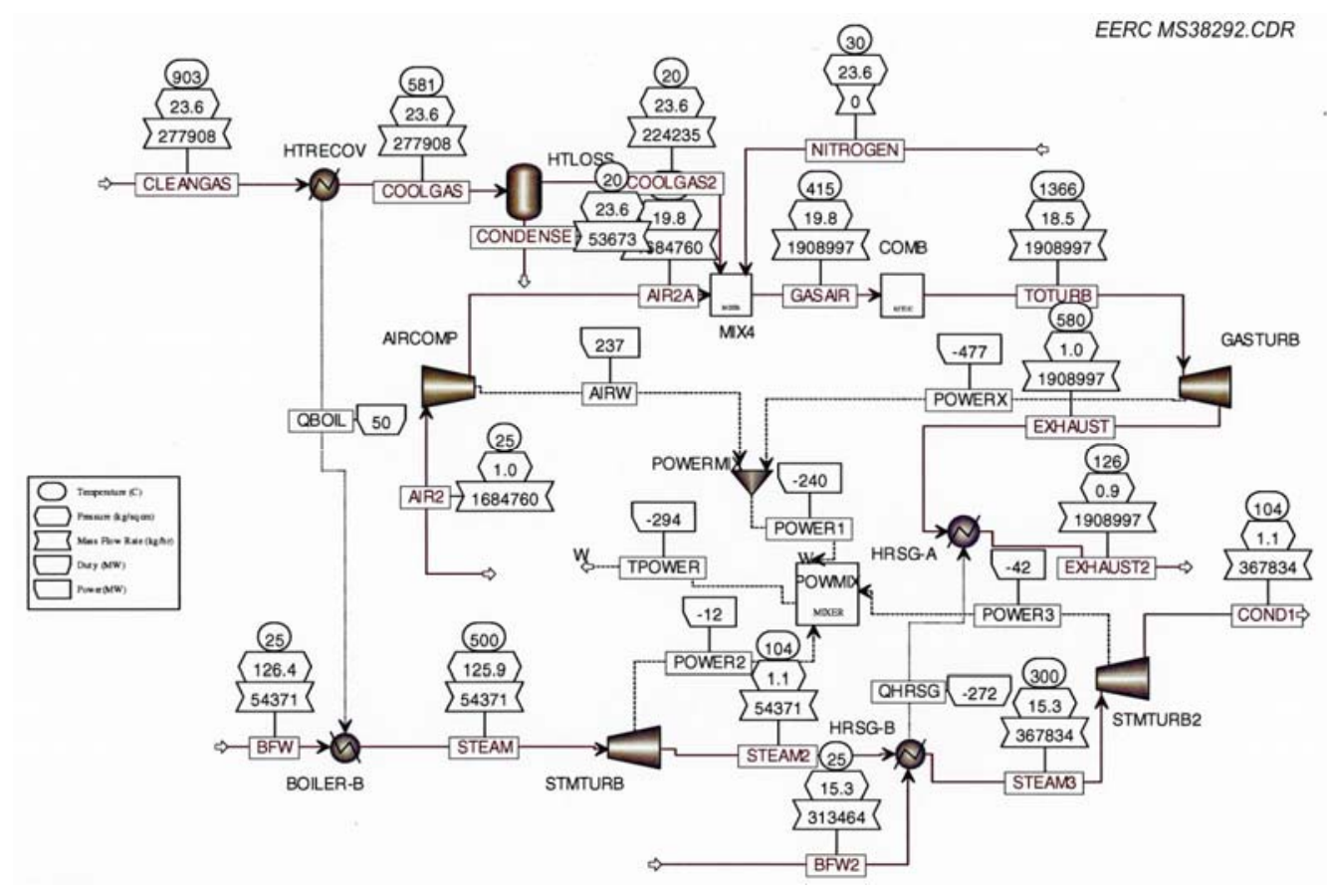

Figure 62. ASPEN model for cold-gas mercury removal at $68^{\circ} \mathrm{F}$.

operating and maintenance costs would amount to approximately $\$ 886,500$ per annum and capital recovery costs would be approximately $\$ 125,200$ per year providing a net profit of $\$ 3.688$ million. However, should the mercury loading be limited to $0.04 \mathrm{wt} \%$ (1/10th the loading of the conventional carbon sorbent as currently appears) then the total annual cost would be approximately $\$ 8.1 \mathrm{M}$ resulting in a net loss of $\$ 3.4$ million, in which case cold-gas cleanup for mercury removal would be more economic. However, should the ability to regenerate the monoliths for use in two to three cycles or more be demonstrated, this could result in a cost advantage for the monoliths over the conventional carbon-based cold-gas cleanup option.

Baseline refers to the parameter value used in the initial analysis. Corning provided the initial preliminary monolith cost data. The purchased equipment values of $\$ 814,000$ and $\$ 2,035,000$ are simply $2 x$ and $5 x$, respectively, of the baseline value of $\$ 407,000$. Similarly, the monolith life values of 0.75 years and 3.0 years are $0.5 x$ and $2 x$, respectively, of the baseline value of 1.5 years. A monolith replacement rate of 10x the baseline was evaluated at a case where the mercury capacity of the treated monolith at process conditions will be limited to a value of $\sim 0.04 \mathrm{wt} \%$.

\section{CONCLUSIONS}

Two Corning monoliths and a non-carbon-based material have been identified as potential additives for mercury capture in syngas at temperatures above $400^{\circ} \mathrm{F}$ and pressure of 600 psig. Both monolith types allowed mercury reduction to below $5 \mu \mathrm{g} / \mathrm{m} 3(\sim 5 \mathrm{ppb})$, a current DOE goal for trace metal control. The Corning monoliths include a new formulation (GR-F1-2189) and the 
SR Liquid, originally tested in 2006 and 2007. Variations in the preparation method for the SR Liquid monolith were determined to impact the ability of the monolith to capture mercury.

The Group IB and IIB metal Noncarbon Sorbents 1 and 2 appeared to offer potential for sustained and significant reduction of mercury concentration in the simulated fuel gas. The Noncarbon Sorbent 1 allowed sustained mercury reduction to below $5 \mu \mathrm{g} / \mathrm{m} 3$ ( $5 \mathrm{ppb})$. The noncarbon-based sorbent appeared to offer the potential for regeneration, that is, desorption of mercury by temperature swing (using nitrogen and steam at temperatures above where adsorption takes place). EERC sorbents prepared with Group IB and IIB metal selenides appeared to have some promise for mercury capture, although these sorbents also released Se, as evidenced by the measurement of $\mathrm{H}_{2} \mathrm{Se}$ in the effluent gas.

The Group IB and IIB metal-based sorbents appear to be the most effective arsine and hydrogen selenide sorbents at $400^{\circ} \mathrm{F}$ and 600 psig. The noncarbon sorbent was able to reduce the arsine concentration to $0 \mathrm{ppb}$ from a starting concentration of $120 \mathrm{ppb}$. The EERC-prepared Group IB and IIB metal-based pellet and coprecipitate sorbents were slightly less effective, exhibiting arsine reductions of $90 \%$ or greater, being below $10 \mathrm{ppb}$. Corning SR Liquid monoliths exhibited brief periods ( $<1$ hour) of attaining $90 \%$ arsine reduction but were able to achieve greater than $80 \%$ reduction for several hours. With respect to hydrogen selenide, all Group IB and IIB metal-based sorbents tested exhibited 100\% reduction from an inlet concentration of approximately $400 \mathrm{ppb}$. Corning SR Liquid monoliths exhibited an 82\% reduction when two monoliths were tested simultaneously in series.

To provide a platform for future testing on high-pressure coal-derived syngas for realistic testing of warm-gas cleanup systems, a fluid-bed gasifier system was designed and built. Details of the system, including the gas conditioning, filtration, and treatment systems, are provided in Appendix B. A summary of several tests performed with coal and coal-biomass blends is also provided.

\section{REFERENCES}

1. Swanson, M.L.; Dunham, G.E.; Musich, M.A. Advanced Gasification Mercury/Trace Metal Control with Monolith Traps; Final Scientific/Technical Report for Year 1 for U.S. Department of Energy National Energy Technology Laboratory Contract No. DE-FC2605NT42461; Energy \& Environmental Research Center: Grand Forks, ND, March 2007.

2. Alptekin, G.; Amalfitano, R.; Dubovik, M.; Cesario, M. Sorbents for Trace Metal Removal from Coal-Derived Synthesis Gas. In Proceedings of the 22nd Annual Pittsburgh Coal Conference; Sept 12-15, 2005.

3. Parsons, Infrastructure and Technology Group Inc. The Cost of Mercury Removal in an IGCC Plant; Final Report for the U.S. Department of Energy; Parsons Infrastructure and Technology Group Inc.: Reading and Pittsburgh, PA, Sept 2002. 
4. Shelton, W.; and Lyons, J. Transport Gasifier IGCC Base Cases PED-IGCC-98-006; EG\&G Technical Services; June 2000, 44 pp.

5. Rutkowski, M.; Klett, M.; Maxwell, R. The Cost of Mercury Removal in an IGCC Plant. Presented at the Gasification Technologies 2002 Conference, San Francisco, CA, October 27-30, 2002.

6. Strege, J.R.; Laumb, J.D.; Stanislowski, J.J.; Snyder, A.C.; Swanson, M.L. FischerTropsch Fuels Development; Final Report for North Dakota Industrial Commission Contract No. R003-009; EERC Publication 2010-EERC-03-10; Energy \& Environmental Research Center: Grand Forks, ND, March 2010. 


\section{APPENDIX A}

\section{BREAKTHROUGH CURVES FOR CORNING MONOLITHS, EERC SORBENTS, AND NONCARBON SORBENTS}




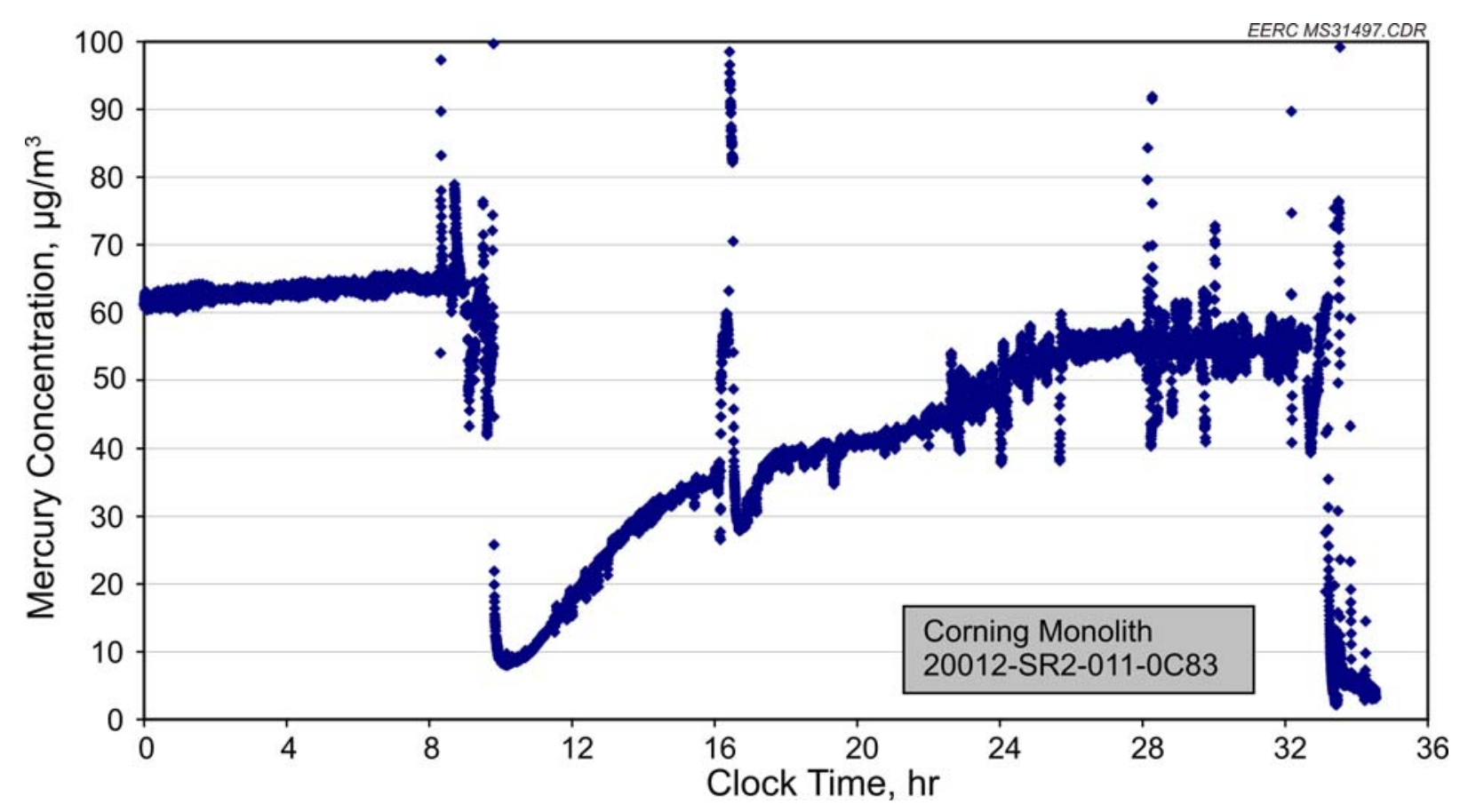

Figure A-1. Mercury sorption curve for Corning Monolith 20012-SR2-011-0C83 at $400^{\circ} \mathrm{F}$ and 600 psig (Test 3).

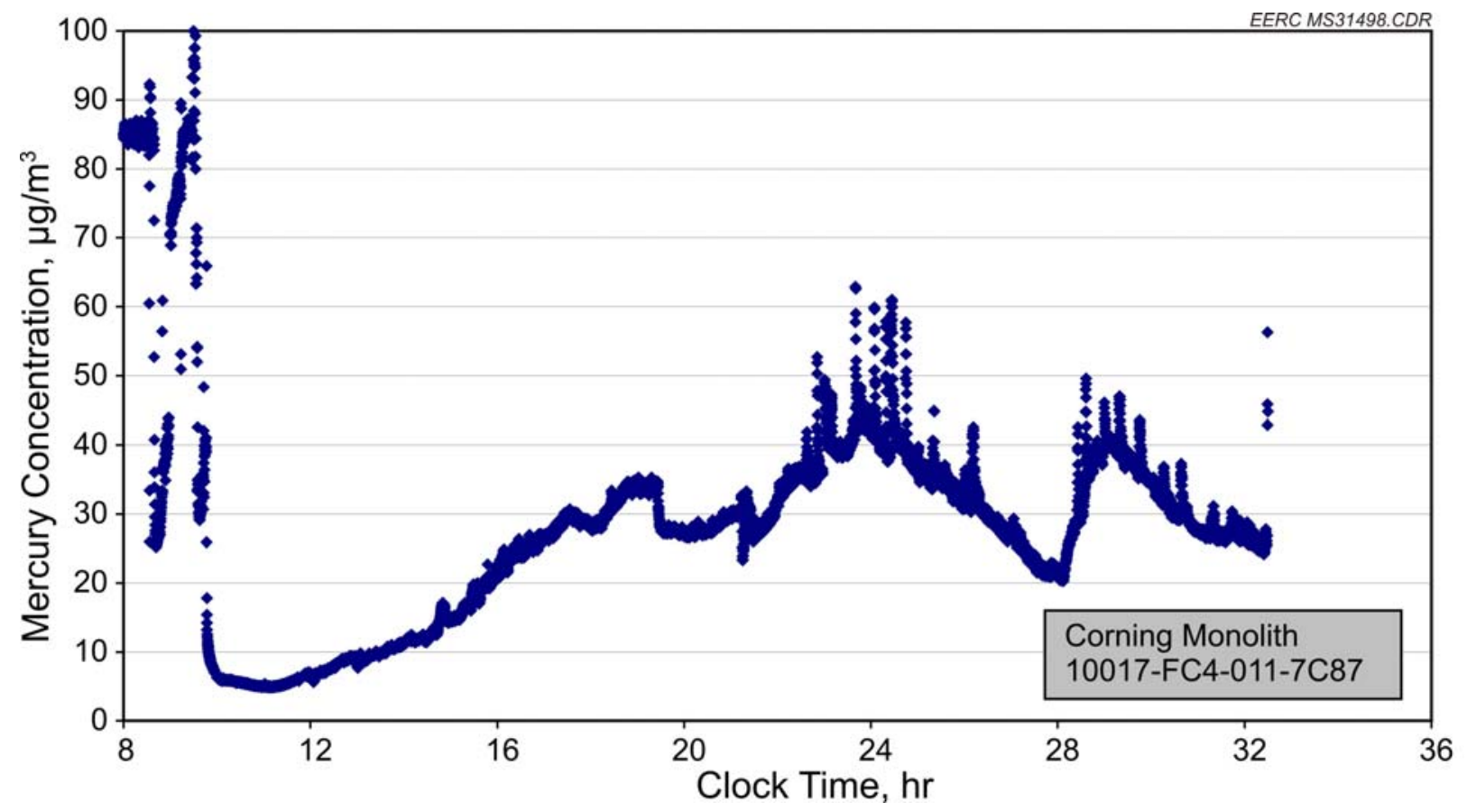

Figure A-2. Mercury sorption curve for Corning Monolith 10017-FC4-011-7C87 at $400^{\circ} \mathrm{F}$ and 600 psig (Test 4). 


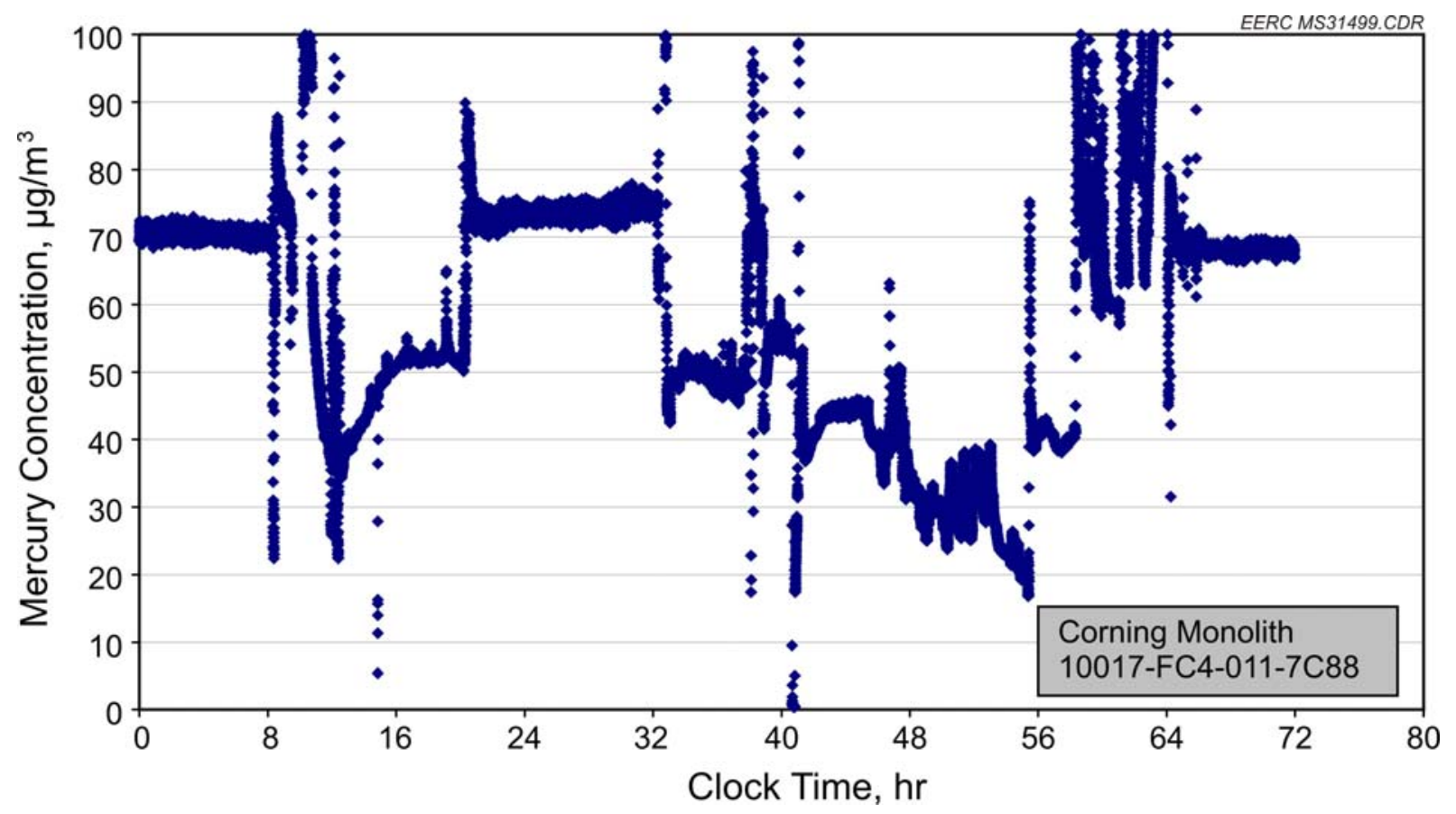

Figure A-3. Mercury sorption curve for Corning Monolith 10017-FC4-011-7C88 at $400^{\circ} \mathrm{F}$ and $600 \mathrm{psig}$ (Test 5).

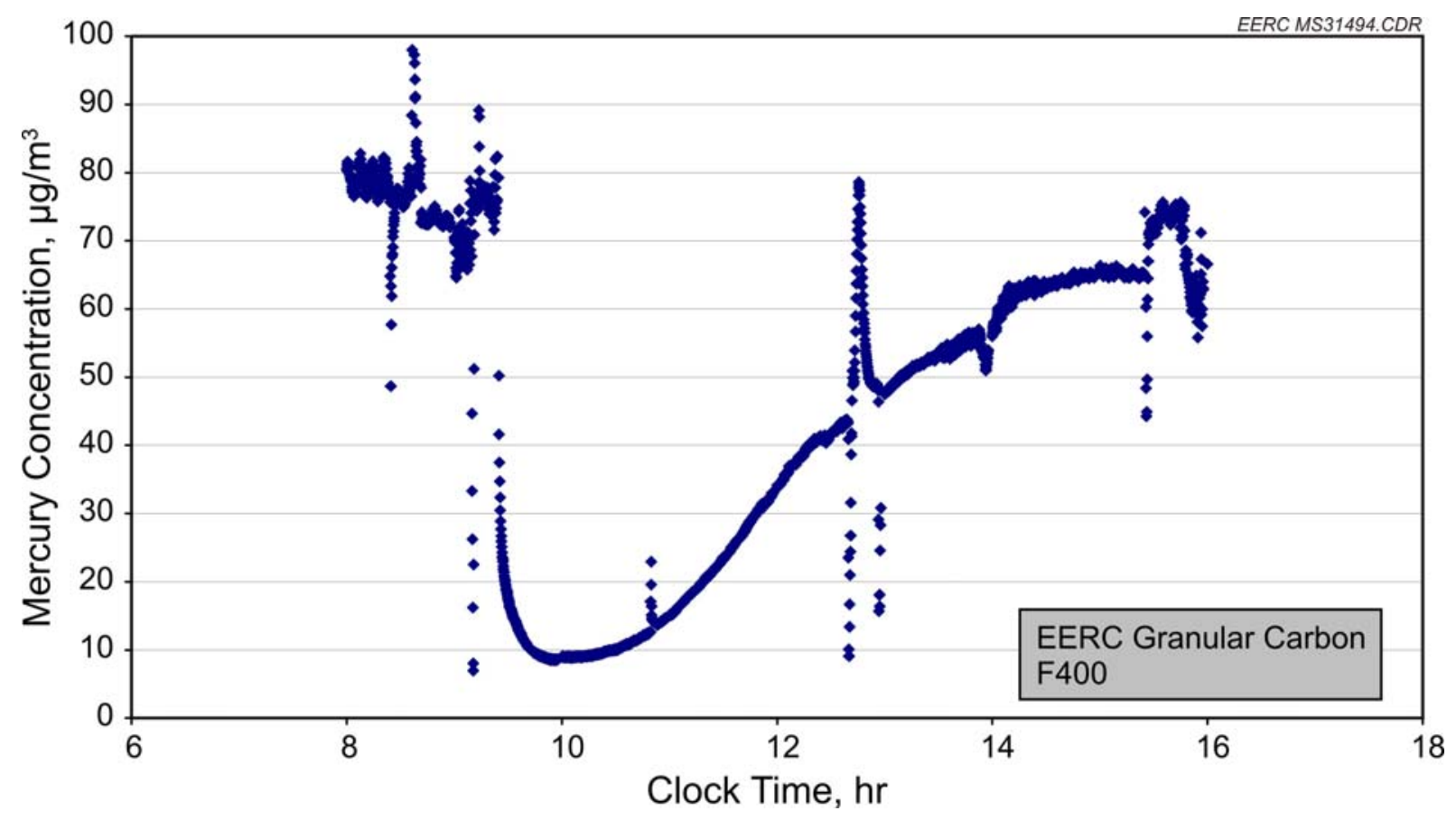

Figure A-4. Mercury sorption curve for EERC Granular Carbon F2Z0 at $400^{\circ} \mathrm{F}$ and 600 psig (Test 6). 


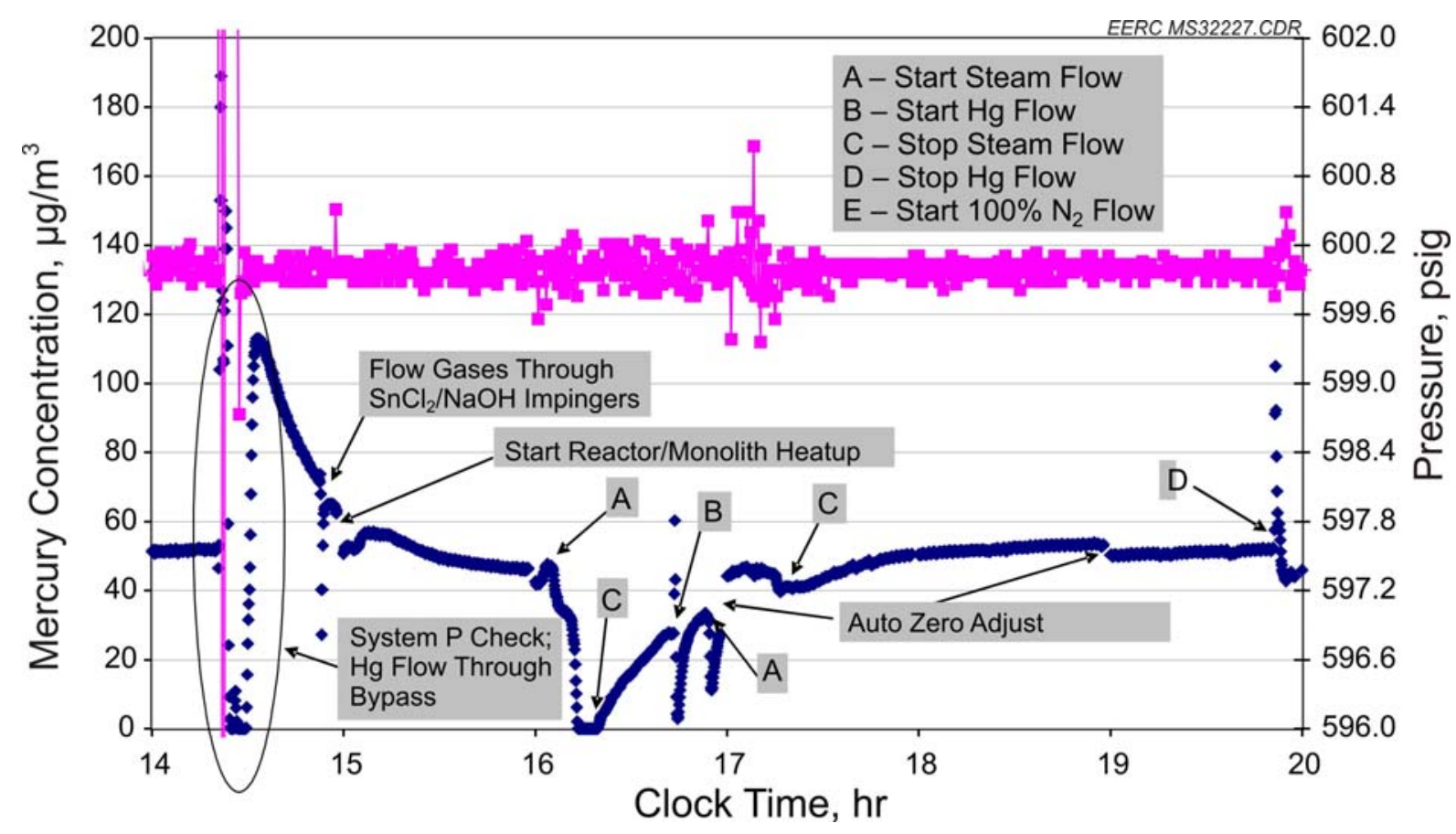

Figure A-5. Mercury sorption curve for Corning Monolith 10017-FC4-011-7C159 at $400^{\circ} \mathrm{F}$ and 600 psig (Test 7).

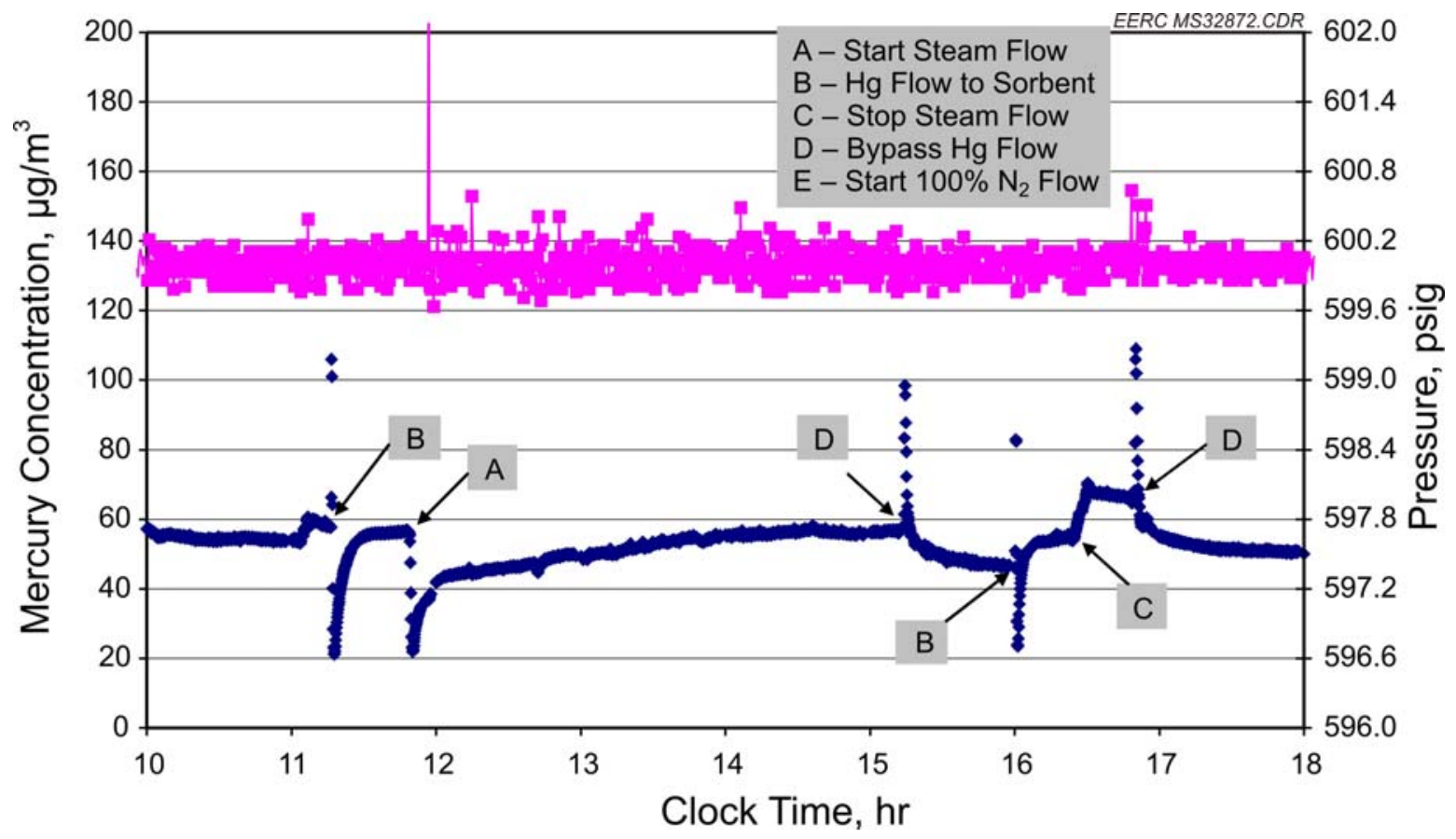

Figure A-6. Mercury sorption curve for Corning Monolith 10017-FC4-011-7C158 at $400^{\circ} \mathrm{F}$ and $600 \mathrm{psig}$ (Test 8). 


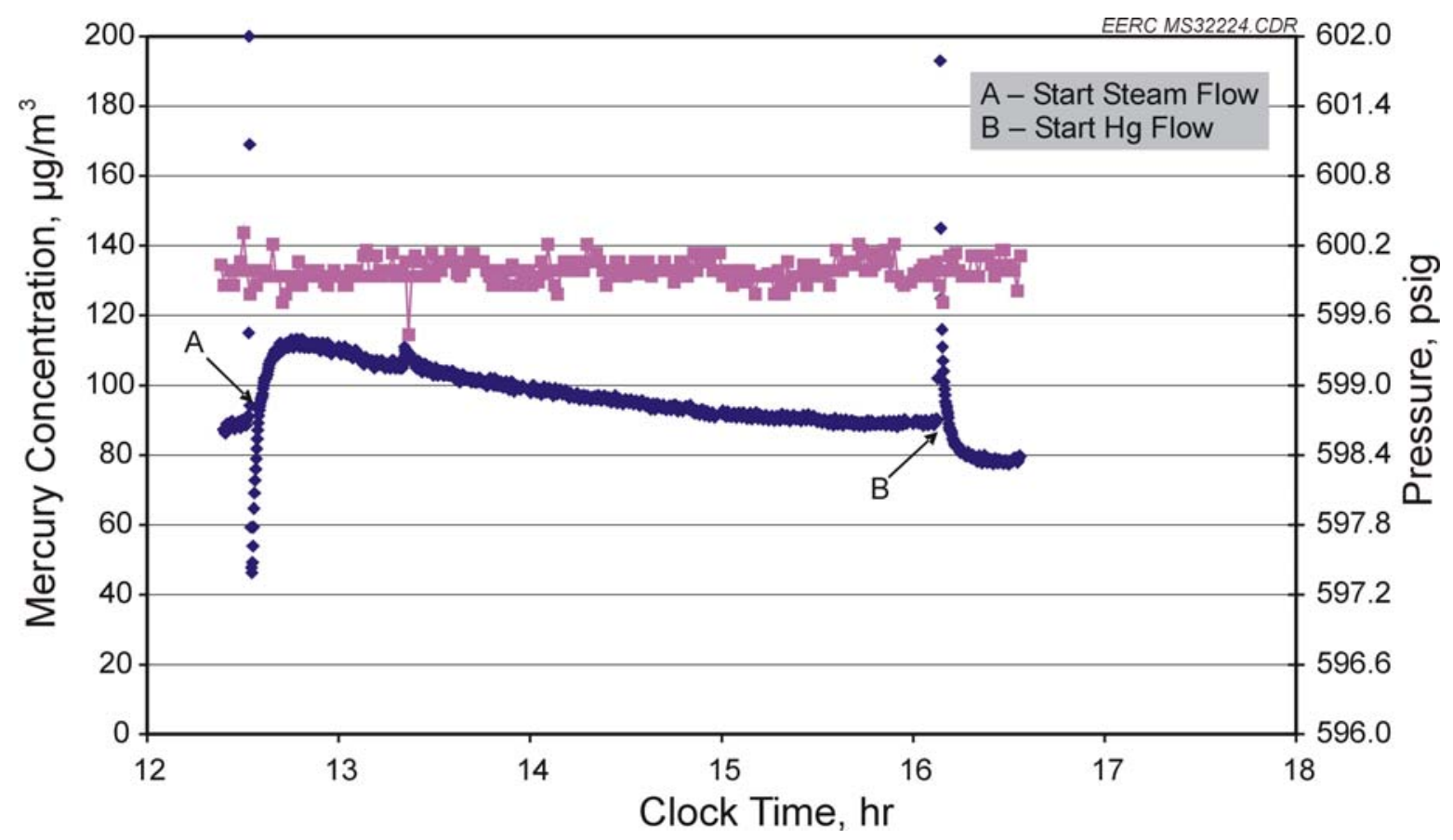

Figure A-7. Mercury sorption curve for Corning Monolith 10017-FC4-011-7C160 at $400^{\circ} \mathrm{F}$ and 600 psig (Test 9).

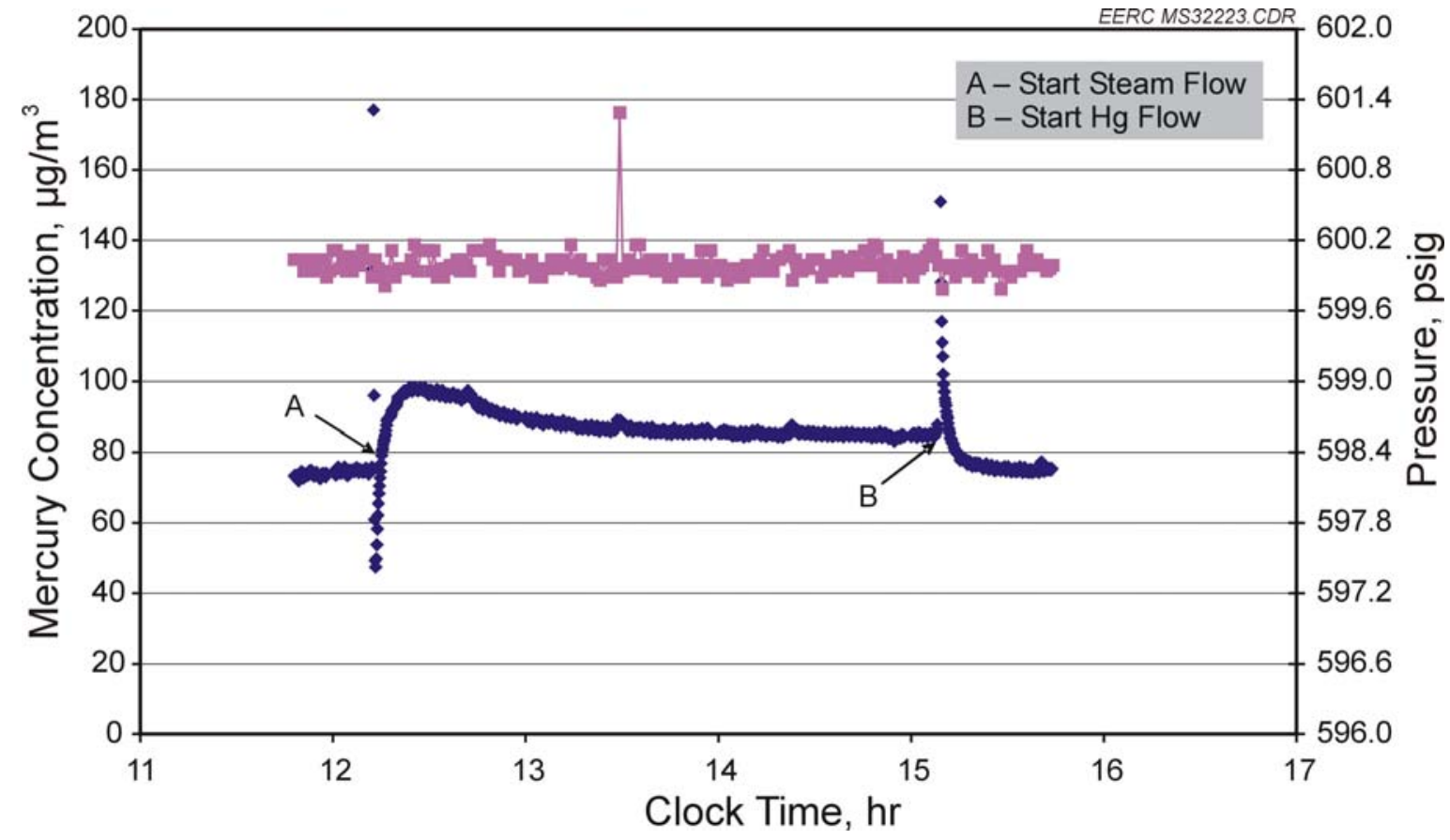

Figure A-8. Mercury sorption curve for Corning Monolith 10017-FC4-011-7C161 at $400^{\circ} \mathrm{F}$ and 600 psig (Test 10). 


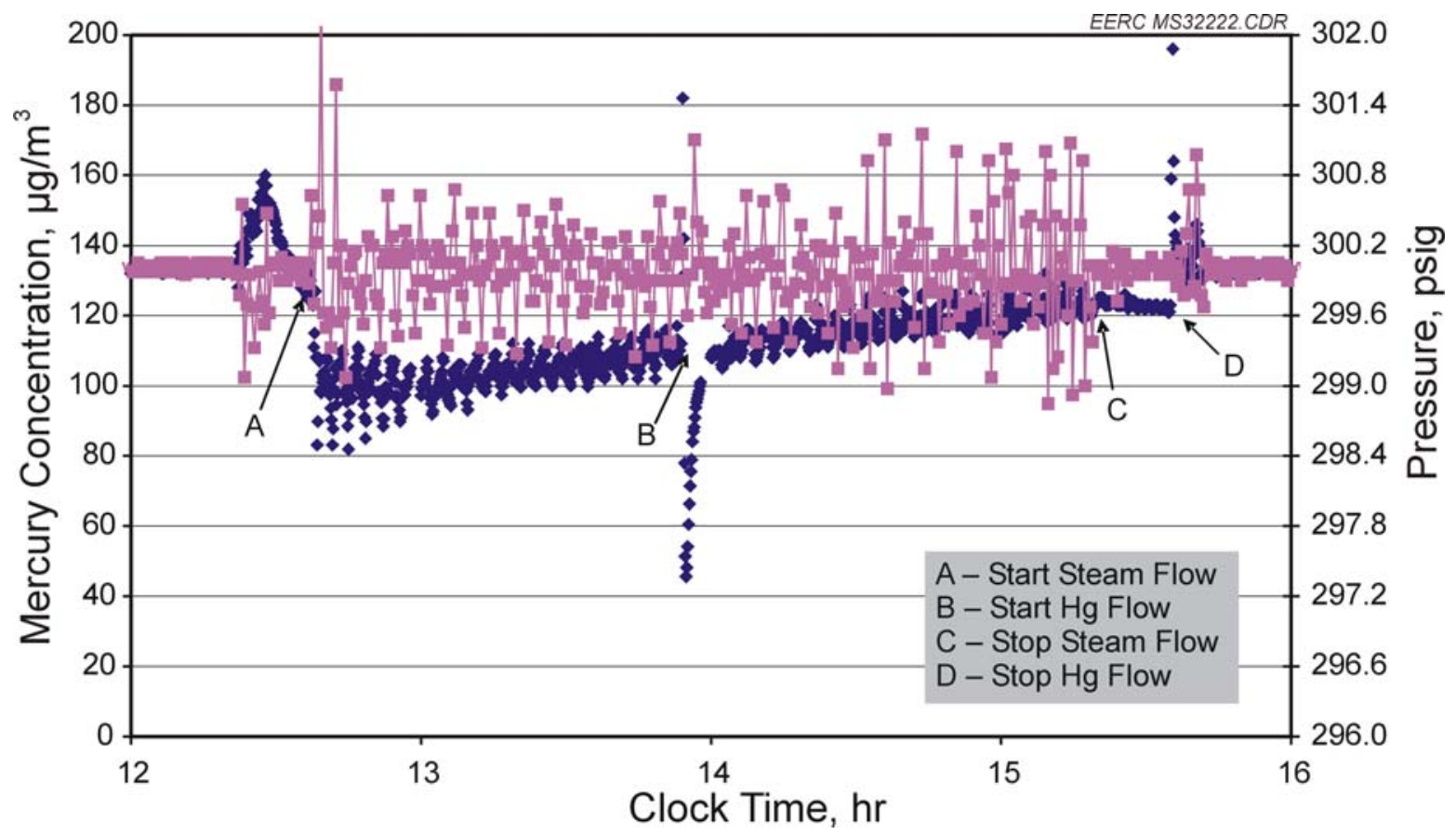

Figure A-9. Mercury sorption curve for Corning Monolith 10017-FC4-011-7C160 (retest) at $350^{\circ} \mathrm{F}$ and 300 psig (Test 11 ).

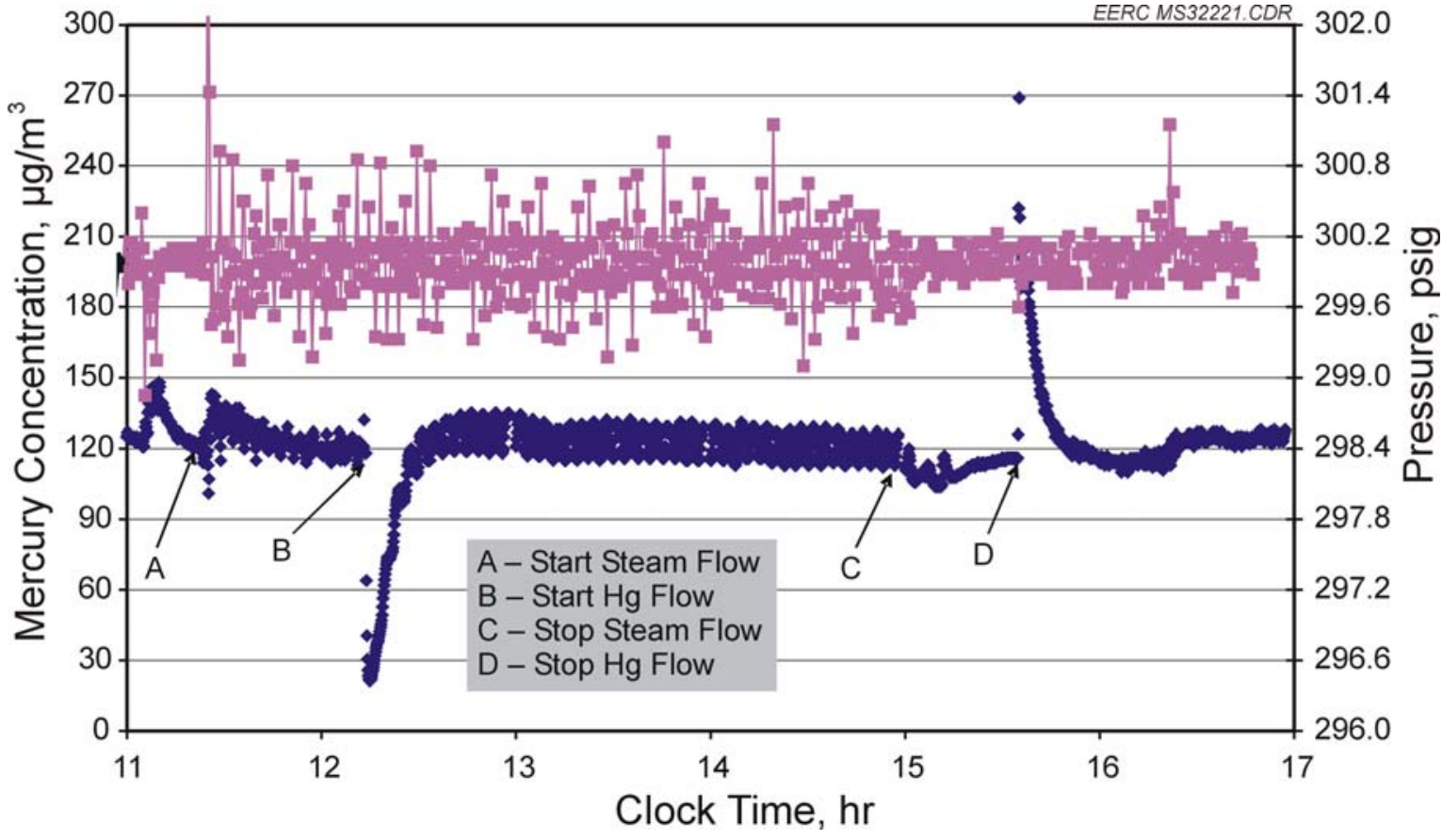

Figure A-10. Mercury sorption curve for EERC Carbon 15615-3-1 at $350^{\circ} \mathrm{F}$ and 300 psig (Test 12). 


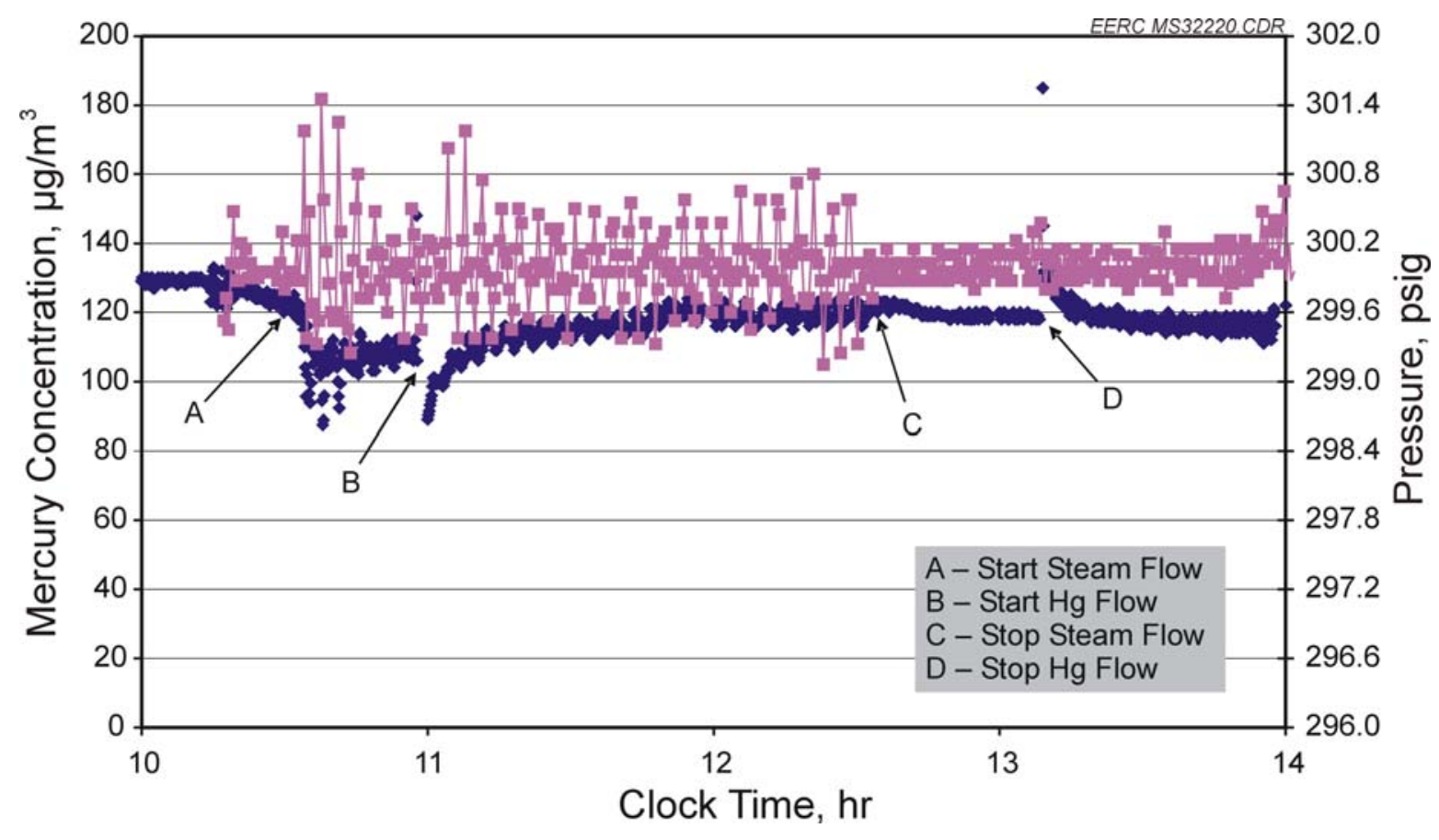

Figure A-11. Mercury sorption curve for Corning Monolith 10017-FC4-011-7C159 (retest) at $350^{\circ} \mathrm{F}$ and 300 psig (Test 13).

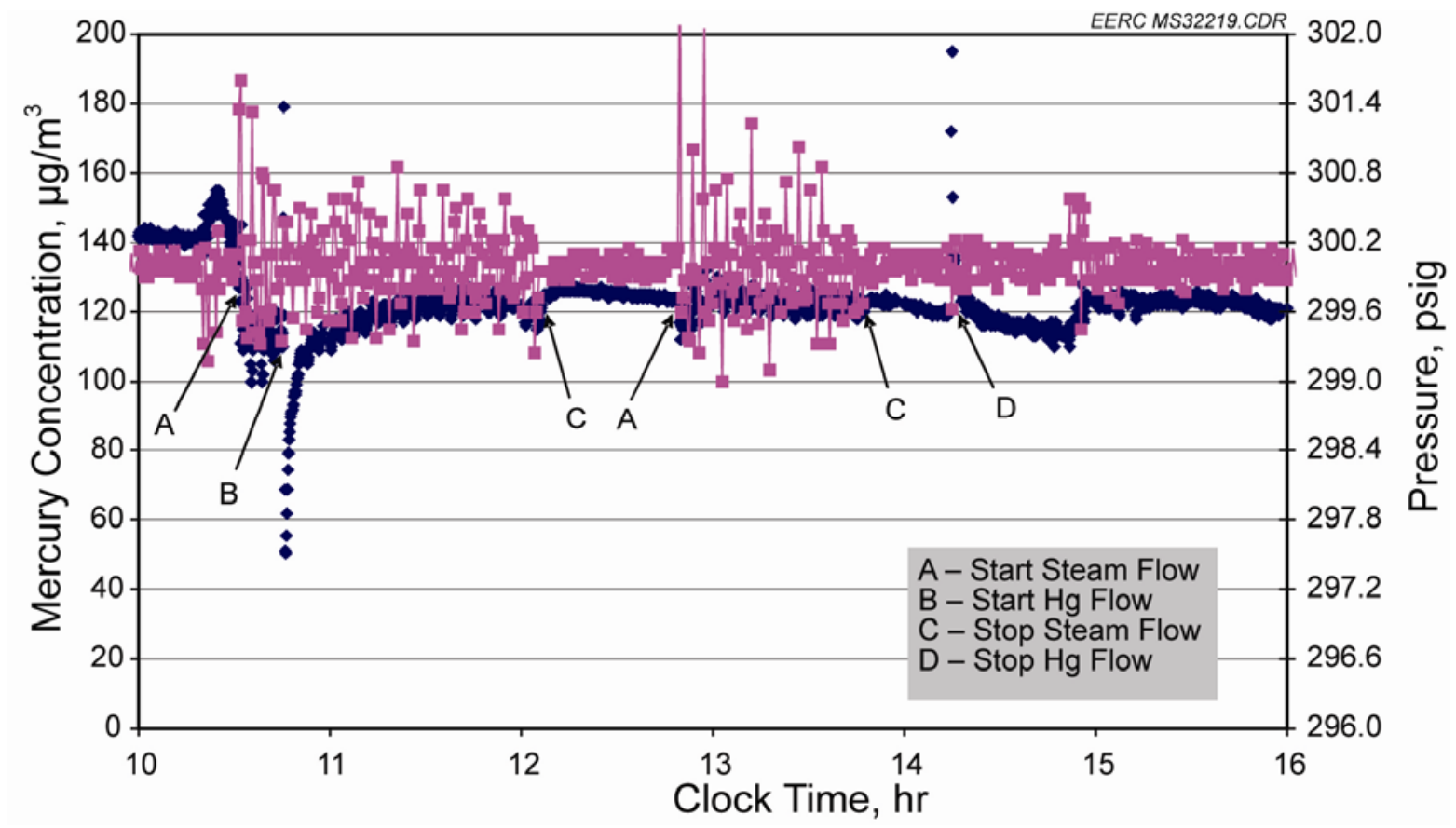

Figure A-12. Mercury sorption curve for Corning Monolith 10017-FC4-011-7C158 (retest) at $350^{\circ} \mathrm{F}$ and 300 psig (Test 14). 


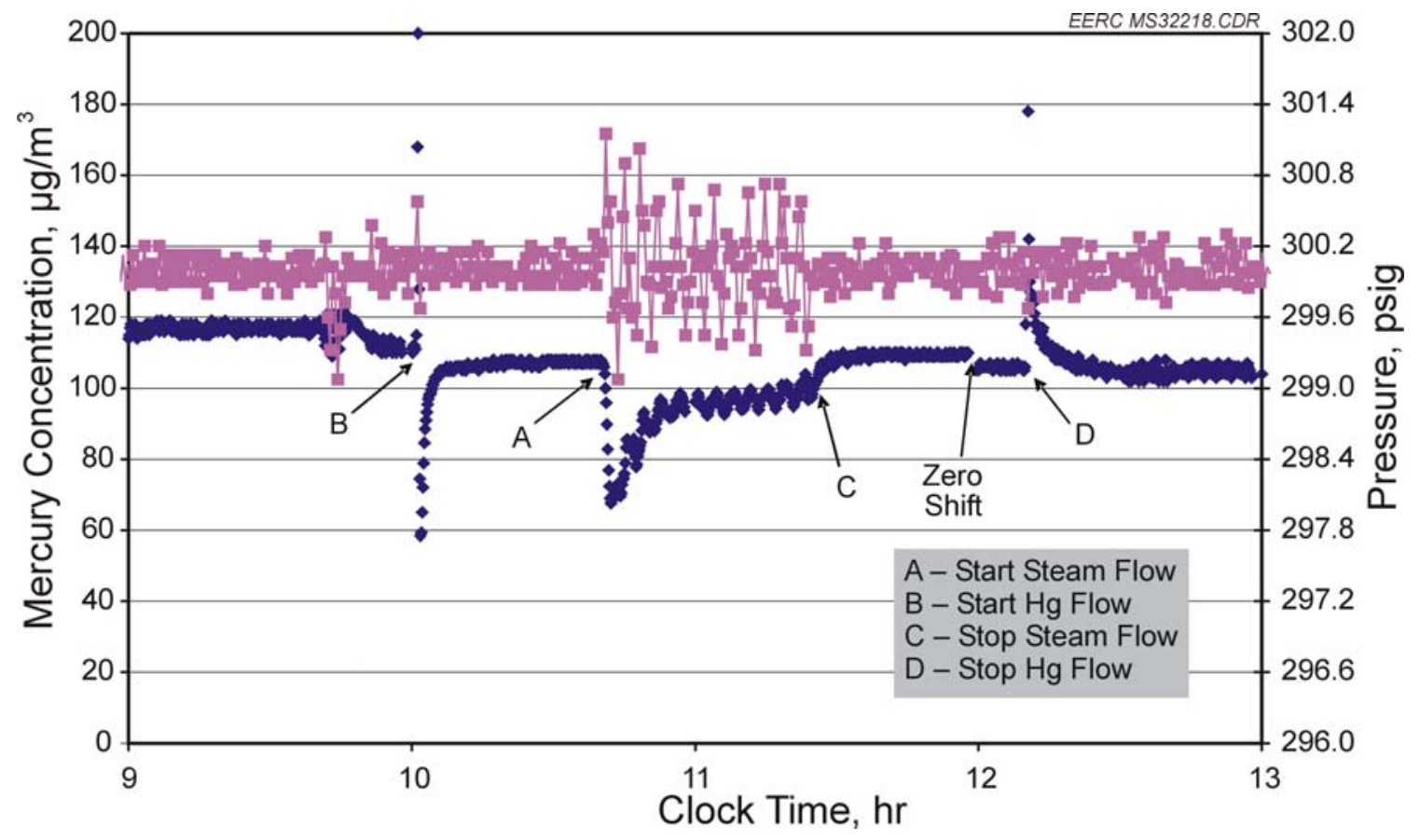

Figure A-13. Mercury sorption curve for Corning Monolith 10017-FC4-011-7C161 (retest) at $350^{\circ} \mathrm{F}$ and 300 psig (Test 15).

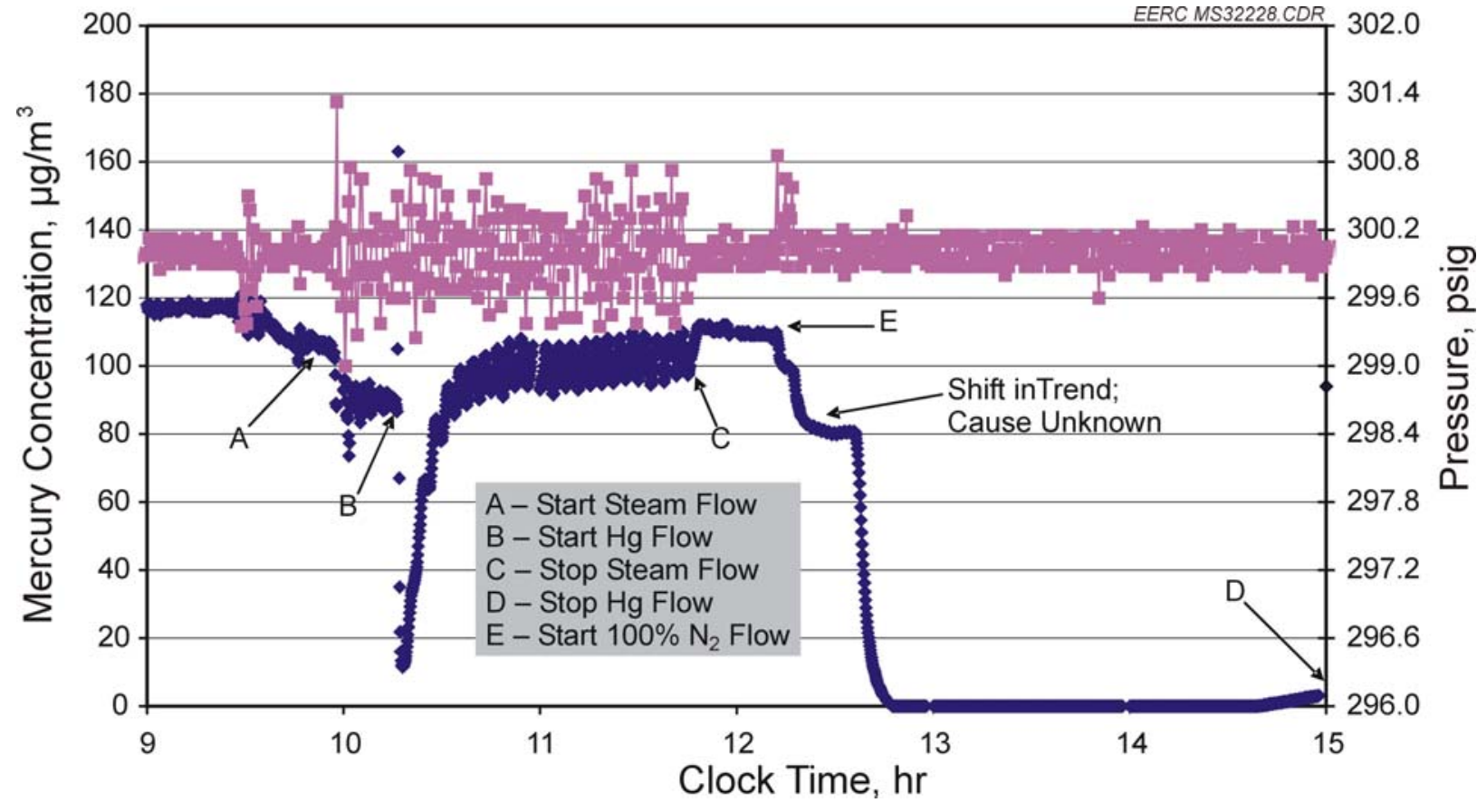

Figure A-14. Mercury sorption curve for EERC Carbon 15615-1-1 at $350^{\circ} \mathrm{F}$ and 300 psig (Test 16 ). 


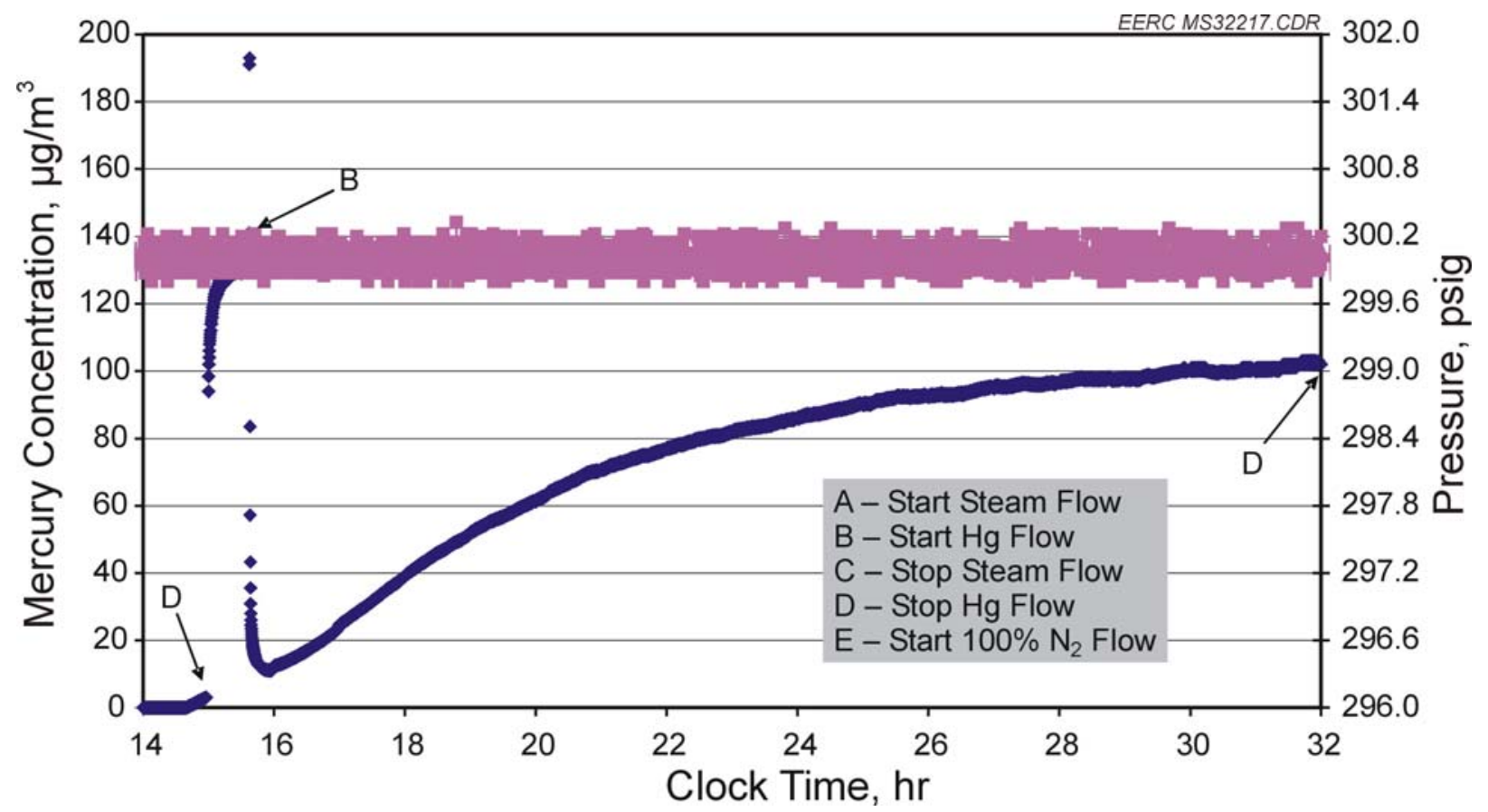

Figure A-15. Mercury sorption curve for EERC Carbon 15615-3-1 at $350^{\circ} \mathrm{F}$ and 300 psig on nitrogen (Test 17).

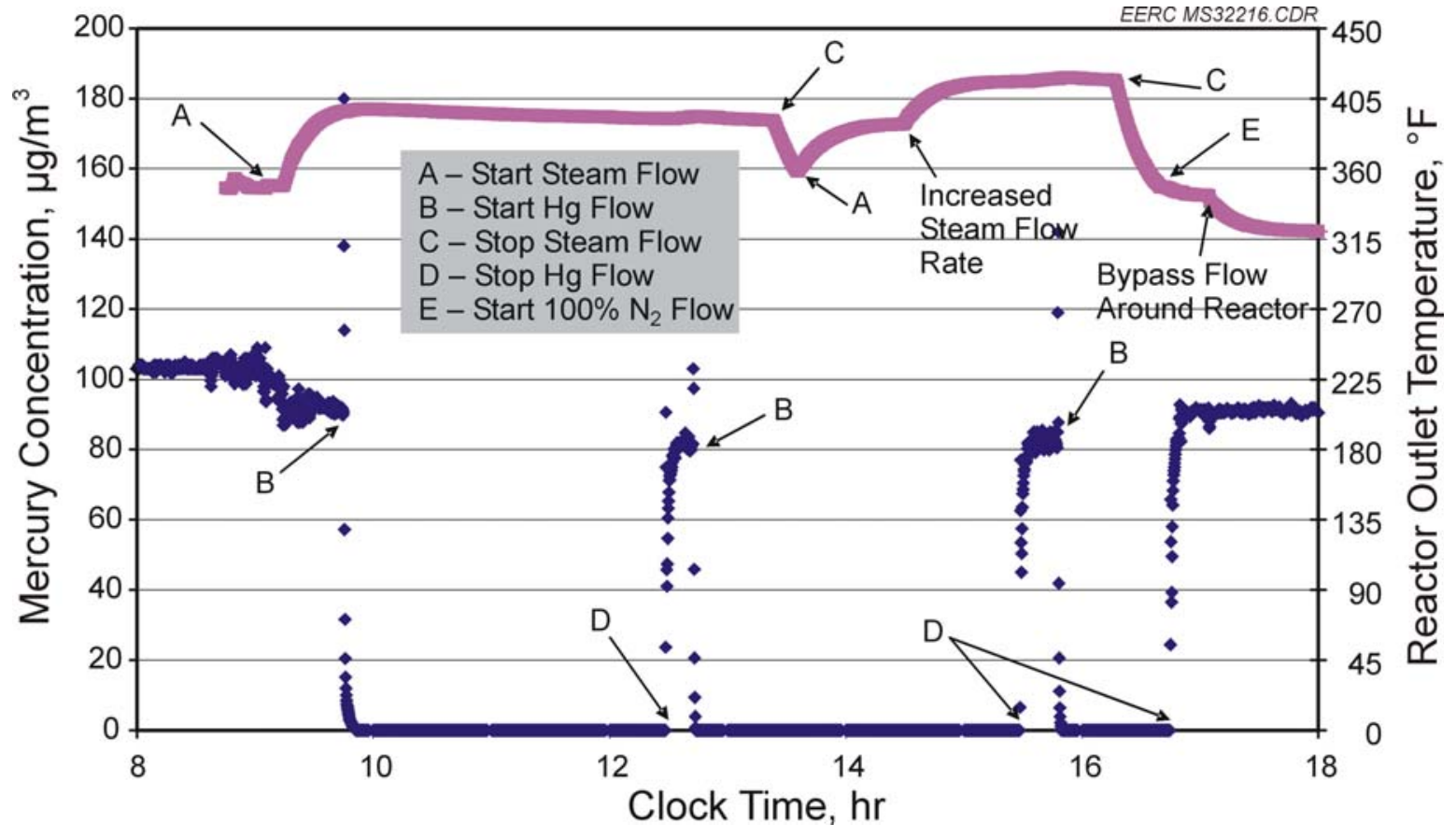

Figure A-16. Mercury sorption curve for EERC Noncarbon Sorbent 1 at $350^{\circ} \mathrm{F}$ and 300 psig (Test 18). 


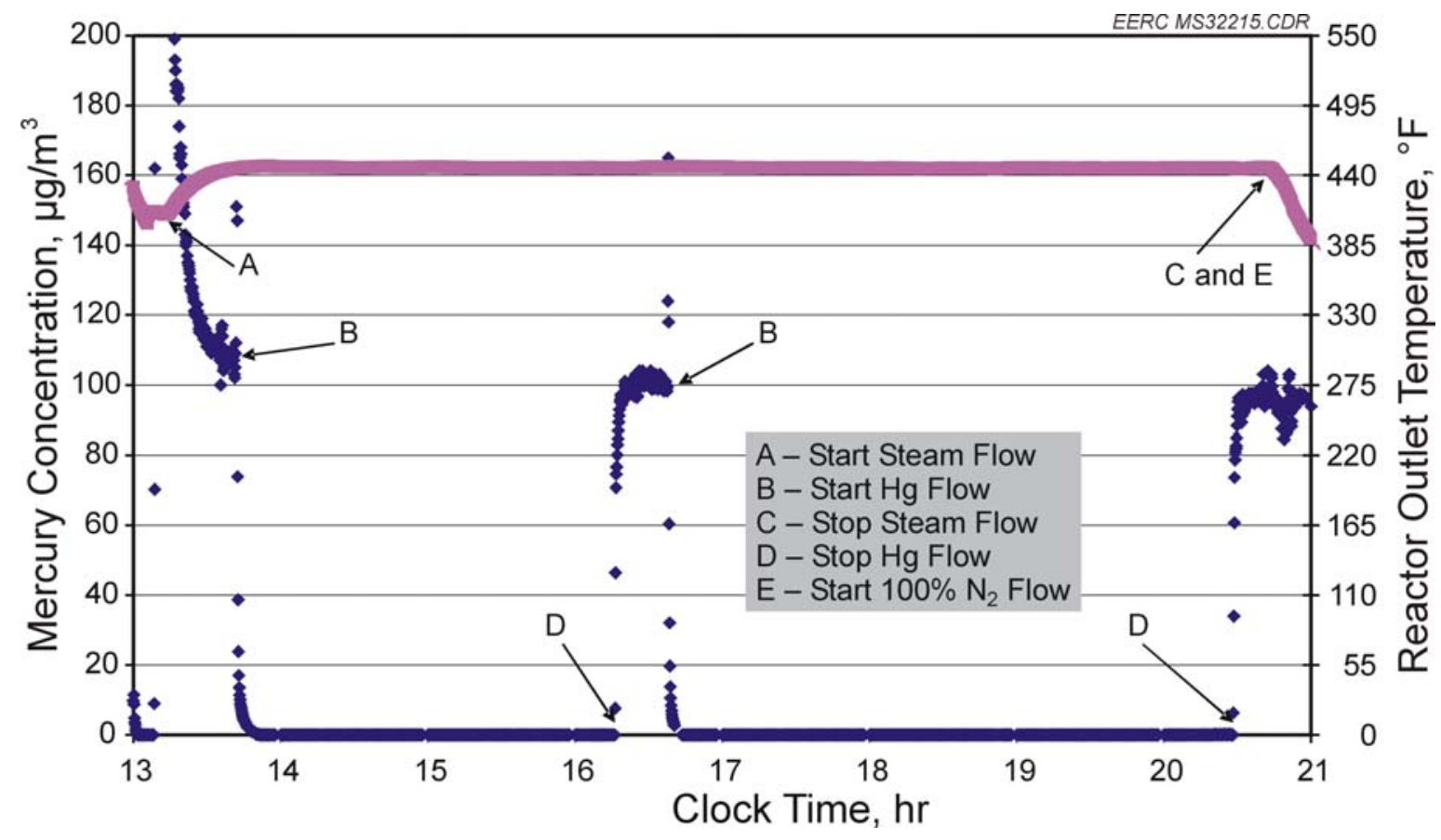

Figure A-17. Mercury sorption curve for EERC Noncarbon Sorbent 1 at $350^{\circ} \mathrm{F}$ and 300 psig (Test 19).

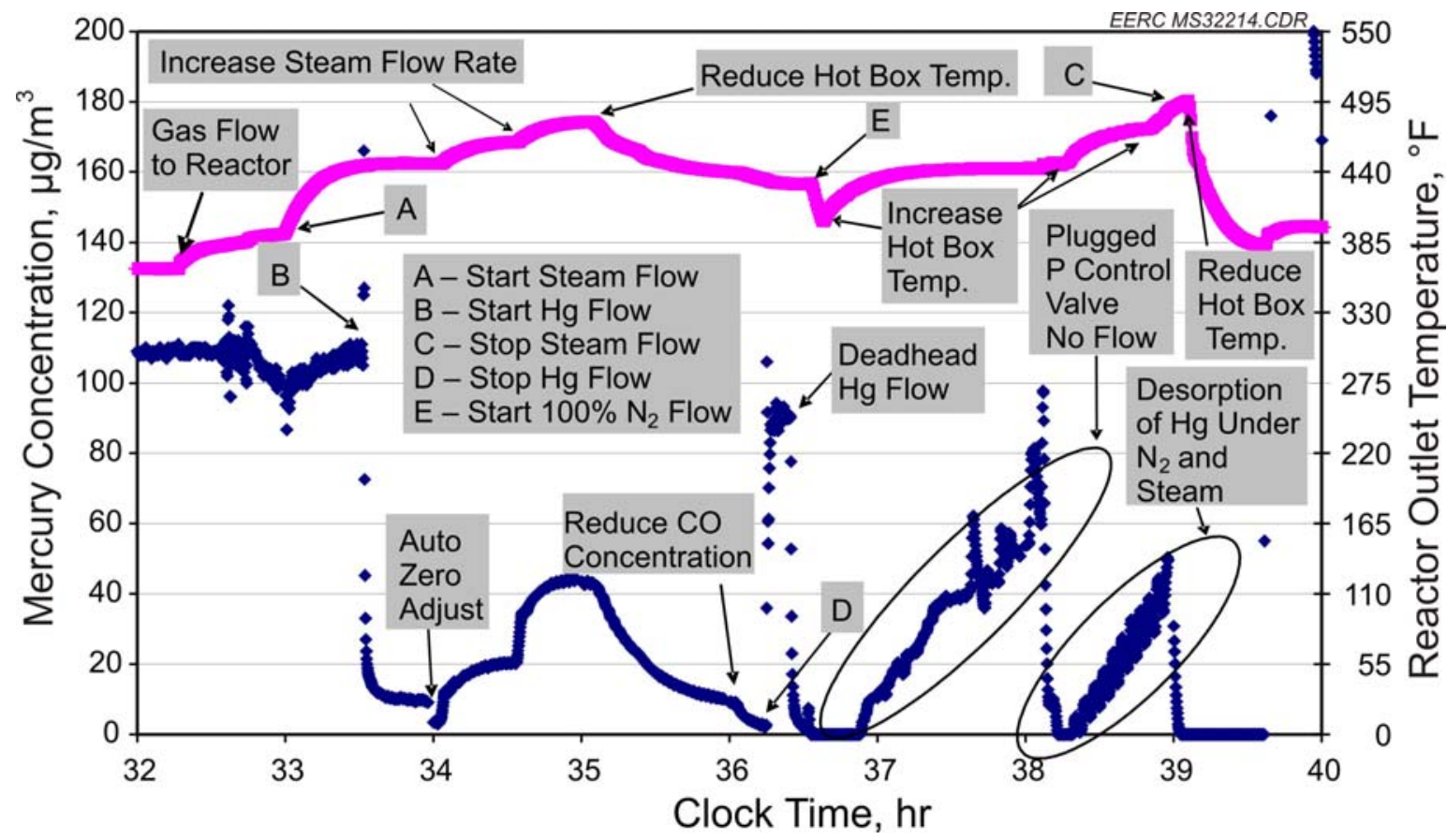

Figure A-18. Mercury sorption curve for EERC Noncarbon Sorbent 1 at $350^{\circ} \mathrm{F}$ and 300 psig (Test 20). 


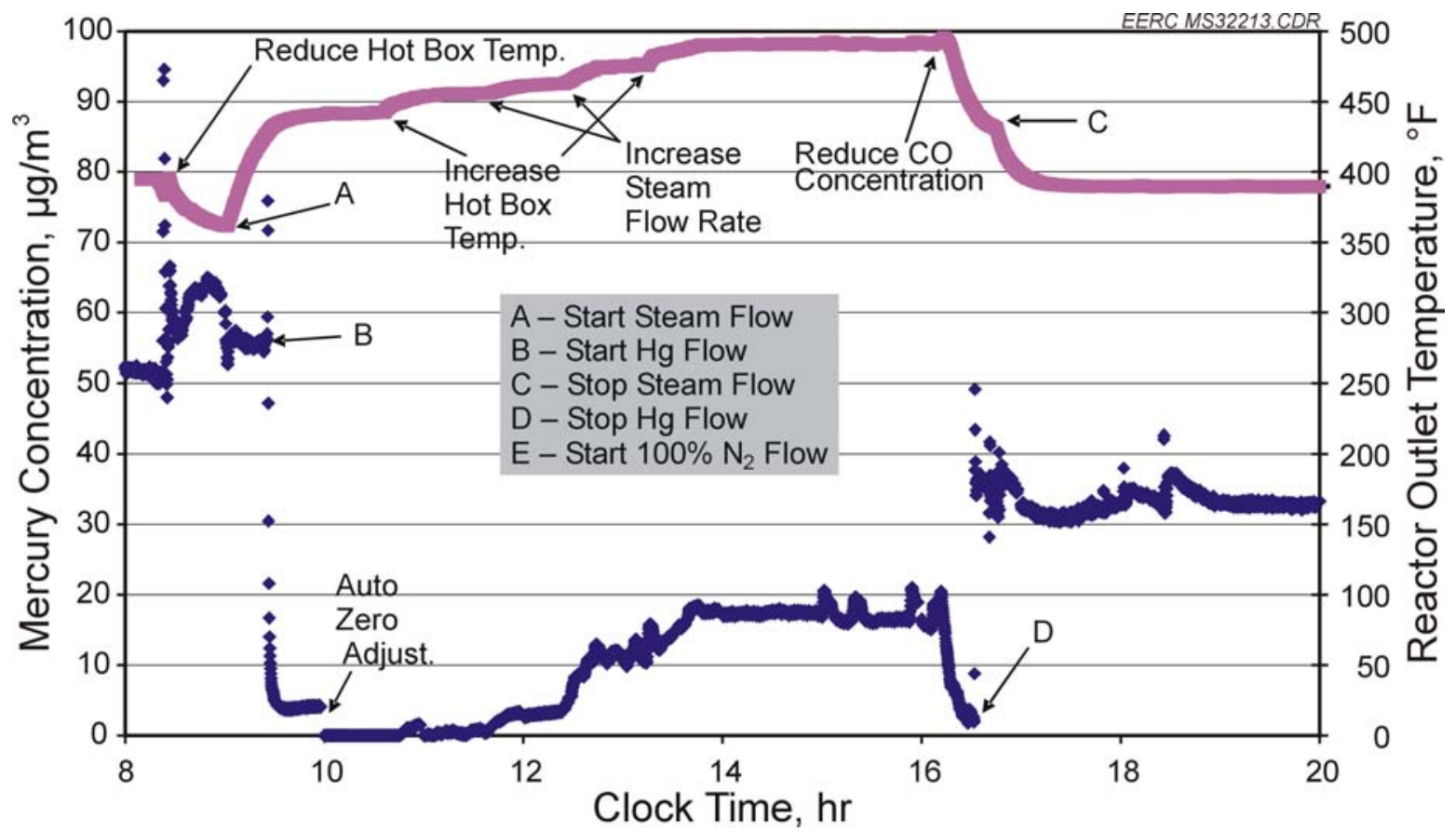

Figure A-19. Mercury sorption curve for EERC Noncarbon Sorbent 1 at $400^{\circ} \mathrm{F}$ and 600 psig (Test 21).

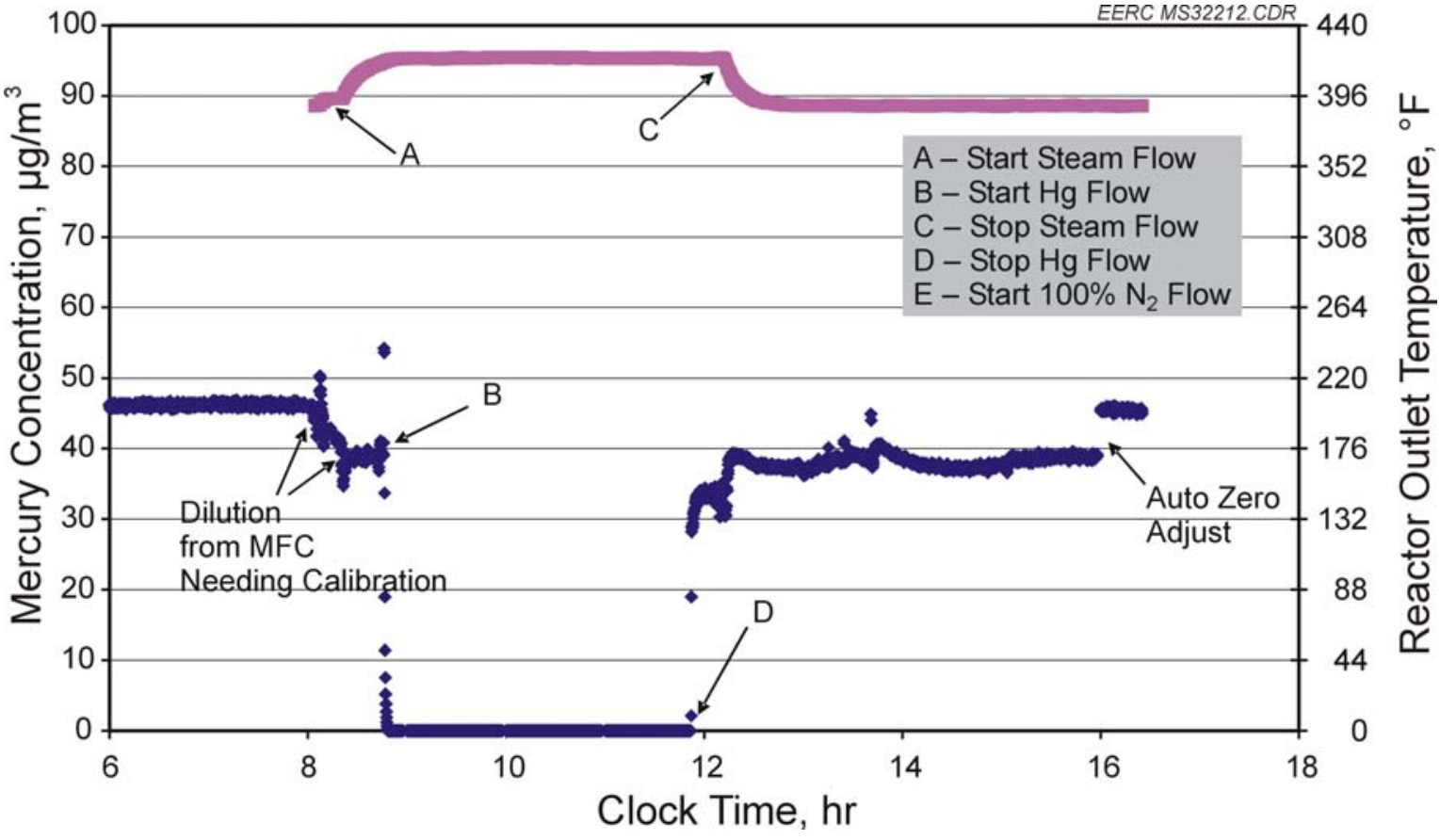

Figure A-20. Mercury sorption curve for EERC Noncarbon Sorbent 1 at $400^{\circ} \mathrm{F}$ and 600 psig (Test 22); MFC is mass flow controller. 


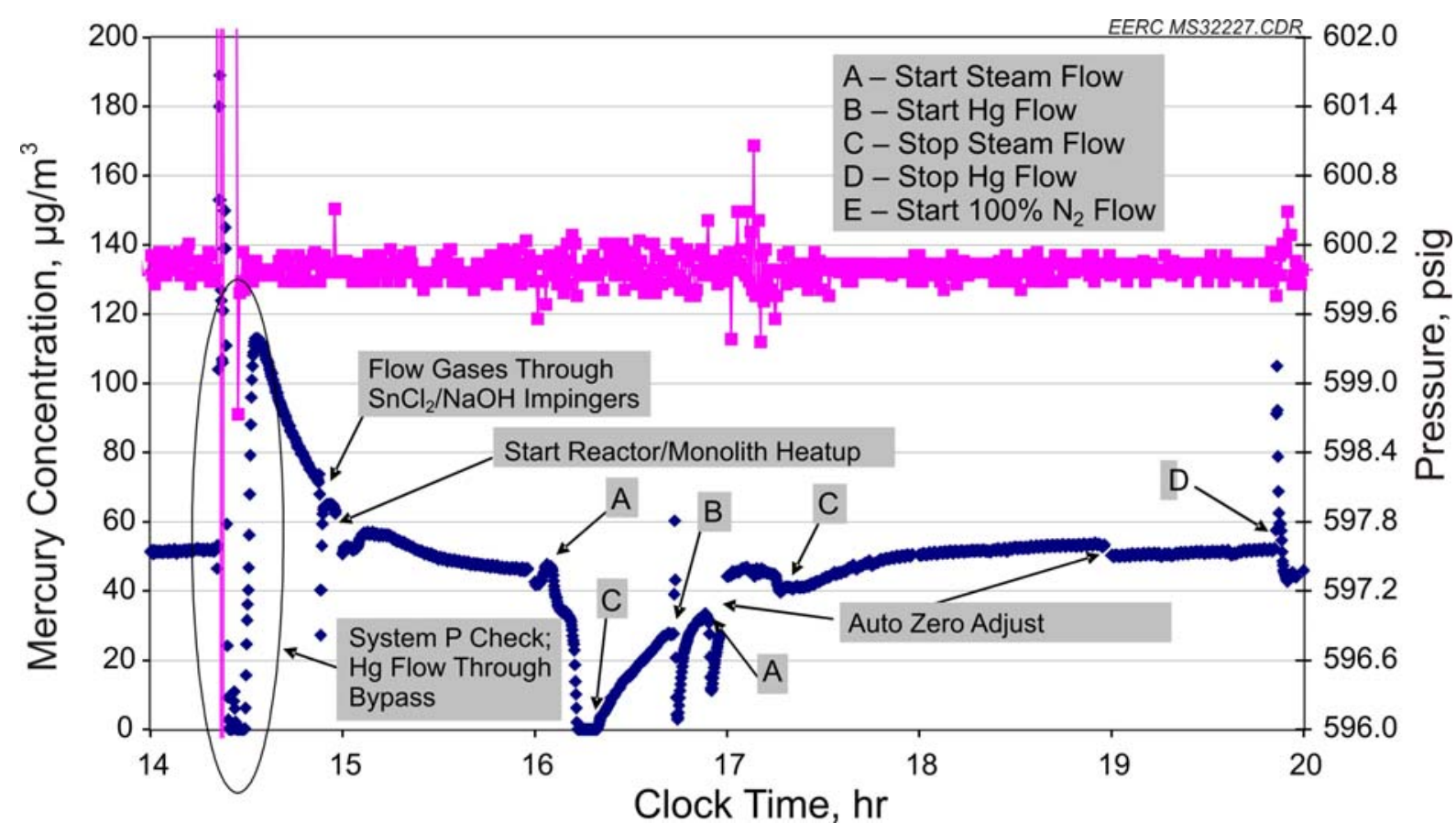

Figure A-21. Mercury sorption curve for Corning Monolith MS23573-1 at $400^{\circ} \mathrm{F}$ and 600 psig (Test 23).

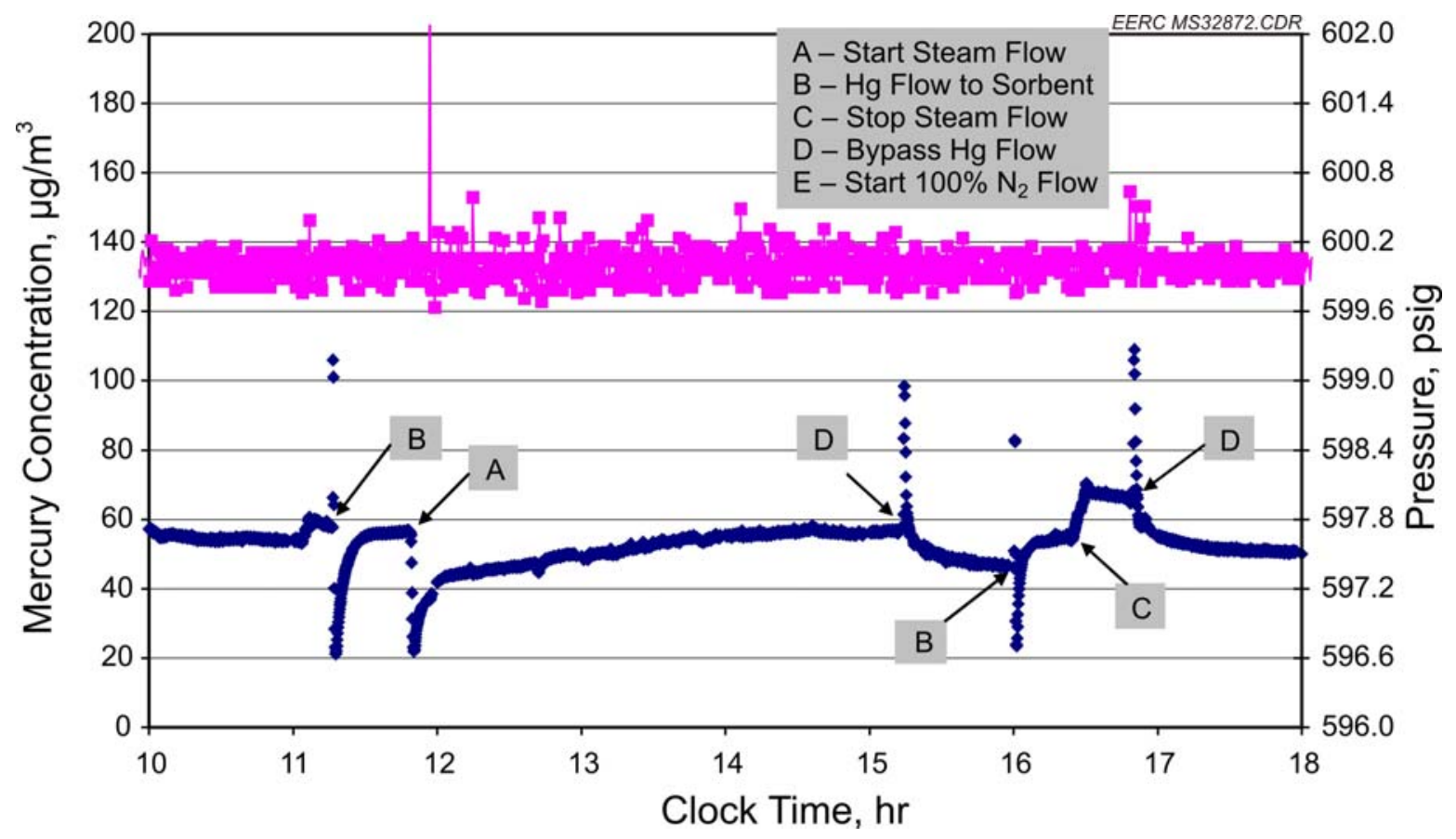

Figure A-22. Mercury sorption curve for Corning Monolith GEN1C-1 at $400^{\circ} \mathrm{F}$ and 600 psig (Test 24). 


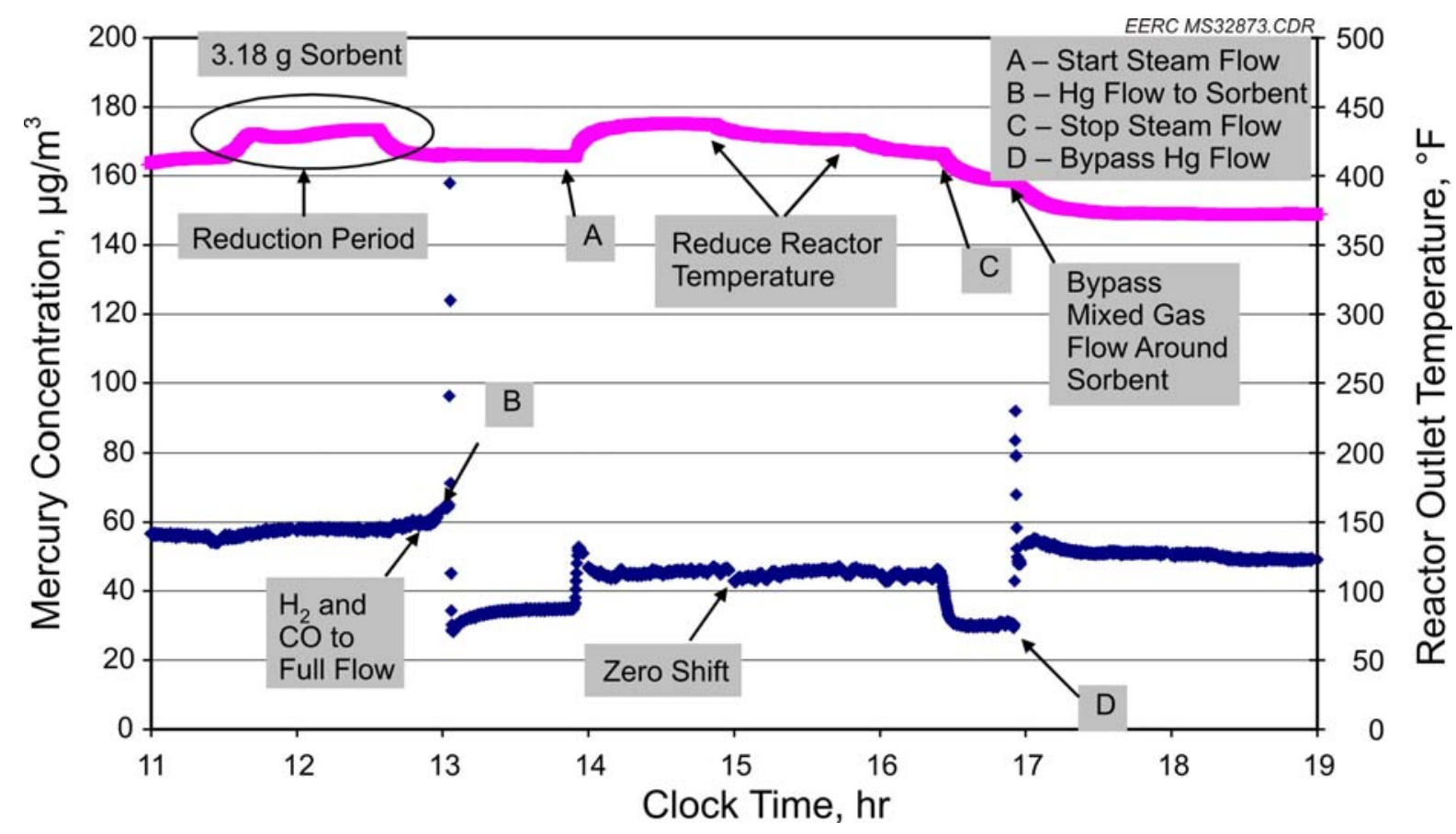

Figure A-23. Mercury sorption curve for EERC Noncarbon Sorbent 2 at $400^{\circ} \mathrm{F}$ and 600 psig (Test 25).

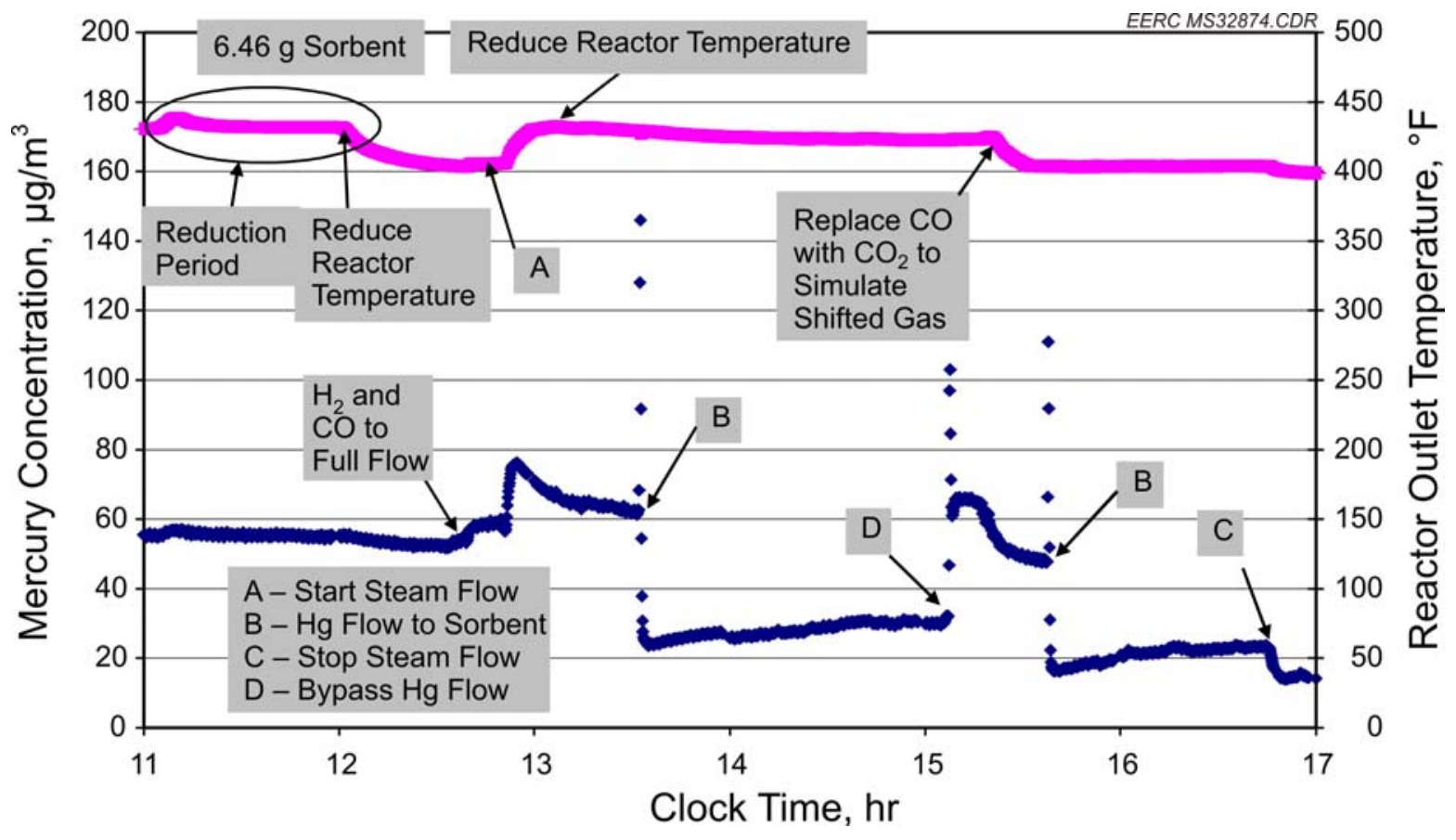

Figure A-24. Mercury sorption curve for EERC Noncarbon Sorbent 2 at $400^{\circ} \mathrm{F}$ and 600 psig (Test 26). 


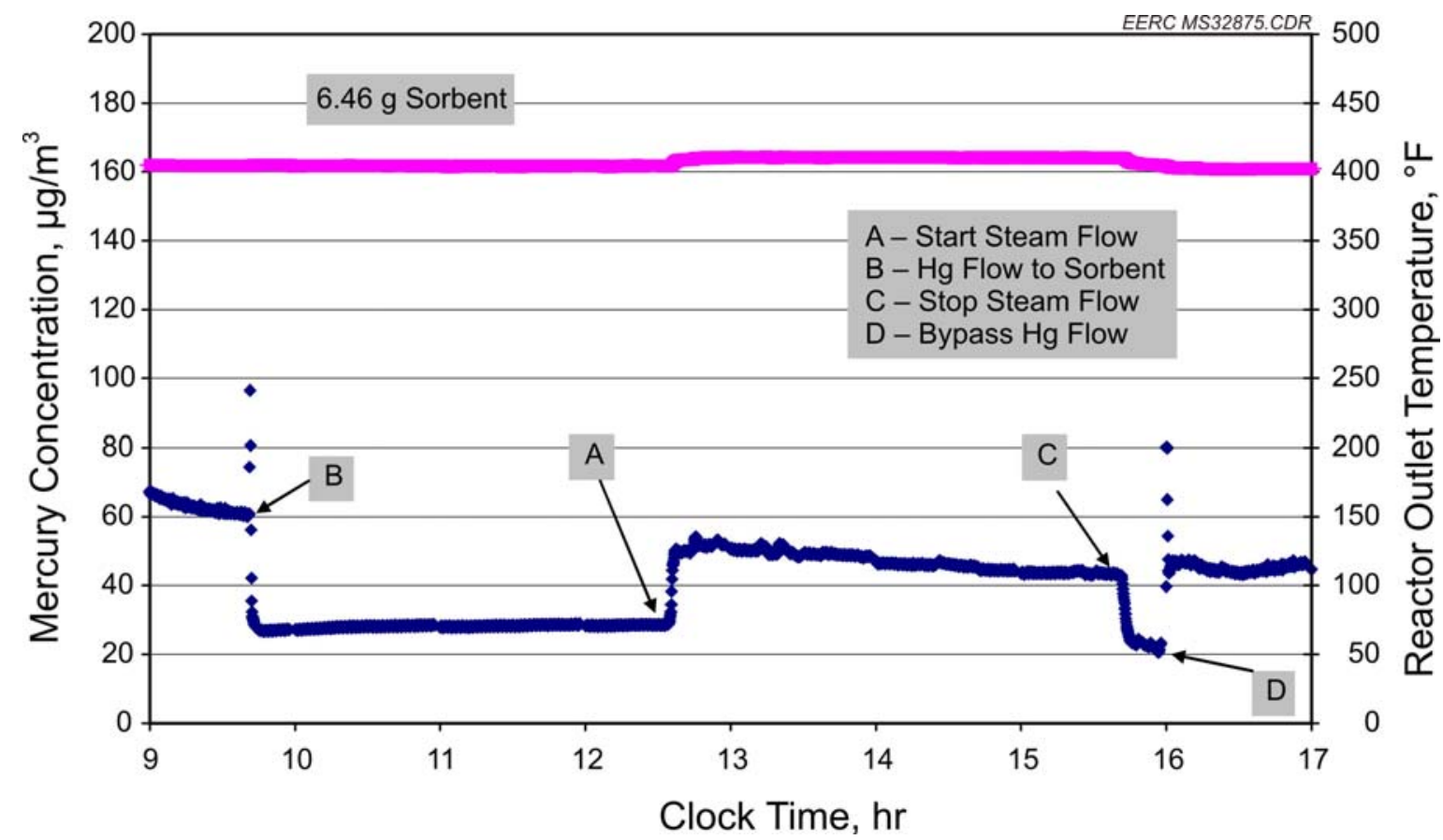

Figure A-25. Mercury sorption curve for EERC Noncarbon Sorbent 2 at $400^{\circ} \mathrm{F}$ and 600 psig (Test 28).

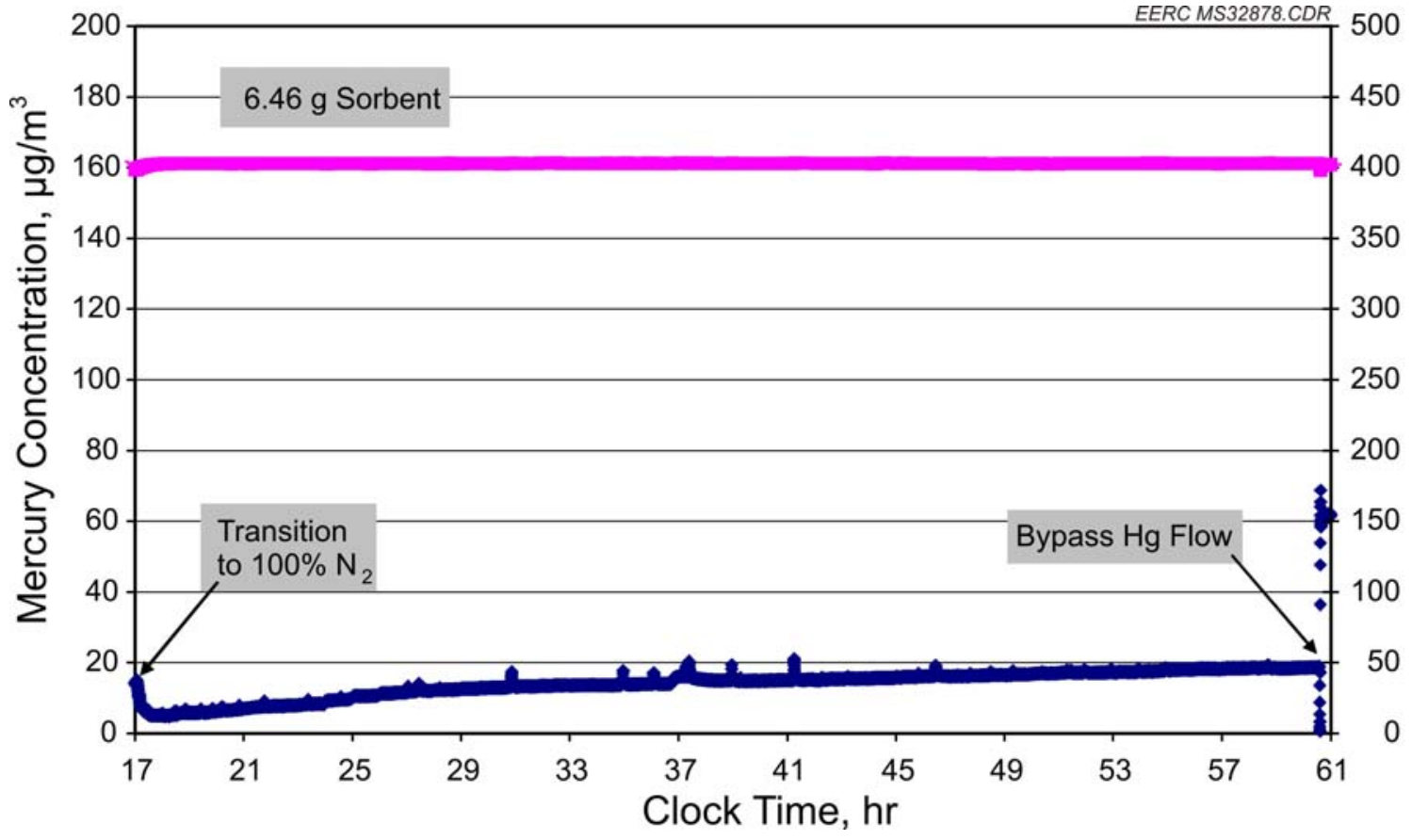

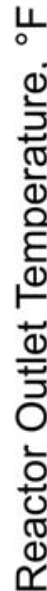

Figure A-26. Mercury sorption curve for EERC Noncarbon Sorbent 2 at $400^{\circ} \mathrm{F}$ and 600 psig (Test 27). 


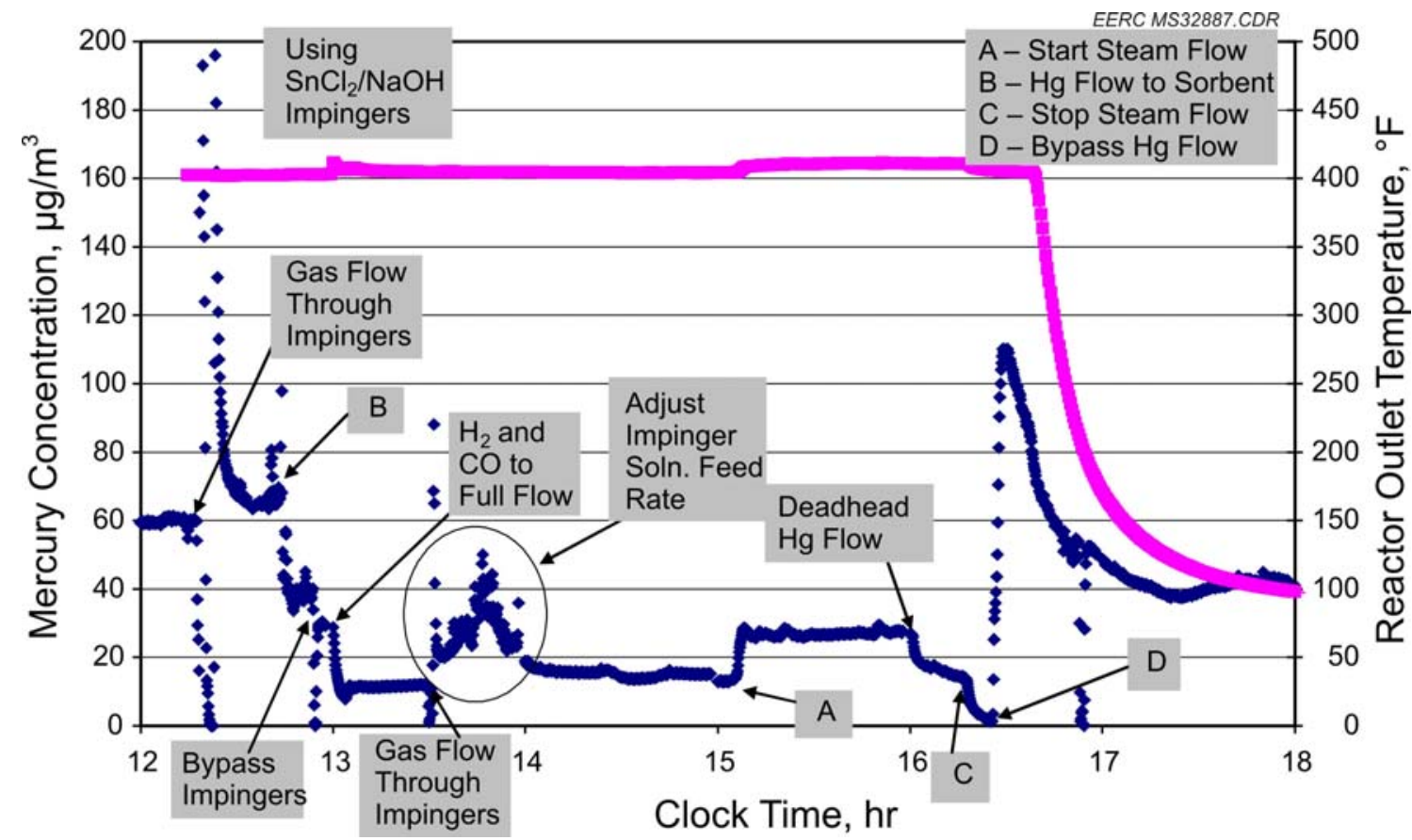

Figure A-27. Mercury sorption curve for EERC Noncarbon Sorbent 2 at $400^{\circ} \mathrm{F}$ and 600 psig (Test 29).

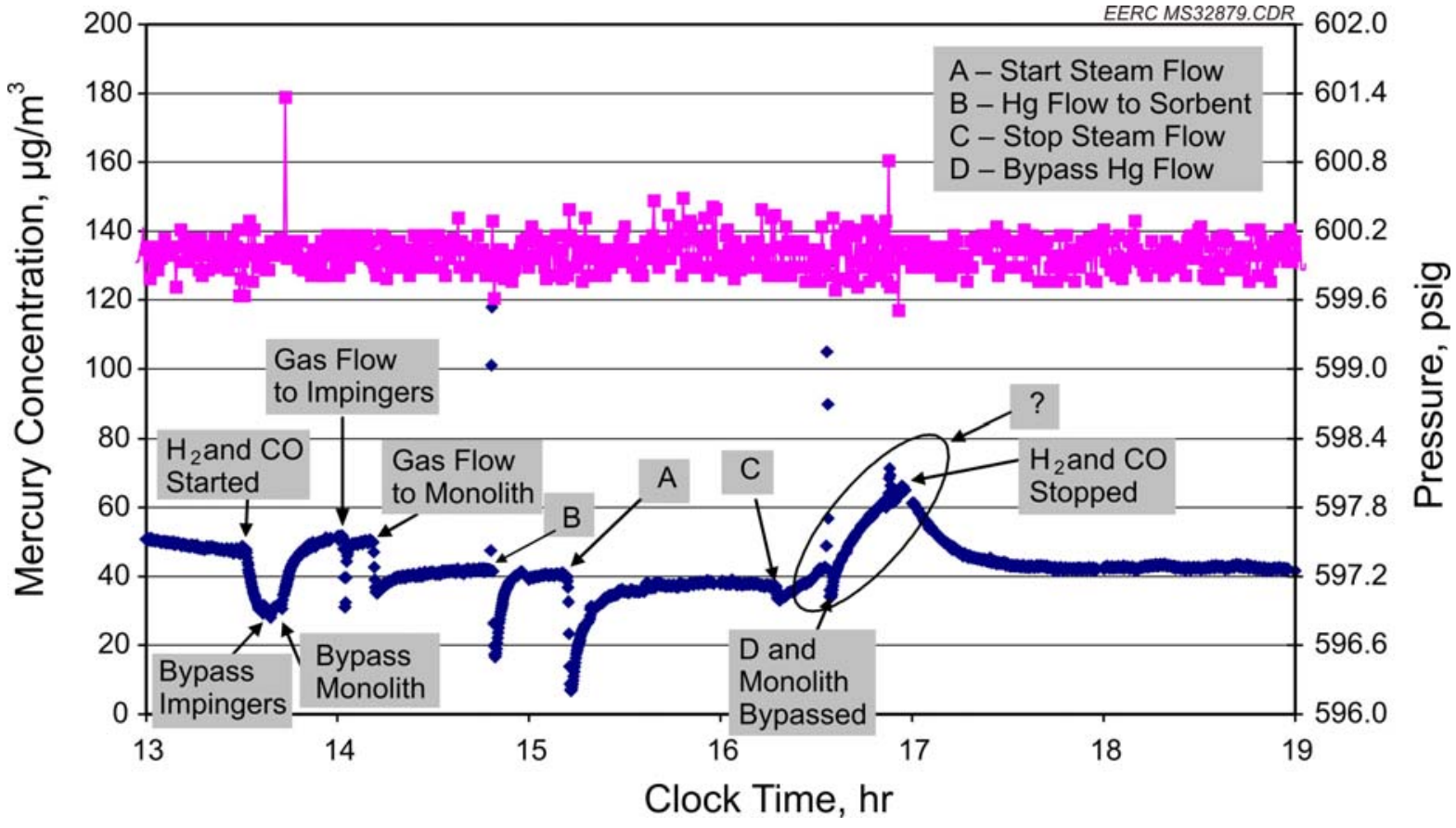

Figure A-28. Mercury sorption curve for Corning Monolith MS23574-1 at $400^{\circ} \mathrm{F}$ and 600 psig (Test 30). 


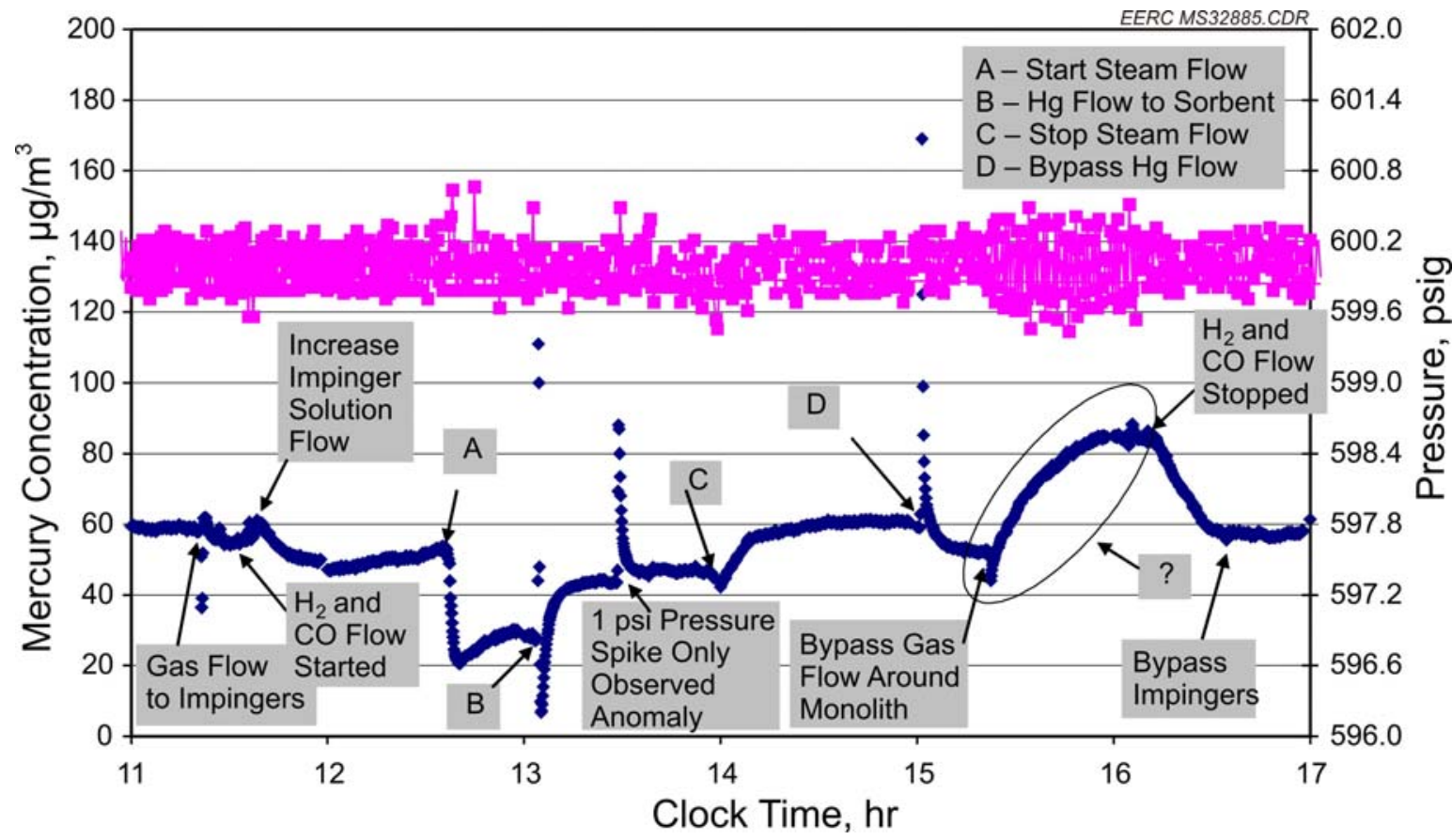

Figure A-29. Mercury sorption curve for Corning Monolith MS23423-1 at $400^{\circ} \mathrm{F}$ and 600 psig. (Test 31).

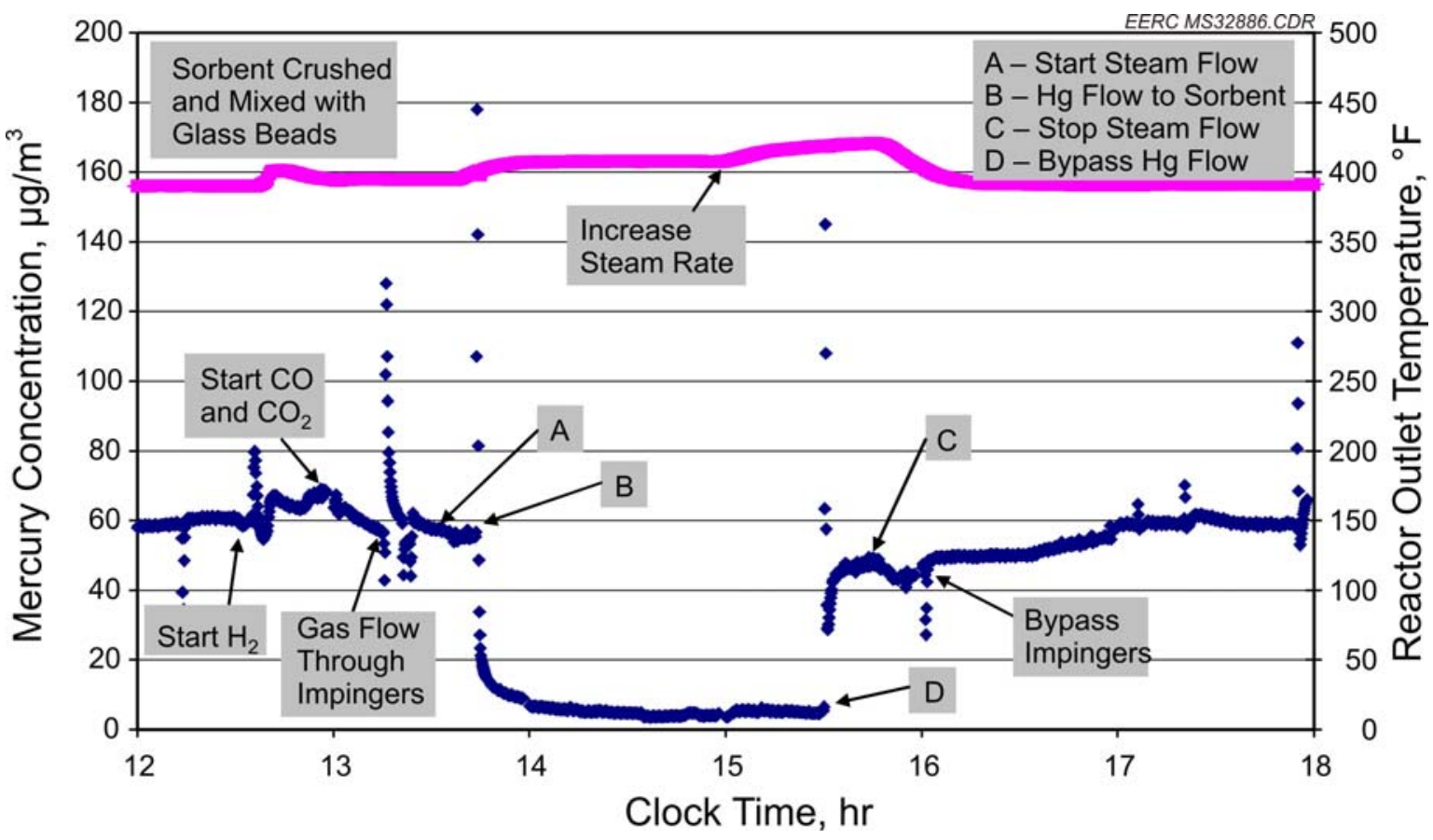

Figure A-30. Mercury sorption curve for EERC Noncarbon Sorbent 1 at $400^{\circ} \mathrm{F}$ and 600 psig (Test 32). 


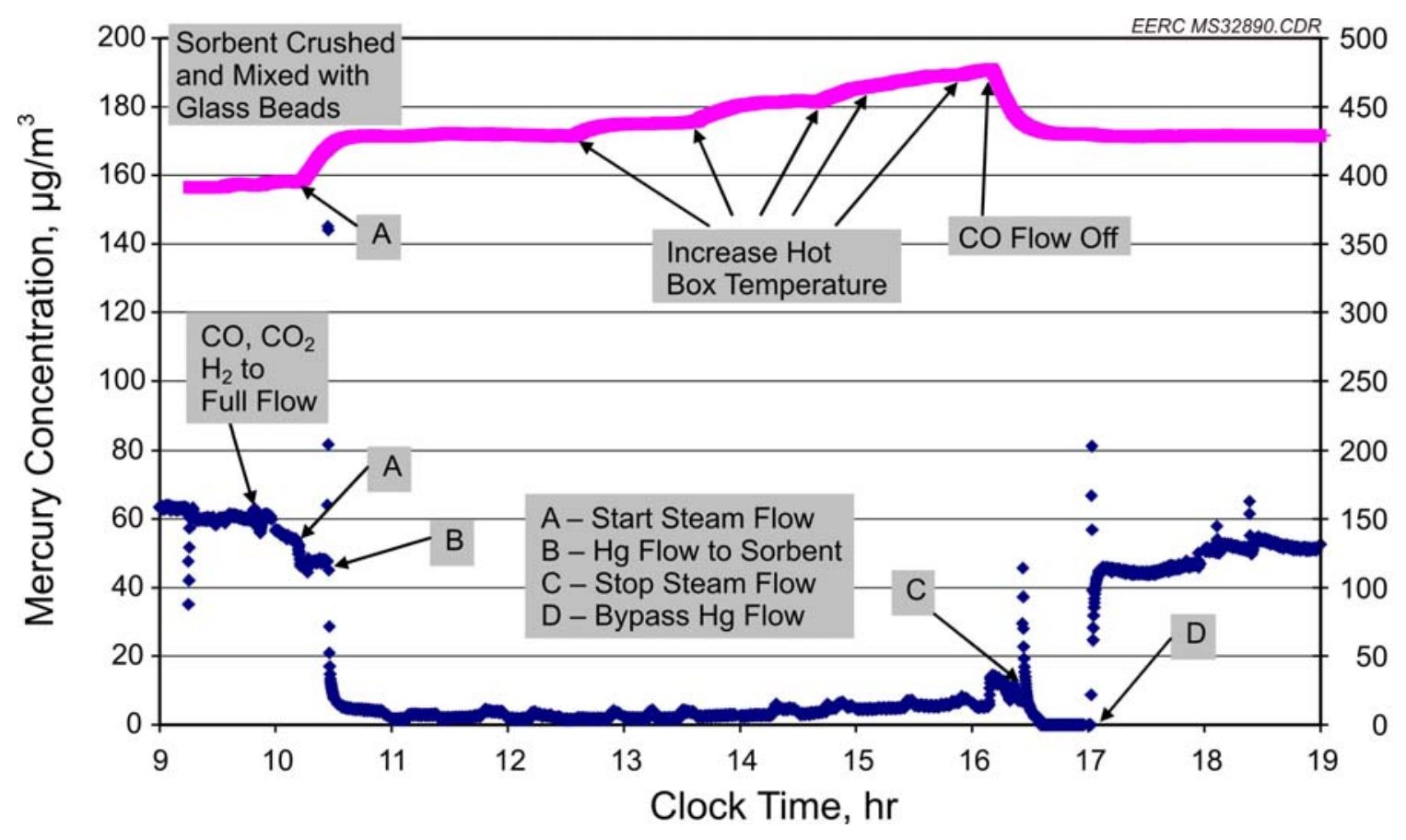

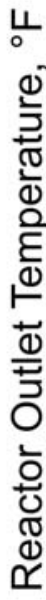

Figure A-31. Mercury sorption curve for EERC Noncarbon Sorbent 1 at $400^{\circ} \mathrm{F}$ and 600 psig (Test 33).

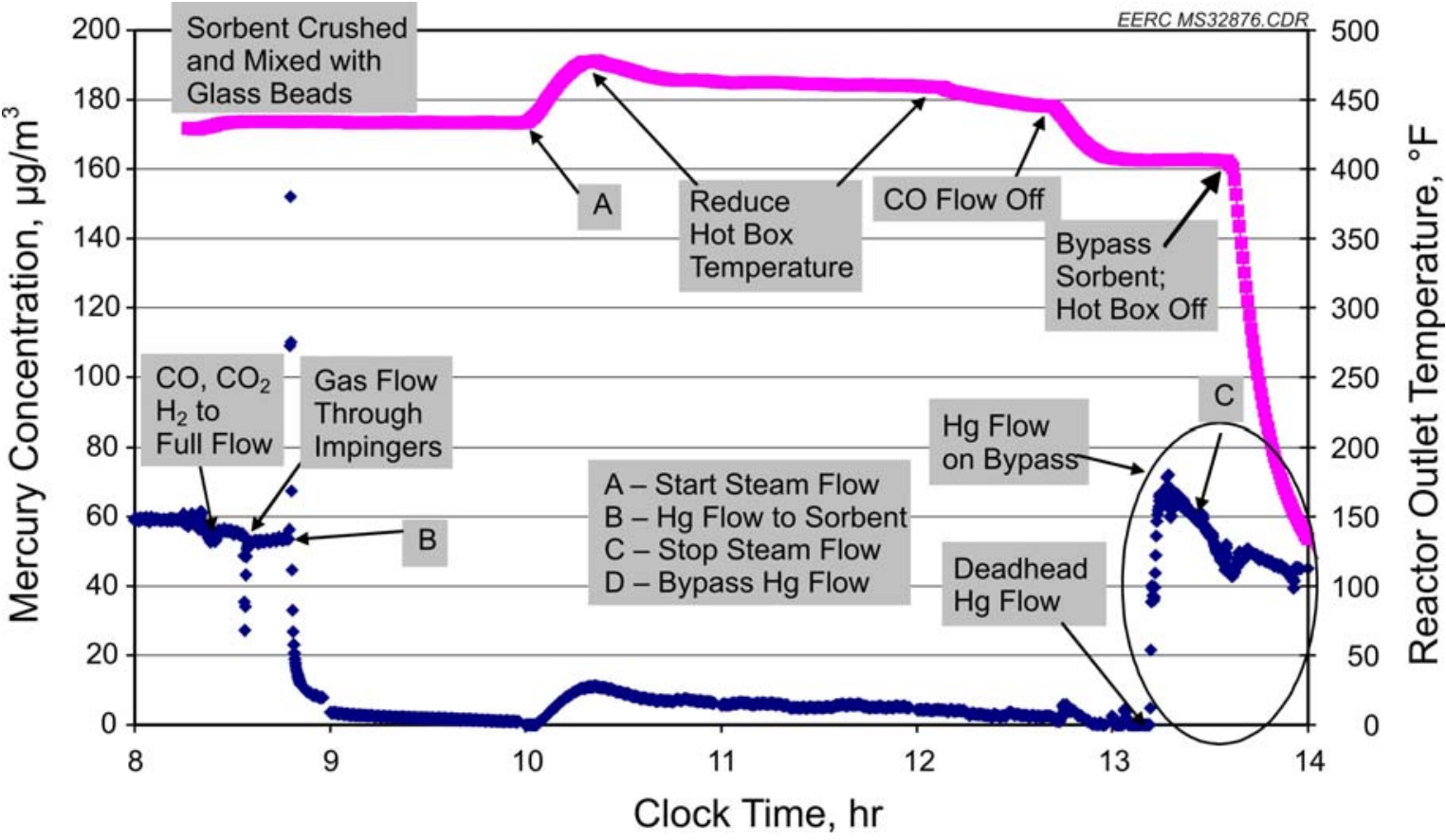

Figure A-32. Mercury sorption curve for EERC Noncarbon Sorbent 1 at $400^{\circ} \mathrm{F}$ and 600 psig (Test 34). 


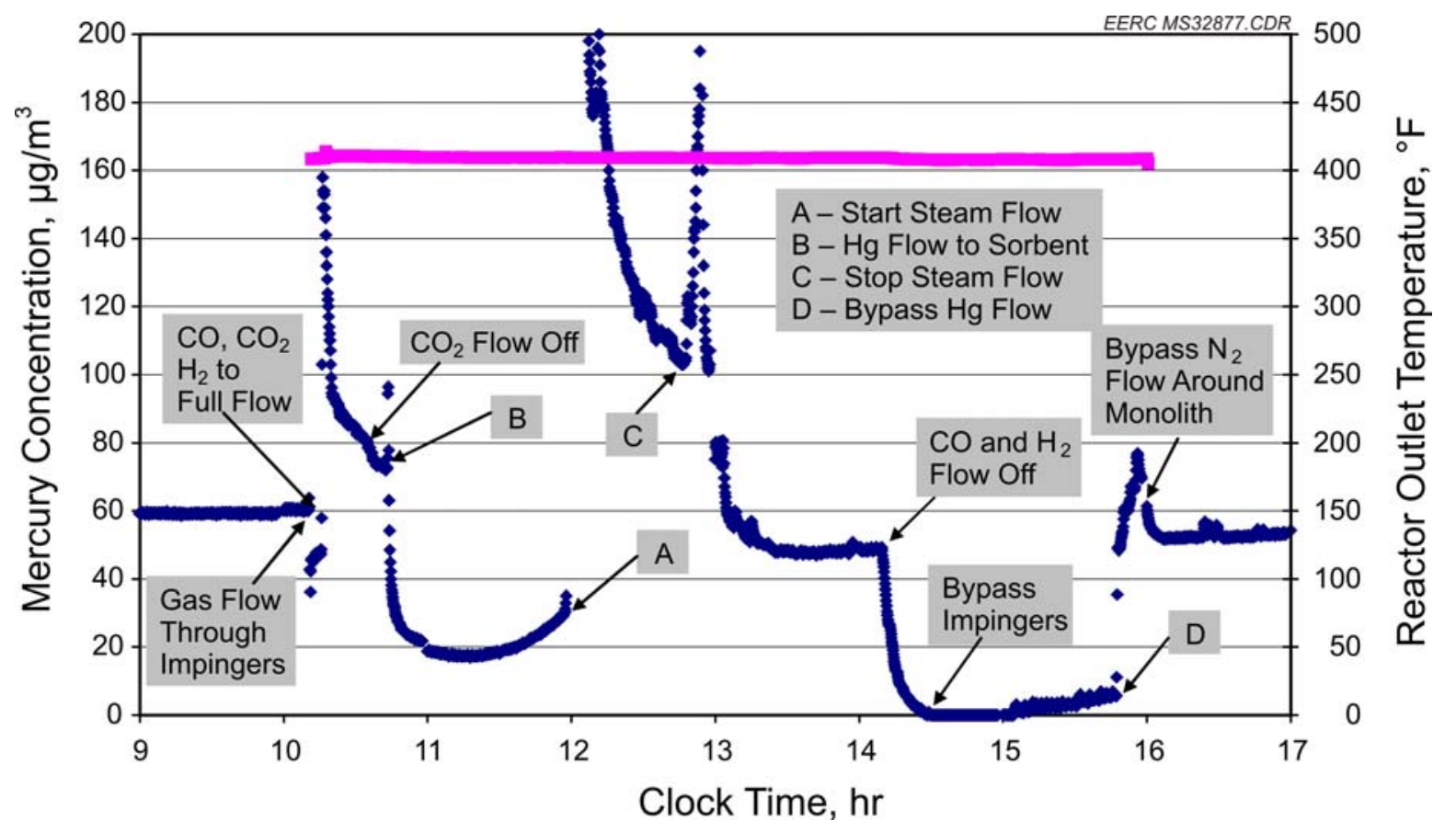

Figure A-33. Mercury sorption curve for CORDH-1 coated and impregnated with Group IB metal at $400^{\circ} \mathrm{F}$ and $600 \mathrm{psig}$ (Test 35).

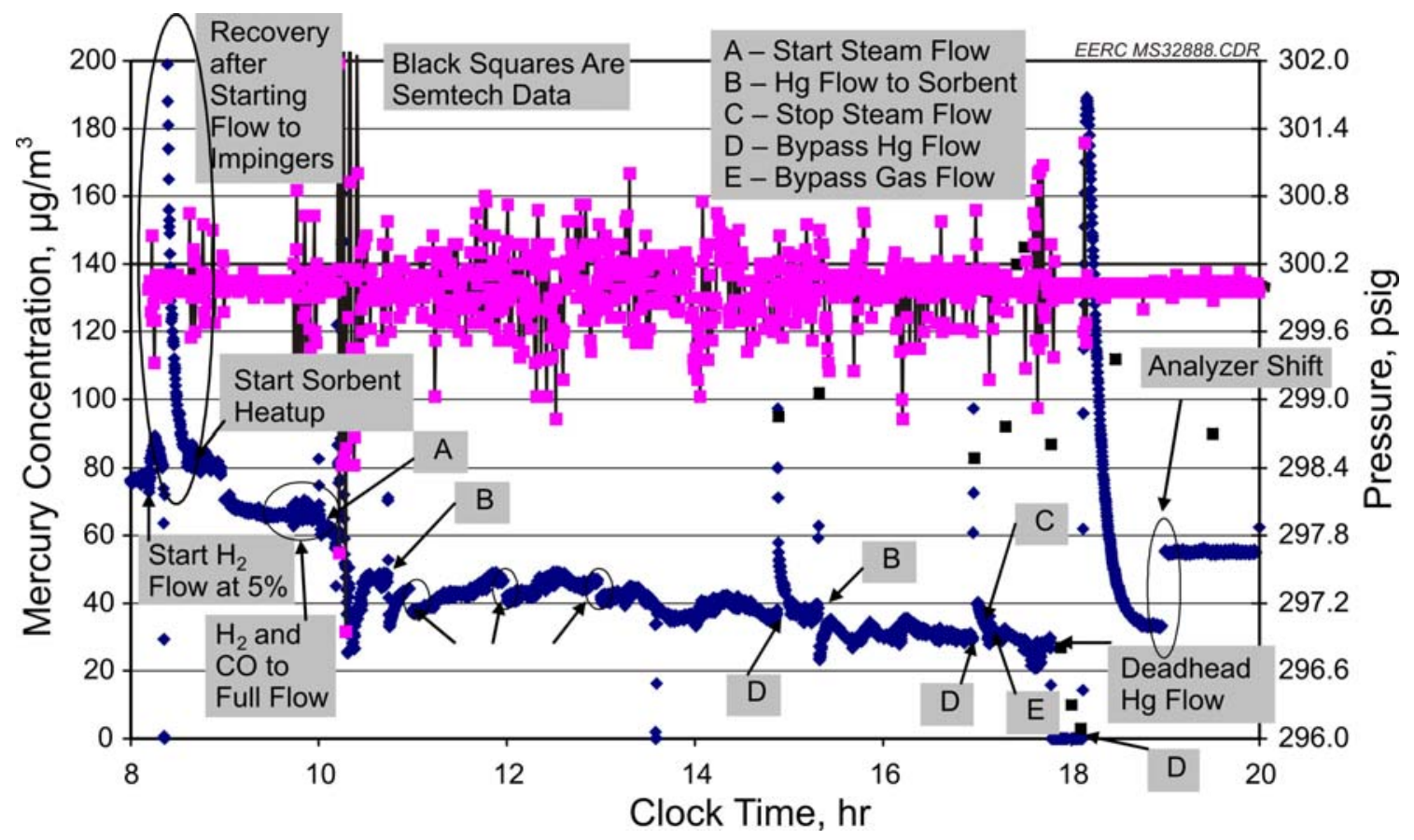

Figure A-34. Mercury sorption curve for Corning Monolith SR Liquid (half monolith) at $350^{\circ} \mathrm{F}$ and 300 psig (Test 36 ). 


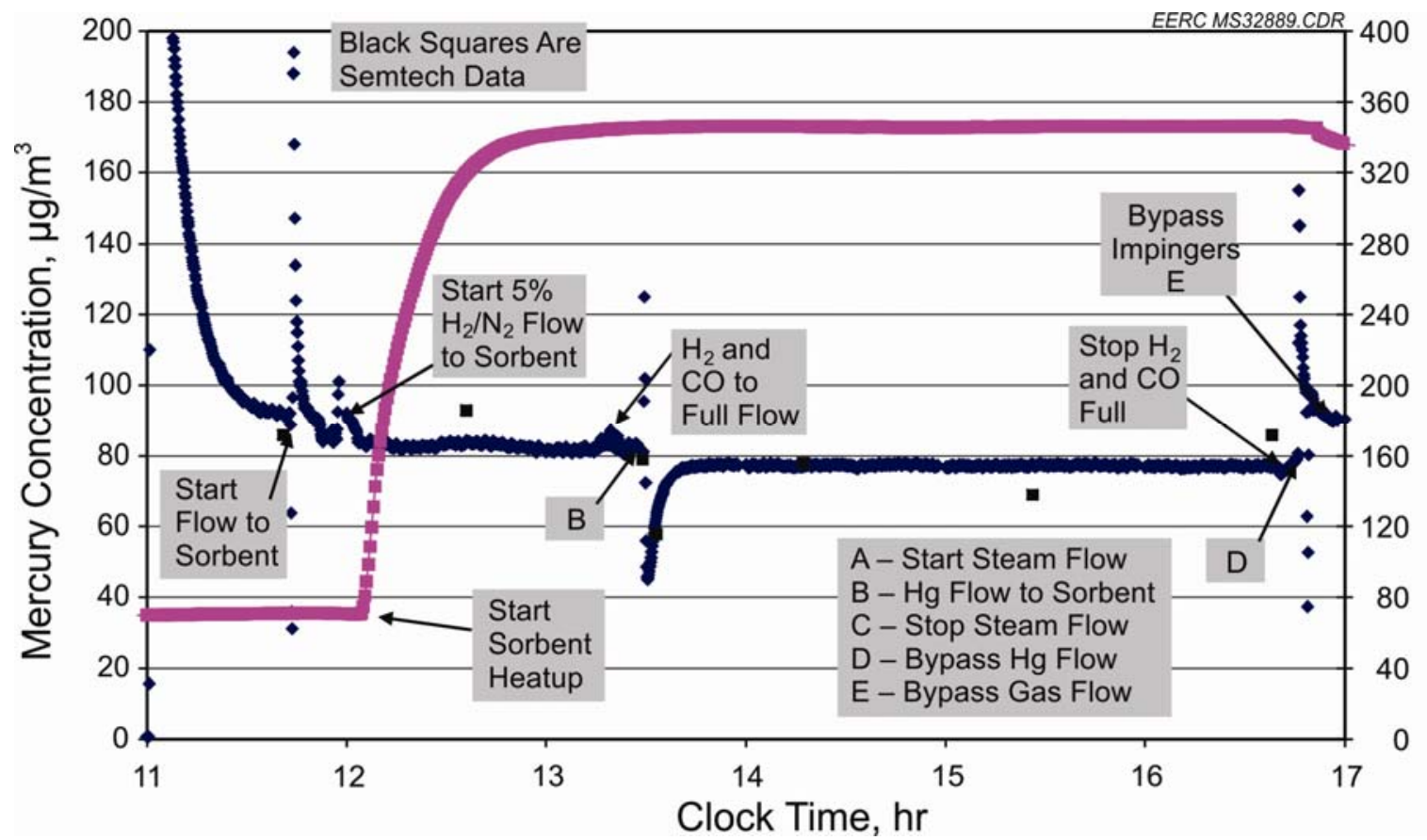

Figure A-35. Mercury sorption curve for Corning Monolith SR Liquid (crushed and blended with silica sand) at $350^{\circ} \mathrm{F}$ and $300 \mathrm{psig}$ - no steam (Test 37).

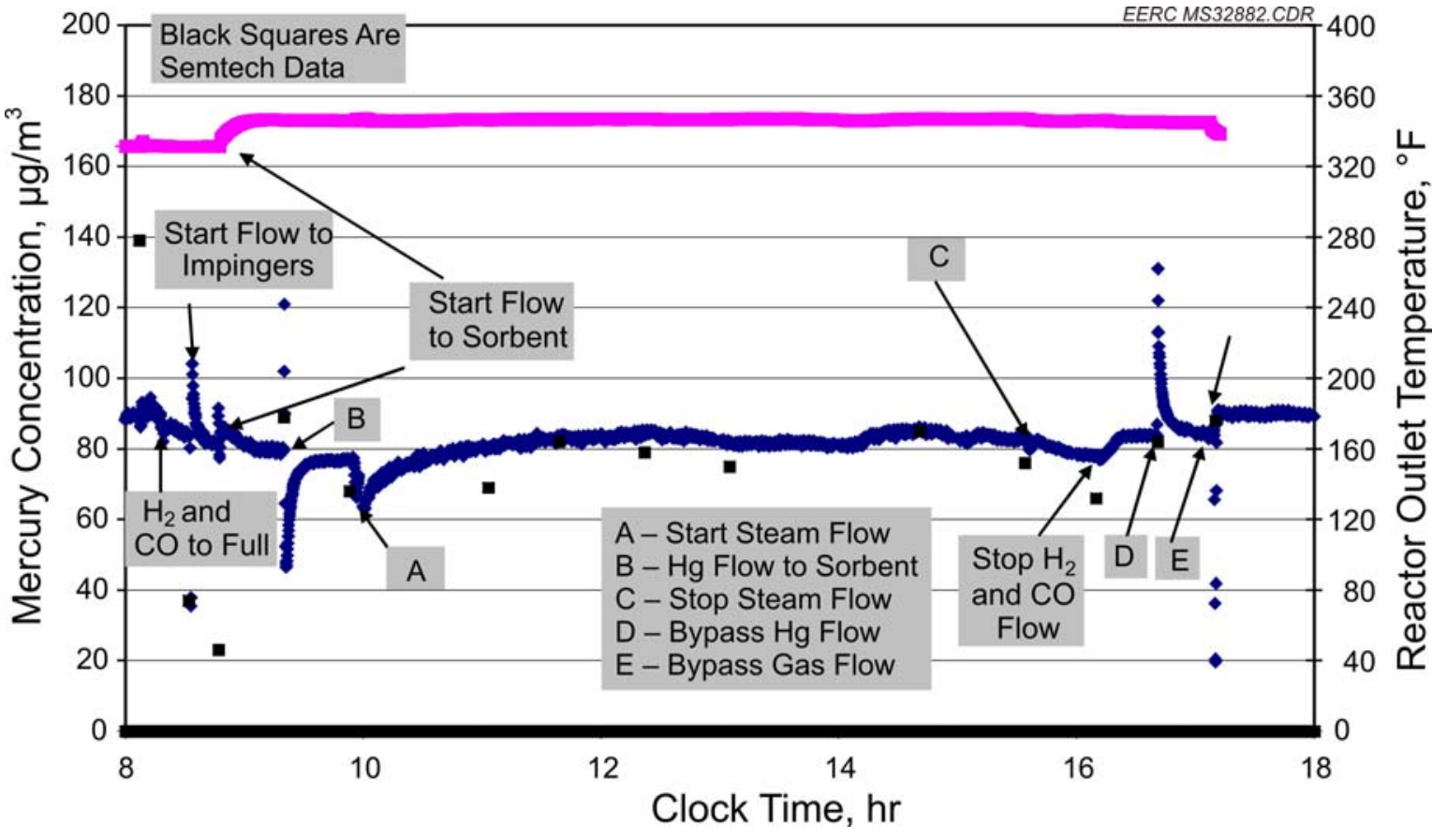

Figure A-36. Mercury sorption curve for Corning Monolith SR Liquid (crushed and blended with silica sand) at $350^{\circ} \mathrm{F}$ and 300 psig - with steam (Test 38). 


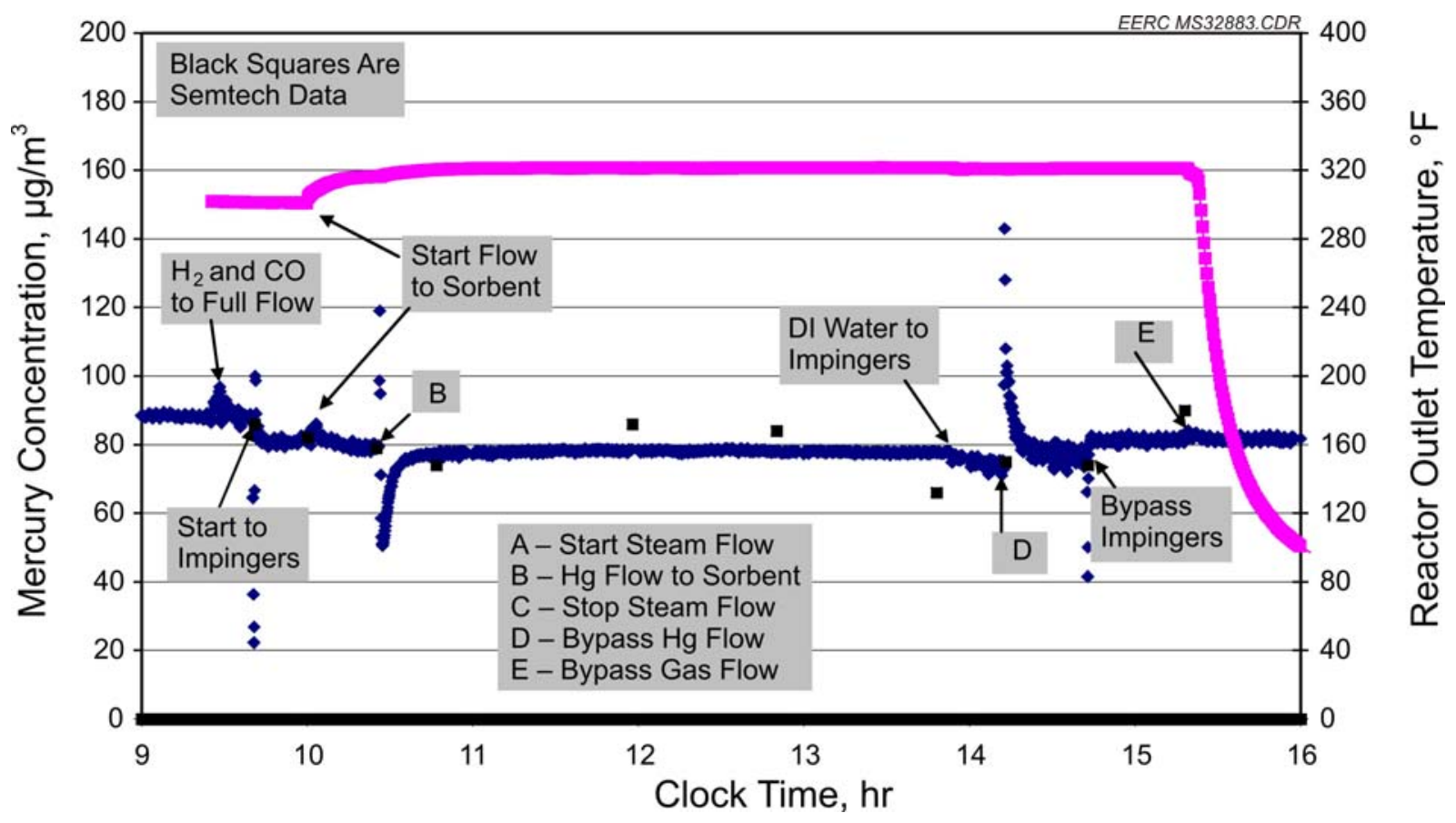

Figure A-37. Mercury sorption curve for Corning Monolith SR Liquid (crushed and blended with silica sand) at $320^{\circ} \mathrm{F}$ and $300 \mathrm{psig}$ - no steam (Test 39); DI is deionized water.

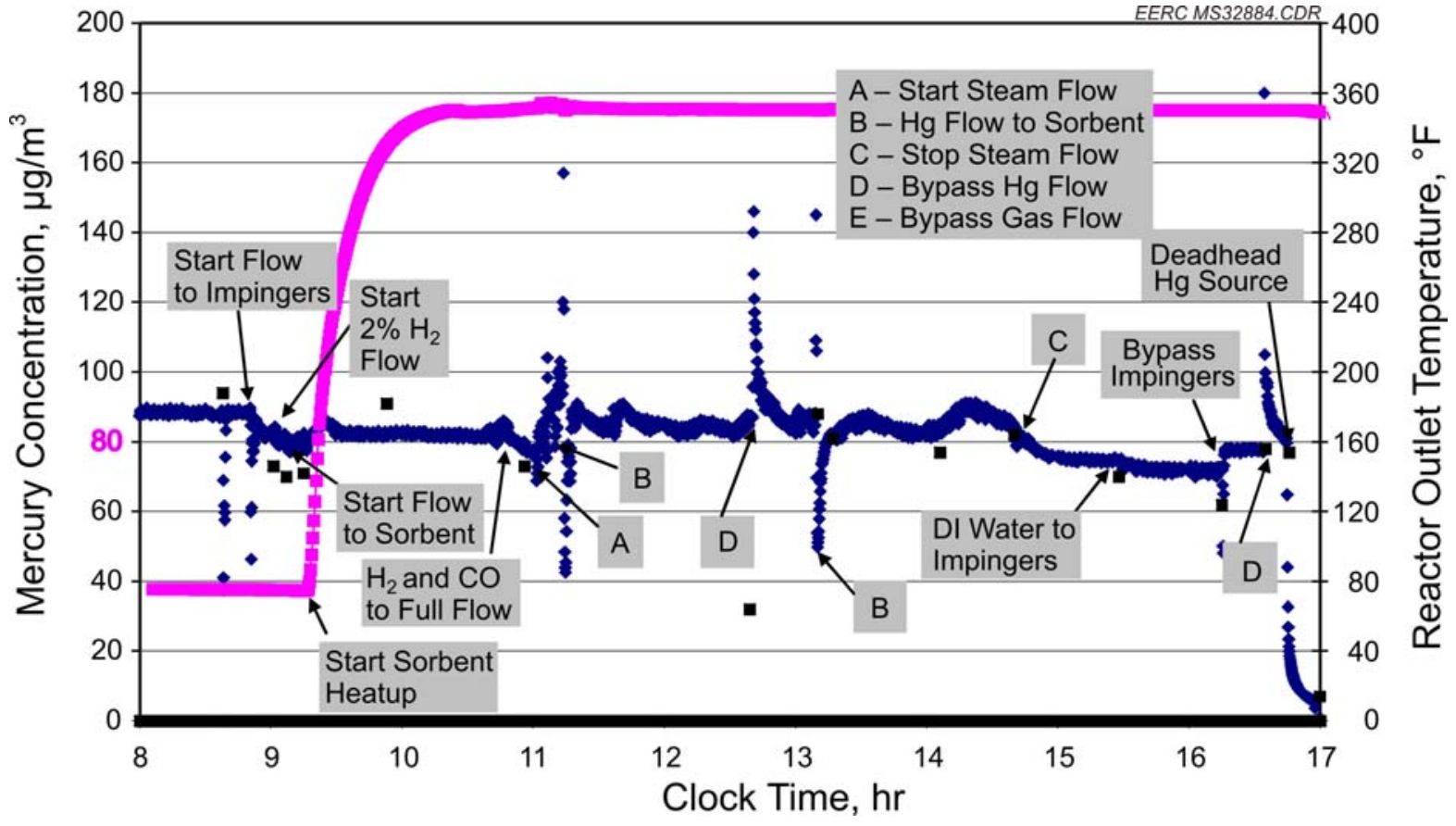

Figure A-38. Mercury sorption curve for Corning Monolith 274 at $350^{\circ} \mathrm{F}$ and 300 psig - with steam (Test 40). 


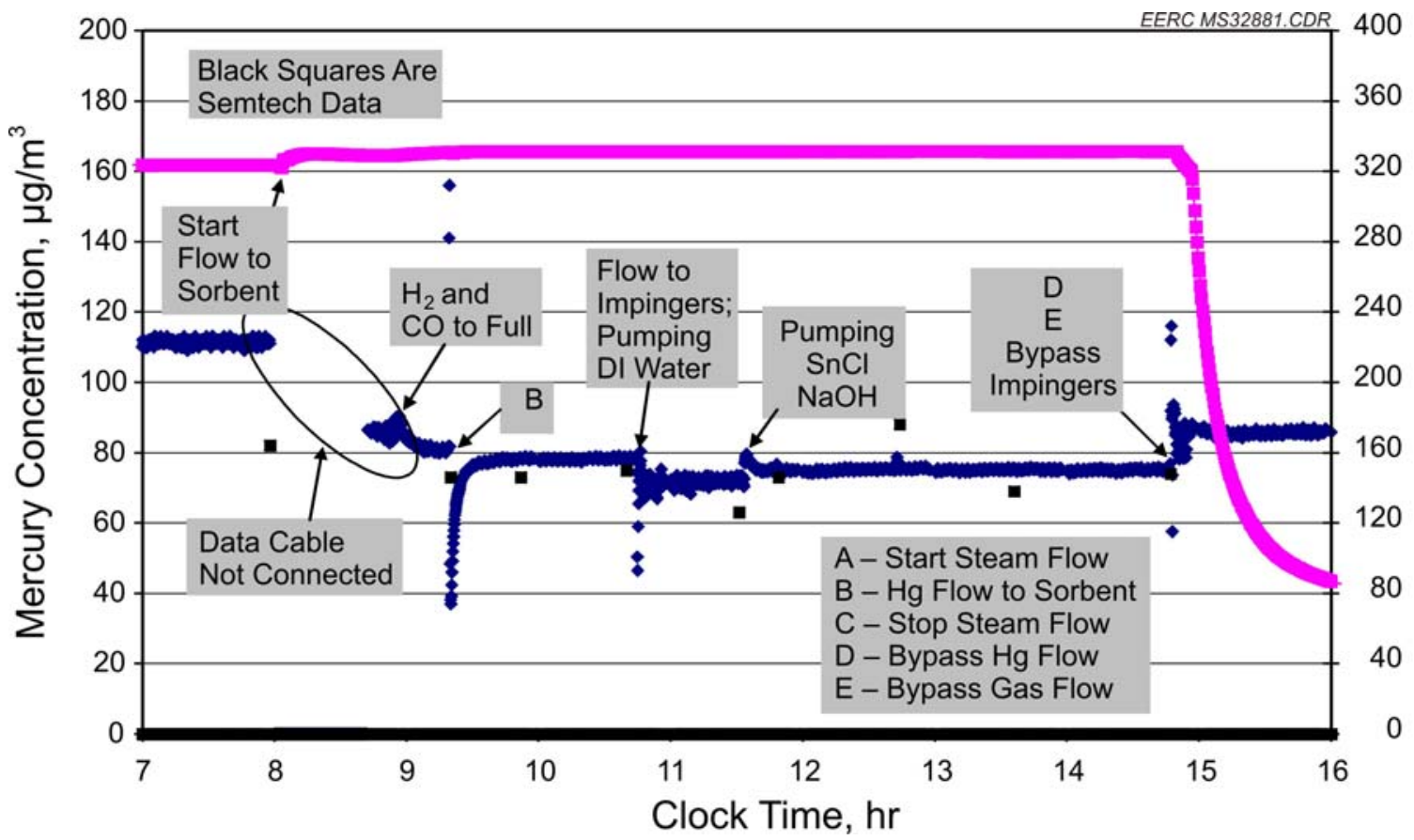

Figure A-39. Mercury sorption curve for Corning Monolith 274 at $330^{\circ} \mathrm{F}$ and 300 psig, without steam (Test 41).

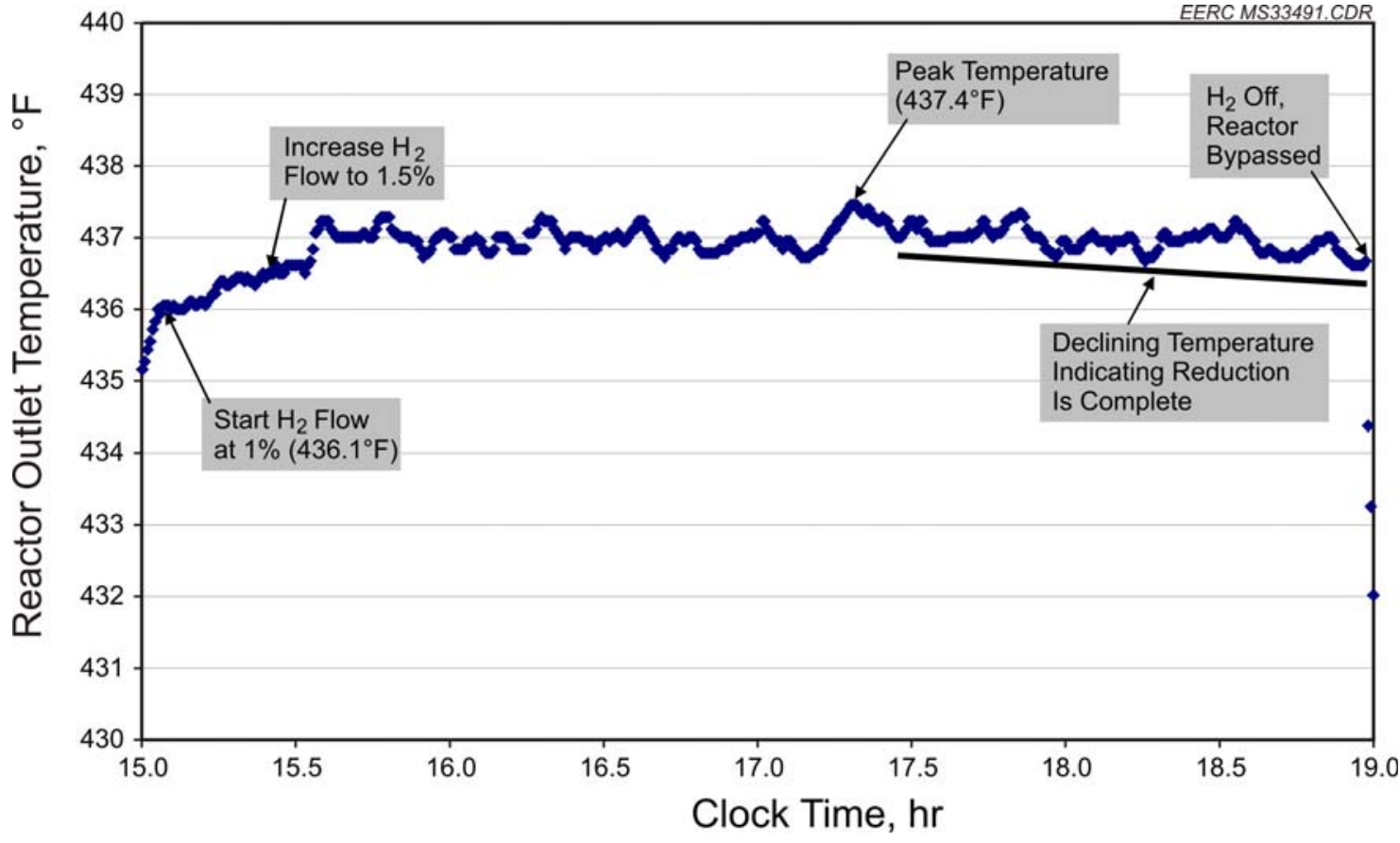

Figure A-40. Reduction of Corning Monolith 272. 


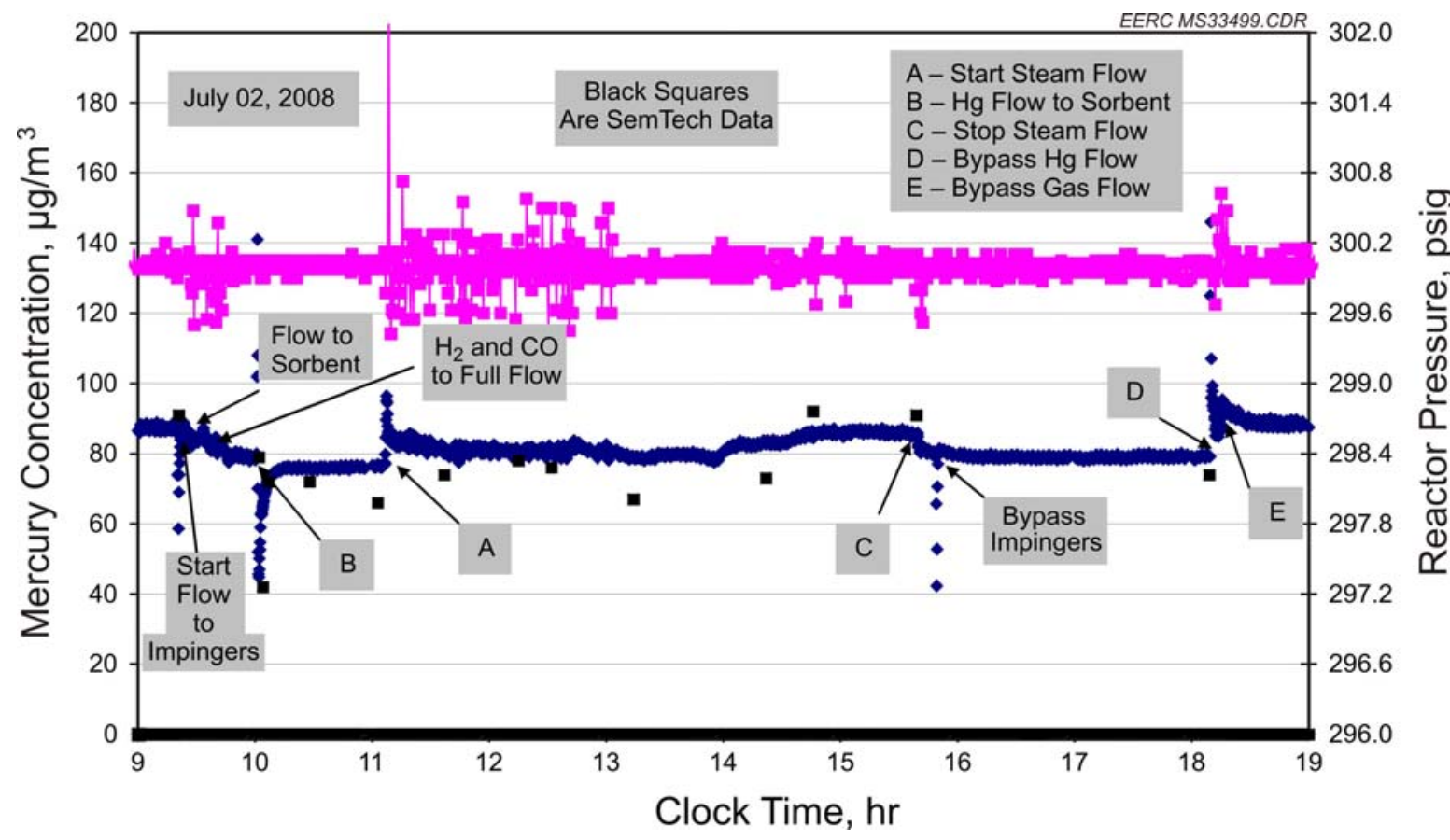

Figure A-41. Mercury sorption curve for Corning Monolith 272, $350^{\circ} \mathrm{F}$ and 300 psig (Test 42 ).

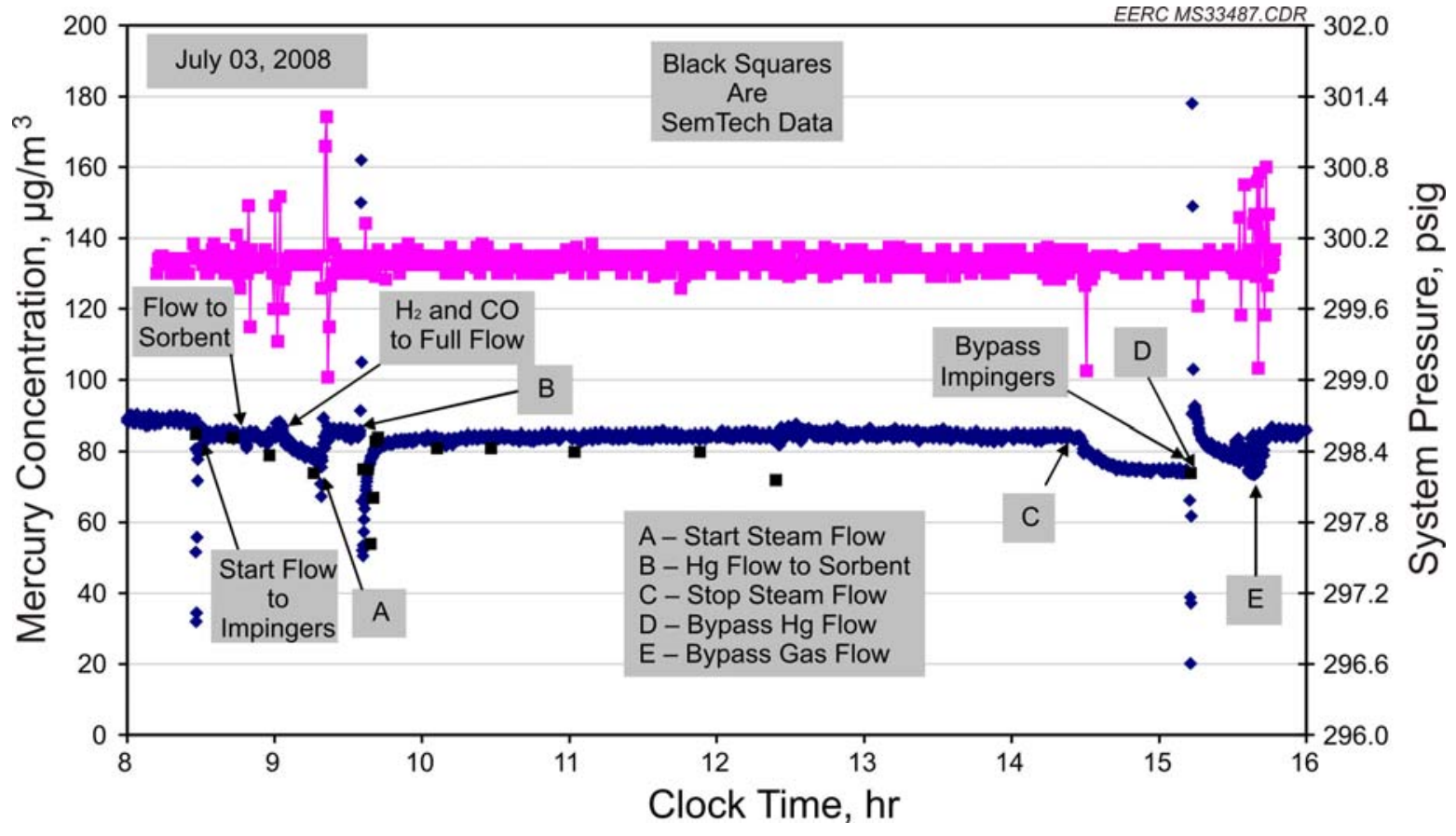

Figure A-42. Mercury sorption curve for Corning Monolith 272 (repeat), $350^{\circ} \mathrm{F}$ and 300 psig (Test 43). 


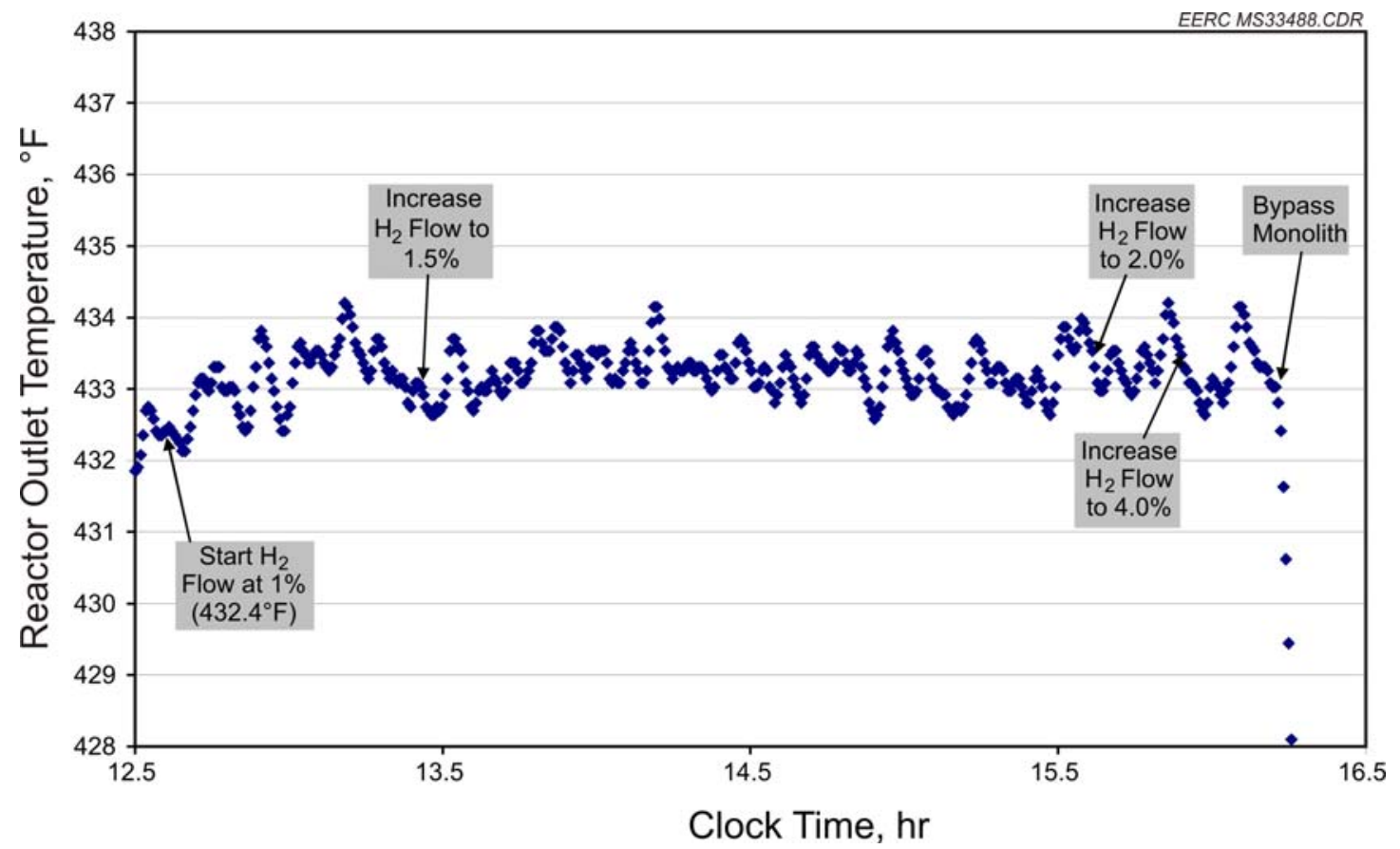

Figure A-43. Reduction of Corning Monolith 276.

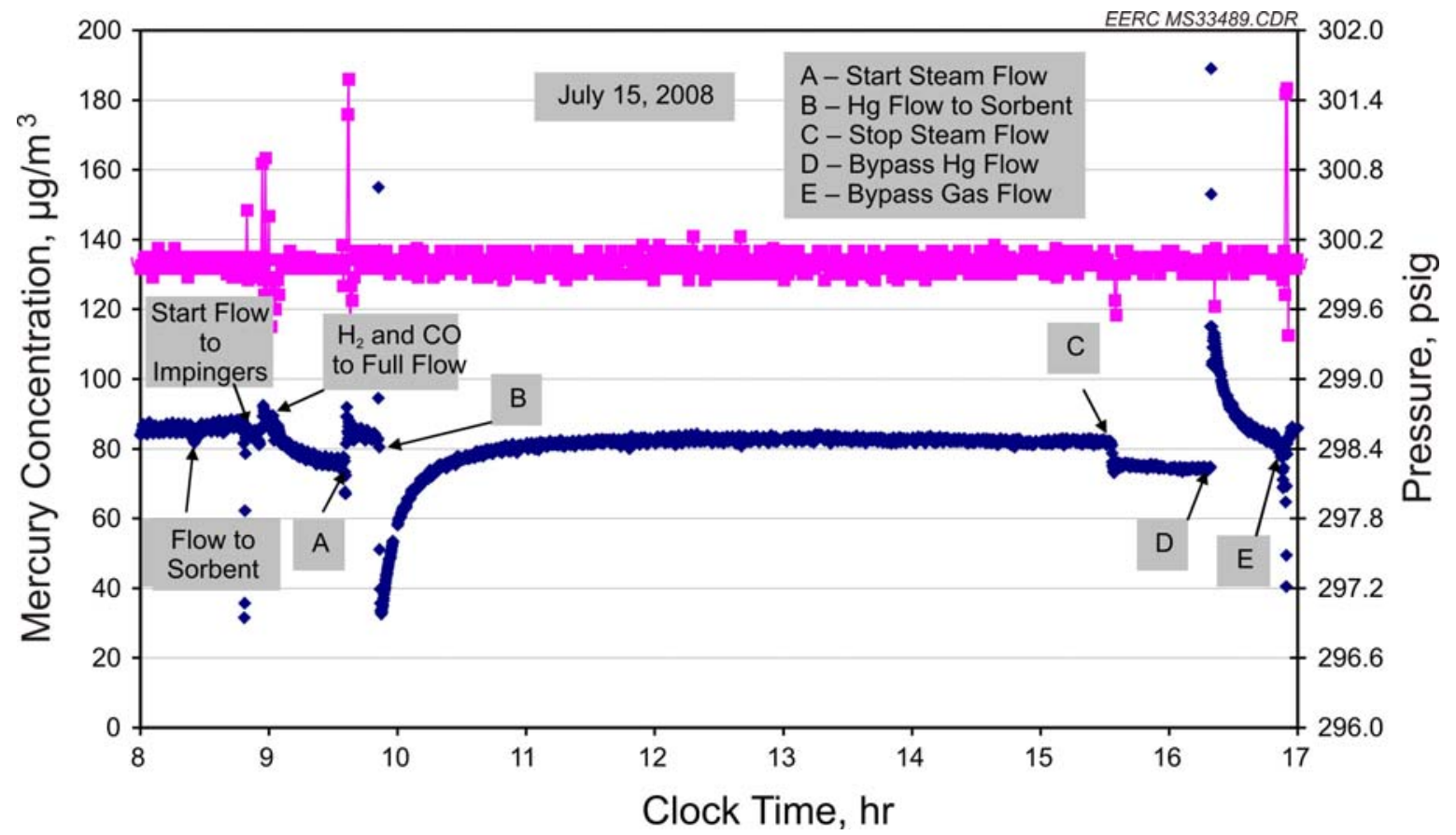

Figure A-44. Mercury sorption curve for Corning Monolith 276, $350^{\circ} \mathrm{F}$ and 300 psig (Test 44). 


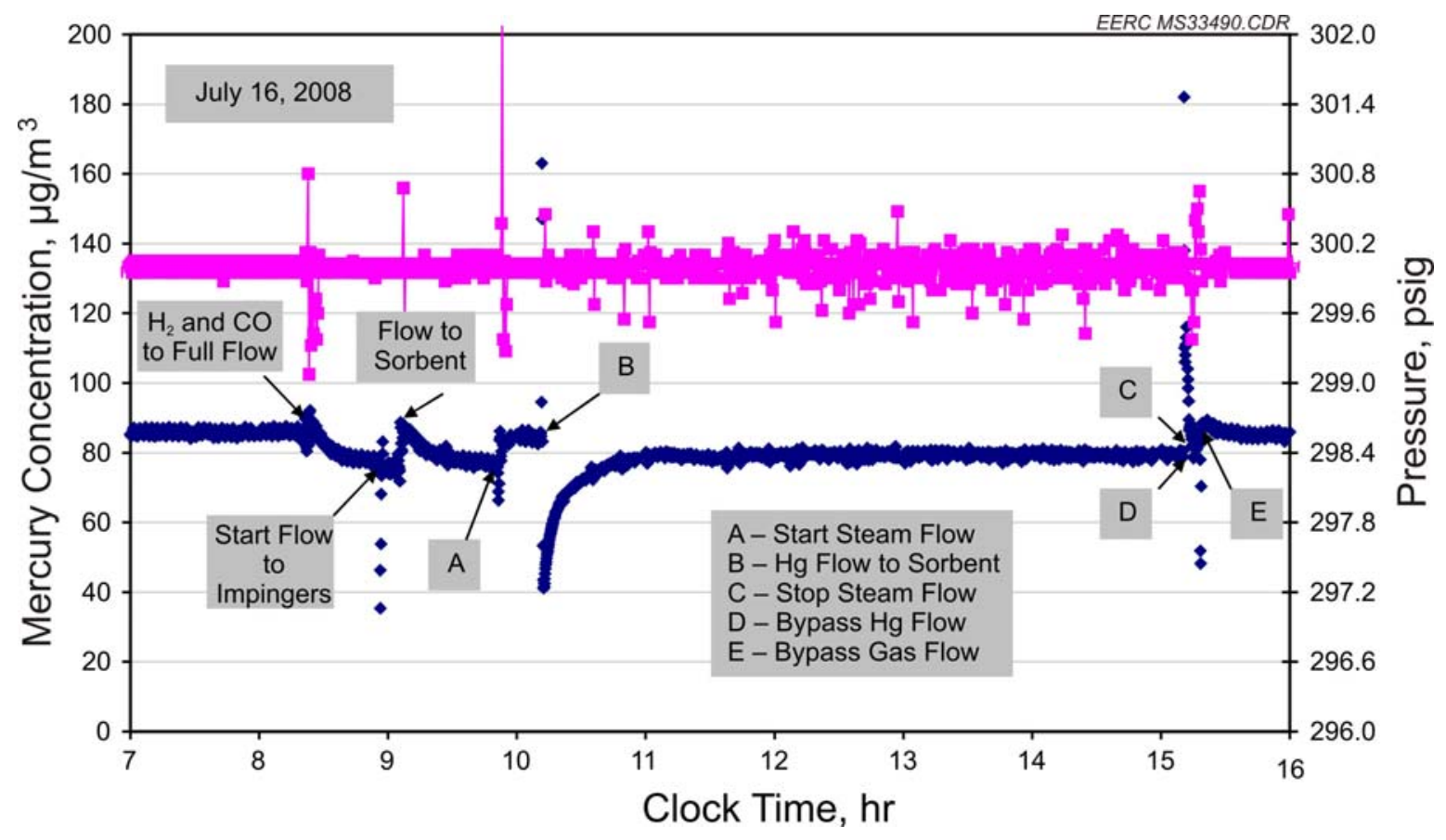

Figure A-45. Mercury sorption curve for Corning Monolith 276 (repeat), $350^{\circ} \mathrm{F}$ and 300 psig (Test 45$)$.

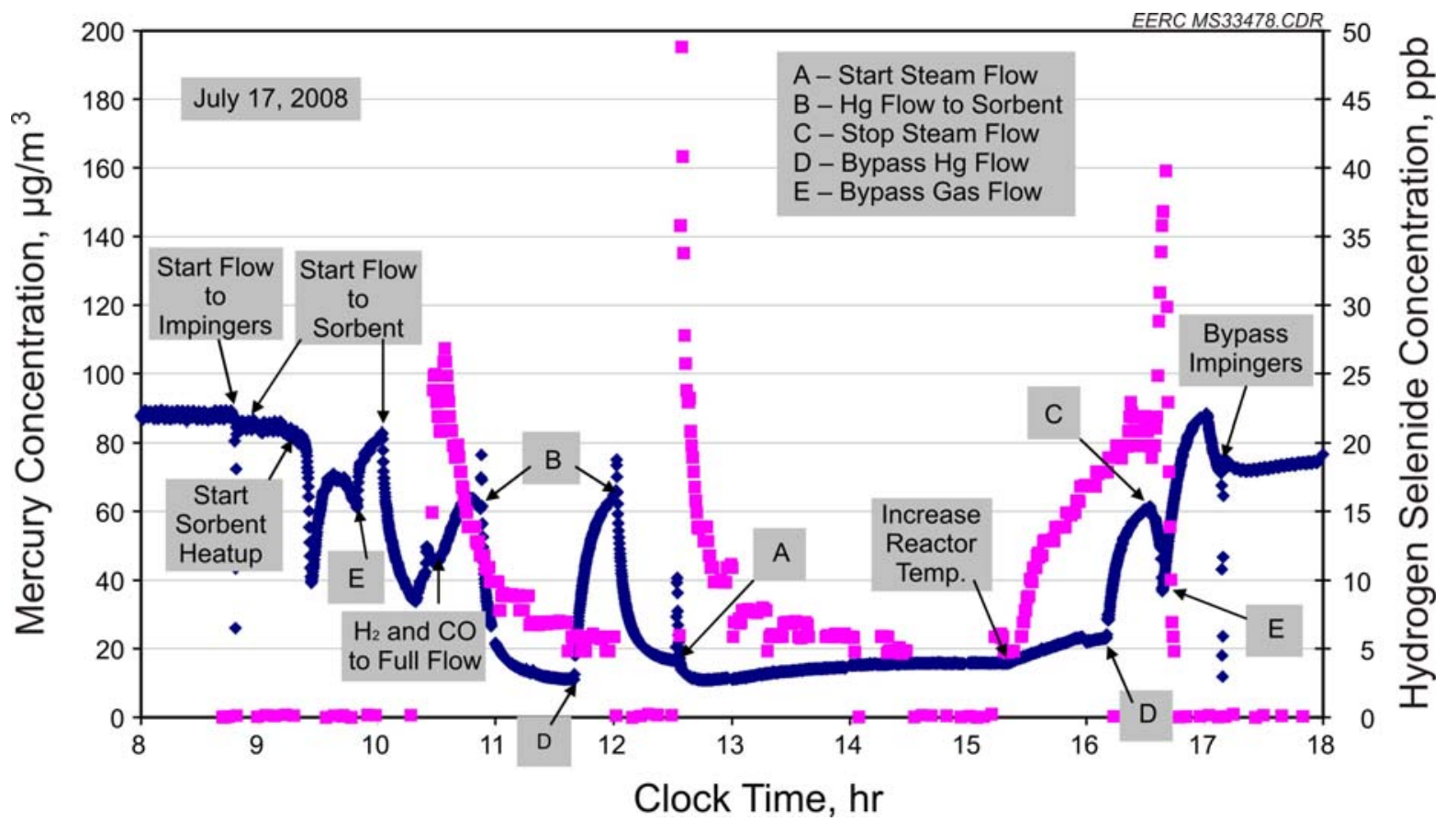

Figure A-46. Mercury sorption curve for EERC Sorbent - with Group IIB metal selenide on zeolite, $\mathrm{H}_{2}$ reduced (15615-23-1) $-350^{\circ}$ to $400^{\circ} \mathrm{F}$ and 300 psig (Test 46). 


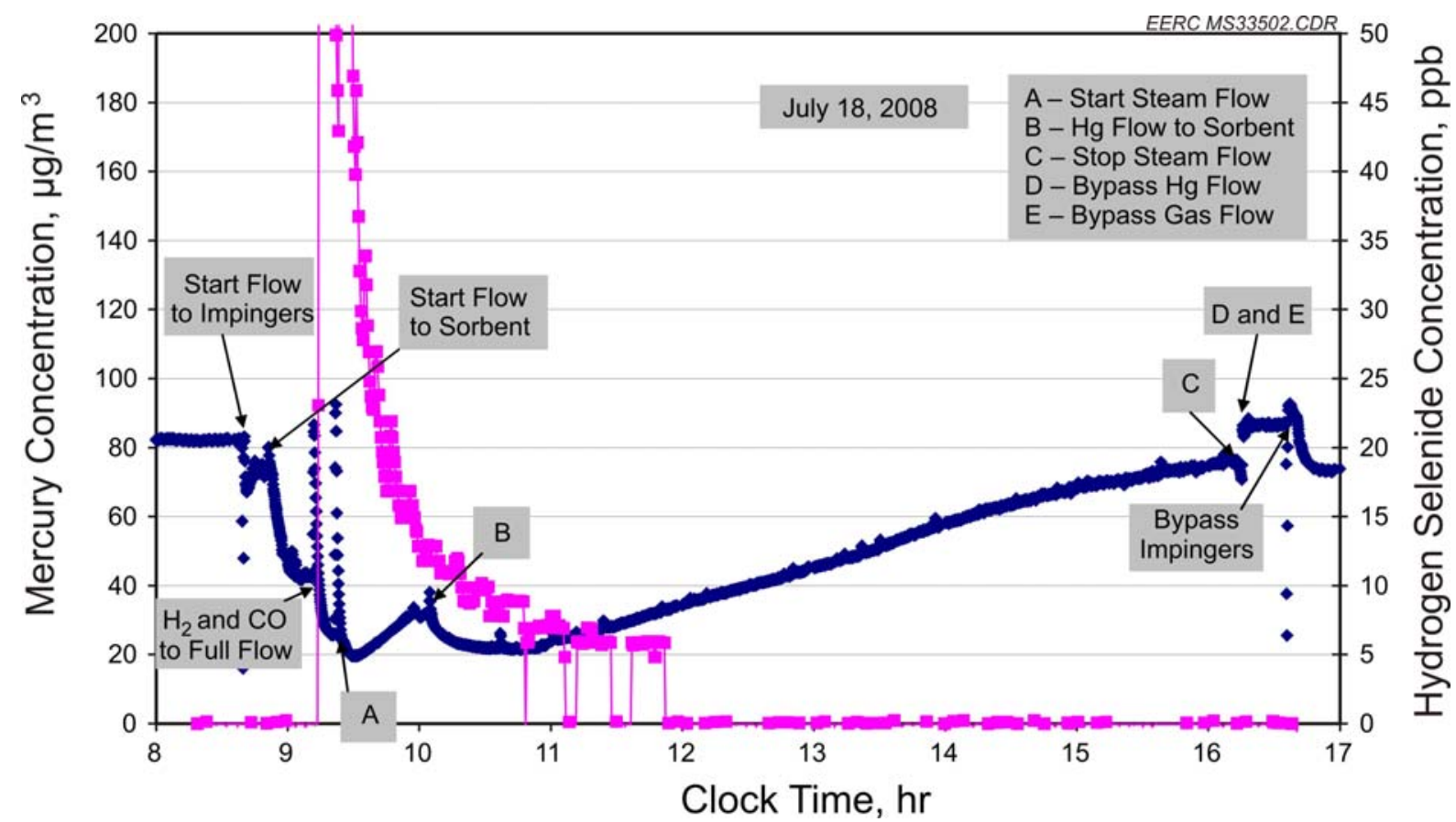

Figure A-47. Mercury sorption curve for EERC Sorbent - Group IIB metal selenide on zeolite, $\mathrm{H}_{2}$ reduced (15615-23-1) $-400^{\circ} \mathrm{F}$ and 300 psig (Test 47).

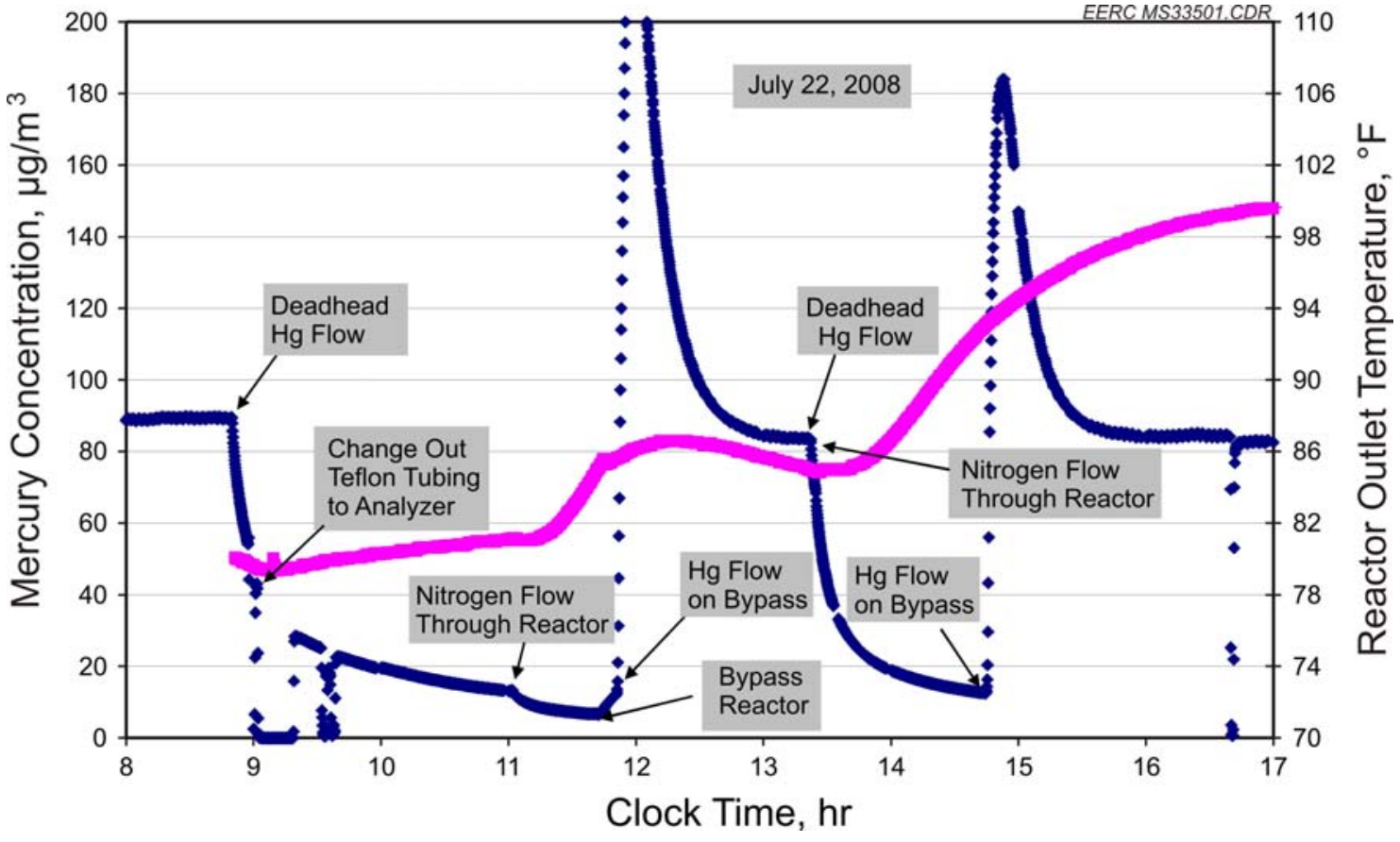

Figure A-48. 300 psig and hot box at ambient temperature. 


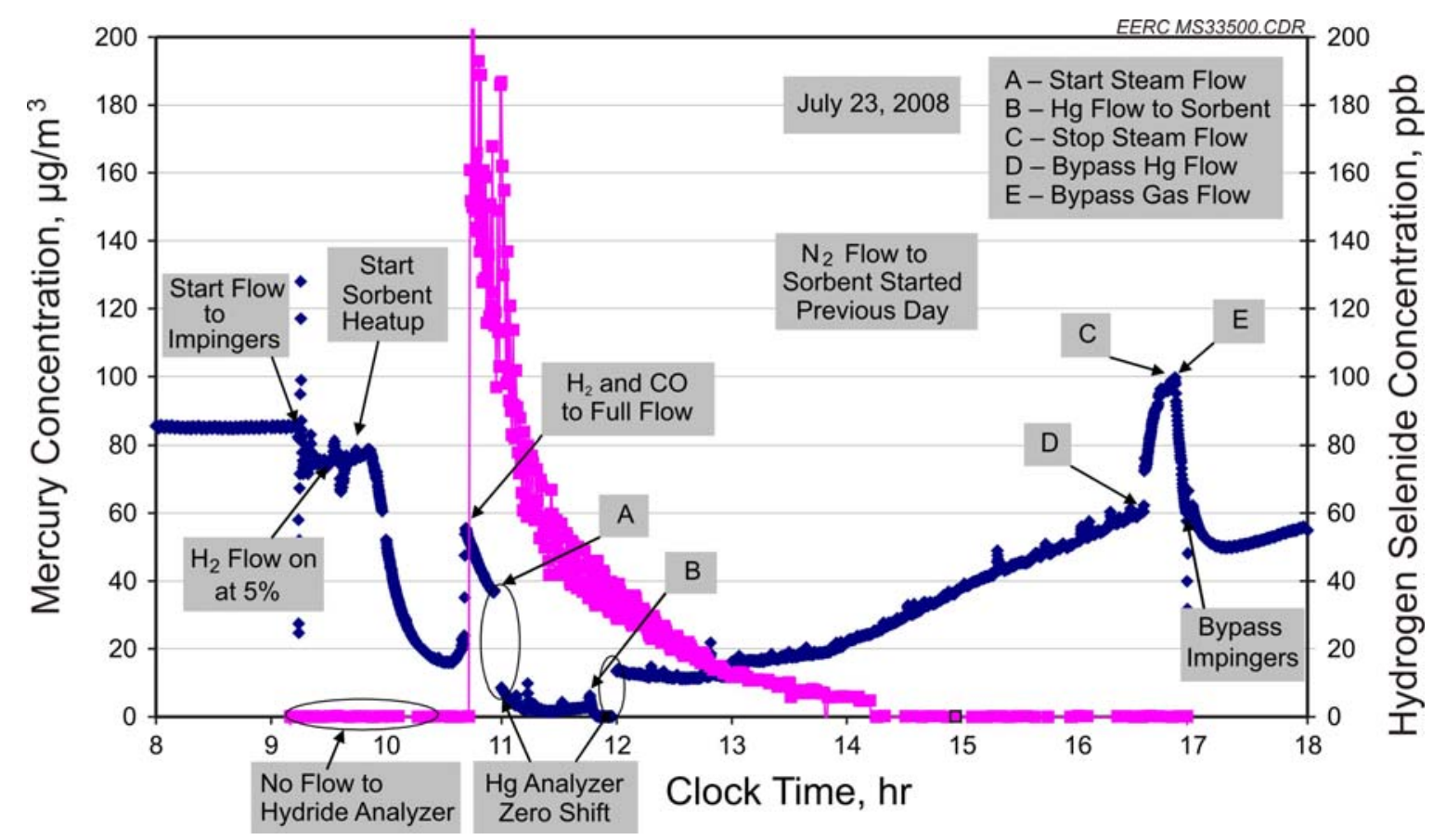

Figure A-49. Mercury sorption curve for EERC Sorbent - Group IB metal selenide on zeolite (15615-101-1) $-400^{\circ} \mathrm{F}$ and 300 psig (Test 48).

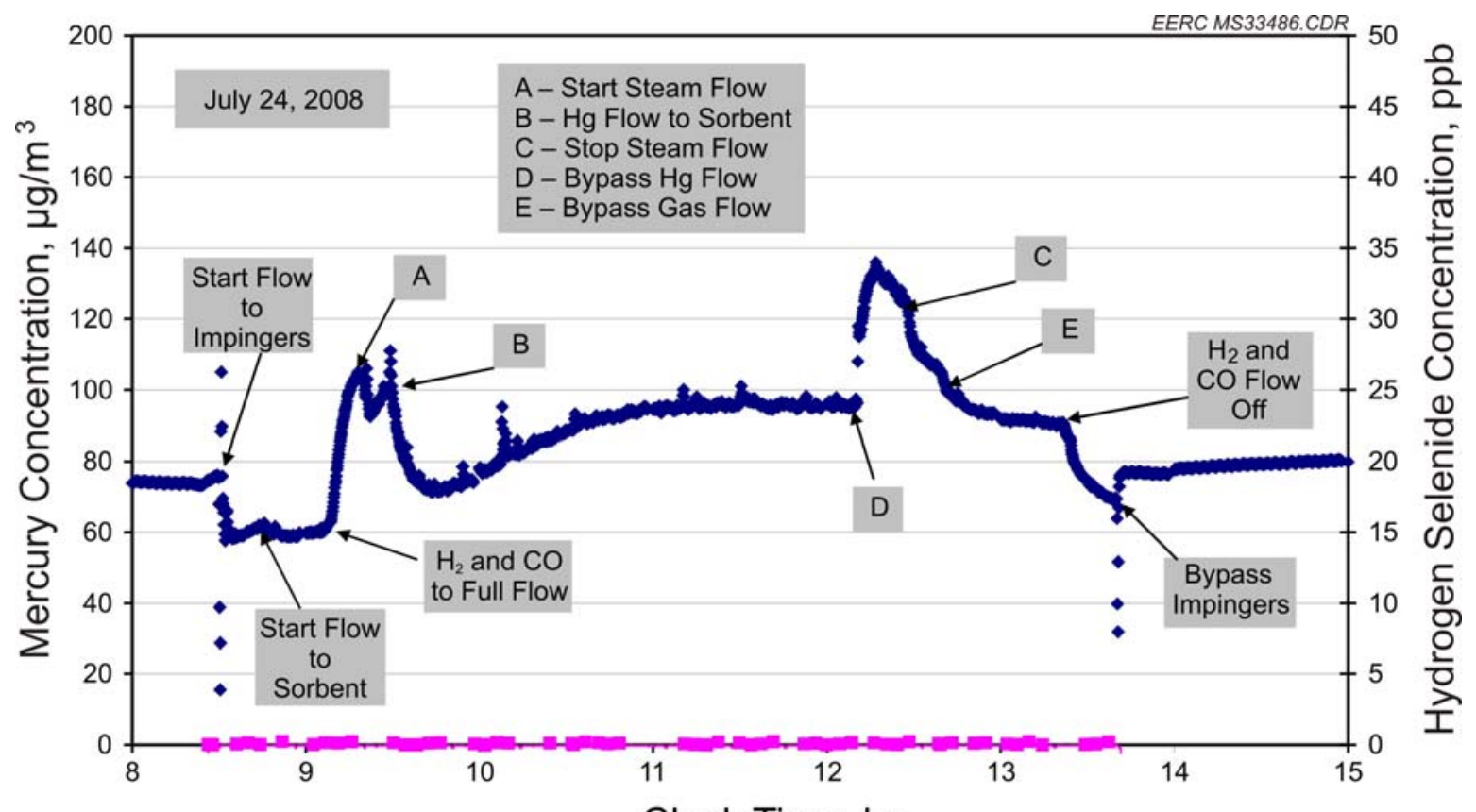

Figure A-50. Mercury sorption curve for EERC Sorbent - Group IB metal selenide on zeolite (15615-101-1) $-400^{\circ} \mathrm{F}$ and 300 psig (Test 49). 


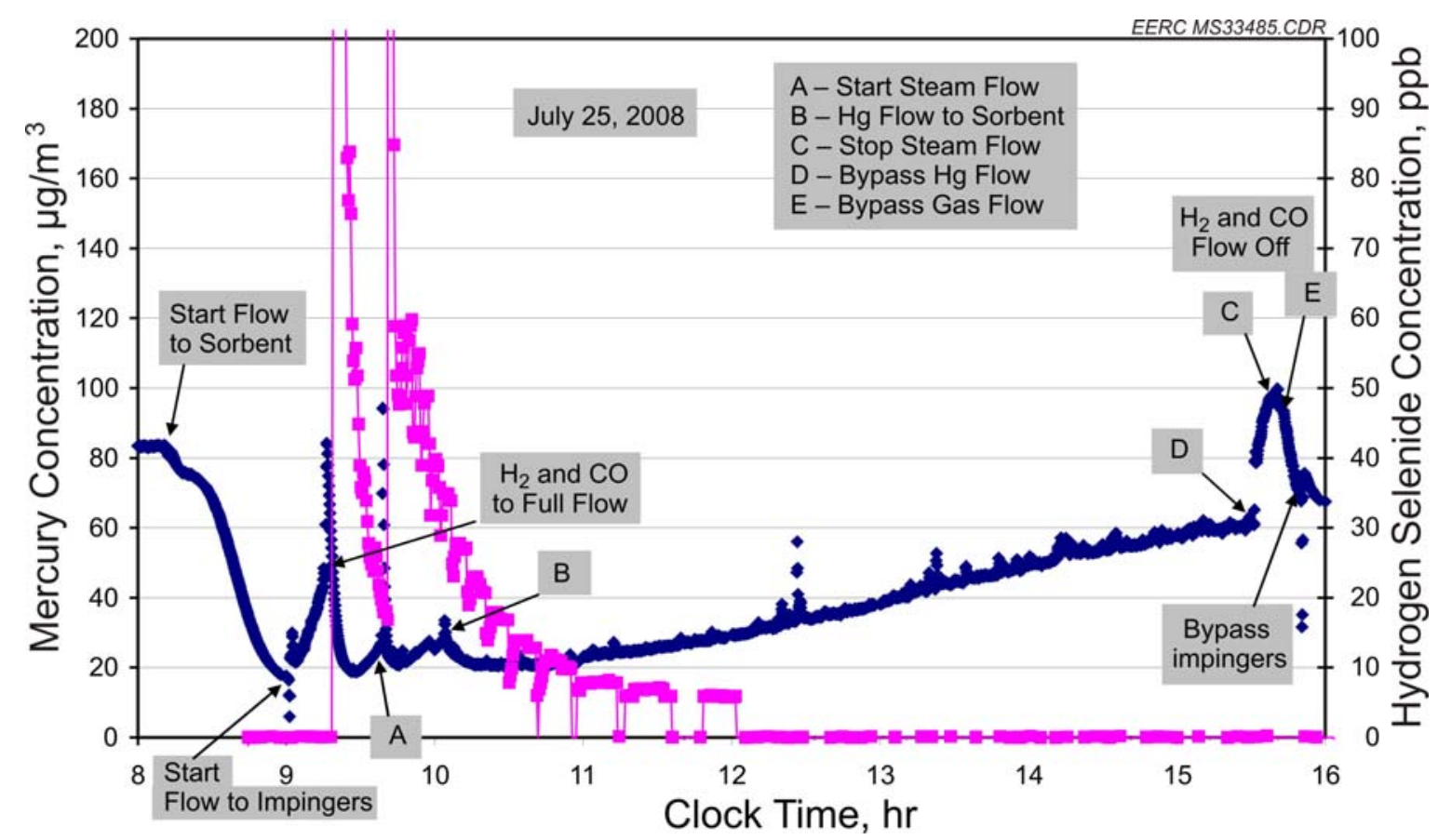

Figure A-51. Mercury sorption curve for EERC Sorbent - Group IIB metal selenide on zeolite, hydrazine reduced (15615-22-1) $-400^{\circ} \mathrm{F}$ and 300 psig (Test 50).

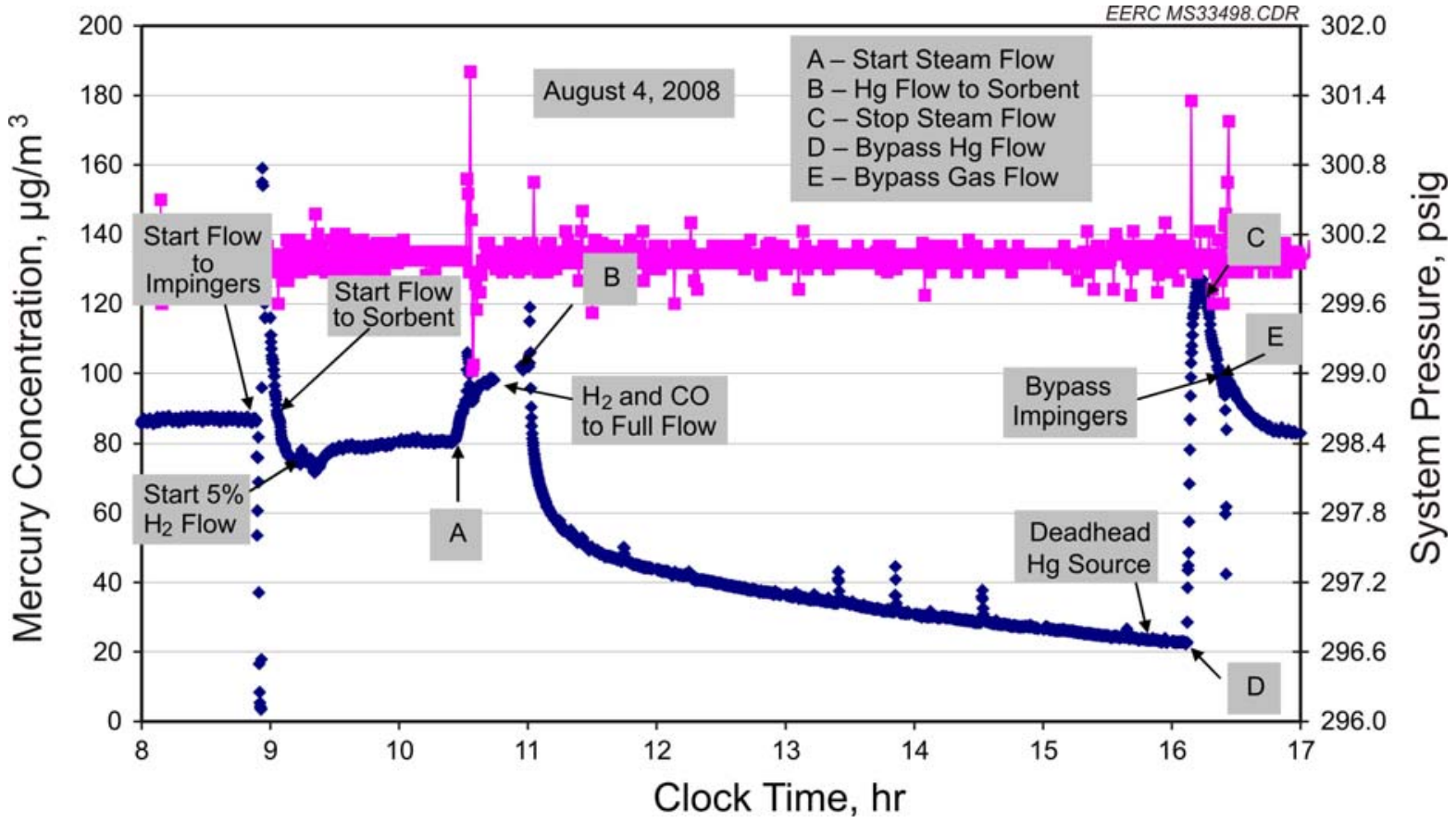

Figure A-52. Mercury sorption curve for Corning Monolith SR Liquid 283, $350^{\circ} \mathrm{F}$ and 300 psig (Test 51). 


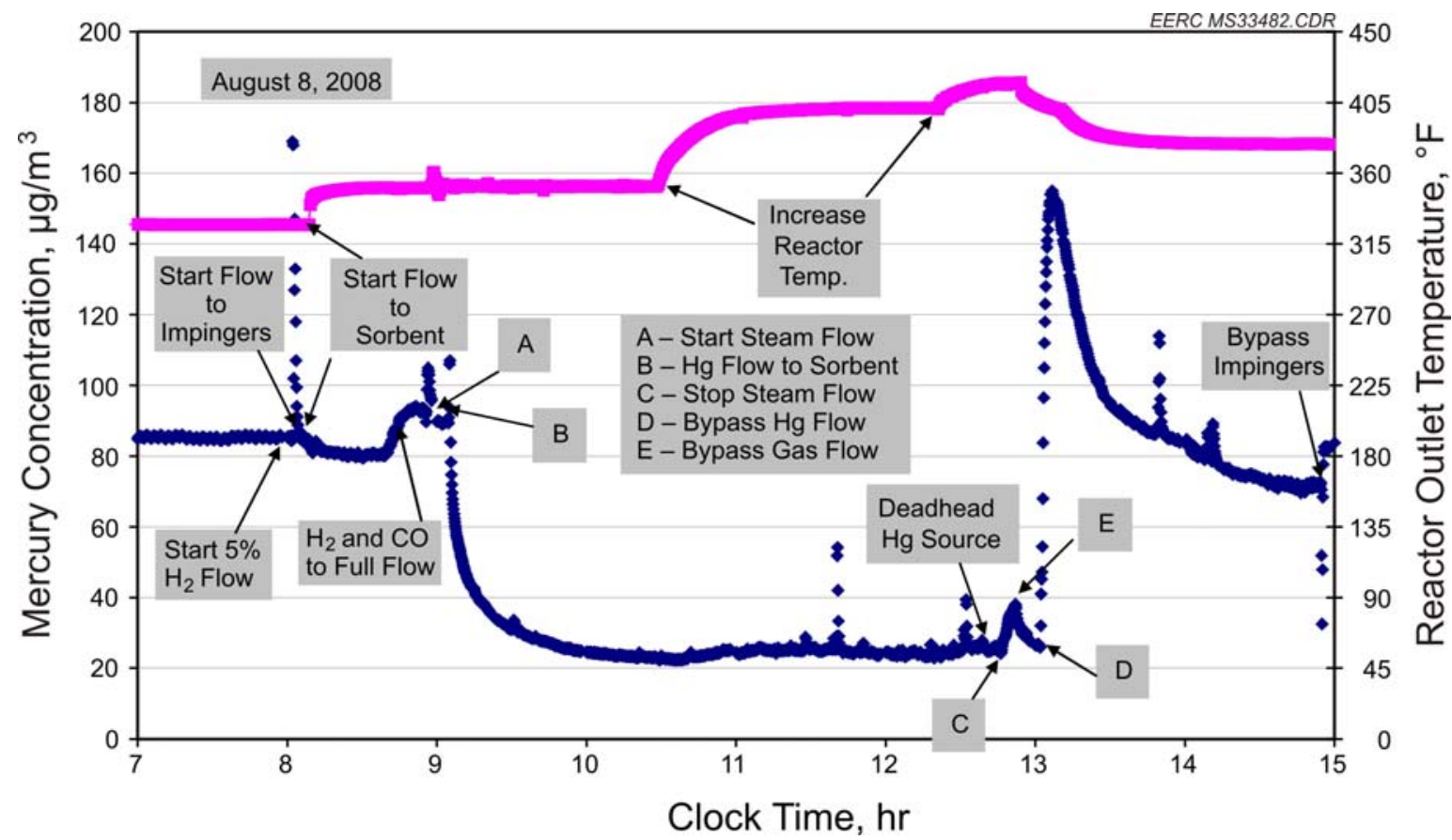

Figure A-53. Mercury sorption curve for Corning Monolith SR Liquid 283, $350^{\circ}-400^{\circ} \mathrm{F}$ and 300 psig (Test 52).

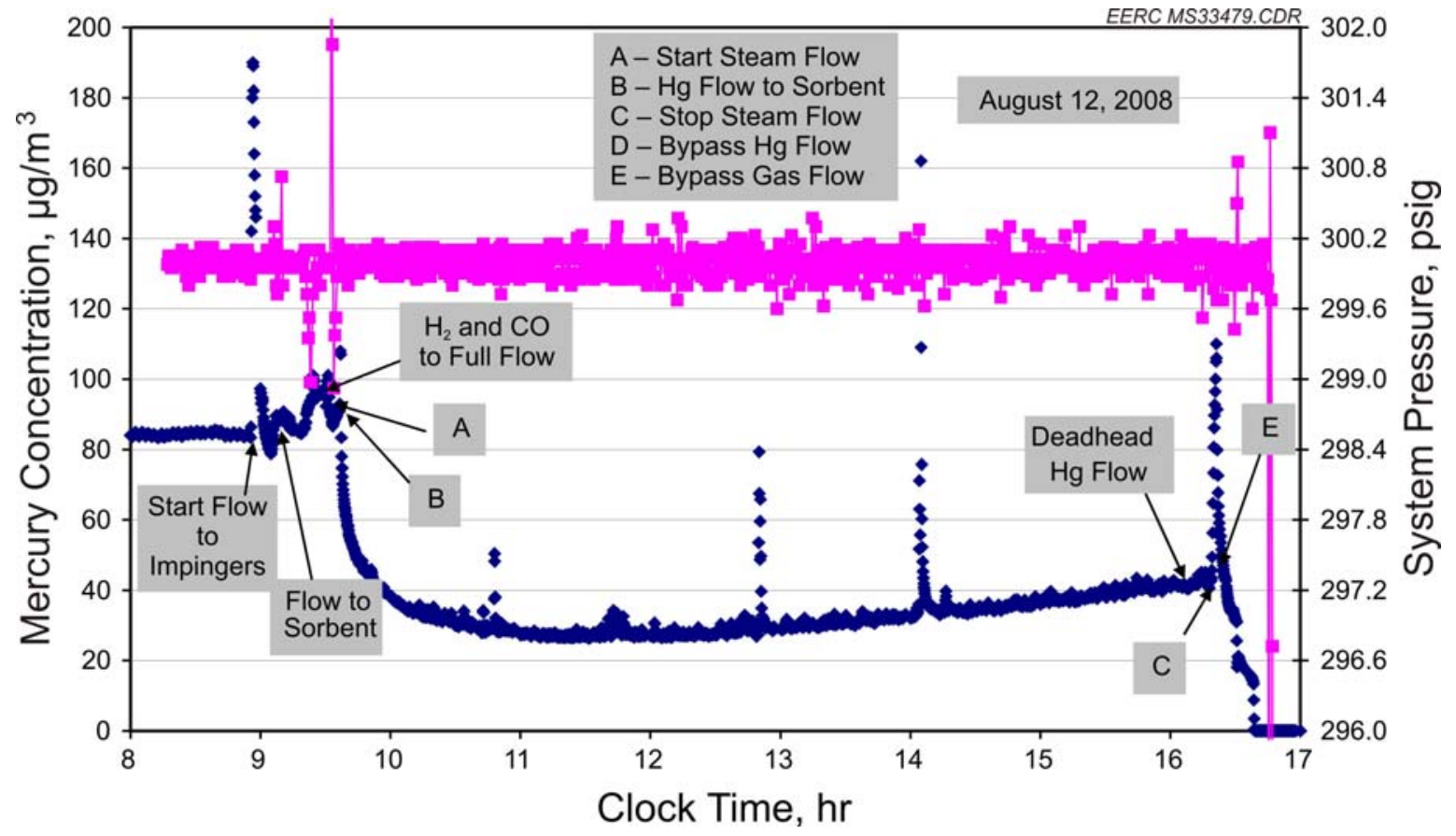

Figure A-54. Mercury sorption curve for Corning Monolith SR Liquid 283, $400^{\circ} \mathrm{F}$ and 300 psig (Test 53). 


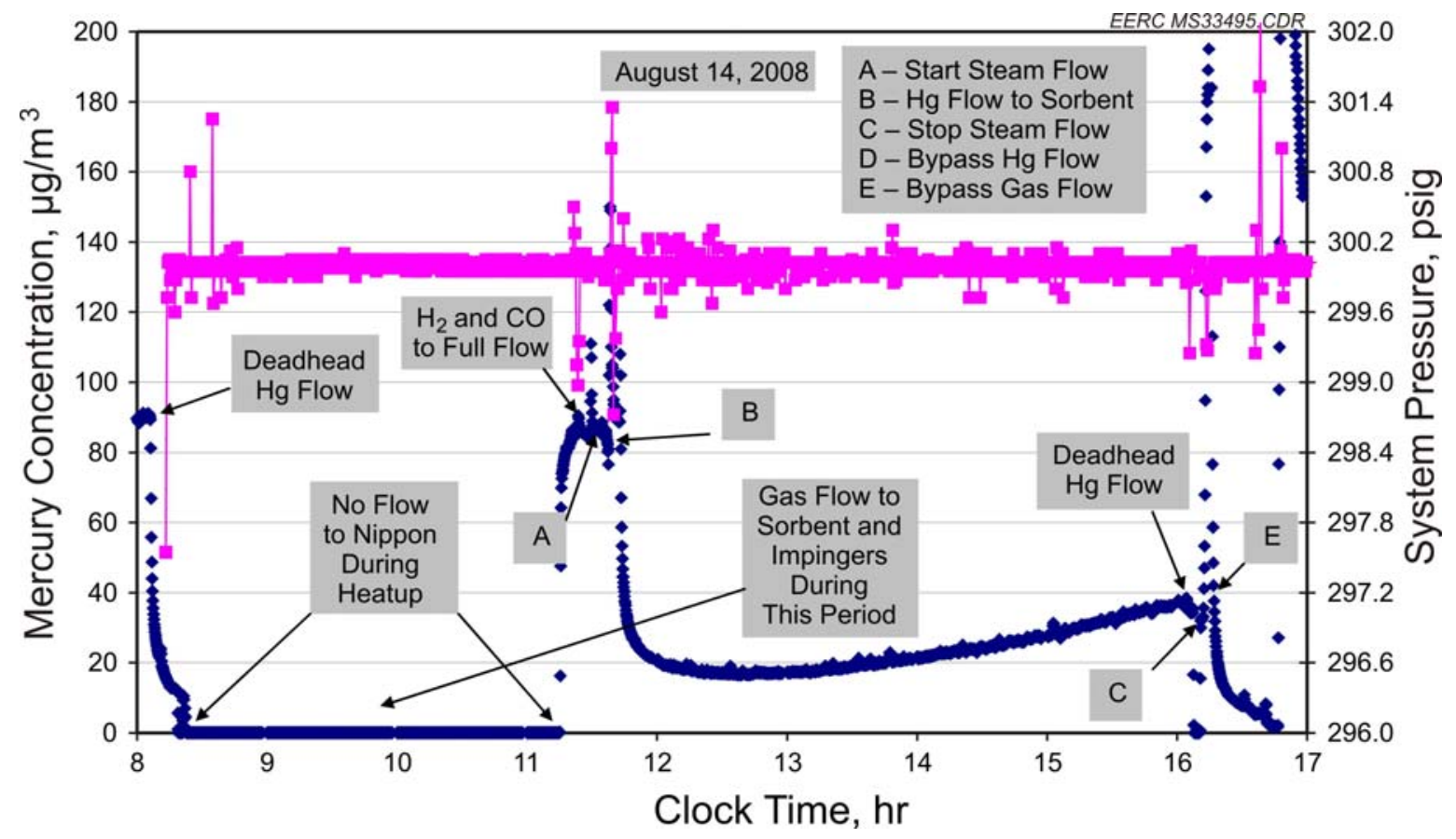

Figure A-55. Mercury sorption curve for Corning Monolith SR Liquid 283, $400^{\circ} \mathrm{F}$ and 300 psig (Test 54).

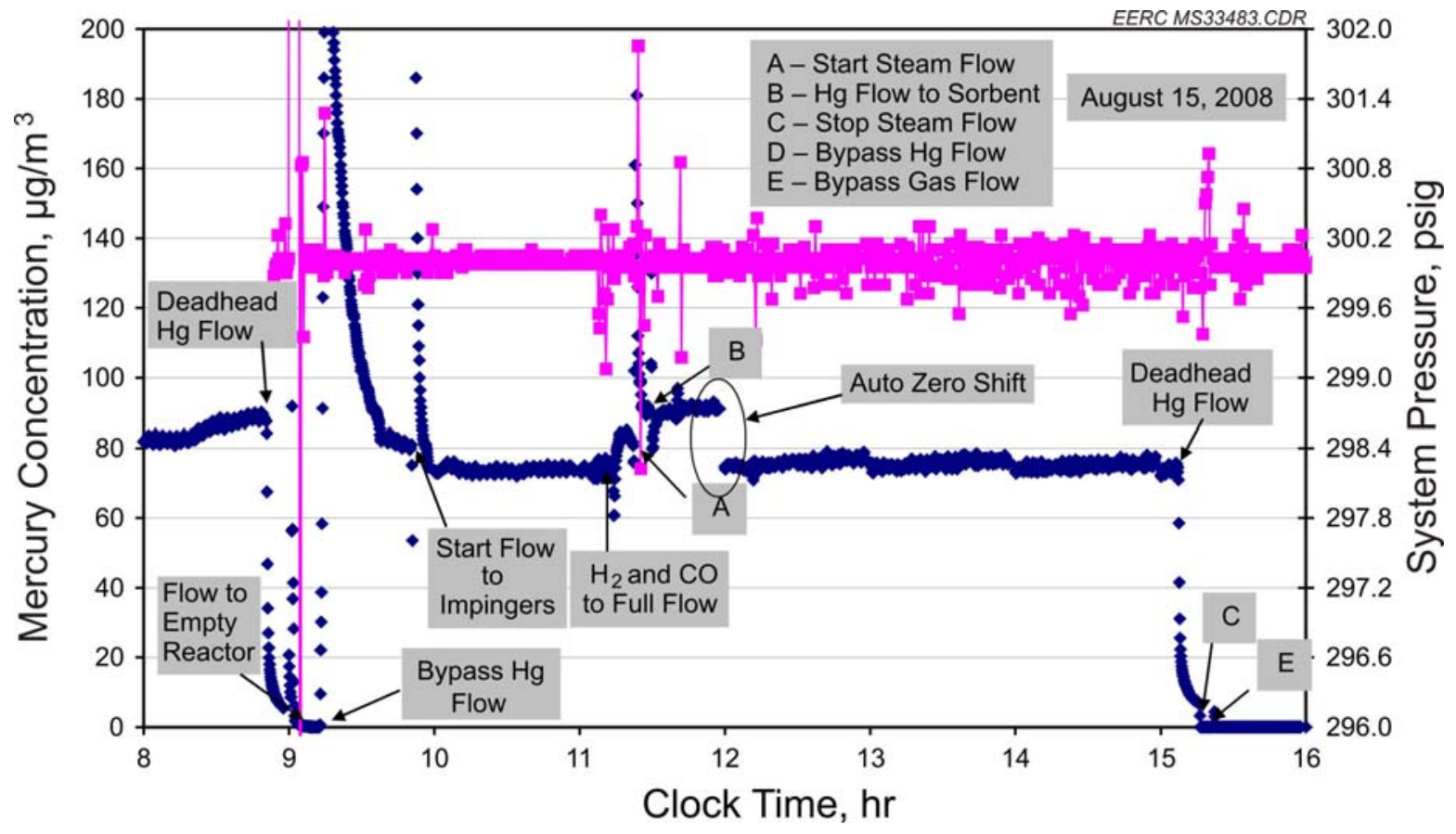

Figure A-56. Empty 1-inch reactor, $400^{\circ} \mathrm{F}$ and 300 psig (Test 55). 


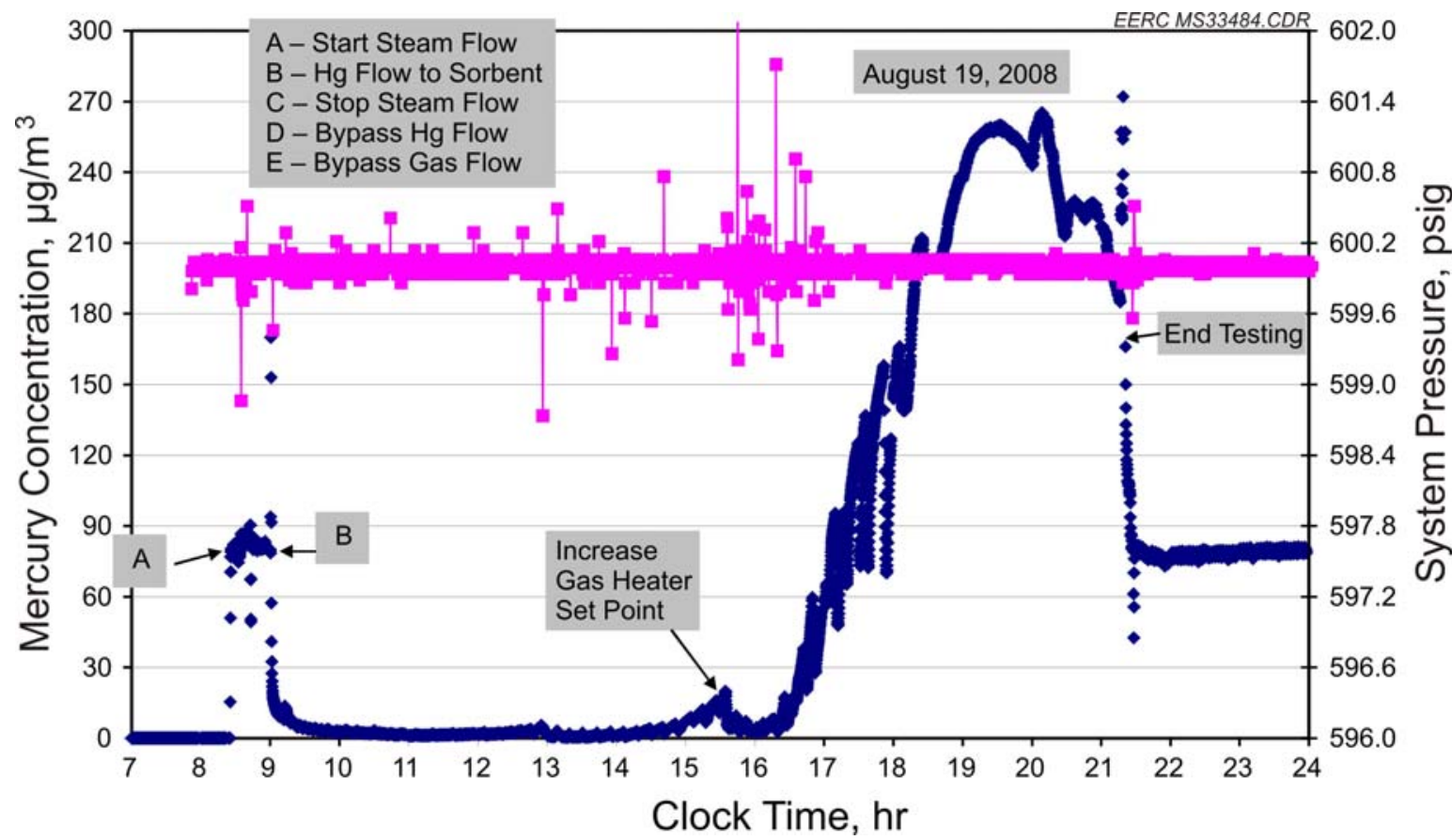

Figure A-57. Mercury sorption curve for Corning Monolith SR Liquid 283 and $284,400^{\circ} \mathrm{F}$ and 600 psig (Test 56).

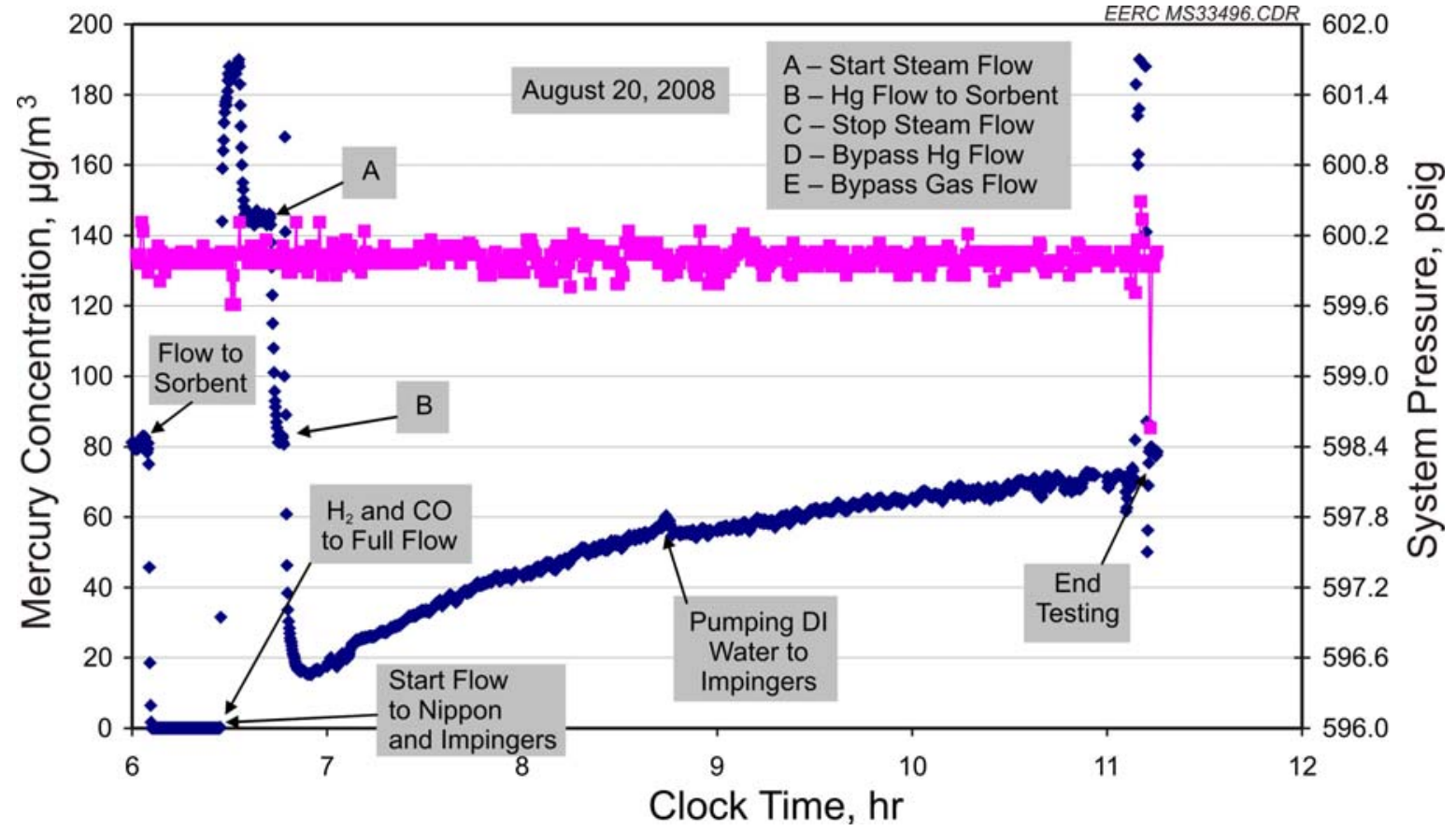

Figure A-58. Mercury sorption curve for Corning Monolith SR Liquid 283 and 284, $400^{\circ} \mathrm{F}$ and 600 psig (Test 57). 


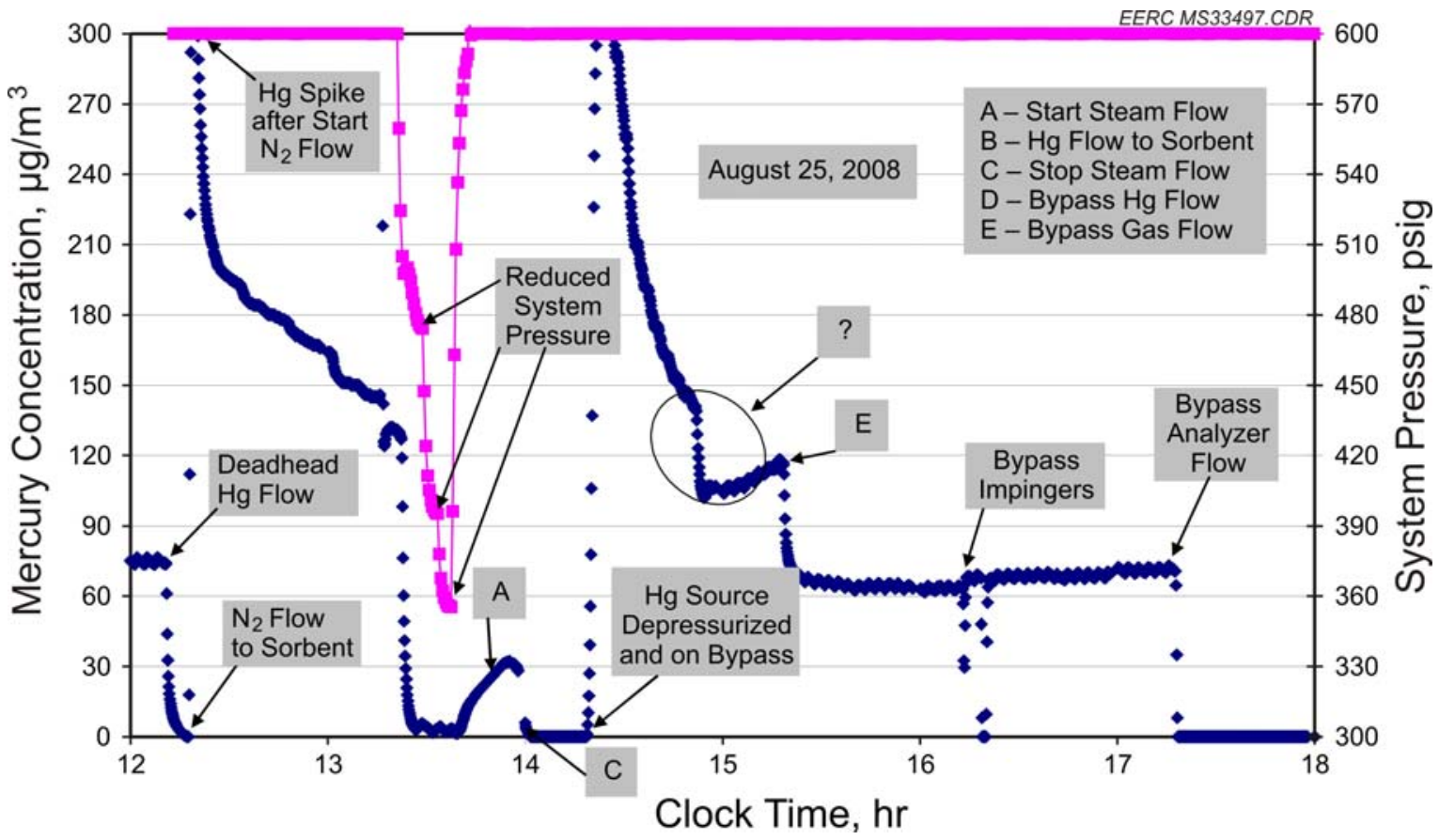

Figure A-59. Mercury sorption curve for SR Liquid Monoliths 283 and 284; attempt at mercury desorption (Test 58).

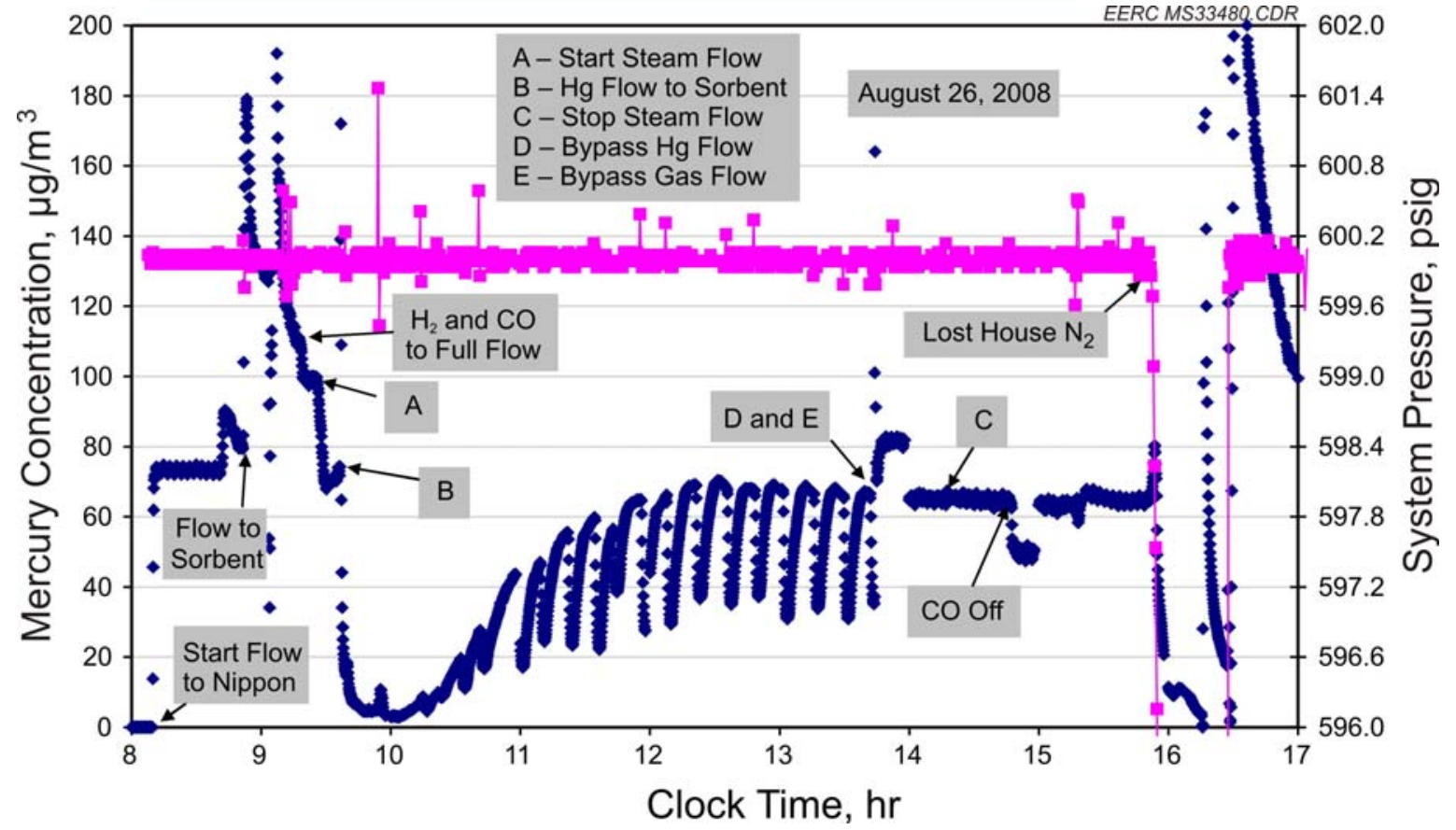

Figure A-60. Mercury sorption curve for Corning Monoliths SR Liquid 283 and 284, $400^{\circ} \mathrm{F}$ and 600 psig (Test 59). 


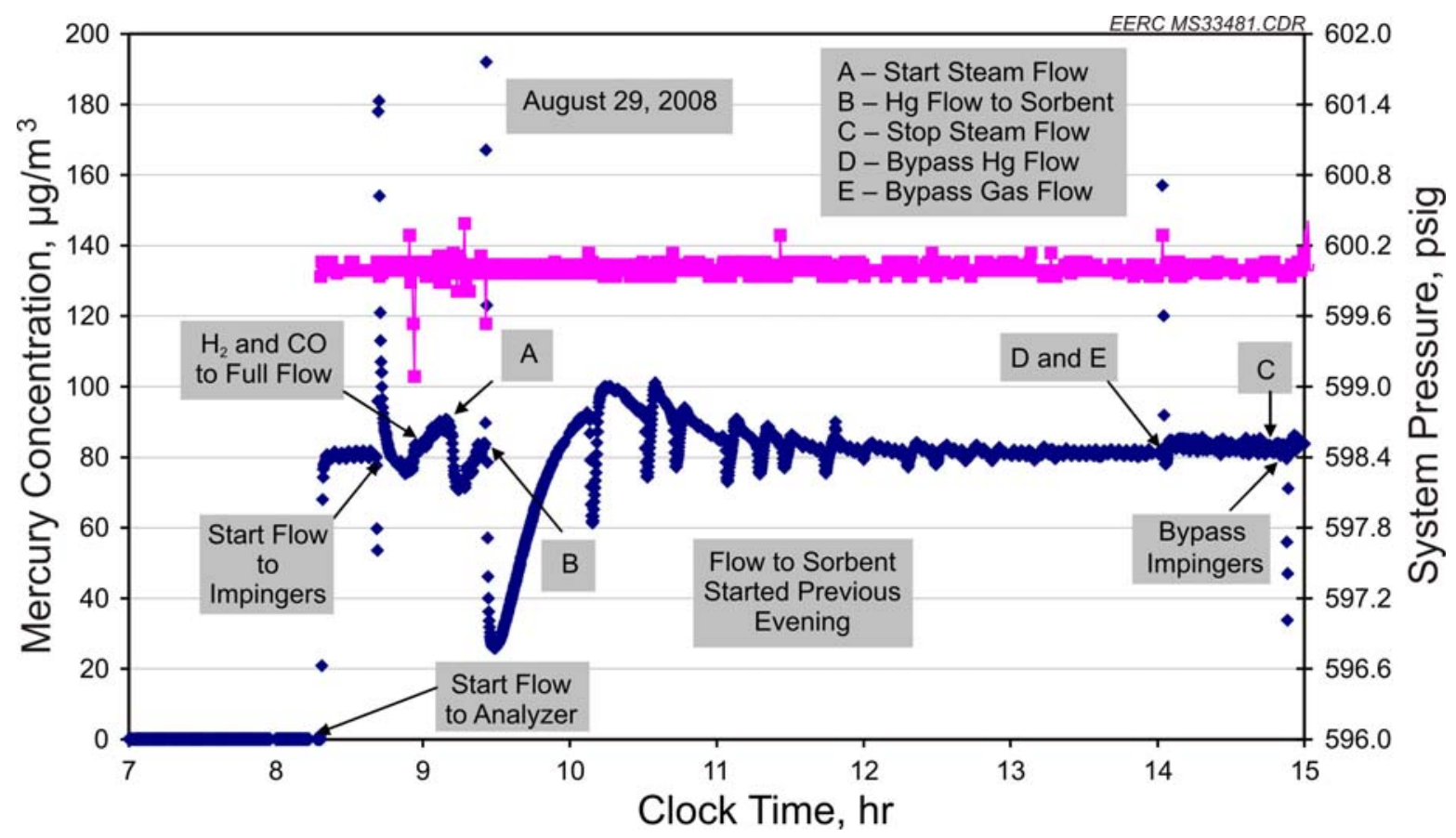

Figure A-61. Mercury sorption curve for Corning Monolith SR Liquid 282, $400^{\circ} \mathrm{F}$ and 600 psig (Test 60).

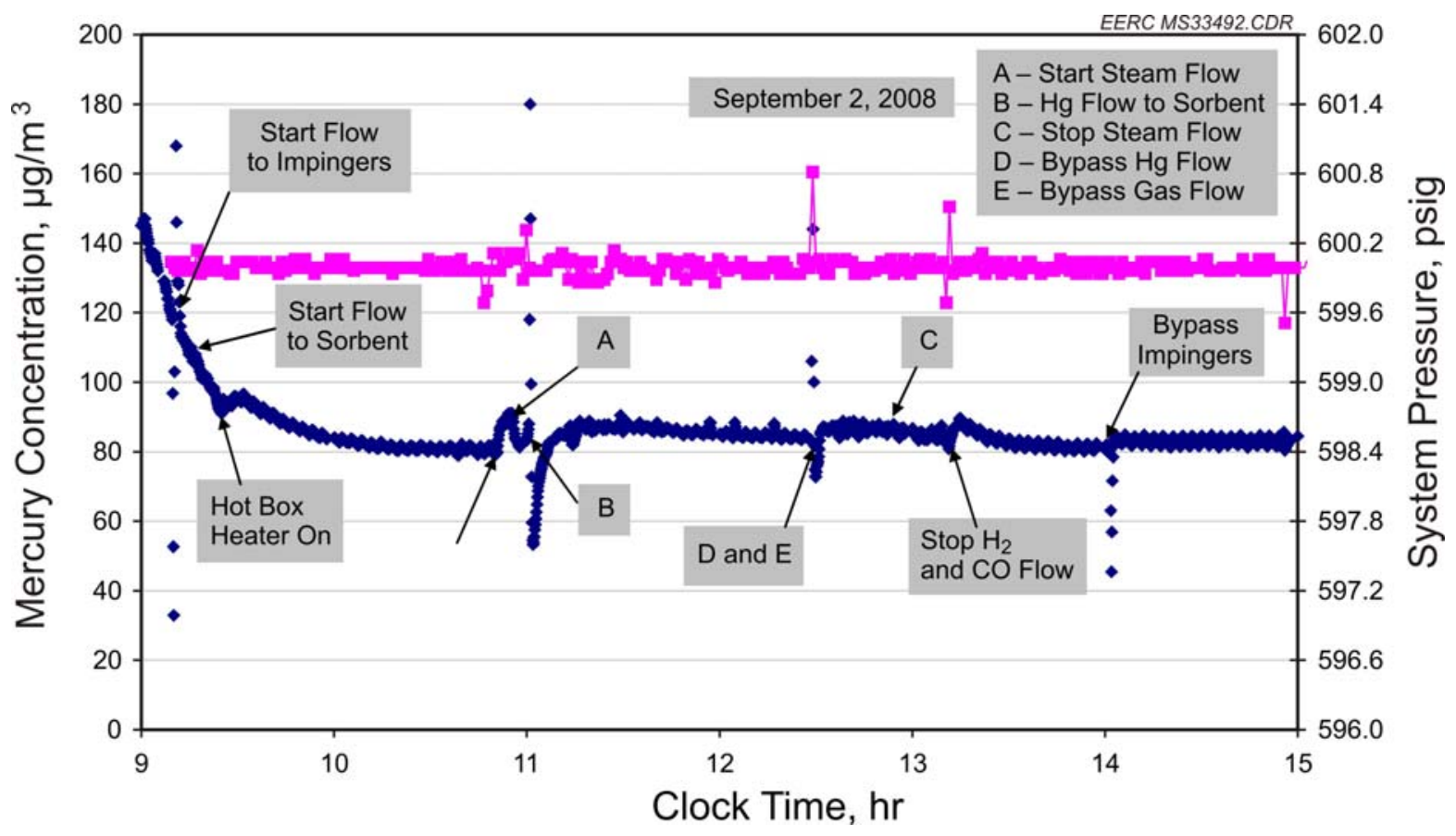

Figure A-62. Mercury sorption curve for Corning Monolith SR Liquid 282, $400^{\circ} \mathrm{F}$ and 600 psig (Test 61). 


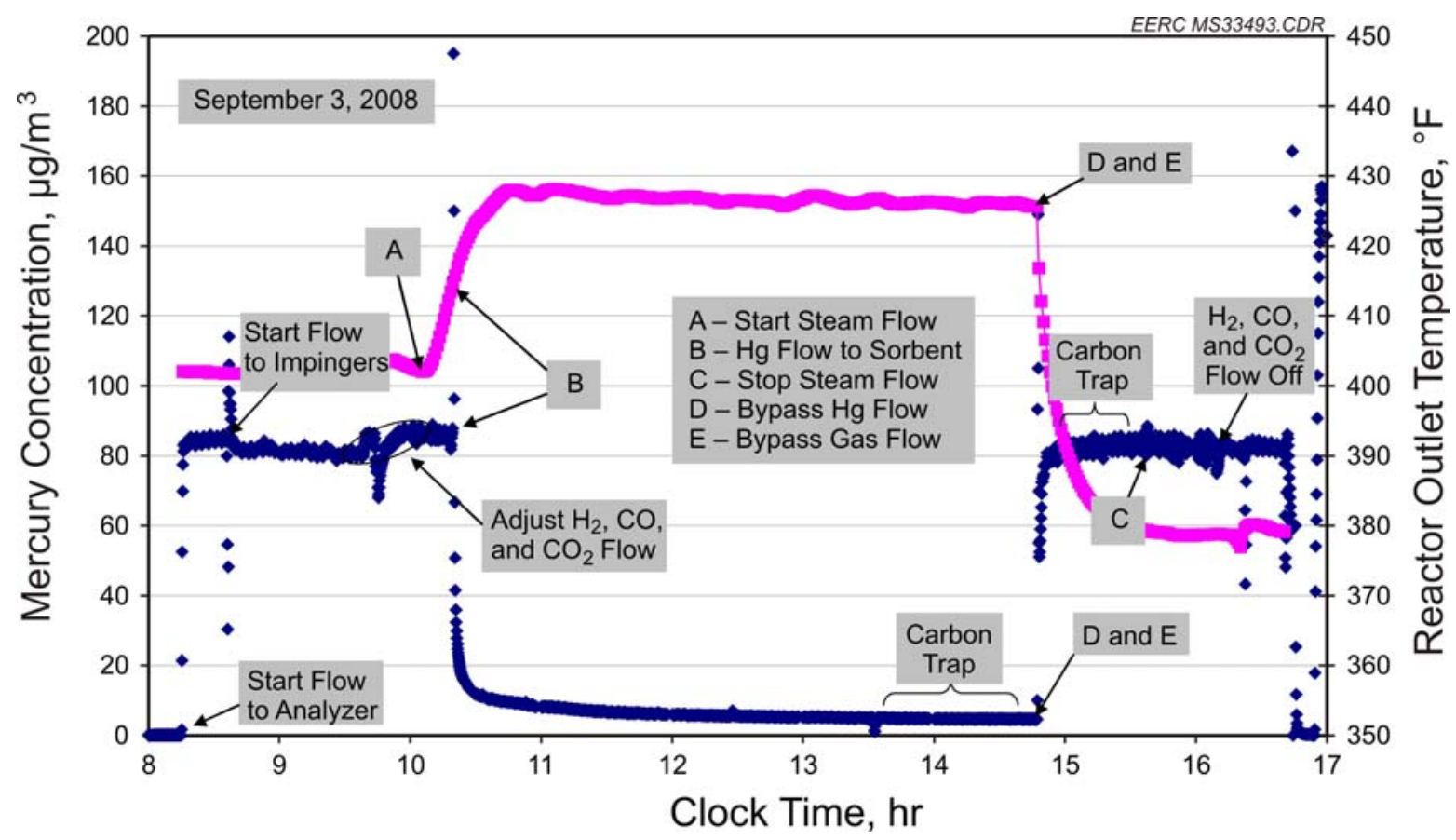

Figure A-63. Mercury sorption curve for EERC Noncarbon Sorbent $1,400^{\circ} \mathrm{F}$ and 600 psig (Test 62).

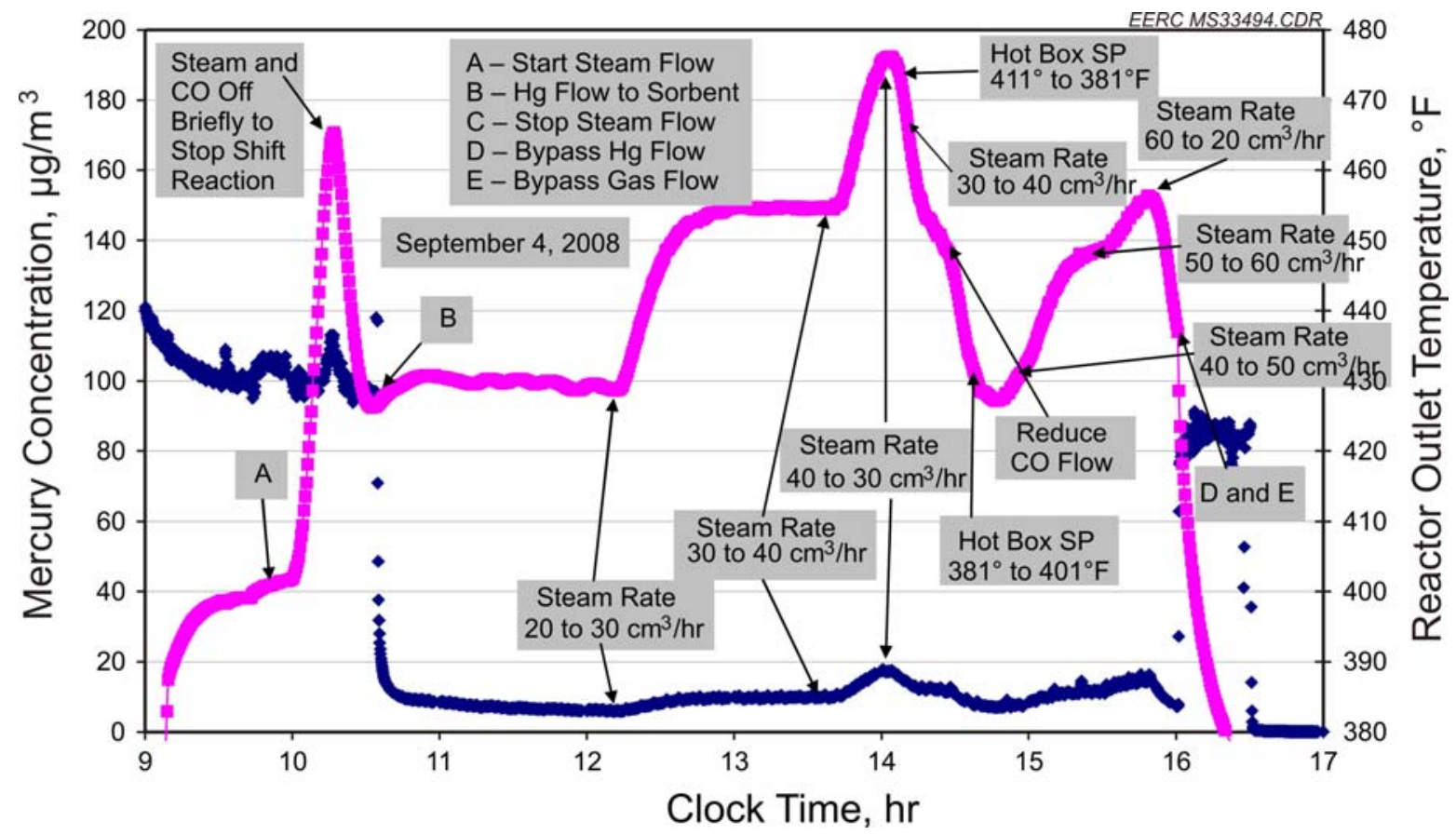

Figure A-64. Mercury sorption curve for EERC Noncarbon Sorbent 1, 600 psig (Test 63). 


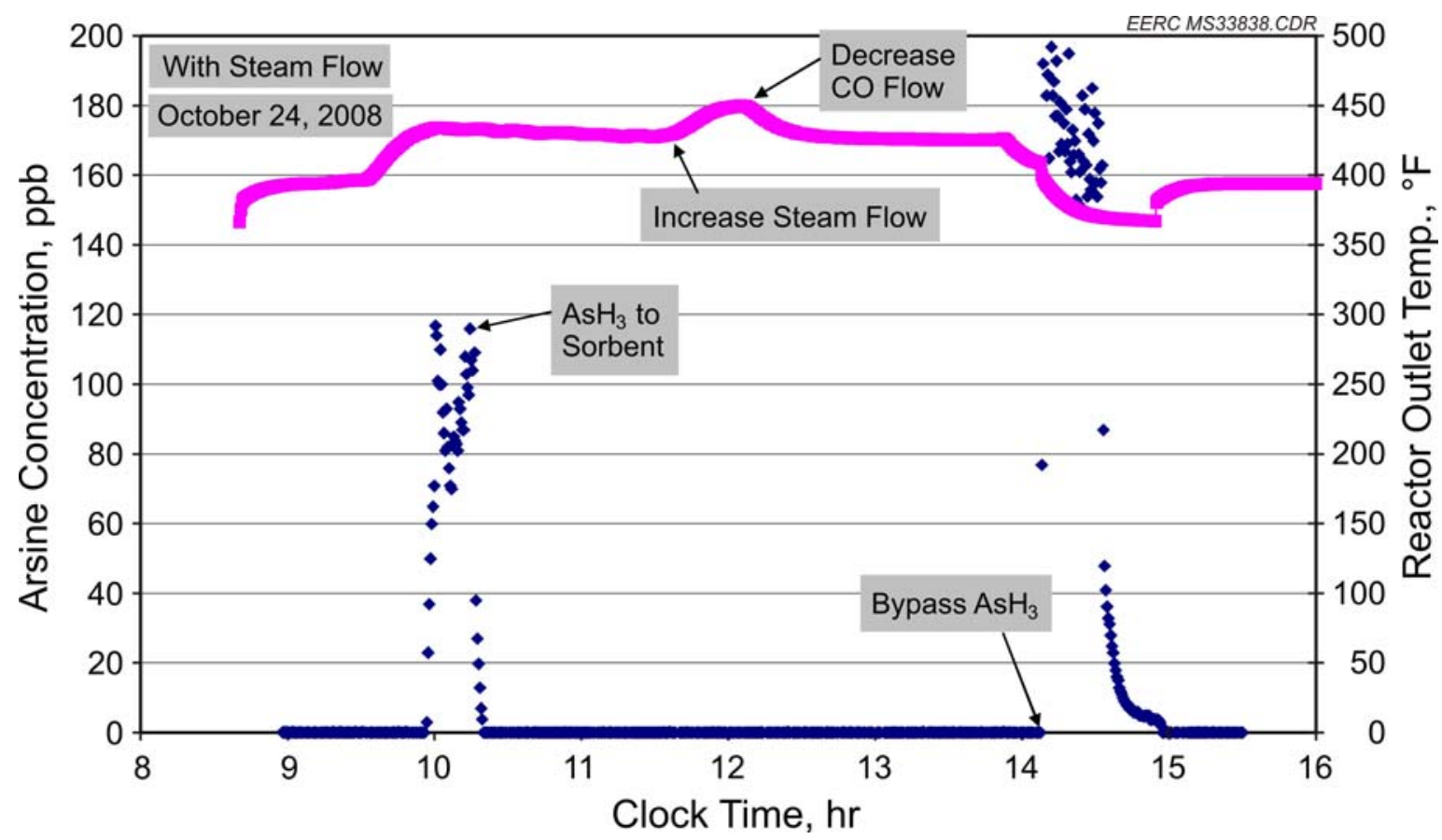

Figure A-65. Arsine sorption curve for EERC Noncarbon Sorbent 1 at $400^{\circ} \mathrm{F}$ and 600 psig (Test 64).

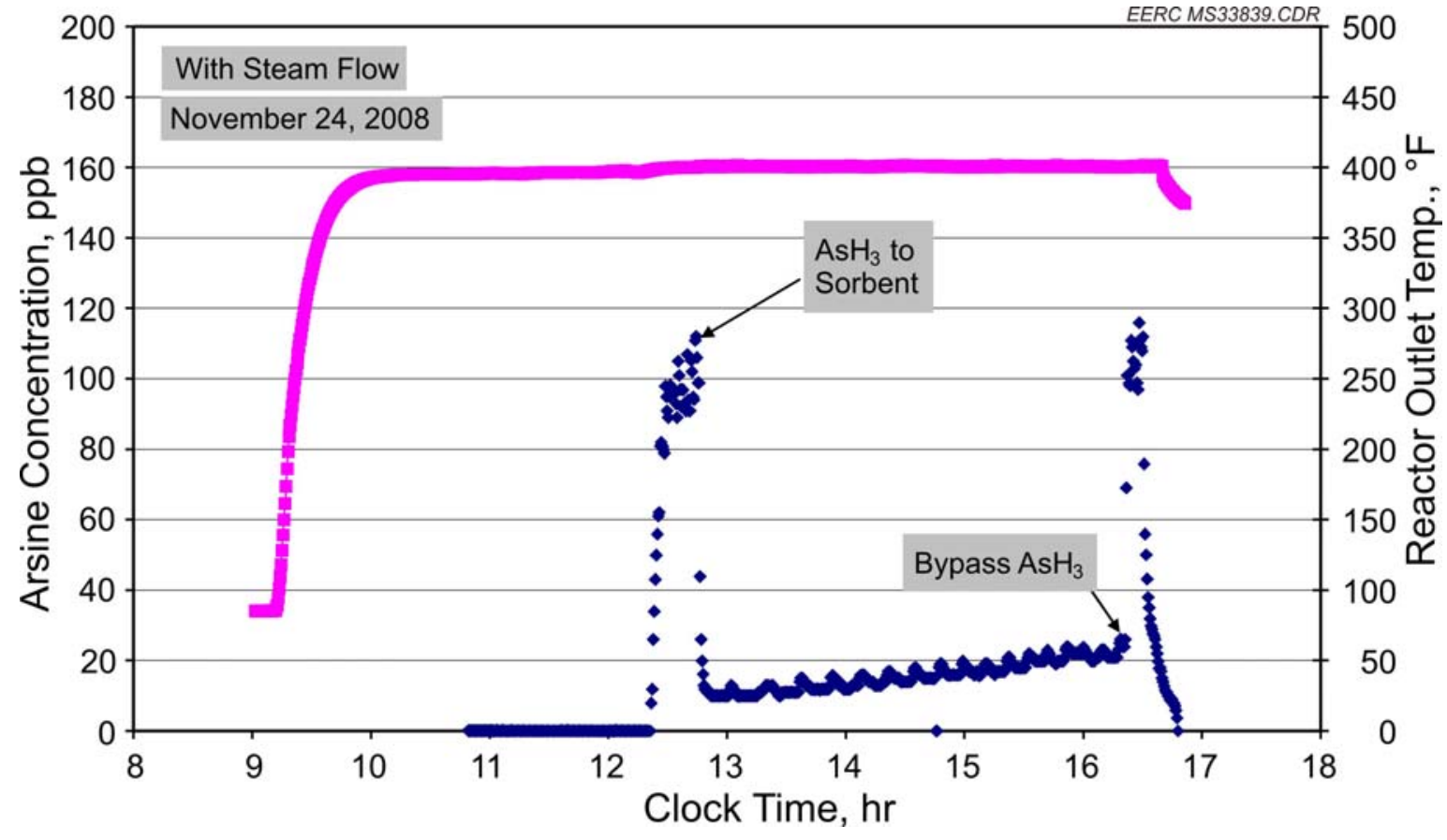

Figure A-66. Arsine sorption curve for Corning Monolith SR Liquid 285 at $400^{\circ} \mathrm{F}$ and 600 psig (Test 65). 


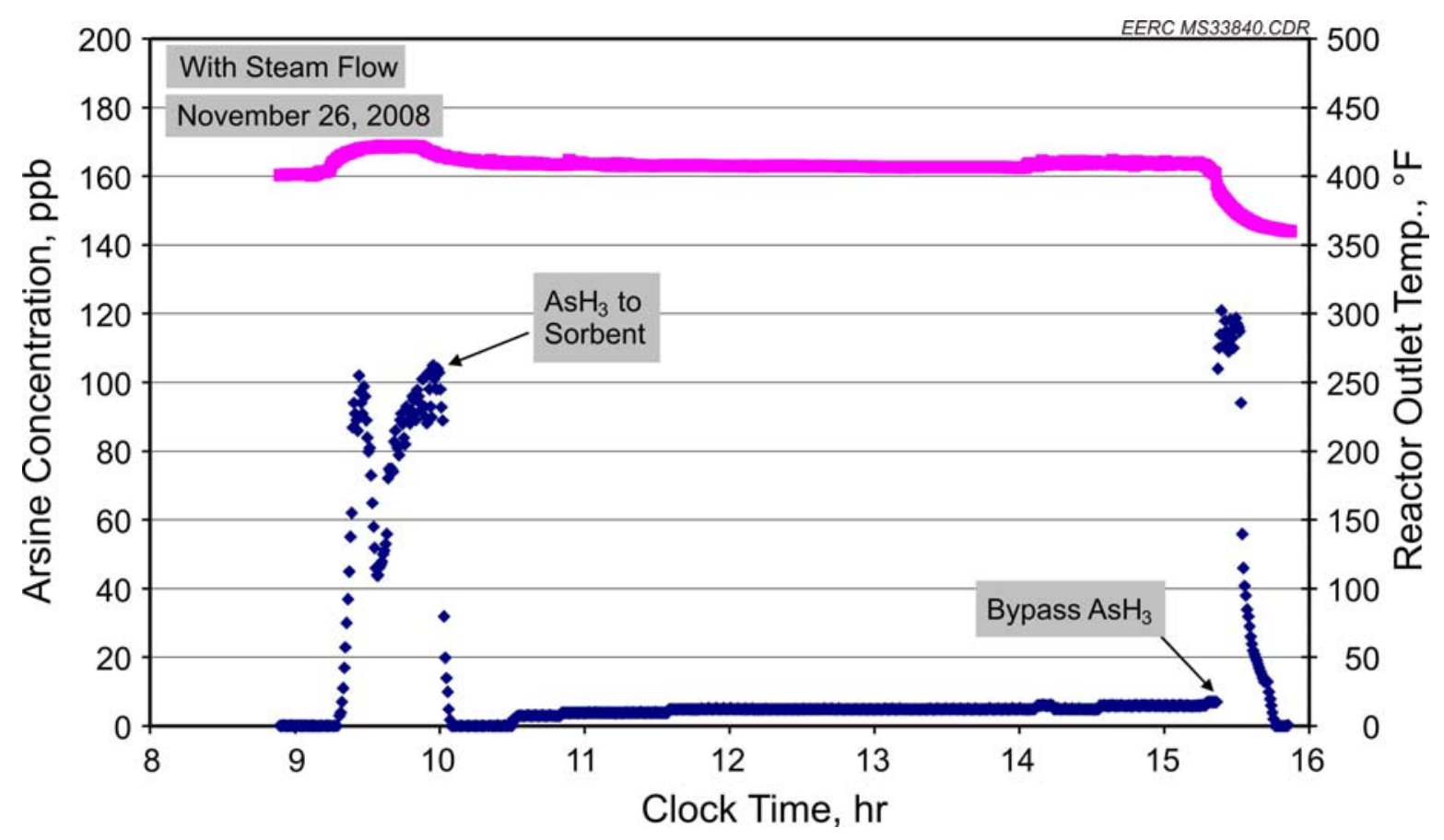

Figure A-67. Arsine sorption curve for EERC Sorbent with Group IB and IIB metals on alumina pellet at $400^{\circ} \mathrm{F}$ and 600 psig (Test 66).

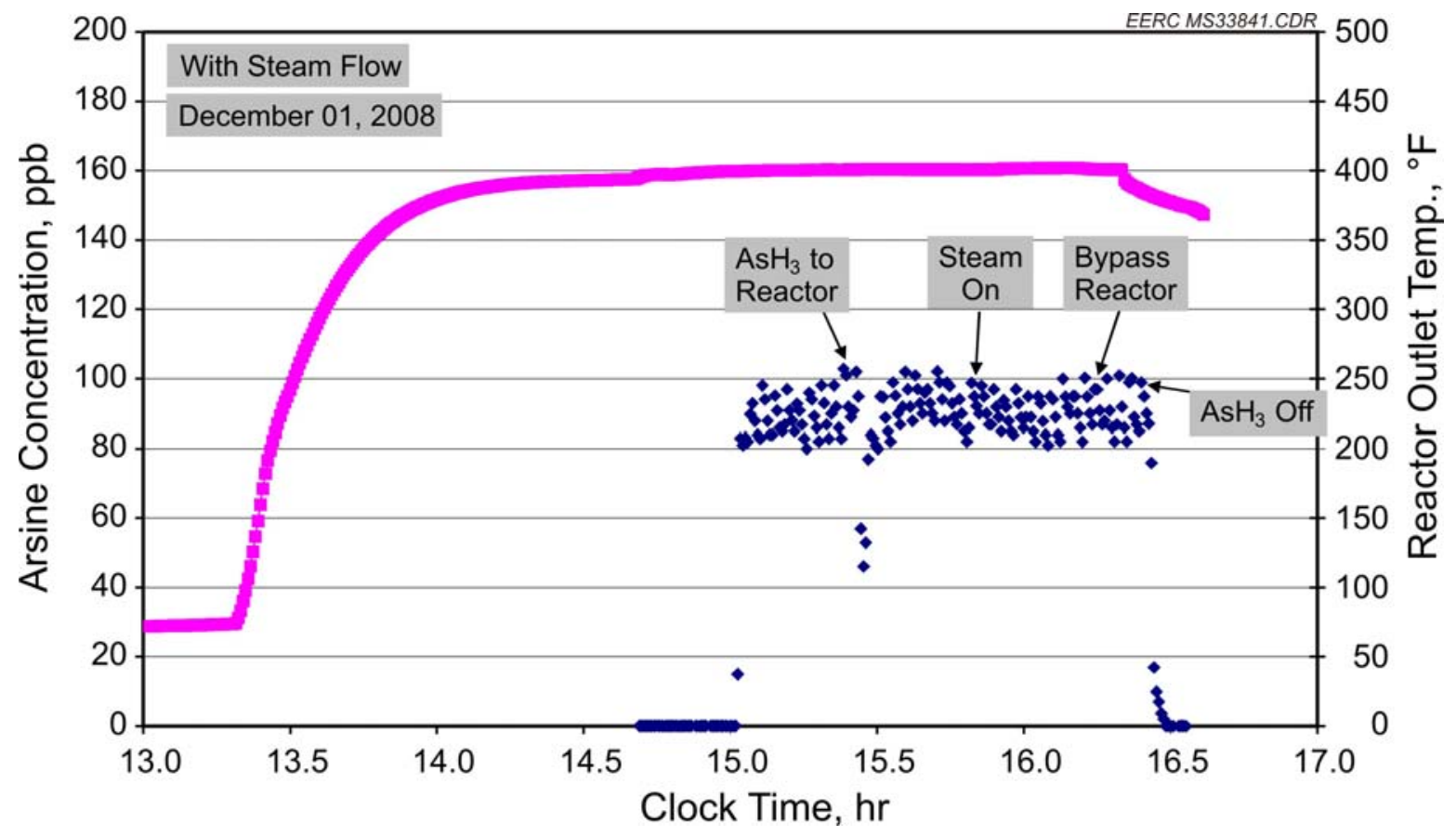

Figure A-68. Empty reactor with arsine flow at $400^{\circ} \mathrm{F}$ and 600 psig (Test 67). 


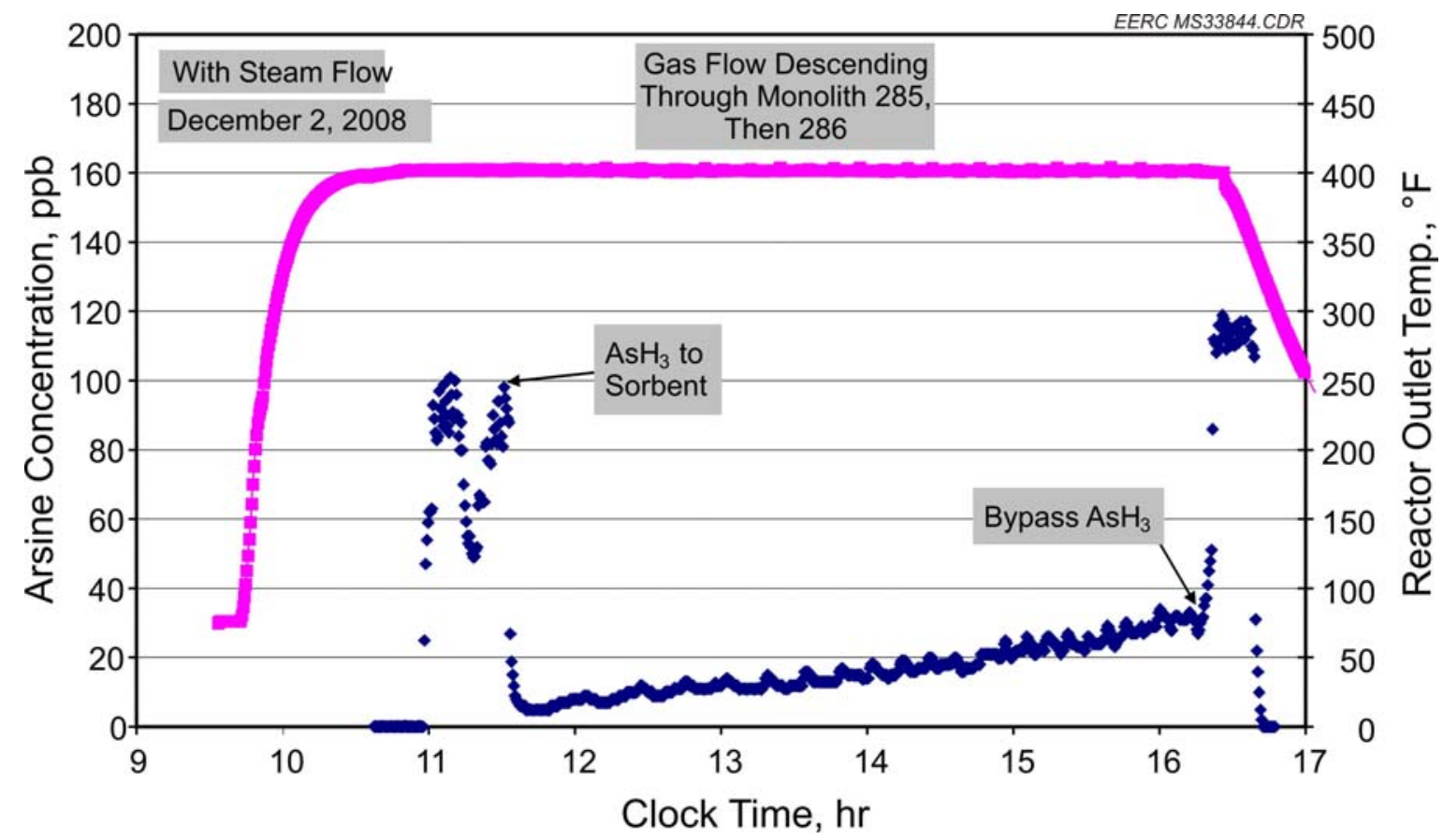

Figure A-69. Arsine sorption curve for Corning Monoliths SR Liquid 285 and 286 at $400^{\circ} \mathrm{F}$ and $600 \mathrm{psig}$ (Test 68).

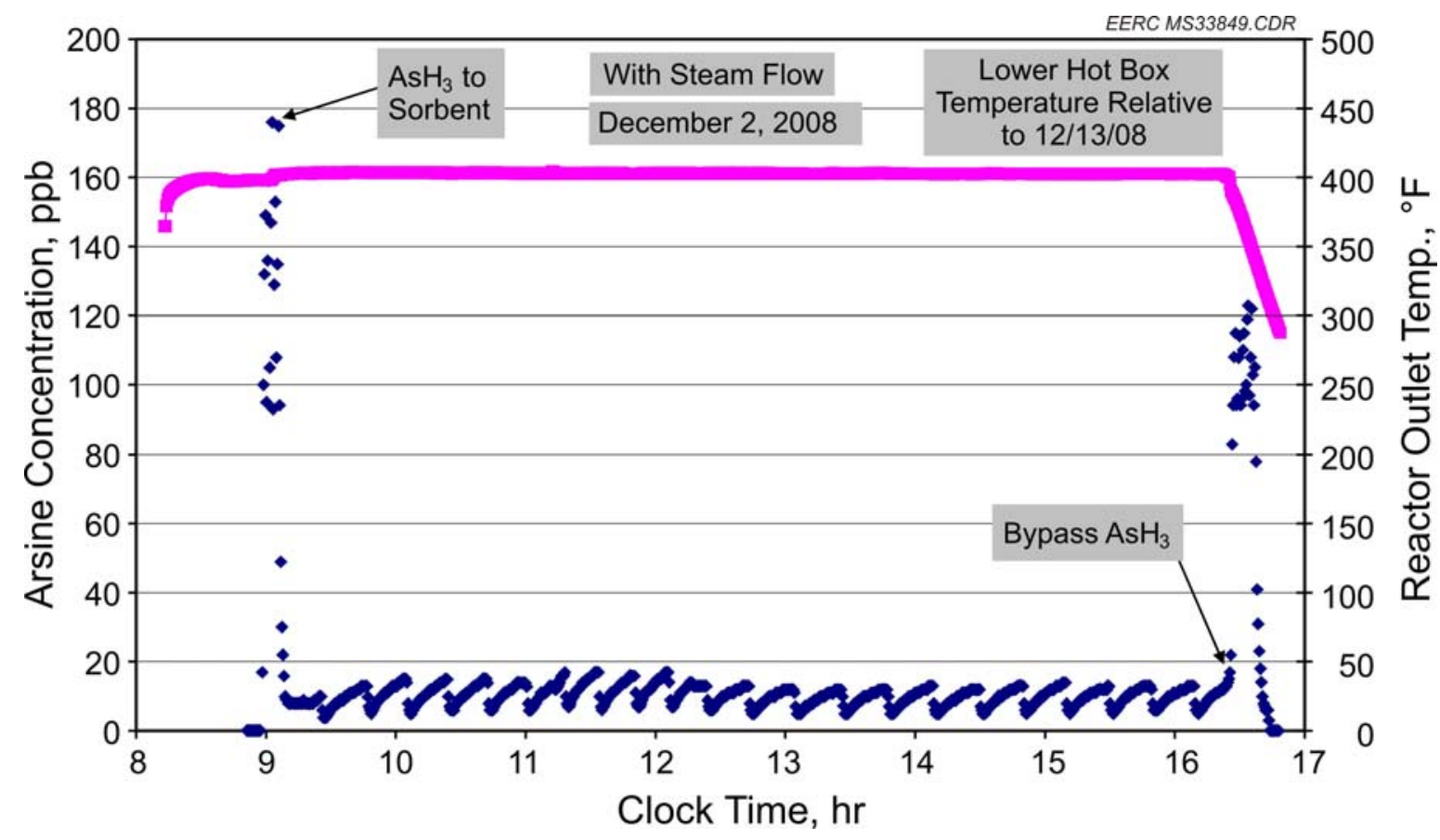

Figure A-70. Arsine sorption curve for EERC Sorbent with Group IB and IIB metals coprecipitated at $400^{\circ} \mathrm{F}$ and $600 \mathrm{psig}$ (Test 69). 


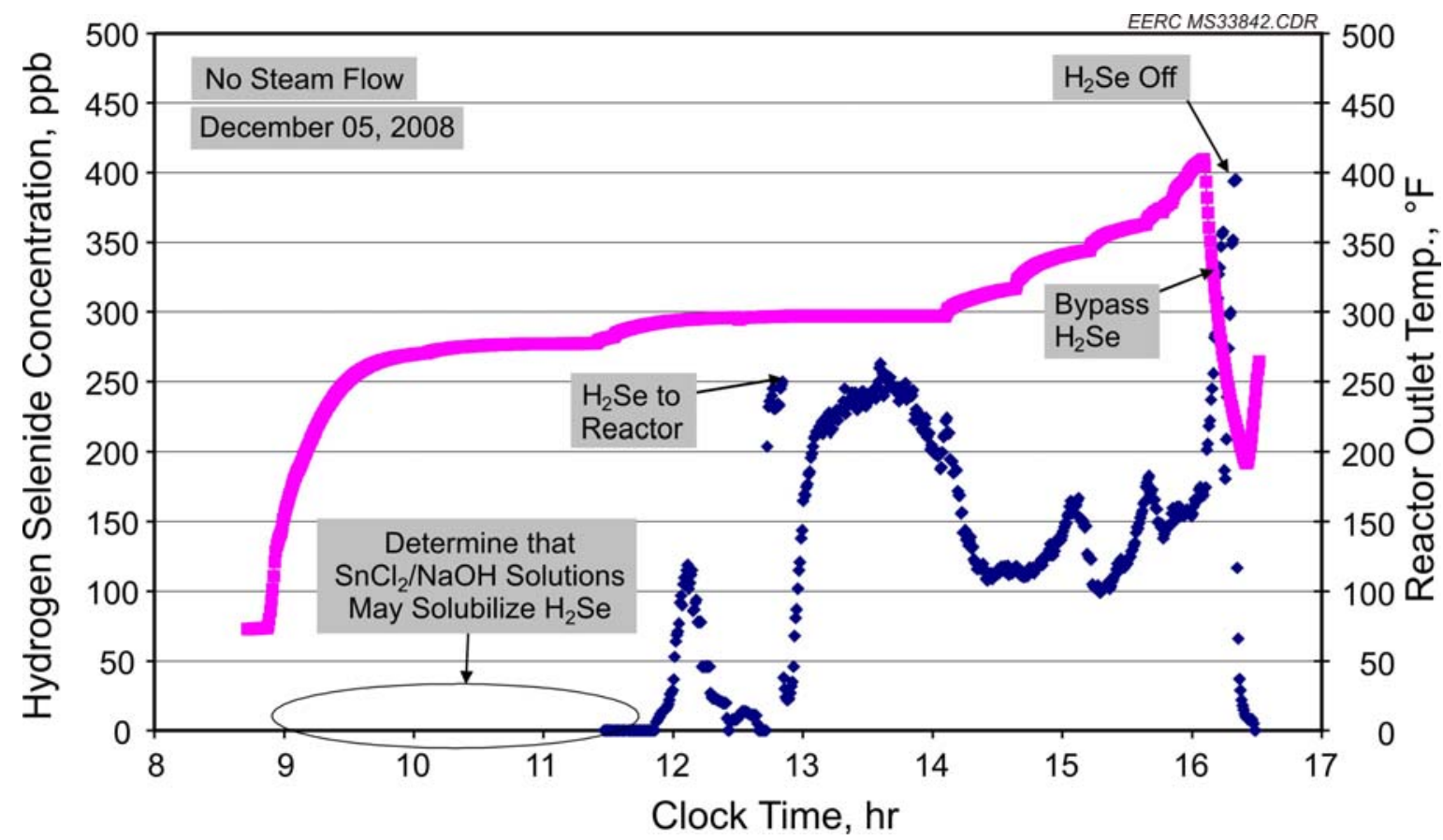

Figure A-71. Empty reactor with hydrogen selenide flow at $275^{\circ}$ to $400^{\circ} \mathrm{F}$ and 600 psig (Test 70 ).

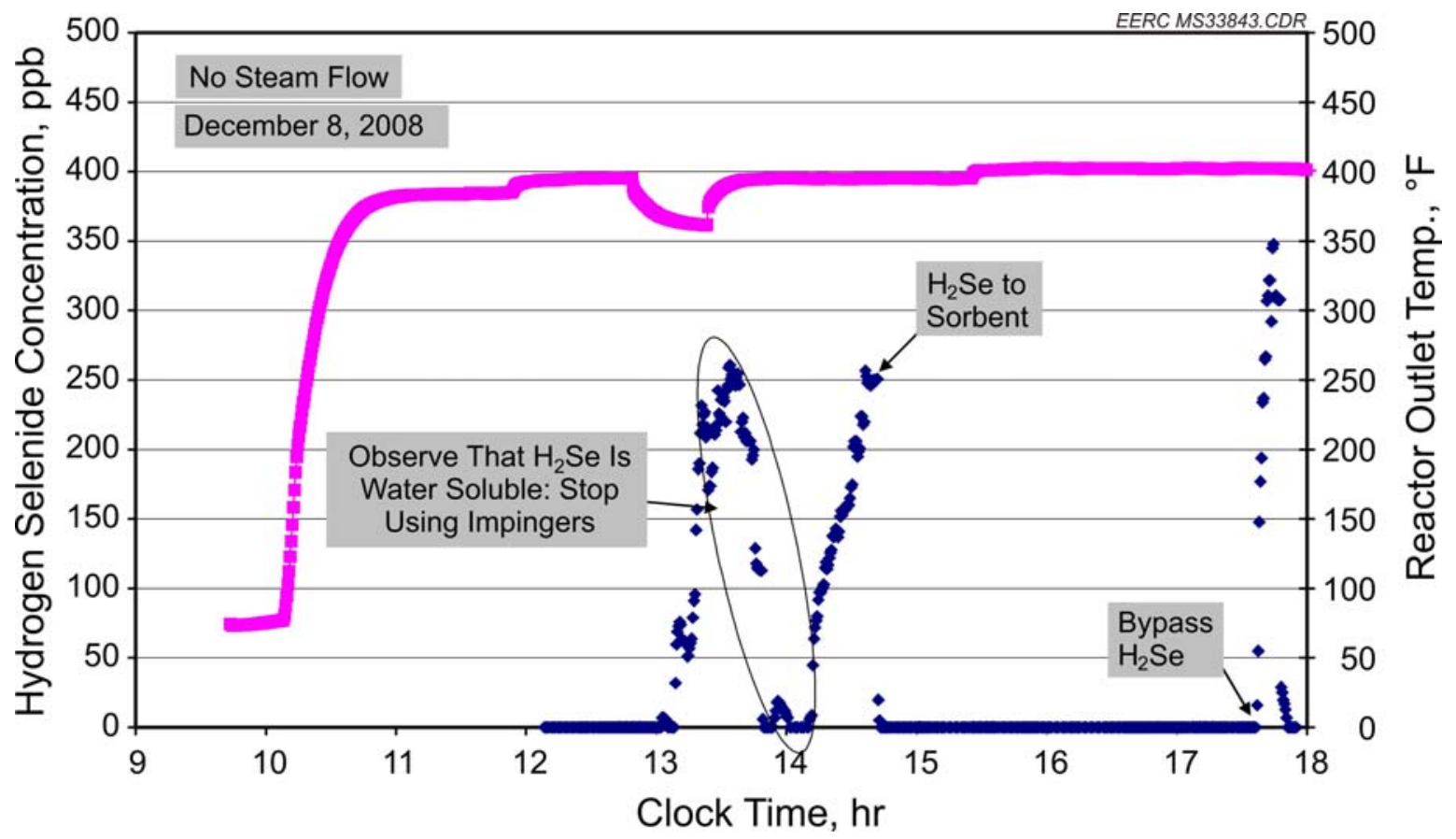

Figure A-72. Hydrogen selenide sorption curve for EERC Sorbent with Group IB and IIB metals coprecipitated at $400^{\circ} \mathrm{F}$ and 600 psig (Test 71). 


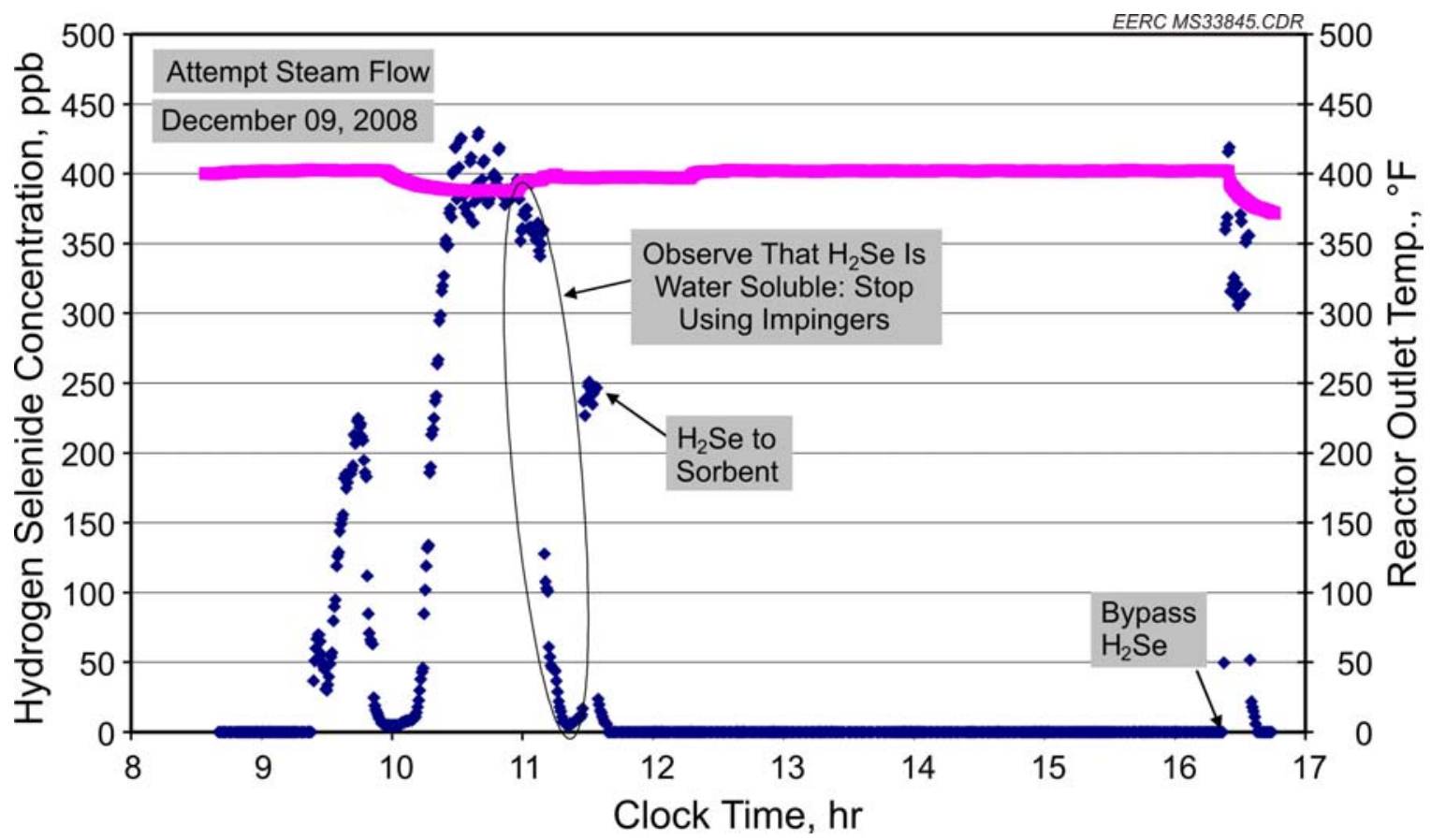

Figure A-73. Hydrogen selenide sorption curve for EERC Sorbent with Group IB and IIB metals coprecipitated at $400^{\circ} \mathrm{F}$ and 600 psig (Test 72).

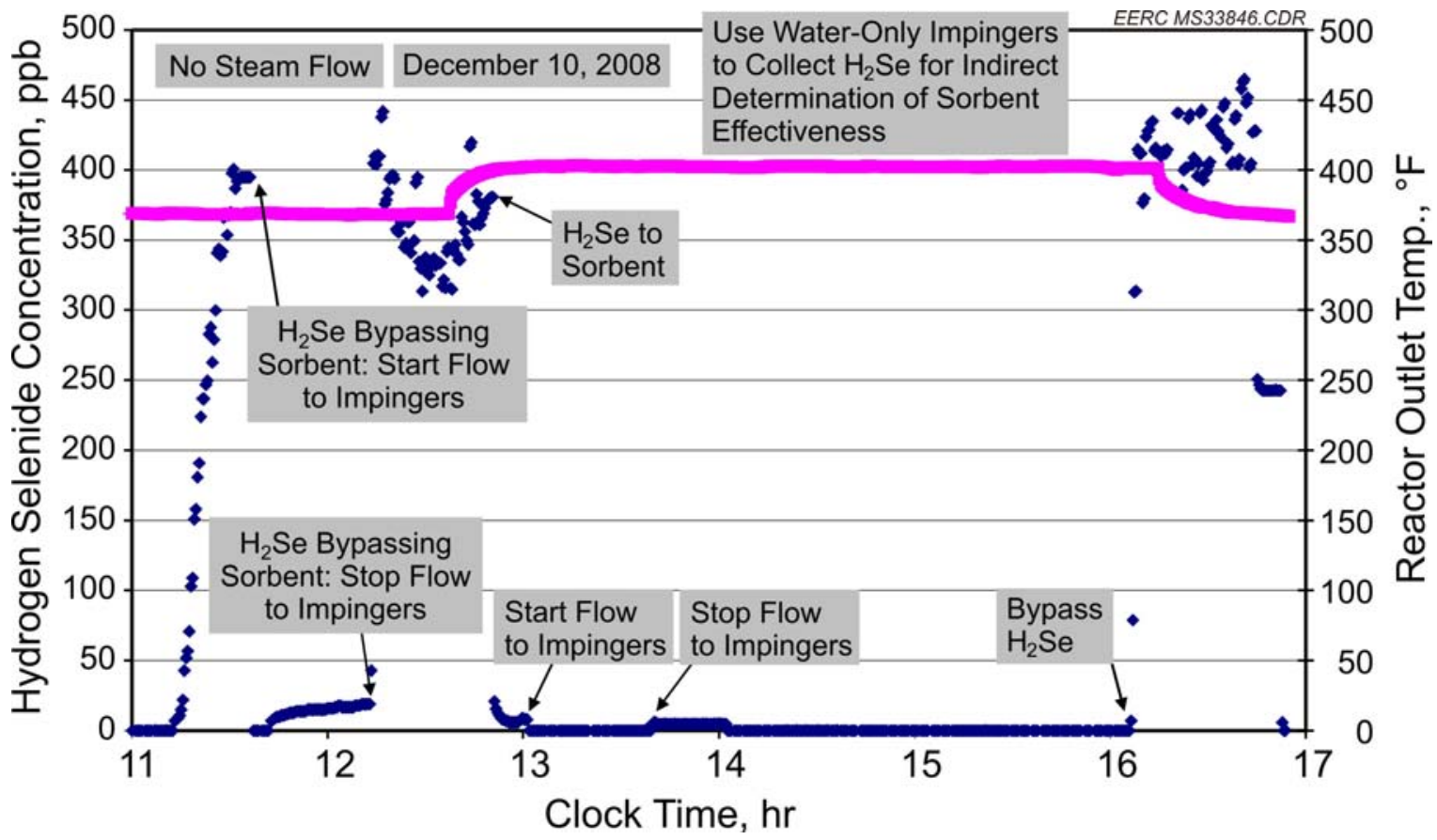

Figure A-74. Hydrogen selenide sorption curve for EERC Sorbent with Group IB and IIB metals coprecipitated at $400^{\circ} \mathrm{F}$ and 600 psig (Test 73). 


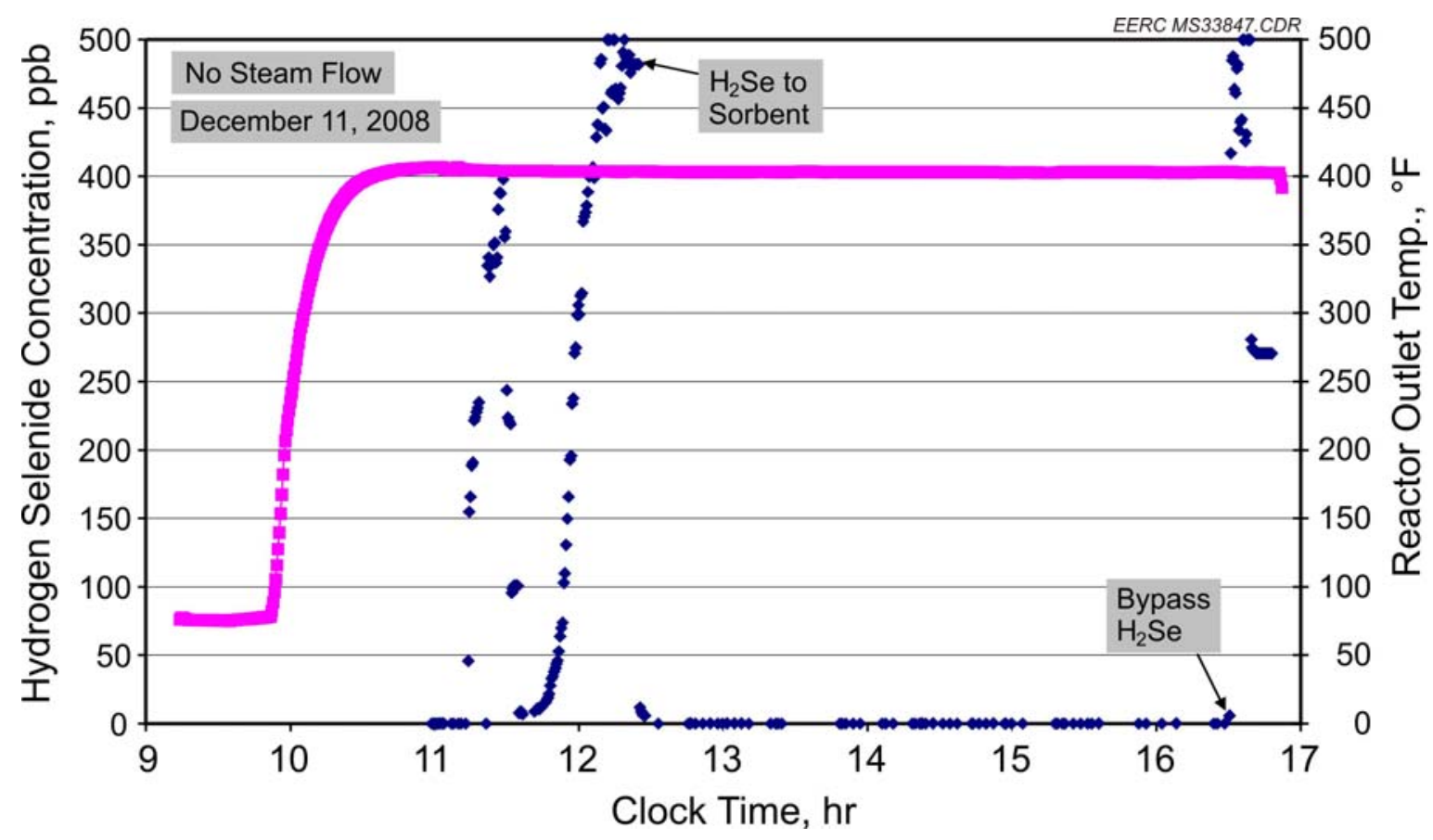

Figure A-75. Hydrogen selenide sorption curve for EERC Sorbent with Group IB and IIB metals on alumina pellet at $400^{\circ} \mathrm{F}$ and 600 psig (Test 74).

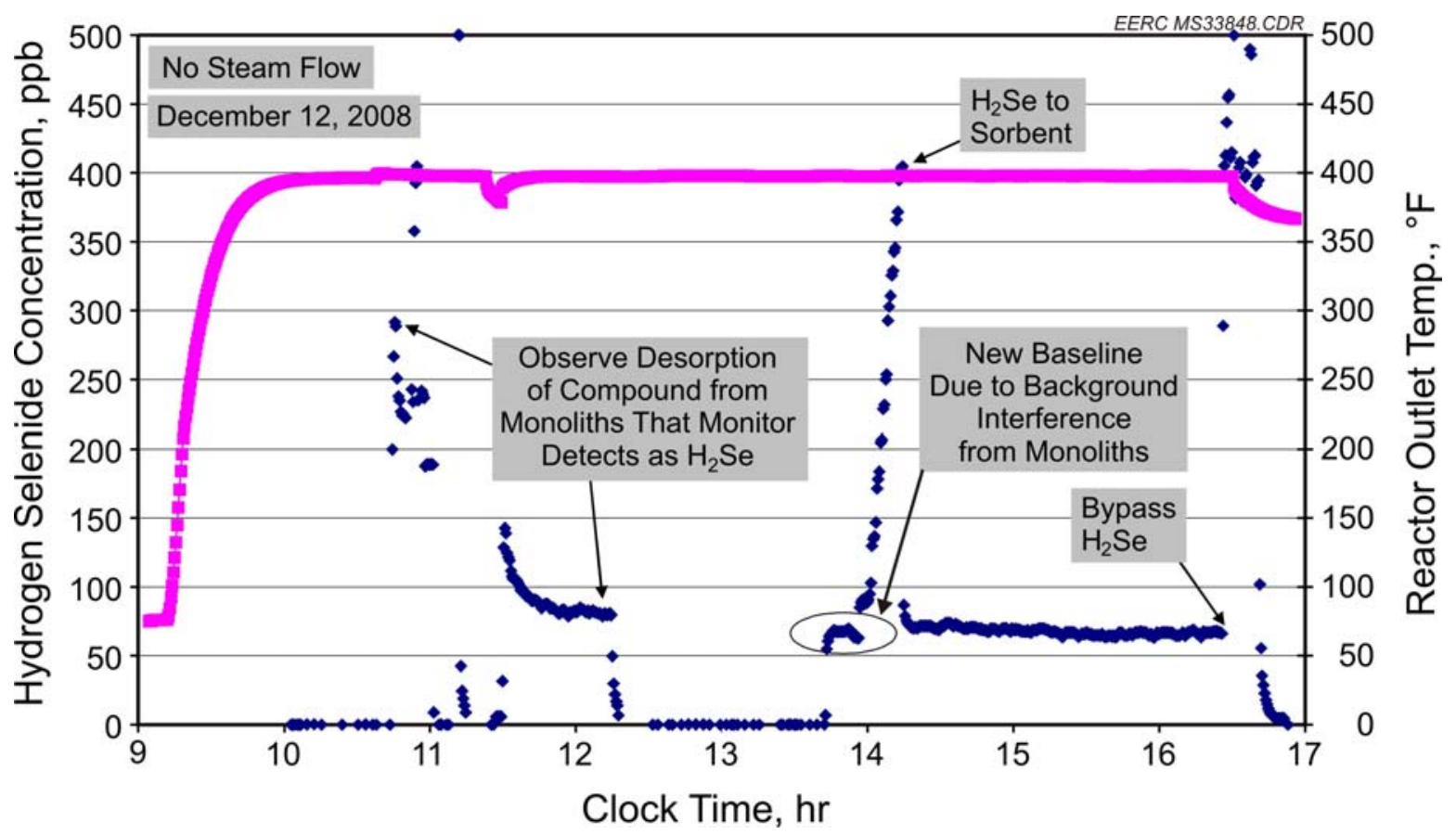

Figure A-76. Hydrogen selenide sorption curve for Corning Monoliths SR Liquid 287 and 288 at $400^{\circ} \mathrm{F}$ and 600 psig (Test 75). 


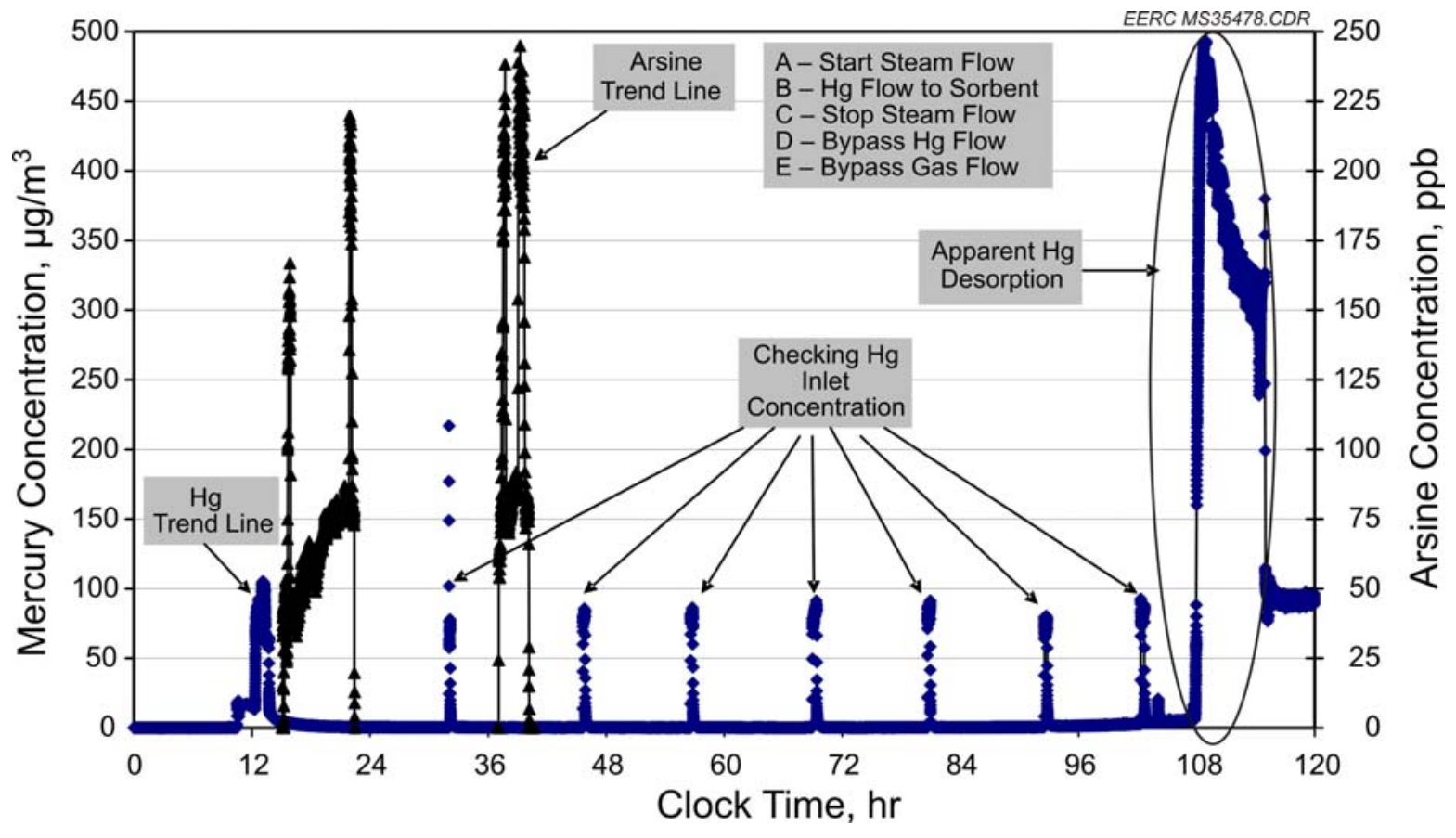

Figure A-77. Mercury and arsine sorption curves for Corning Monolith GR-P1-2189 at $400^{\circ} \mathrm{F}$ and $600 \mathrm{psig}$ (Test 76).

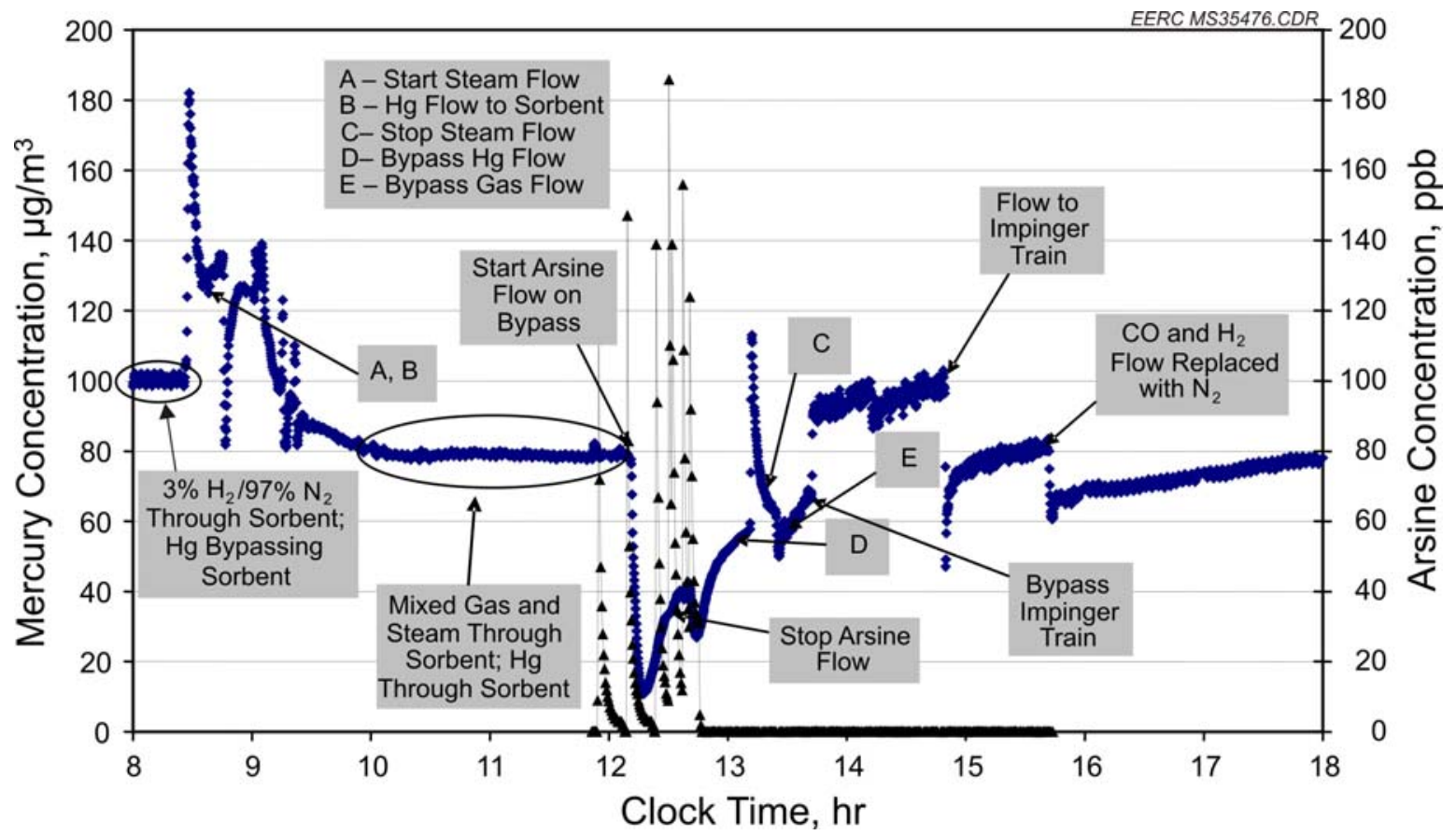

Figure A-78. Mercury and arsine sorption curves for Corning Monoliths 31082-1, $-7,-13$, and -18 at $400^{\circ} \mathrm{F}$ and 600 psig (Test 77). 


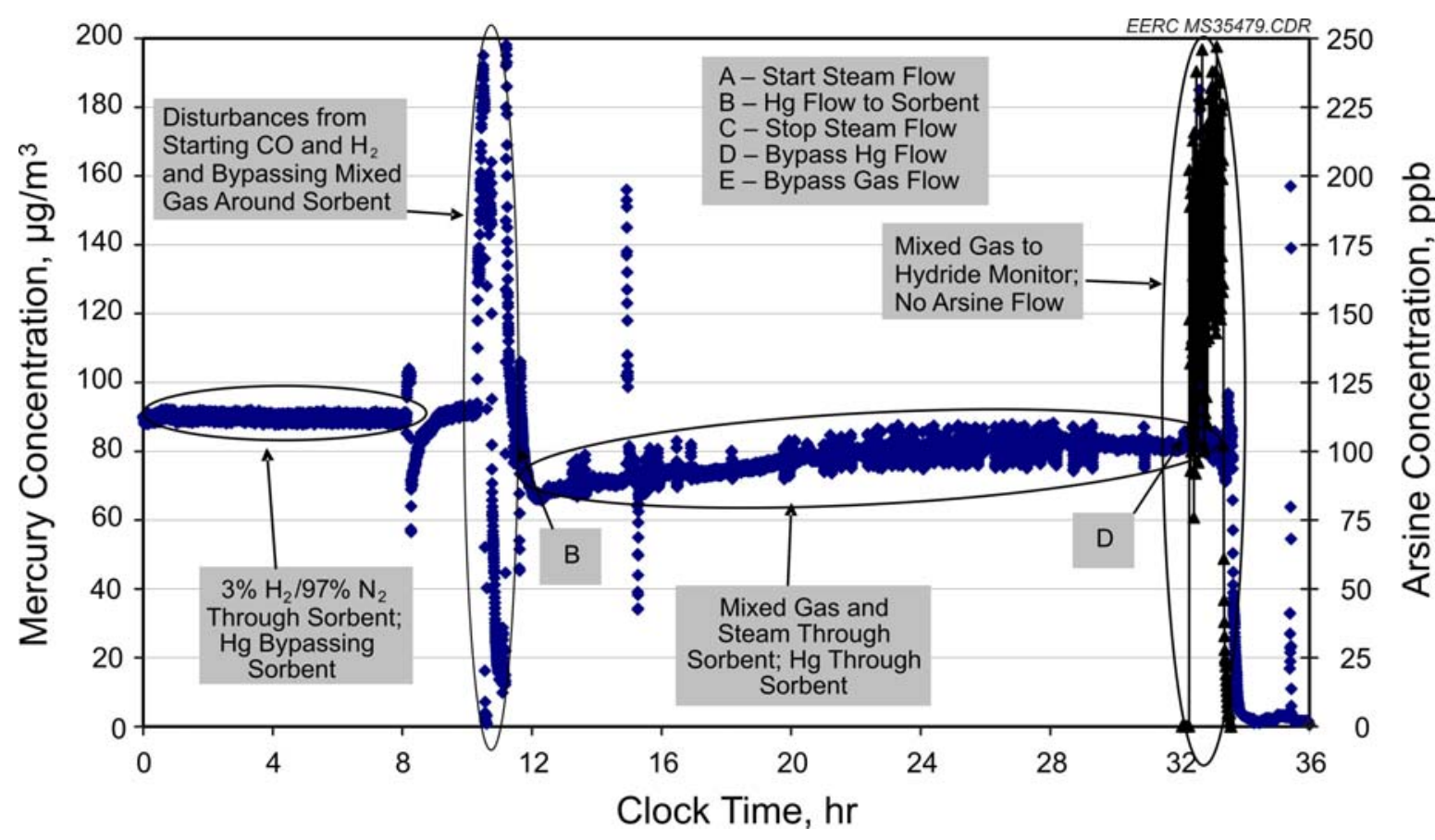

Figure A-79. Mercury and arsine sorption curves for Corning Monoliths 31082-1, $-7,-13$, and -18 at $400^{\circ} \mathrm{F}$ and 600 psig (Test 77 ).

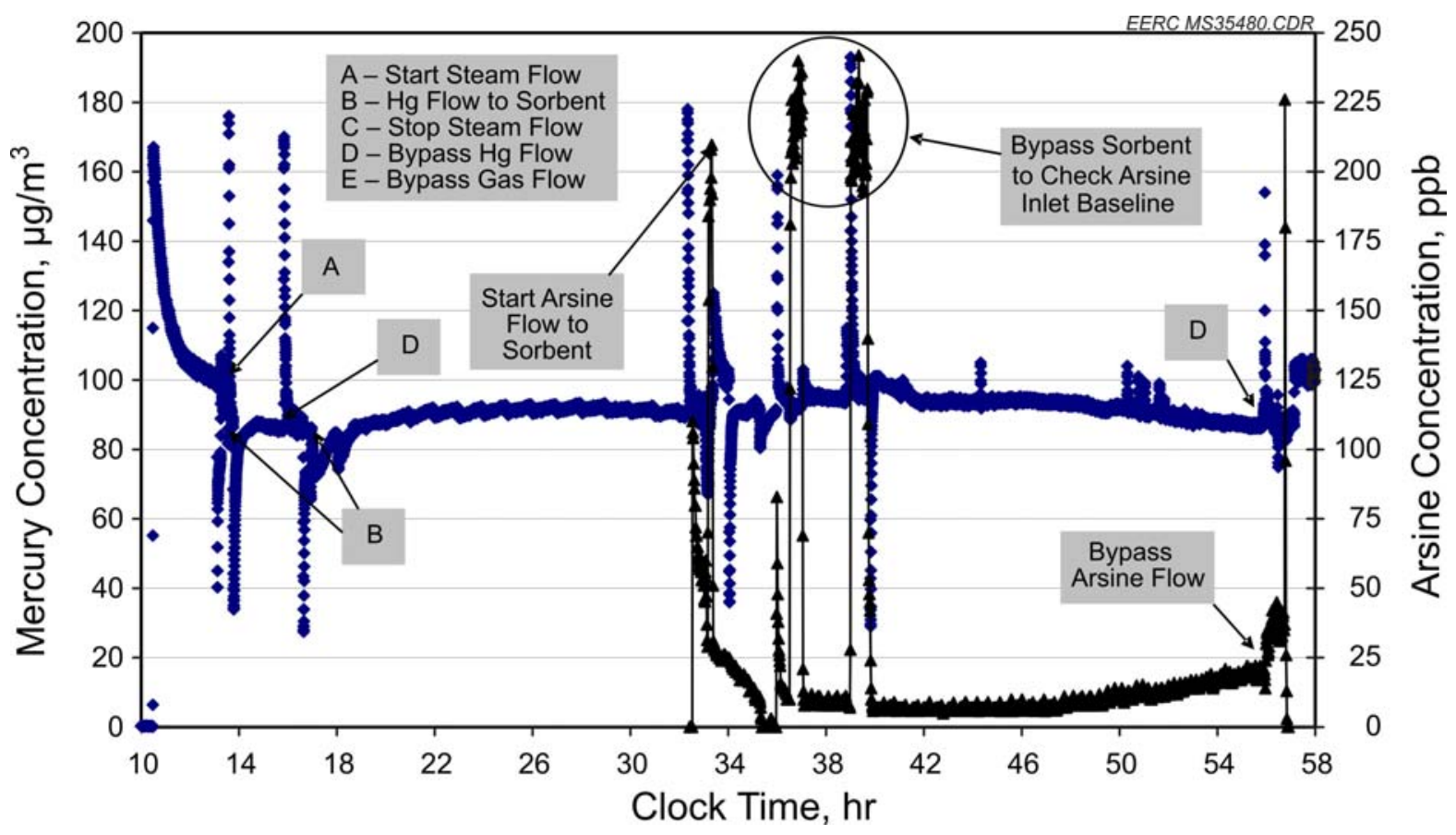

Figure A-80. Mercury and arsine sorption curves for Corning Monoliths 31083-3, $-8,-13$, and -17 at $400^{\circ} \mathrm{F}$ and 600 psig (Test 78). 


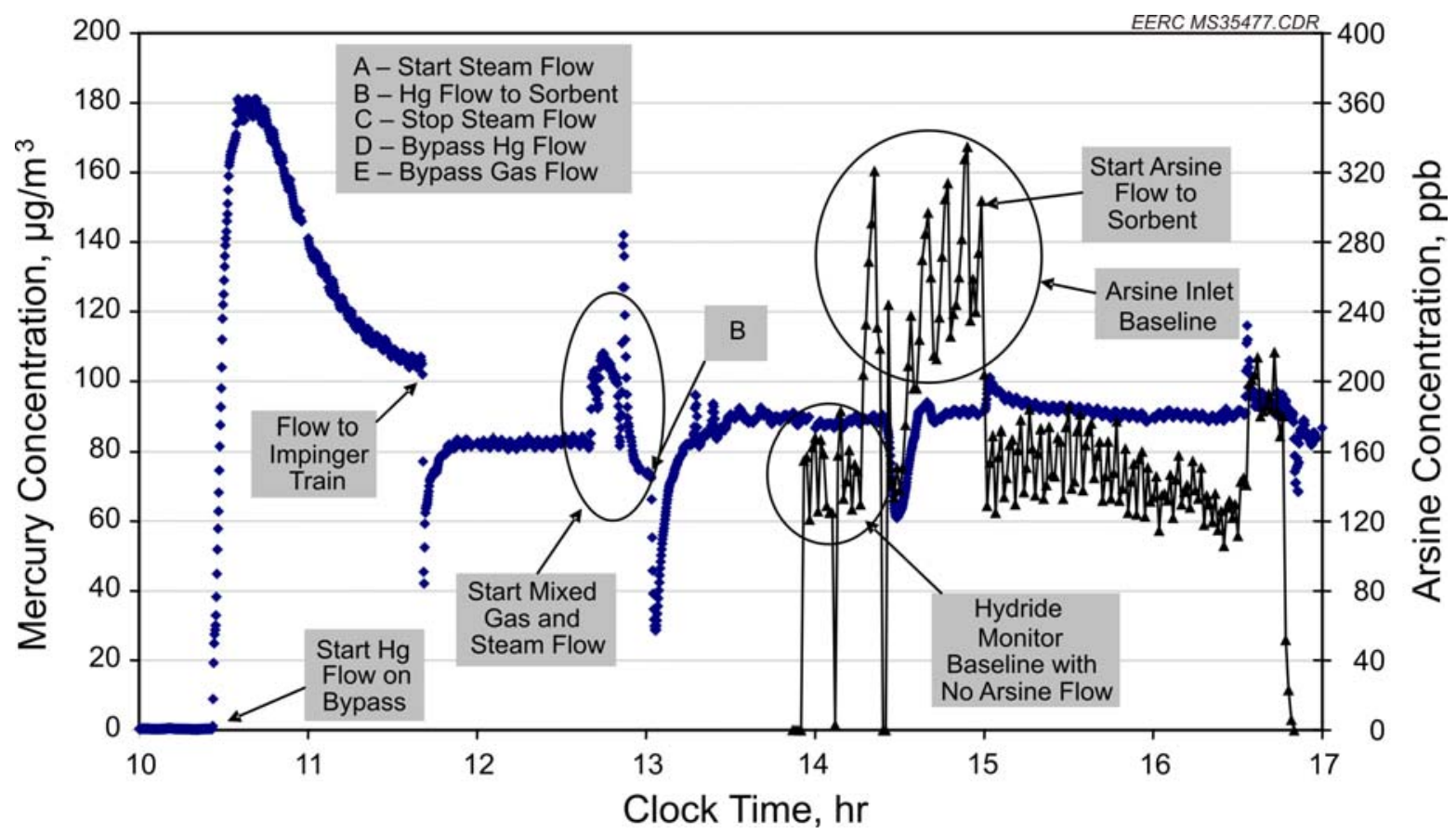

Figure A-81. Mercury and arsine sorption curves for Corning Monoliths 31085-6, $-11,-17$, and -21 at $400^{\circ} \mathrm{F}$ and 600 psig (Test 79).

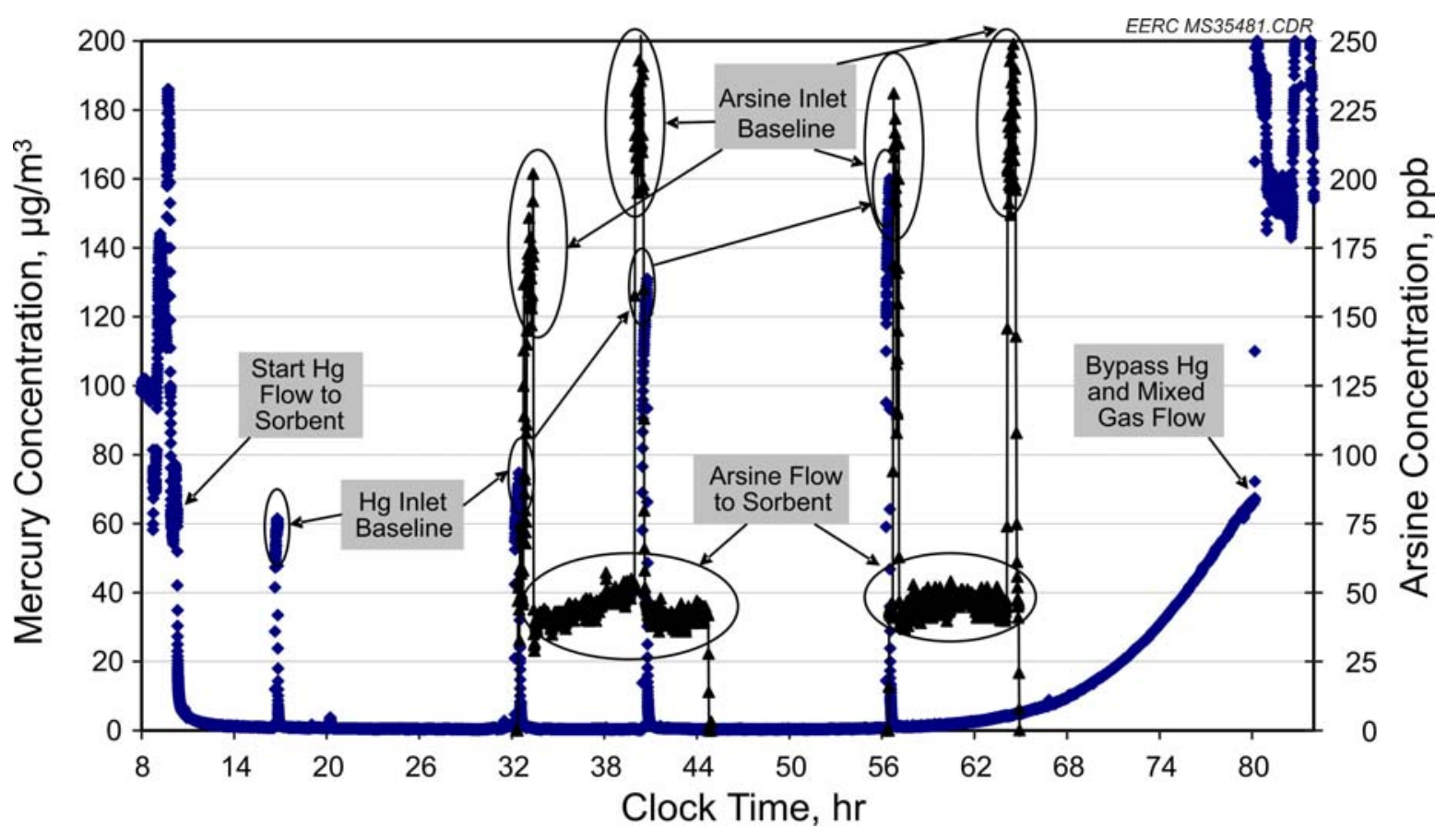

Figure A-82. Mercury and arsine sorption curves for Corning Monoliths 31308-2, $-7,-12$, and -16 at $400^{\circ} \mathrm{F}$ and 600 psig (Test 80 ). 


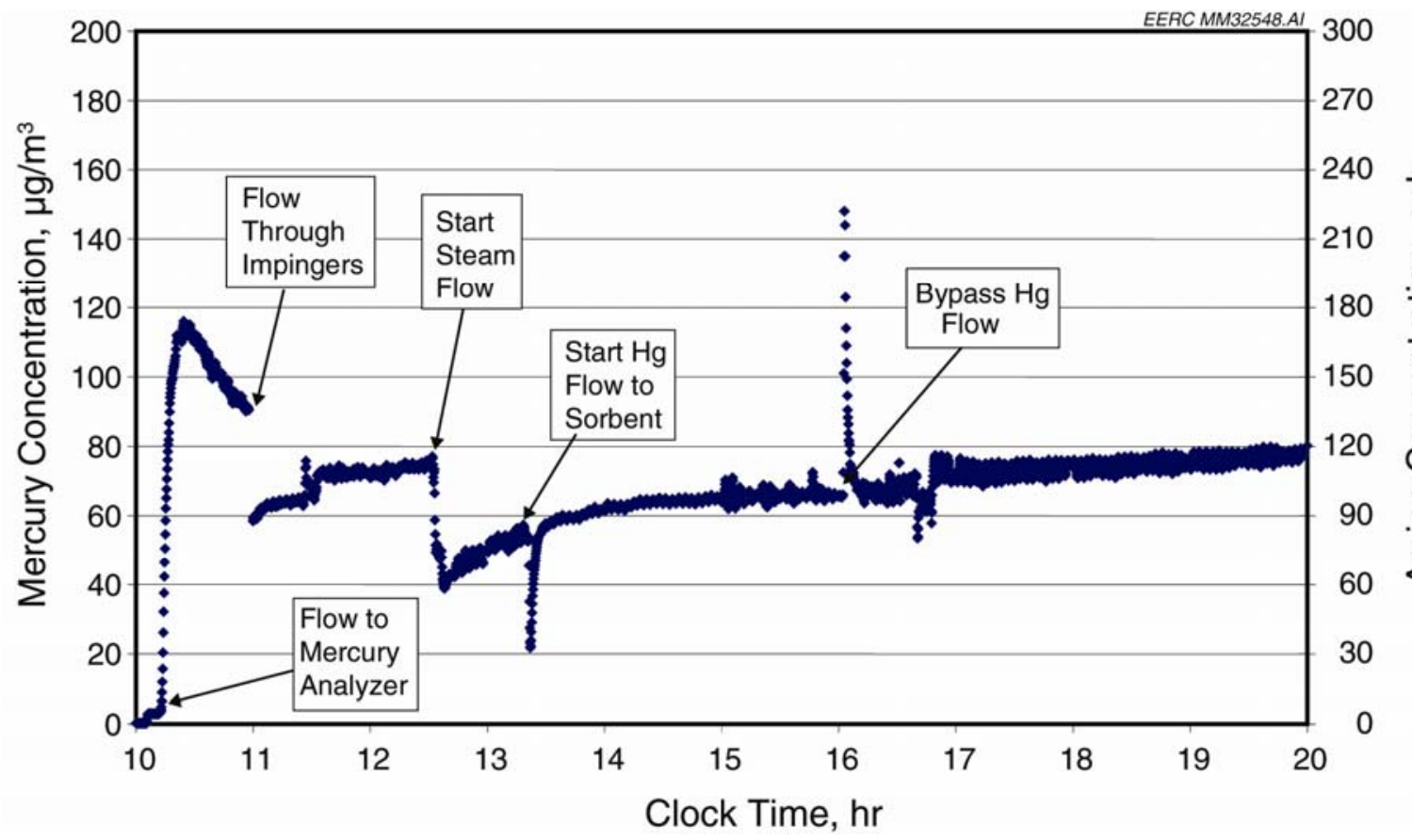

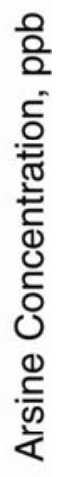

Figure A-83. Mercury sorption curve for Corning Monoliths 31082-6, -12, and -19 at $400^{\circ} \mathrm{F}$ and 600 psig (Test 81 ).

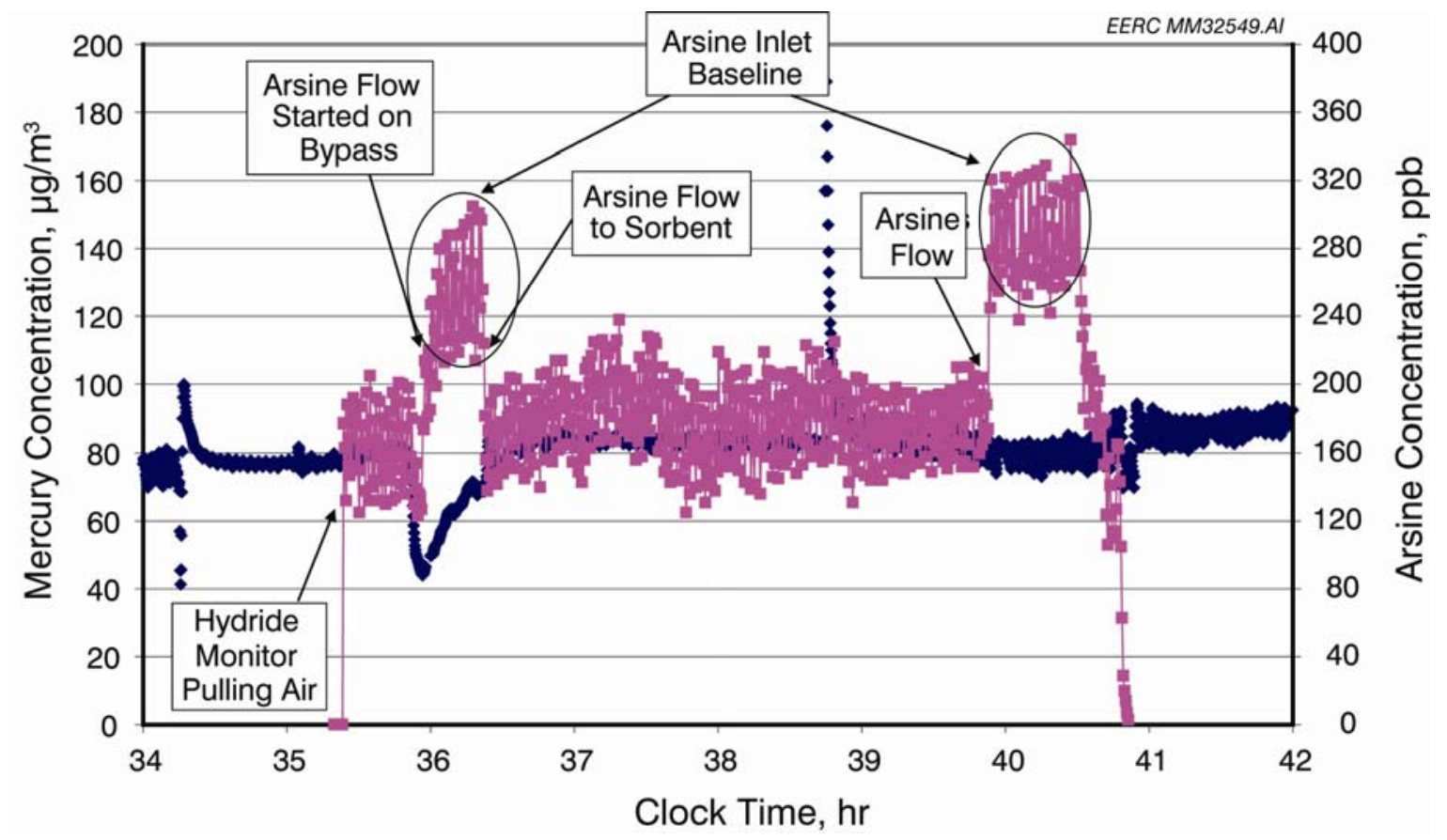

Figure A-84. Mercury and arsine sorption curve for Corning Monoliths 31082-6, -12 , and -19 at $400^{\circ} \mathrm{F}$ and 600 psig (Test 82). 


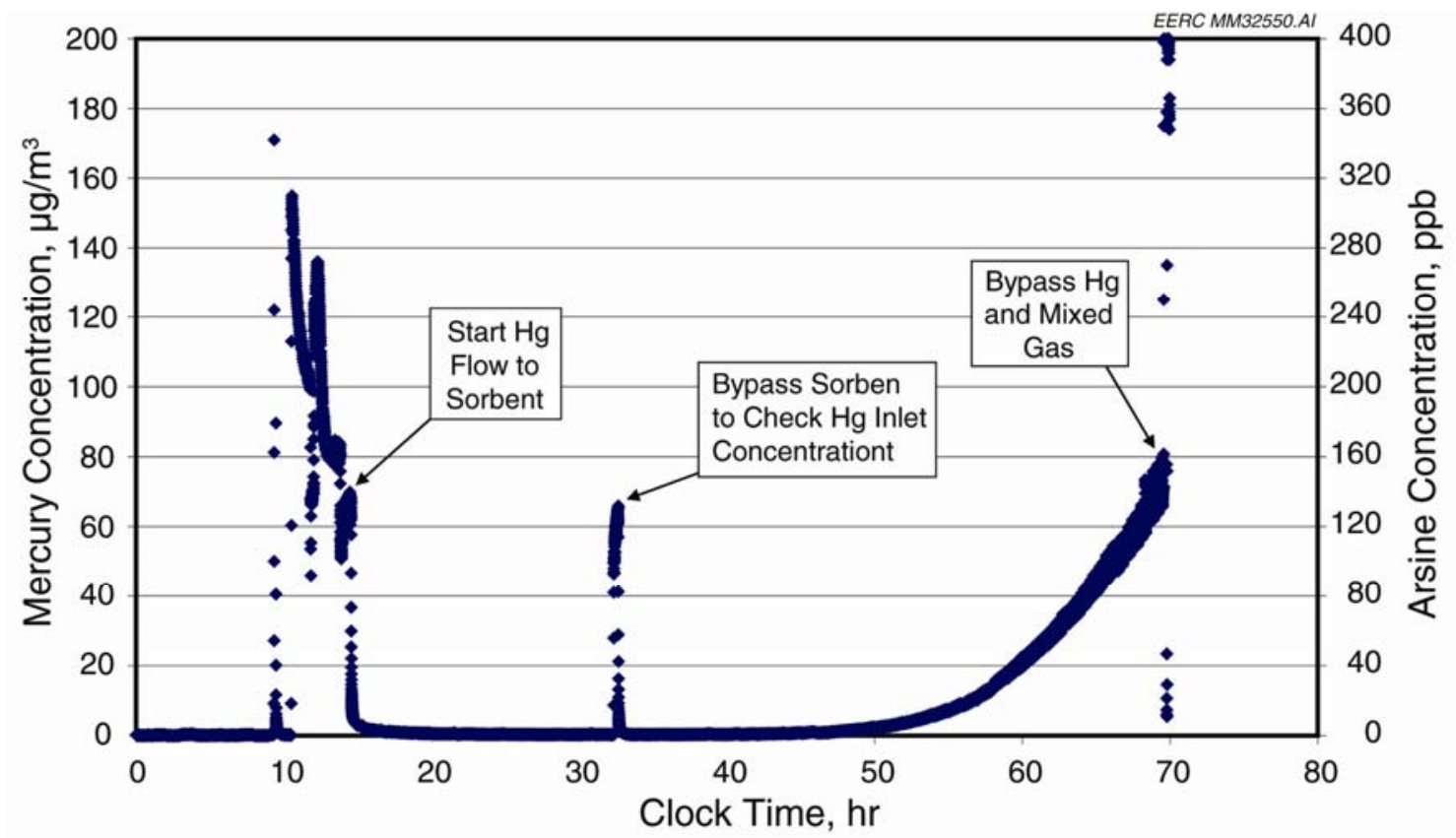

Figure A-85. Mercury sorption curve for Corning Monoliths 31308-3, $-10,-20$ at $400^{\circ} \mathrm{F}$ and 600 psig (Test 83 ).

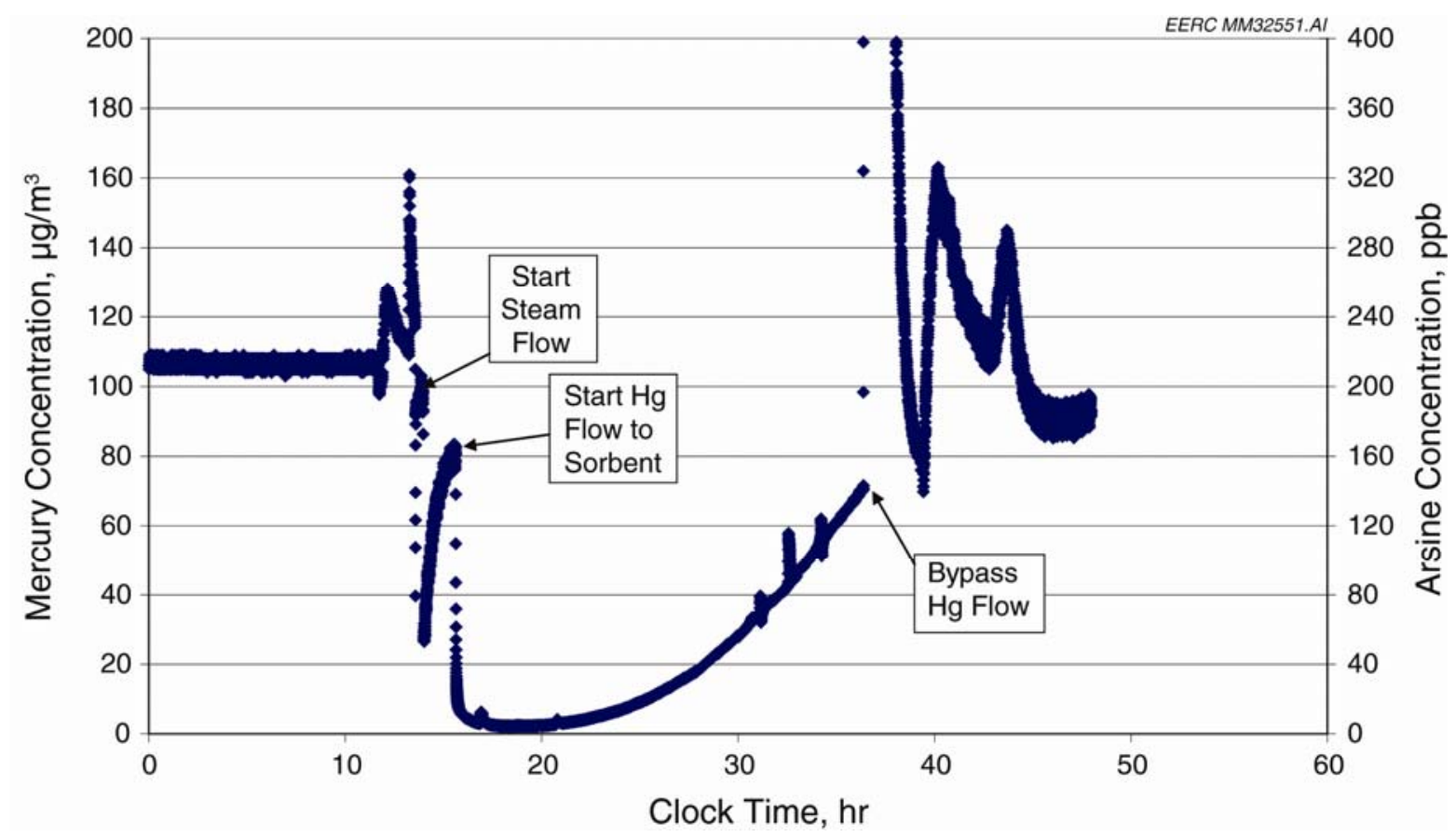

Figure A-86. Mercury sorption curve for regenerated Corning Monoliths 31308-3, $-10,-20$ at $400^{\circ} \mathrm{F}$ and 600 psig (Test 84). 


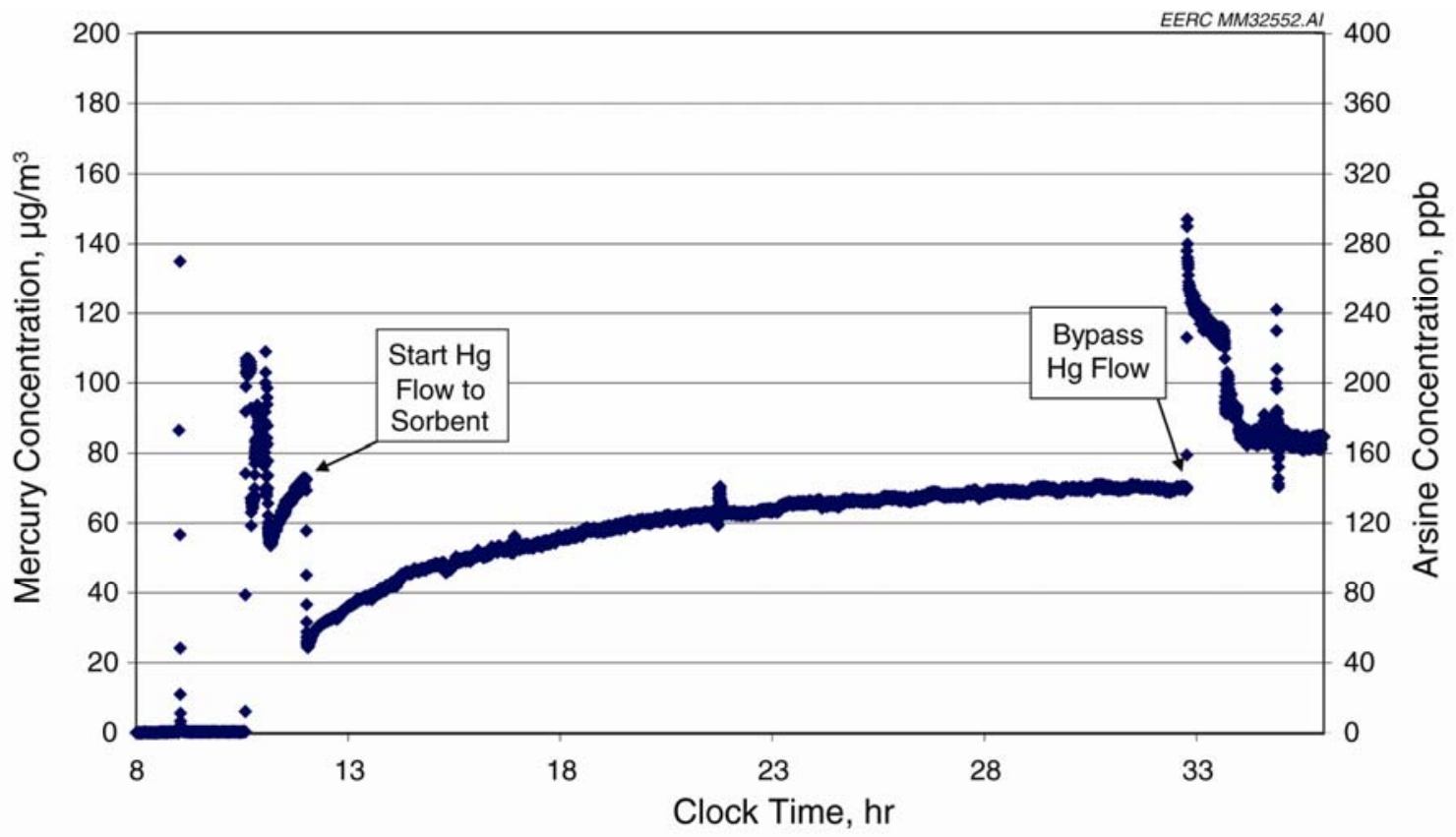

Figure A-87. Mercury sorption curve for EERC Sorbent with Group IB and IIB metals coprecipitated at $400^{\circ} \mathrm{F}$ and 600 psig (Test 85).

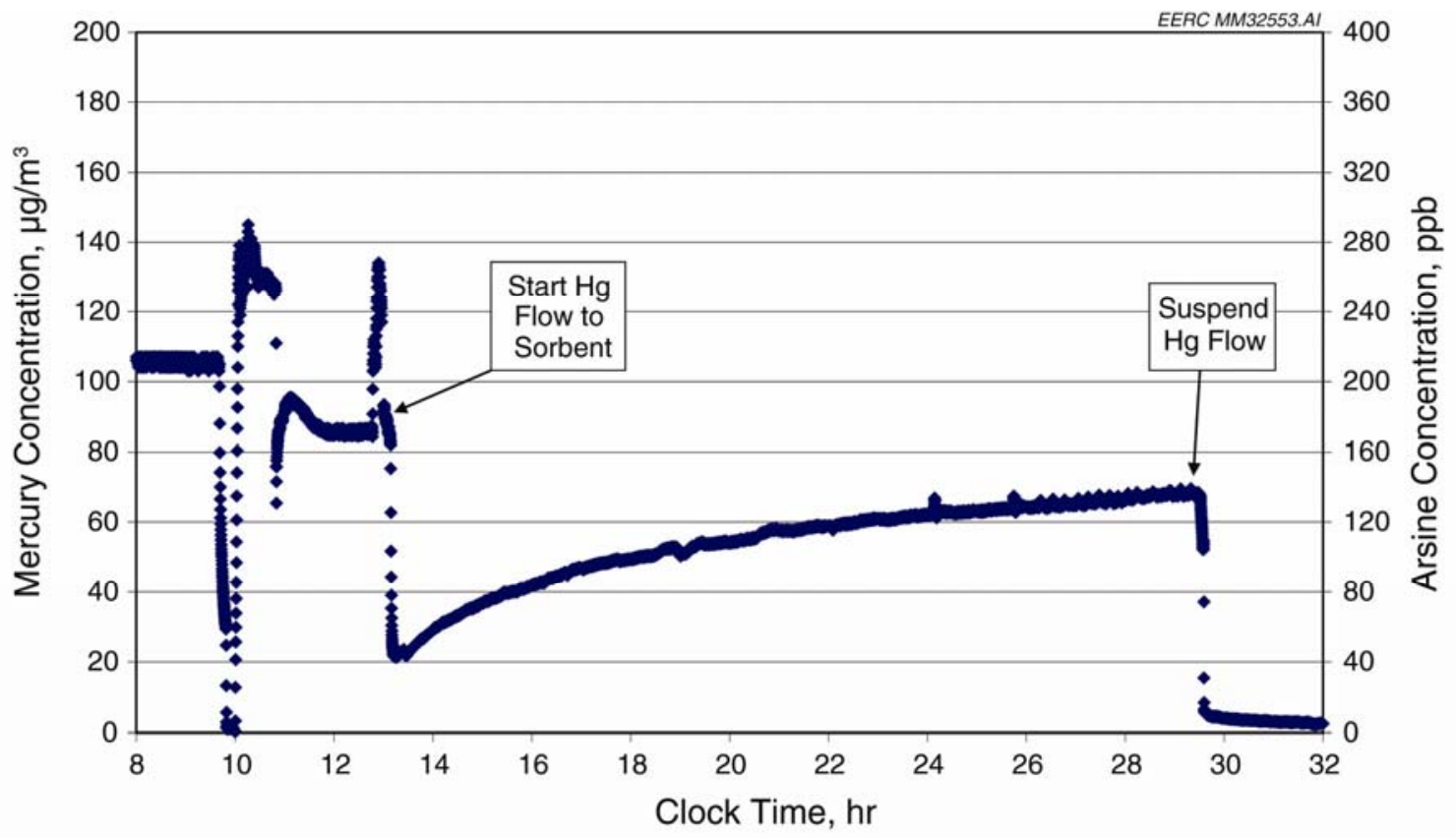

Figure A-88. Mercury sorption curve for EERC Sorbent with Group IB and IIB metals on alumina at $400^{\circ} \mathrm{F}$ and 600 psig (Test 86). 


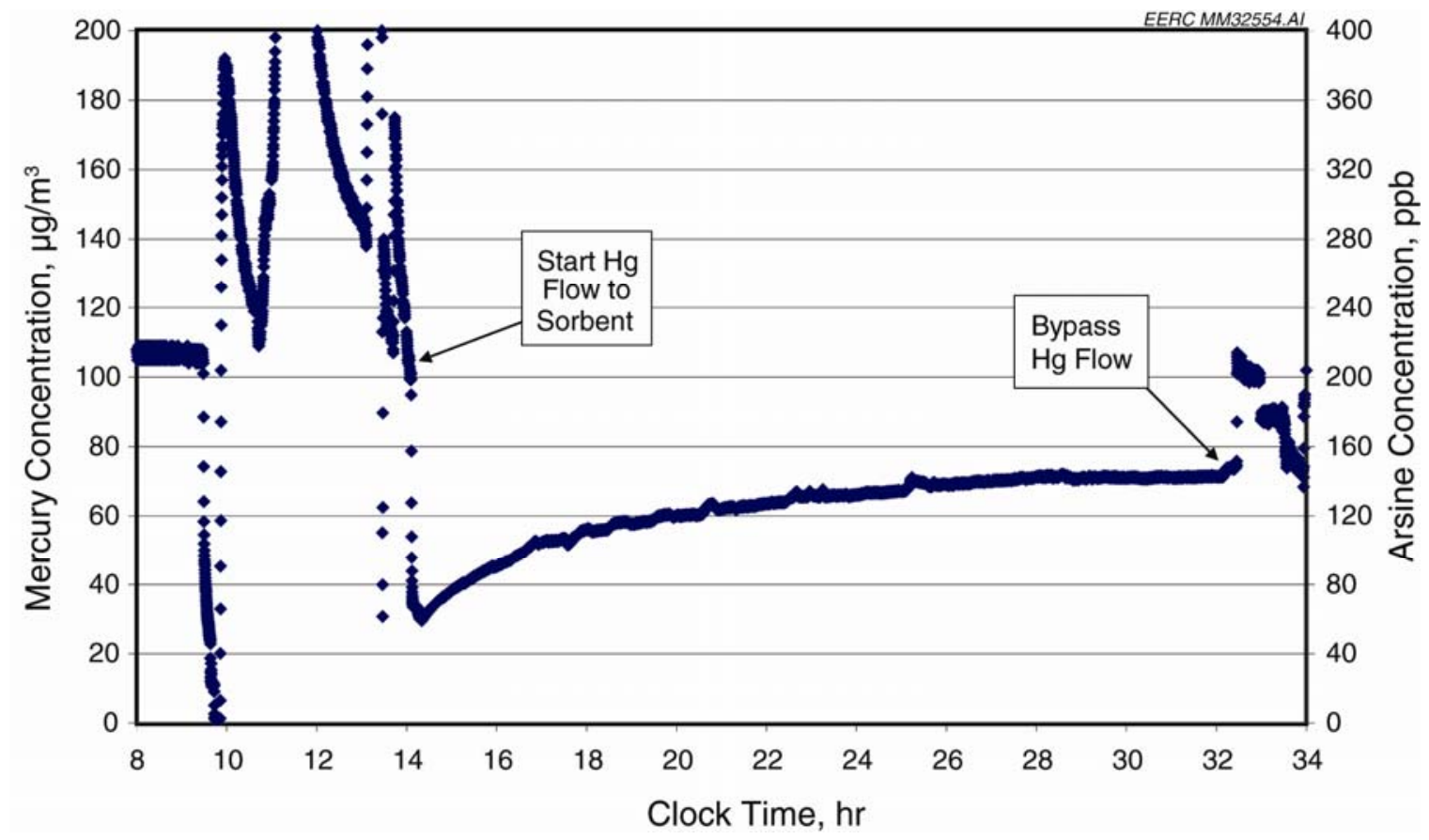

Figure A-89. Mercury sorption curve for regenerated EERC Sorbent with Group IB and IIB metals on alumina at $400^{\circ} \mathrm{F}$ and 600 psig (Test 87).

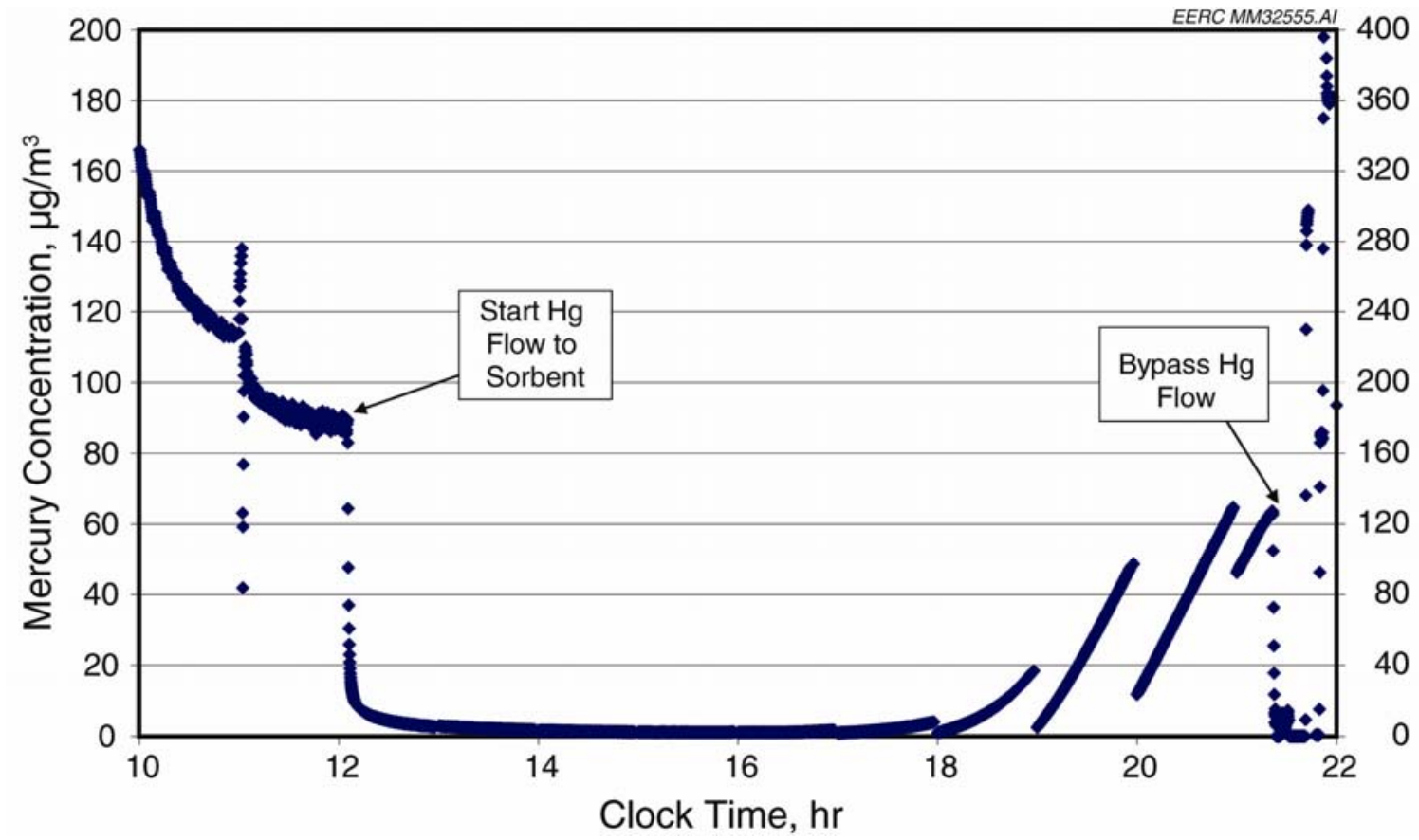

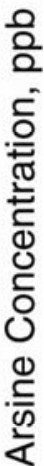

Figure A-90. Mercury sorption curve for Corning Monoliths 31308-4, -13, -15 at $400^{\circ} \mathrm{F}$ and 600 psig (Test 88 ). 


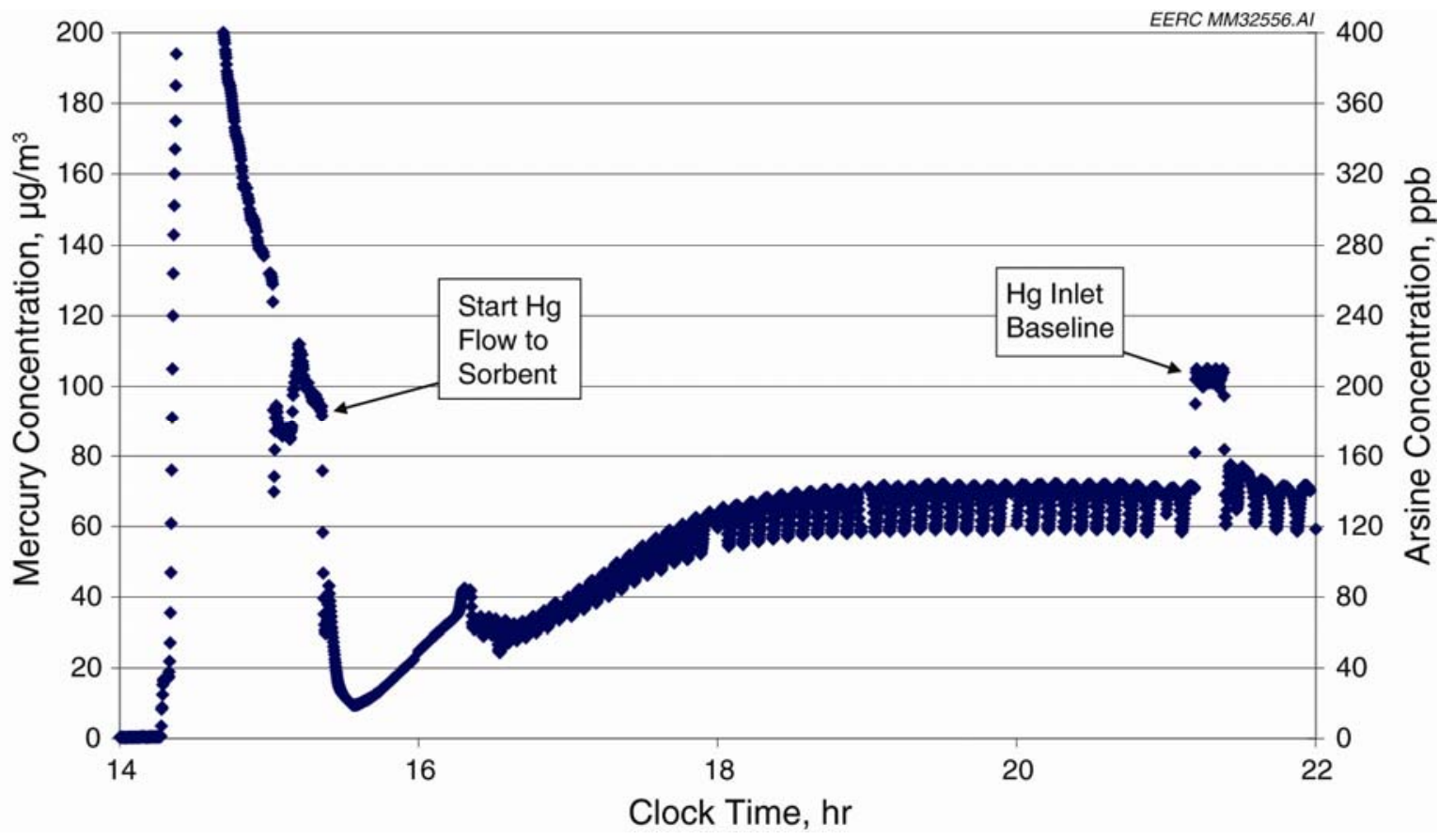

Figure A-91. Mercury sorption curve for regenerated Corning Monoliths 31308-4, $-13,-15$ at $400^{\circ} \mathrm{F}$ and 600 psig (Test 89). 
APPENDIX B

\section{DESIGN AND CONSTRUCTION OF A HIGH- PRESSURE FLUID-BED GASIFIER}




\section{DESIGN AND CONSTRUCTION OF A HIGH-PRESSURE FLUID-BED GASIFIER}

\section{SYSTEM SPECIFICATIONS}

This system has been designed according to ASME B31.3 Process Piping Code specifications. The internal reactor dimensions are based upon the existing operational continuous fluidized-bed reactor (CFBR) that currently operates up to a maximum operating pressure (MOP) of $1.0 \mathrm{MPa}(150 \mathrm{psig})$. After a review of available alloys, Haynes $556^{\circledR}$ was selected as the material most suitable for fabrication of this high-temperature, high-pressure system. The reactor was designed with the capability to operate at a MOP of 6.9 MPa (1000 psig) at an operational temperature of $843^{\circ} \mathrm{C}\left(1550^{\circ} \mathrm{F}\right), 4.5 \mathrm{MPa}(650 \mathrm{psig})$ at an operational temperature of $917^{\circ} \mathrm{C}\left(1650^{\circ} \mathrm{F}\right)$, and $2.0 \mathrm{MPa}(300 \mathrm{psig})$ at an operational temperature of $1800^{\circ} \mathrm{F}$. This system is designed to be externally electrically heated in a similar manner to the CFBR. The 2500 -pound $316 \mathrm{H}$ stainless steel flanged connections at the top and bottom of the reactor will be limited to a maximum operating temperature of $677^{\circ} \mathrm{C}\left(1250^{\circ} \mathrm{F}\right)$ for a $\mathrm{MOP}$ of $6.9 \mathrm{MPa}$ (1000 psig), $732^{\circ} \mathrm{C}\left(1350^{\circ} \mathrm{F}\right)$ for a $\mathrm{MOP}$ of $4.5 \mathrm{MPa}(650 \mathrm{psig})$, and an operational temperature of $816^{\circ} \mathrm{C}\left(1500^{\circ} \mathrm{F}\right)$ for a MOP of $2.0 \mathrm{MPa}$ (300 psig). Haynes 556 alloy was selected as the material of construction for the reactor, all reactor nozzles, and the cyclone.

\section{ACCOMPLISHMENTS}

The fluid-bed gasifier (FBG) was operated four times this quarter, starting with a shakedown test on August 18. Weeklong tests were performed during the weeks of August 24, September 8, and October 4. Fuels tested included Antelope Mine subbituminous coal, North Dakota lignite, and blends of each of these coals with switchgrass, olive pits, and dried distiller's grains (DDG), as well as periods of operation with 100\% DDG and 100\% olive pits (5).

In addition to gathering data on the operation of the FBG, two downstream components were utilized. During all 3 full weeks of testing, a Fischer-Tropsch reactor was brought online during steady-state gasifier operation; during the September test, a thermal oxidizer with a downstream catalyst system was tested. Both downstream components used syngas that had passed through the gasifier's hot-gas filter vessel and quench system, so the gas was dry and free of particulate.

\section{DESCRIPTION OF EQUIPMENT}

The bench-scale FBG is capable of feeding up to $9.0 \mathrm{~kg} / \mathrm{hr}(20 \mathrm{lb} / \mathrm{hr})$ of pulverized coal or biomass at pressures up to 70 bar absolute (1000 psig). The externally heated bed is initially charged from an independent hopper with silica sand or, in the case of high-alkali fuels, an appropriate fluidization media. Independent mass flow controllers meter the flow of nitrogen, oxygen, steam, and recycled syngas into the bottom of the fluid bed. Various safety interlocks prevent the inadvertent flow of pure oxygen into the bed or reverse flow into the coal feeder. 
After a review of available alloys, Haynes 556 was selected as the material most suitable for fabrication of the high-temperature, high-pressure system as well as for all of the reactor nozzles and the cyclone. The reactor was designed with an MOP of 70 bar (1000 psig) at operational temperatures of $843^{\circ} \mathrm{C}\left(1550^{\circ} \mathrm{F}\right), 45.8 \mathrm{bar}(650 \mathrm{psig})$ at an operational temperature of $917^{\circ} \mathrm{C}\left(1650^{\circ} \mathrm{F}\right)$, and $21.7 \mathrm{bar}(300 \mathrm{psig})$ at an operational temperature of $1018^{\circ} \mathrm{C}\left(1800^{\circ} \mathrm{F}\right)$. The 2500 -pound $316 \mathrm{H}$ stainless steel flanged connections at the top and bottom of the reactor are limited to somewhat lower maximum operating temperatures but do not greatly impact the operation of the gasifier, as they are generally cooler than the reactor bed itself. A design drawing of the reactor is shown in Figure B-1, and a photograph of the gasifier is shown in Figure B-2. Although omitted from the drawing for clarity, 16 thermocouple ports are spaced every 10-13 cm (4-5 inches) up the bed to monitor for loss of fluidization, solids agglomeration, and localized combustion zones, and the feed line extends up two stories to the coal hopper.

Coal is fed from a pressurized K-tron ${ }^{\circledR}$ loss-in-weight feeder that provides an online measurement of coal feed rate at pressures up to 70 bar (1000 psig). This system (shown schematically in Figure B-3) allows instantaneous measurement of the fuel feed rate to the gasification system. The feed system electronic controls are interfaced to a data acquisition system that allows for local or remote computer control of the fuel feed rate. Above the main feed hopper is the fuel charge hopper. The fuel charge hopper is manually charged with fuel through the top valve while at atmospheric pressure. It is then sealed and pressurized. Finally, the fuel feed material is transferred by gravity feed to the weigh hopper inside through the lower dual-valve system. The entire feed system pressure vessel is on a movable platform to allow easy transition from the FBG to the EERC's entrained-flow gasifier (not used in this testing but located adjacent to the FBG.

Coal feed from the K-tron system drops through a long section of vertical tubing and is then pushed quickly into the fluid bed through a downward-angled feed auger, as seen in Figure B-2. Syngas exiting the fluid bed passes through a cyclone before flowing into a transport reactor that uses regenerable sorbent to remove sulfur from the syngas stream. The syngas then passes through a hot candle filter to remove fine particulate before entering a series of fixed beds. One bed is a polishing bed of $\mathrm{ZnO}$ that removes all remaining traces of sulfur from the syngas. Other beds can be loaded with water-gas shift catalyst, heavy metal sorbent, a chlorine guard, or other sorbents and catalysts. The clean, shifted syngas, still hot and pressurized, is then routed through a series of water-cooled condensers to remove volatile organics and moisture. Syngas can be sampled upstream of the condensers for hot tests. The clean, dry syngas exiting the condensers is then recycled through a compressor to the bottom of the FBG, and a portion is vented through a control valve to maintain system pressure. The syngas exiting the system passes through a dry-gas meter for mass balance. A slipstream of this depressurized dry gas is also fed to a laser gas analyzer (LGA) and a gas chromatograph for online analysis of major gas components and for low-level (ppb) analysis of sulfur species. In addition, operators periodically sample syngas from various points throughout the system using Dräger ${ }^{\circledR}$ tubes for $\mathrm{H}_{2} \mathrm{~S}$ and other trace gases to verify low-level chromatographic data. Figures B-4-B-7 are photographs of the back-end gas cleanup system, including the transport sulfur reactor, filter vessel, fixed sorbent/catalyst beds, and quench system. 


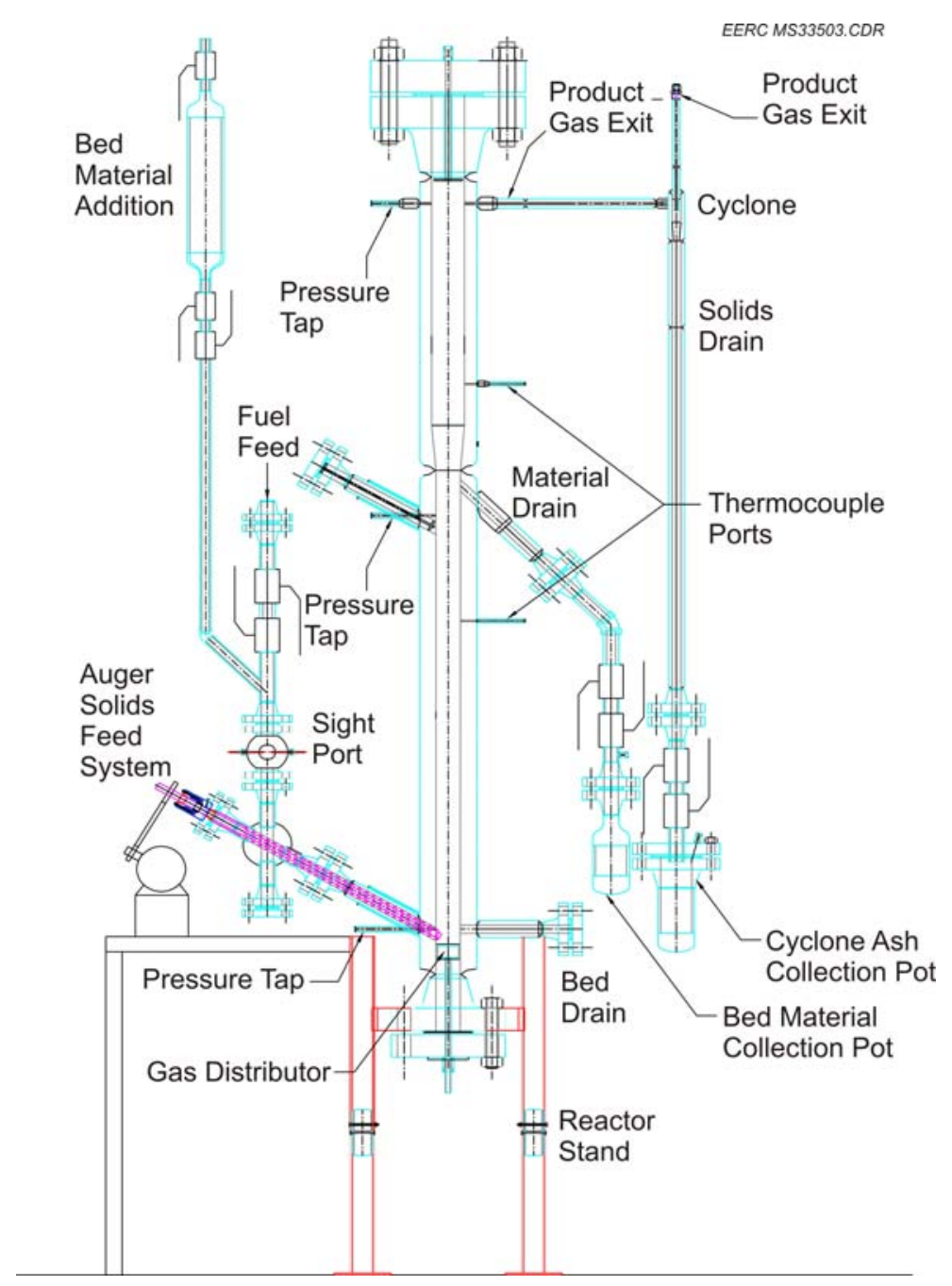

Figure B-1. Design drawing of the pressurized, fluidized gasification reactor. 


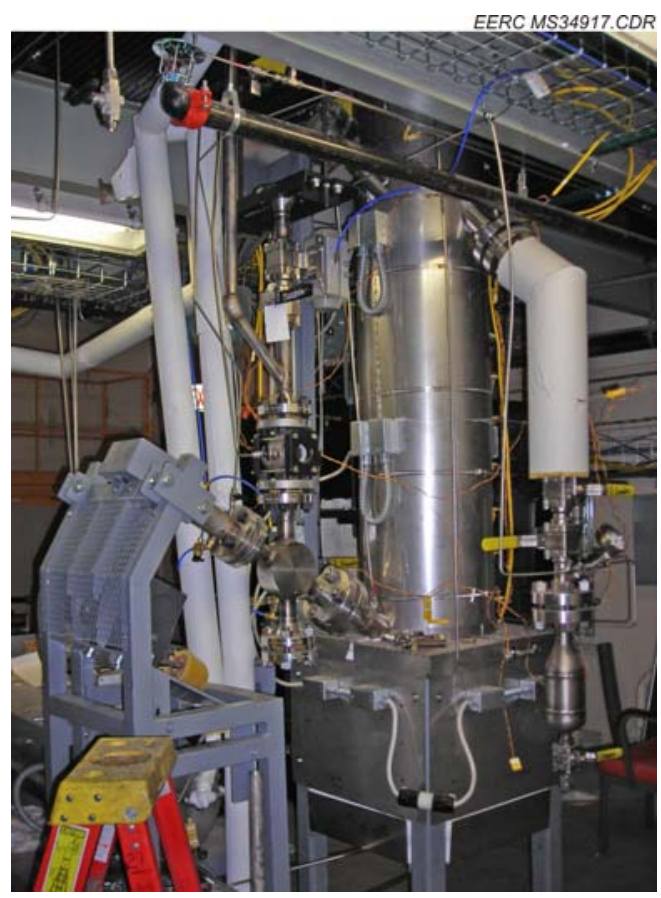

Figure B-2. Photograph of the lower section of the high-pressure FBG. Visible at left is the feed auger angled downward into the bed.

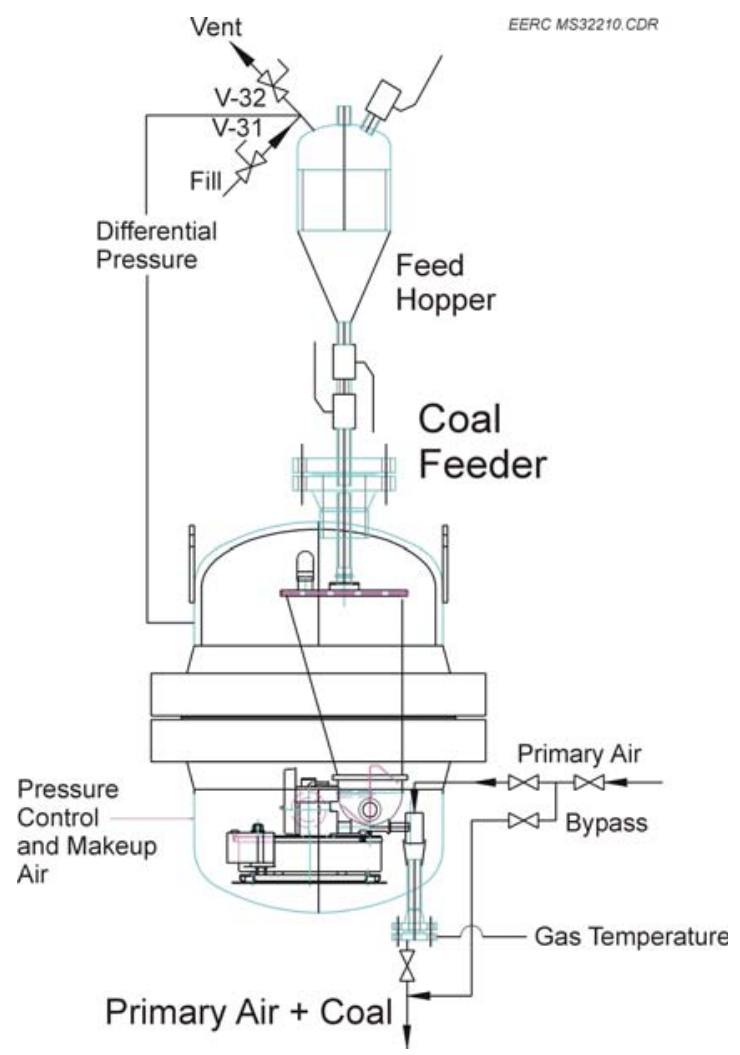

Figure B-3. Cross-sectional view of the fuel feed system. 


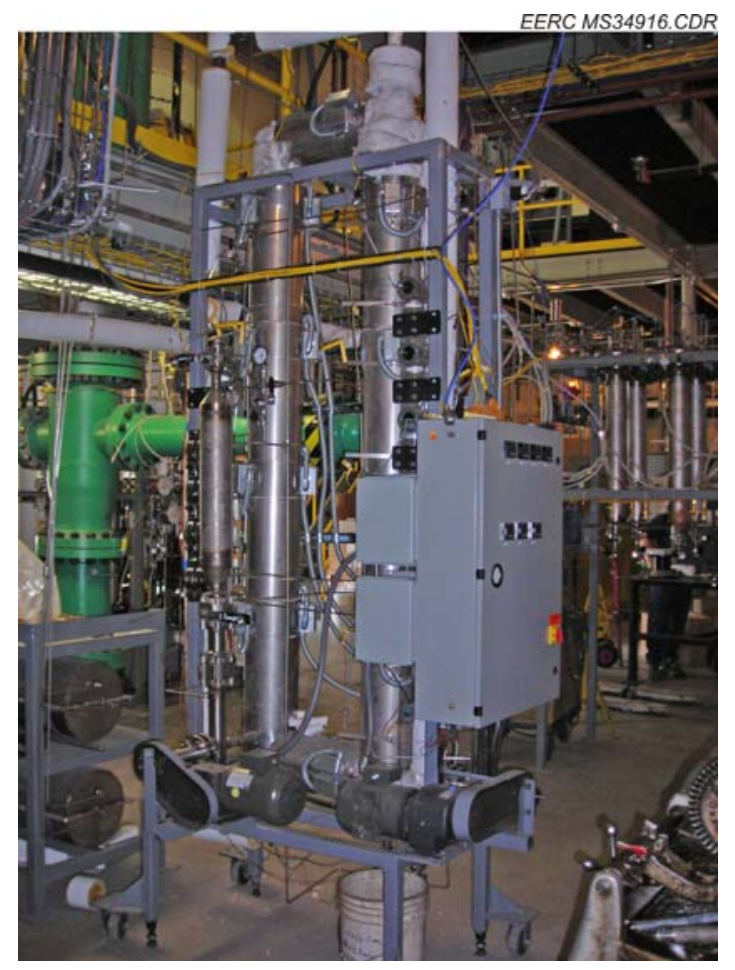

Figure B-4. Photograph of the EERC circulating fluid-bed desulfurizer.

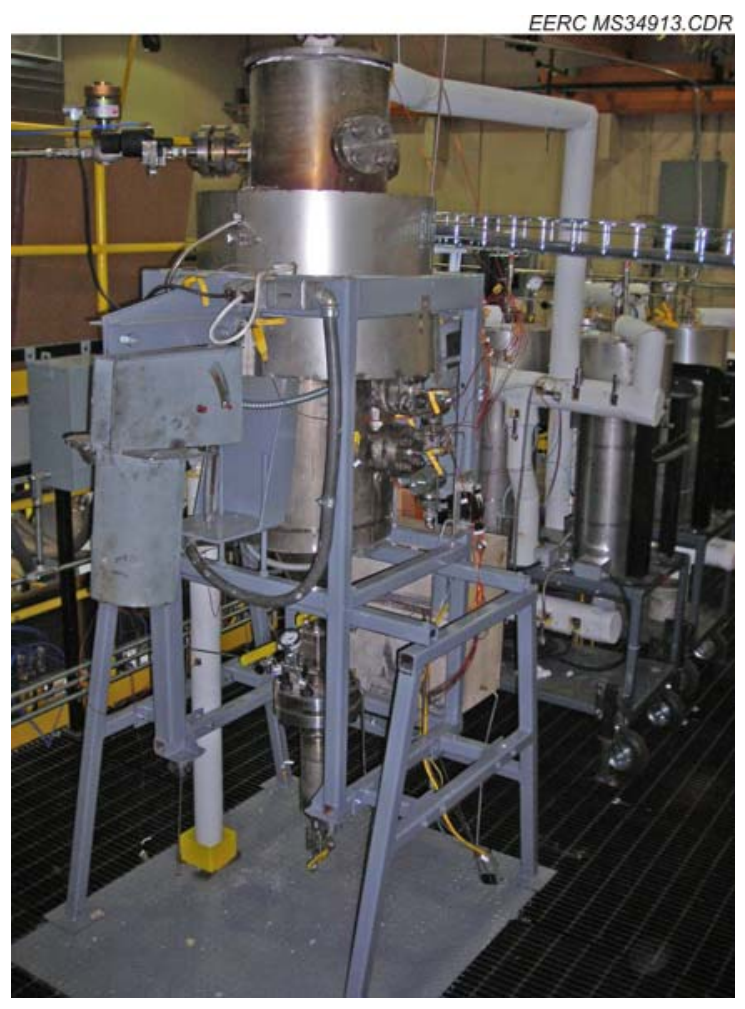

Figure B-5. Photograph of the EERC hot-gas filtration system. 


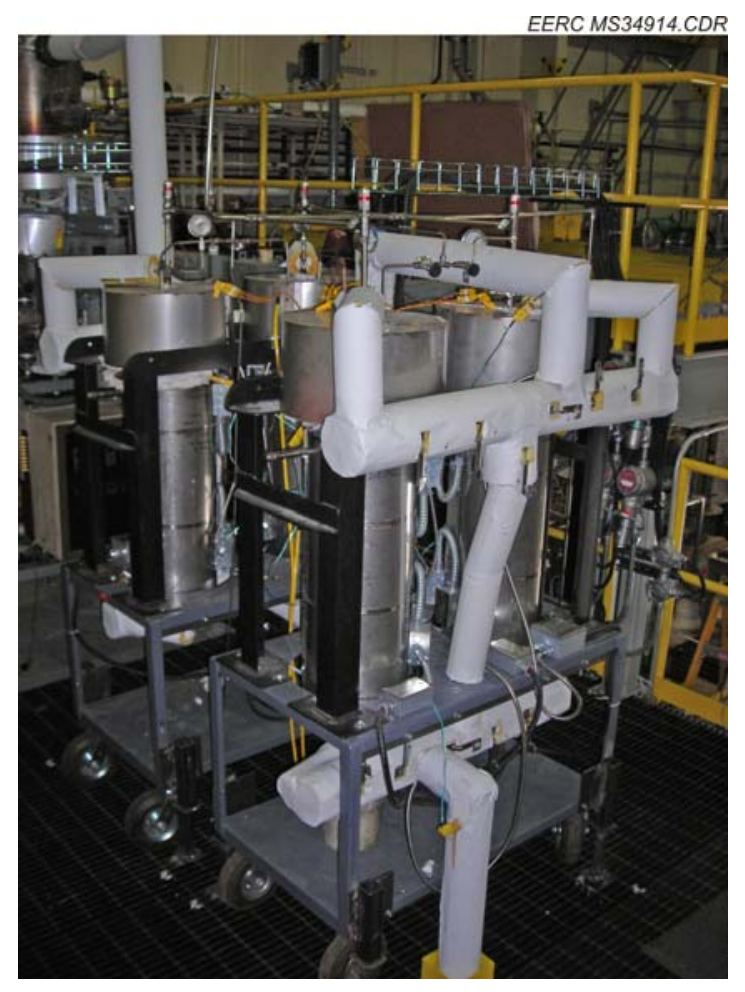

Figure B-6. Photograph of the EERC fixed-bed reactor/sorbent contactors.

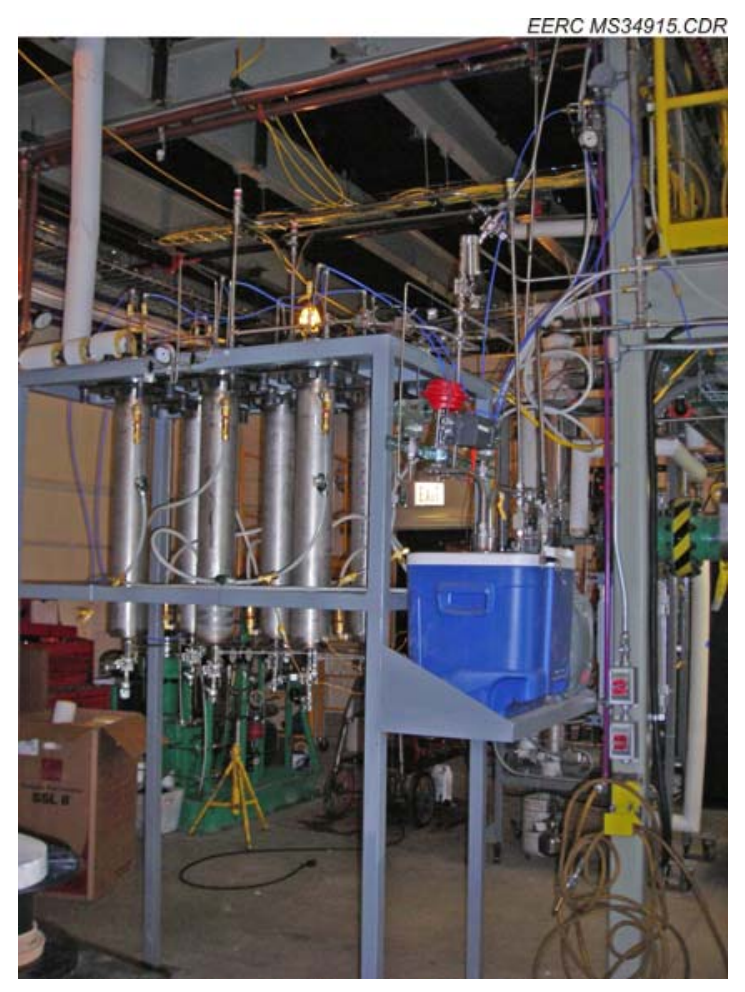

Figure B-7. Photograph of the gasification system quench pots and back-pressure control valve. 


\section{EXPERIMENTAL CONDITIONS}

Table B-2 shows the range of operating conditions during each of the 3 weeks of oxygenblown testing. While an attempt was made to maintain fairly uniform operating conditions in the gasifier during testing of downstream components, feeding different fuels had an impact on fuel feed rate and bed temperature. The wide variation in operating pressure during the October test stemmed from a leaking valve at the cyclone pot. During the week, the valve was replaced, and the desired operating pressure was maintained.

Table B-3 shows the analyses of the fuels used during the August and September test runs (6). An analysis of the North Dakota lignite has not yet been performed.

Carbon conversions (based on a solid carbon mass balance) for the September and October tests are shown in Table B-4. They ranged from a low of $79 \%$ for a blend of lignite and switchgrass to a high of $96 \%$ for $100 \%$ leached olive pits. Generally carbon conversion was around $90 \%$.

During the September test, while the goal was full oxygen-blown operation, nitrogen was added to prevent hot spots in the bed. As a result, the syngas was heavily diluted with nitrogen (about 57\%). There was less difficulty with controlling bed temperature during the October test, and it was possible to get the nitrogen in the syngas down to about $18 \%$. Nitrogen was used to backpulse the hot-gas filter vessel, and recycling that diluted syngas into the reactor prevented the total elimination of nitrogen from the system. Table B-5 shows the average syngas composition for selected fuels from the September and October tests, normalized to a nitrogenfree basis.

Table B-2. Summary of Operating Conditions

\begin{tabular}{lccc}
\hline & August 24-28 & September 7-11 & October 5-9 \\
\hline Hours of Operation & 82 & 73 & 74 \\
Fuel Feed Rate, lb/hr & 7.5 to 9.0 & 11.4 to 15.5 & 7.5 to 9.0 \\
Pressure, psig & 300 & 500 & $340-450$ \\
Bed Temperature, ${ }^{\circ} \mathrm{F}$ & $1500-1530$ & $1520-1560$ & $1520-1560$ \\
$\mathrm{O}_{2}$ Flow, scfh & 60 & 80 & $85-90$ \\
Steam Flow, lb/hr & 20 & 17 & 17 \\
Bed Velocity, ft/sec & $0.9-1.2$ & 0.8 & 0.9 \\
\hline
\end{tabular}


Table B-3. Fuel Analyses

\begin{tabular}{|c|c|c|c|c|c|c|}
\hline & $\begin{array}{c}\text { PRB }^{\mathrm{a}} \\
\text { Antelope } \\
\text { Mine Coal }\end{array}$ & $\begin{array}{l}\text { Treated } \\
\text { Olive Pits }\end{array}$ & $\begin{array}{l}\mathrm{TL}^{\mathrm{b}} \\
\text { Olive } \\
\text { Pits }\end{array}$ & $\begin{array}{c}\text { Treated } \\
\text { DDG }\end{array}$ & Switchgrass & DDG \\
\hline Leached? & & Yes & Yes & Yes & Yes & No \\
\hline Torrefied? & & No & Yes & No & No & No \\
\hline Air-Dry Loss & 16.62 & 44.40 & 39.40 & 22.00 & 59.60 & 0.40 \\
\hline \multicolumn{7}{|c|}{ Proximate Analysis (all values reported as weight percent as determined) } \\
\hline Moisture & 6.94 & 9.39 & 5.70 & 10.57 & 4.87 & 7.12 \\
\hline Volatile Matter & 42.32 & 62.78 & 43.27 & 65.47 & 63.69 & 69.01 \\
\hline Fixed Carbon & 43.85 & 24.70 & 47.44 & 21.43 & 16.54 & 19.99 \\
\hline Ash & 6.89 & 3.13 & 3.58 & 2.53 & 14.90 & 3.88 \\
\hline \multicolumn{7}{|c|}{ Ultimate Analysis (all values reported as weight percent as determined) } \\
\hline $\mathrm{H}$ & 4.86 & 6.65 & 5.29 & 7.40 & 6.46 & 7.14 \\
\hline $\mathrm{C}$ & 82.83 & 50.16 & 66.66 & 49.02 & 44.11 & 48.31 \\
\hline $\mathrm{N}$ & 1.17 & 1.60 & 1.43 & 4.28 & 1.21 & 3.66 \\
\hline $\mathrm{S}$ & 0.38 & 0.13 & 0.11 & 0.34 & 0.20 & 0.39 \\
\hline $\mathrm{O}$ & 3.87 & 38.33 & 22.93 & 36.43 & 33.12 & 36.58 \\
\hline $\mathrm{HHV}, \mathrm{Btu} / \mathrm{lb}^{\mathrm{c}}$ & 10,550 & 8282 & 10,994 & 8584 & 6750 & 8532 \\
\hline $\mathrm{CCV}, \mathrm{Btu} / \mathrm{lb}^{\mathrm{d}}$ & 14,611 & 9060 & 11,504 & 9290 & 8279 & 9078 \\
\hline \multicolumn{7}{|c|}{ Ash Analysis (all values reported as weight percent on an ash basis) } \\
\hline $\mathrm{SiO}_{2}$ & 32.6 & 6.6 & 10.1 & 3.0 & 40.4 & 5.2 \\
\hline $\mathrm{Al}_{2} \mathrm{O}_{3}$ & 15.0 & 1.5 & 2.6 & 0.8 & 1.5 & 0.0 \\
\hline $\mathrm{Fe}_{2} \mathrm{O}_{3}$ & 7.48 & 1.80 & 3.72 & 0.60 & 2.14 & 0.43 \\
\hline $\mathrm{iO}_{2}$ & 1.17 & 0.11 & 0.18 & 0.04 & 0.12 & 0.02 \\
\hline $\mathrm{P}_{2} \mathrm{O}_{5}$ & 1.08 & 2.10 & 3.59 & 43.12 & 1.93 & 39.65 \\
\hline $\mathrm{CaO}$ & 21.3 & 51.7 & 54.9 & 23.5 & 40.0 & 1.9 \\
\hline $\mathrm{MgO}$ & 5.86 & 0.77 & 3.22 & 6.10 & 2.86 & 13.41 \\
\hline $\mathrm{Na}_{2} \mathrm{O}$ & 0.84 & 0.03 & 0.91 & 3.95 & 0.23 & 5.26 \\
\hline $\mathrm{K}_{2} \mathrm{O}$ & 0.56 & 0.68 & 13.24 & 13.47 & 5.26 & 30.68 \\
\hline $\mathrm{SO}_{3}$ & 13.25 & 1.78 & 4.73 & 4.70 & 1.47 & 2.84 \\
\hline $\mathrm{Cl}$ & 0.00 & 0.10 & 0.08 & 0.55 & 0.12 & 0.64 \\
\hline Unknown & 0.00 & 32.63 & 0.73 & 0.00 & 3.80 & 0.00 \\
\hline
\end{tabular}


Table B-4. Carbon Conversion for FBG Tests

\begin{tabular}{lcc}
\hline Run Number & Fuel & $\begin{array}{c}\text { Carbon } \\
\text { Conversion, \% }\end{array}$ \\
\hline FBG3 & 100\% PRB Antelope Mine coal & 82.3 \\
FBG3 & 100\% DDG & 84.3 \\
FBG3 & 100\% leached olive pits & 96.0 \\
FBG4 & $96 \%$ lignite + 4\% PRD & 84.4 \\
FBG4 & 96\% Lignite + 4\% Plum Run dolomite (PRD) & 79.2 \\
FBG4 & 30\% switchgrass/70\% lignite + PRD & 83.6 \\
FBG4 & 30\% DDG/70\% lignite + PRD & 89.4 \\
FBG4 & 30\% DDG/70\% lignite + PRD & 89.9 \\
FBG4 & 30\% olive pits/70\% lignite + PRD & 89.5 \\
\hline
\end{tabular}

Table B-5. Major Syngas Components

\begin{tabular}{lccccc}
\hline & $\begin{array}{c}\text { PRB Antelope } \\
\text { Mine }\end{array}$ & ND Lignite & $\begin{array}{c}\text { Lignite/ } \\
\text { Switchgrass }\end{array}$ & Lignite/DDG & Lignite/ \\
& 11.4 & 15.0 & 12.9 & 15.8 & 16.6 \\
\hline $\mathrm{CO}$ & 61.7 & 71.1 & 75.1 & 67.0 & 66.6 \\
$\mathrm{CO}_{2}$ & 7.4 & 3.5 & 2.4 & 6.1 & 5.7 \\
$\mathrm{CH}_{4}$ & 19.5 & 10.5 & 9.6 & 11.1 & 11.1 \\
$\mathrm{H}_{2}$ & & &
\end{tabular}

